\section{The Late Helladic IIB to IIIA2 Pottery Sequence from the Mycenaean Palace at Ayios Vasileios, Laconia}

\author{
Eleftheria Kardamaki
}

\section{Schlüsselbegriffe}

Ájios Wassílios, Menelaion, Lakonien, Griechenland, mykenische Paläste, späthelladisch, Keramiksequenz, Zerstörungshorizonte.

\section{Introduction}

The excavations on the site of the newly discovered palace at Ayios Vasileios in Laconia have added significantly to our understanding of the Aegean Late Bronze Age. The most important new finds, which include an archive of Linear B-Tablets ${ }^{1}$ and wall paintings, suggest the existence of a palatial administration at Ayios Vasileios and the presence of elites who shared values and ideas with those known from the other palaces. Even more intriguing is the fact that many of the finds are related to early destruction horizons and therefore promise to reveal valuable new information regarding the formative phase of the palatial system. The present study is part of a larger project that focuses on the pottery sequence and dating of the major building and destruction phases of the palace. As the excavations continue it is becoming evident that the palace as a whole encompassed several major and minor building and rebuilding phases, which have resulted in a complex stratigraphic situation that presents numerous interpretative challenges. These rebuilding phases include cleaning and levelling activities, the partial or complete renovation of walls and the laying of floors, which do not always coincide with significant changes in the styles of the associated pottery.

In this article, the first preliminary evidence for the continuous occupation of the palace from LH IIB - LH IIIA2 will be presented. The majority of the material discussed here derives from a small area in the eastern part of the palace where a sequence of at least three floors has been documented (Trench I18 $\alpha / \beta$ in Building B). In addition, pottery from various other contexts, mainly secondary dumps

1 Aravantinos, Vasilogamvrou 2012. 
(south-eastern deposit and the fresco dump) but also from the destruction horizon of the southern stoa and the great court will be described. This evidence will provide further information regarding the pottery styles in use during the periods discussed.

\section{The Contexts Studied at Ayios Vasileios}

This paper describes material drawn principally from three areas of the palace: trenches I18 $\alpha$ (Room 6) and I18 $\alpha / \beta$ in Building $B$, located in the easternmost part of the excavated area, the fresco dump on the south-western terrace and west to the court (trench $\Delta 6 \delta$ ), and the south-eastern depos-

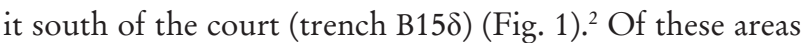
only one, Building B, trench $\mathrm{I} 18 \alpha / \beta$, produced a small sequence of closed and sealed deposits. These were related to the pebble surfaces of a road (Tab. 1). A group of vessels was recovered from Room 6 (Trench I18 $\alpha$ ), directly to the west, but the floor itself was very poorly preserved. The other two deposits, particularly the fresco dump, most probably represent deliberate dumping actions but as they are not related to any specific floor surfaces they may contain material from more than one phase of activity. However, in both cases the pottery appears to be relatively homogeneous and the percentage of later or earlier material is negligible.

Only a small part of the pottery assemblage discovered in the area of the southern and western stoa and the collapsed archive from the upper storey ${ }^{3}$ will be considered here as the study of this area is still in progress and the results will be presented elsewhere. A few vessels were found lying in situ on the floor of the south sto $a^{4}$ and a few sherds came from the deposits sealed by the floor of the west stoa. ${ }^{5}$ The vessels from the floor of the south stoa were heavily burnt suggesting that a severe fire was responsible for the destruction of the palace during this phase. The latest Mycenaean pottery identified so far in the area of the palace belongs to the earliest LH IIIC horizon, a pottery phase roughly equivalent to Penelope Mountjoy's Transitional LH IIIB2 - LH IIIC Early. ${ }^{6}$ Sherds dating to this period have been discovered

2 Vasilogamvrou 2013, 69-70, 80 and Pl. 45. - Vasilogamvrou 2014, Fig. 1, Pl. 55. - The dominant features in trench B15 $\delta$ (southeastern deposit) are the very long wall (101) and a second wall (103), the latter unrelated to the first and of a later date. The pottery deposit relates to wall (101).

3 Vasilogamvrou 2015b, Pl. 74.

4 Fig. 20/318-321.

5 Fig. 20/313-317. - For the stratigraphy and architectural remains under the floor of the stoa visible in the sides of the Byzantine pits, see VAsilogamvrou 2015b, 105-106, 109 and Pls. 71-74.

6 Mountjoy 1997. - Mountjoy 1999. - For a discussion on the earliest phase of LH IIIC Early (LH IIIC Early 1) see KARDAMAKI 2013, 392-402. almost exclusively within secondary fills that cut through the debris of the court.?

\section{Early Mycenaean and LH IIIA2 Contexts from Other Regions} The majority of the material presented here covers the period from LH IIB to LH IIIA2. Earlier material is also present, not only in the contexts discussed here but also from other parts of the site, although it was stratified in only a few cases. ${ }^{8}$ To date, LH IIIB and LH IIIC Early pottery has only been recovered from secondary contexts. For the later phases (especially LH IIIB1, LH IIIB2 and LH IIIC Early) there is enough relevant material for comparative purposes, although this comes mainly from beyond Laconia. ${ }^{9}$ In contrast, the pottery phases LH II and LH IIIA1 are still inadequately represented by reliable stratified settlement deposits. ${ }^{10}$ The following sites are considered to provide contexts typical of these periods: Mansion 1 in Menelaion and Building B at the Aetos South Slope (LH IIIA1), Ayios Stephanos (LH IIA, LH IIIA1) in Laconia, Nichoria (LH II - LH IIIA1) and Pylos (LH IIIA1) in Messenia, Atreus Bothros in Mycenae (LH IIIA1), House D1 in Tiryns (LH IIB), Asine (LH IIB and LH IIIA1) in the Argolid, Tsoungiza EU10 (LH IIA), East Alley pit in Korakou (LH IIA and LH IIB), the four wells on the south slope of the Acropolis in Athens (LH IIIA1), Mitrou (LH IIIA1) in Phthiotis, and Ayia Irini Phases VII-VIII in Kea (LH IIA - LH IIIA1). Unfortunately many of these contexts are not well preserved, nor do they always represent sealed floor deposits. In the present study, particular emphasis is laid on the pottery sequence from the Laconian sites.

At the Menelaion the evidence from the latest mansion floors (mansions 2 and 3), which sealed the earlier levels (Mansion 1 and fill above), was inadequately documented in Richard Dawkins' excavation reports. ${ }^{11}$ A group of 133 vases and sherds lying in situ on the pebble floor of the rooms of Mansion 1 were excavated by Richard Catling or were found within a series of artificial and natural pits or holes,

7 Vasilogamvrou 2015b, 109. - The study of the material from these layers is in preparation.

8 See especially Hachtmann forthcoming for the area around the early Mycenaean cemetery.

9 E. g. French 1964. - French 1965. - Wardle 1973. - Schönfeld 1988. - Mountjoy 1997. - Thomas 2005. - Podzuweit 2007 (for the Argolid, Corinth, and Laconia). - MounTJoy 2008, 302-313, 316-320. - Thomas 2011a.

10 The statement by Mountjoy 1986, 51 that 'the change from LH IIB to LH IIIA1 is so far a stylistic division' still holds good. 11 Catling 2009a, 17-19, 33, 52-53. - For a report on the early excavation see Dawrins 1910. - See also CatLing 2009a, Appendix A for excavation notes dating to 1910 . 


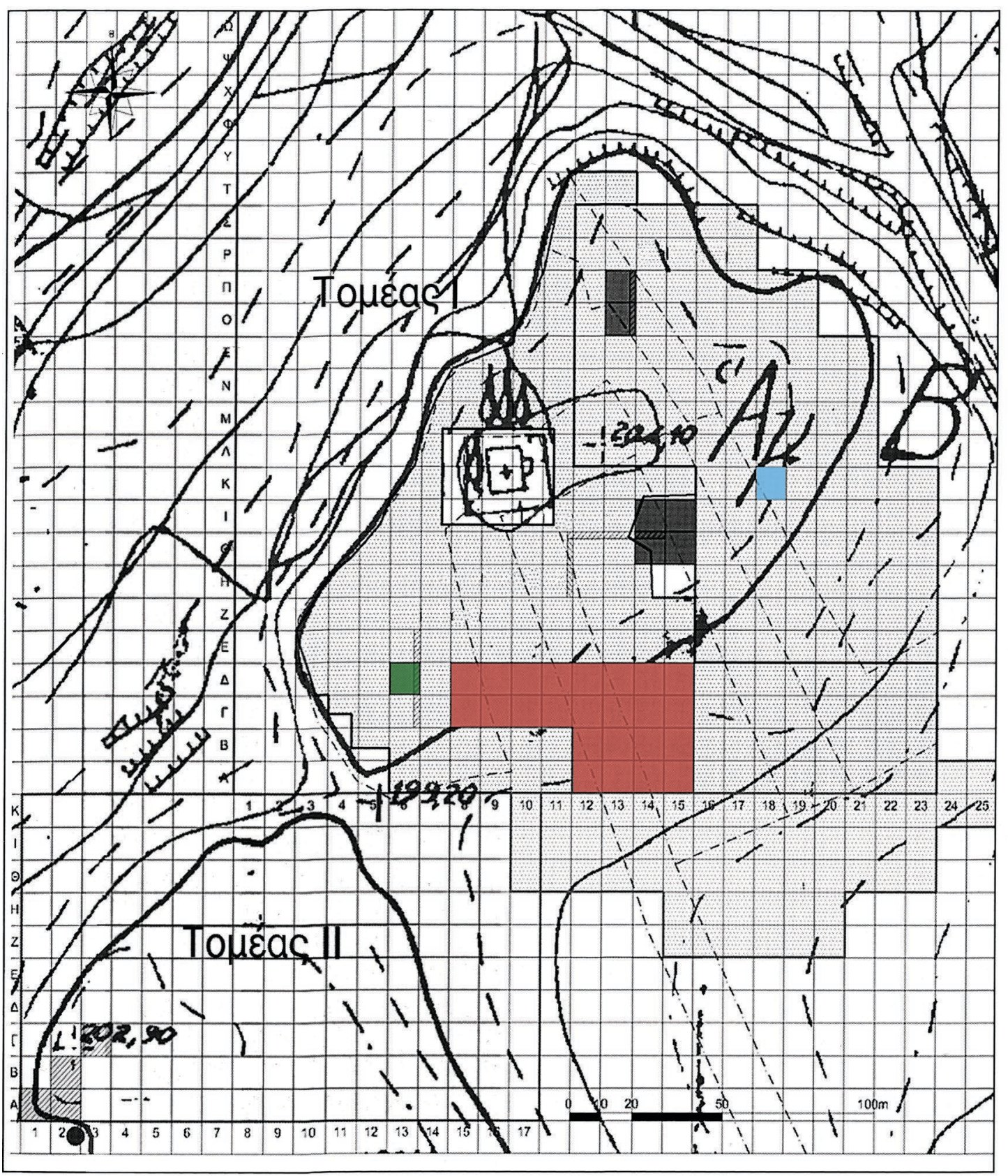

Excavated part of Building B

Complex $\Delta$ - E with trench B15d

(south-eastern deposit), court, stoas

Southwest Terrace (dump with frescos)

Fig. 1. Plan of the excavation with trenches (modified from Vasilogamvrou 2015a, 65 and Fig. 1). 
Tab. 1. Stratigraphic sequence in Trench $I 18 \alpha / \beta(1.70 \times 2.40 \mathrm{~m})$ in Building B.

\begin{tabular}{|c|c|c|}
\hline Stratigraphic units & $\begin{array}{l}\text { Excavation } \\
\text { depths }\end{array}$ & Features of stratigraphic units with relevant pottery groups \\
\hline upper fill & $1.39 \mathrm{~m}$ & $30-40 \mathrm{~cm}$ thick fill of reddish and yellowish soil in I18 $\alpha$ and $\mathrm{I} 18 \alpha / \beta$. \\
\hline 'Ditch’ & $? 1.98 \mathrm{~m}-2.36 \mathrm{~m}$ & $\begin{array}{l}\text { Fill of yellowish soil, large quantity of sherds, some fresco fragments and other small finds, } \\
\text { running across the centre of the trench, parallel to the walls } 42 \text { and } 71 \text {. The fill interrupts the } \\
\text { pebble surfaces but its upper limits (at the level of 'Floor 1' and 'Floor 2') were not iden- } \\
\text { tified with certainty. Pottery groups 6217, 6218, 6242-6243, 6254, 6256, 6259, 6264, 6266, } \\
6268-62706301,6303,6304,6305-6306 \text {. }\end{array}$ \\
\hline ?'Floor’ 1? & $1.73 \mathrm{~m}$ & $\begin{array}{l}\text { Patch of reddish hard soil identified as a floor in the northwest corner of the trench. At the } \\
\text { same level are two stone slabs placed horizontally and connected with wall } 71 \text {. Sherds above } \\
\text { patch of reddish hard soil are pottery group } 6192 \text {. }\end{array}$ \\
\hline ?'Floor’2? & $1.81 \mathrm{~m}$ & $\begin{array}{l}\text { Possible surface. Hard yellowish soil. Surface not well preserved or identified with certainty. } \\
\text { Pottery groups from related levels } 6193,6194,6195,6197 \text {. }\end{array}$ \\
\hline $\begin{array}{l}\text { highest pebble surface } \\
\text { /'Floor' } 3\end{array}$ & $1.84 / 2.00 \mathrm{~m}$ & $\begin{array}{l}\text { Surface consisting of hard packed pebbles in the west part of the trench (road?). Sherds and } \\
\text { animal bones on the surface; torus of naturalistic figurine lying directly on pebble surface } \\
\text { and some other small finds (bronze objects). Very thin soil between highest and lowest peb- } \\
\text { ble surface; pottery groups found between pebbles and lying directly on surfaces } 6213,6229 \text {, } \\
6233,6236,6238,6240 \text {. East of the ditch, the pebble surface is disturbed; the pottery from } \\
\text { this level is referred to as 'above Floor 4-east'. }\end{array}$ \\
\hline $\begin{array}{l}\text { lowest pebble surface } \\
\text { /‘Floor' } 4\end{array}$ & $2.06 \mathrm{~m}$ & $\begin{array}{l}\text { Surface consisting of hard packed pebbles (interrupted by the 'Ditch') (road?). Sherds and } \\
\text { animal bones on the surface. Pottery groups } 6255,6309 .\end{array}$ \\
\hline $\begin{array}{l}\text { fill between 'Floor' } 5 \text { and } \\
\text { 'Floor } 4 \text { ' (test trench) }\end{array}$ & $2.09-2.17 \mathrm{~m}$ & $\begin{array}{l}\text { Test trench }(1.00 \times 0.60 \mathrm{~m}) \text { under lowest pebble surface in the western part of the trench. } \\
\text { Pottery groups } 6310,6311 \text {. }\end{array}$ \\
\hline 'Floor' 5 (test trench) & $2.17 \mathrm{~m}$ & $\begin{array}{l}\text { Test trench }(1.00 \times 0.60 \mathrm{~m}) \text { under the lowest pebble surface in the western part of the trench. } \\
\text { Hard reddish soil with few pebbles, identified as a surface but this interpretation has to } \\
\text { remain open until further excavation takes place. Interrupted by the foundation trench for } \\
\text { wall } 71 \text { to the west and by the 'Ditch' to the east. Pottery groups } 6312,6315-6318 \text {. Pottery } \\
\text { groups } 6316 \text { and } 6318 \text { belong to the foundation trench of wall } 71 \text {. }\end{array}$ \\
\hline $\begin{array}{l}\text { lowest fill above bedrock } \\
\text { (test trench) }\end{array}$ & $2.20-2.36 \mathrm{~m}$ & $\begin{array}{l}\text { Test trench }(1.00 \times 0.60 \mathrm{~m}) \text { under the lowest pebble surface in the western part of the trench. } \\
\text { Red soil containing few sherds. Pottery groups } 6319-6322 \text {. Pottery groups } 6320 \text { and } 6322 \\
\text { belong to the foundation trench of wall } 71 \text {. }\end{array}$ \\
\hline
\end{tabular}

which cut the pebble floors of Mansion $1 .^{12}$ The floor deposit of Mansion 1 was sealed by a fill, which was originally some 1.50 m thick. ${ }^{13}$ This was interpreted as a construction layer on top of which the floor of Mansion 2 would have been laid. Catling dated the pottery from the floor deposit and the holes to LH IIB/LH IIIA1 and the pottery from the construction fill to the same phase or slightly earlier. Some later features ${ }^{14}$ were considered to be intrusive and were assigned to the so-called Mansion $3 .{ }^{15}$ The construction and use of Mansion 1 itself he dated to LH IIB as he

12 Catling 2009a, 16. - For the list of the in situ vessels and sherds see CATLing 2009a, 50-51.

13 Catling 2009a, 53.

14 Catling 2009a, 96. - Catling 2009b, Fig. 109/ST75-ST77.

15 See CATLing 2009a, 53-54, 87, 94 for a discussion of the deposit and for catalogued pieces from the construction fill. did not associate the vessels from the above mentioned floor deposit with the actual use-life of the building but rather with the construction period of Mansion 2. The reason for this was that Catling did not consider the pebble floor to be the real floor of the building but rather the sub-floor of an original walking surface that was presumably removed during the construction period of Mansion 2. As a result he assigned this pottery assemblage to both the period of the use of Mansion 1 as well as to the period of the construction of Mansion 2. Later pottery, assigned to the period of mansions 2 or 3, was identified, in a few rare cases, in the area of Mansion 2. ${ }^{16}$ The pebble floor from Building B at the Aetos South Slope is contemporary with the floor of Mansion 1, although only a few vessels were discovered in situ. In this

16 Catling 2009a, 33, 112. 
paper, an attempt is made to avoid the use of transitional dating such as LH IIB/LH IIIA1 for the pottery deposit associated with Mansion 1. The assemblage has been treated as a single unit dated to LH IIIA1, probably early in this phase. ${ }^{17}$ This dating is implied by the fact that the percentage of 'innovative' (LH IIIA1) vessels is large (kylikes, craters, and cups with stipple pattern). The pottery from the construction fill consists predominantly of wares dating to LH IIIA1 along with some LH II pottery as Catling suggested. However, part of the material that was found especially in the fill of the East Terrace of Mansion $2^{18}$ is considered here to belong rather to LH IIIA2. The original amount of this material and its origin - intrusive from higher levels or from the original construction fill - cannot be estimated any more.

At Nichoria no fine pottery (plain-decorated) has been published from the floor of the Megaron (the deposit in unit IV-A). ${ }^{19}$ The largest component of the LH IIB and LH IIIA1 assemblage was recovered principally from wash deposits, which in some cases included evidence for internal stratification and gradual filling. ${ }^{20}$ Real LH IIA floor assemblages are very rare. ${ }^{21}$ Moreover, although the existence of early and later stages of LH IIIA1 has been proposed, it has not been possible to define clear features for these phases. ${ }^{22} \mathrm{At}$ Pylos few deposits date to LH IIIA1. The material under the floor of Hall 65 contained some characteristic painted sherds $^{23}$ and more material was found in the lower town. A well-known LH IIIA1 deposit with architectural remains and evidence for destruction by fire came from trench LTI outside Hall 65. This layer contained, amongst other things, cups with a stipple pattern and a kylix with strap handles. ${ }^{24}$ This, however, was a small group and was not related to any specific floor. In some areas it was also mixed with LH IIIB

17 Mountjoy 1993, 63 dates the deposit to LH IIB/IIIA1, which should pre-date other typical LH IIIA1 contexts. - A similar approach has been followed by MounTjoy 1999, 244 where the floor deposit of Mansion 1 is placed in the early stages of LH IIIA1.

18 Catling 2009b, Figs. 92/ET62-ET63; 93/ET68; 97/ET125ET127 (goblets with short rims, semiglobular kylikes and some carinated kylikes).

19 The fragments of some vessels from the floor of the Megaron join with pieces from the adjacent room (Room 3): AsCHENBRENNER et al. 1992, 435.

20 See the LH IIA material from Area IV SW (1) and (2): Dickinson 1992, 469 - 470. - Next to the Megaron other LH IIIA1 deposits include Unit IV-B, which precedes the IV-A deposit (Megaron) but is contaminated with earlier material, whereas another dump (L23Pfg, level 7-9) is also mixed with earlier pottery. - See Martin 1992, 488. 21 A possible LH IIA deposit in an architectural context was found only in Area IV NE: Dickinson 1992, 469.

22 Martin 1992, 489.

23 Blegen et al. 1973, Figs. 139, 141.

24 Blegen et al. 1973, Figs. 153; 155/11-18. - Cf. Mountjoy 1999, Figs. 111/47-50; 112/56. pottery. ${ }^{25}$ Another group with typical LH IIIA1 pottery came from the southern corner of the palace where some vessels were found on floors under a thick accumulation of stones and mudbricks. ${ }^{26}$

Levels X-V identified at Korakou-East Alley pit have been re-dated by Oliver Dickinson to LH IIA and LH IIB. ${ }^{27}$ The LH IIA level was separated from the higher deposit by a possible floor between layers VIII and VII. However, cross-context joins between these strata suggest some degree of mixing. The most distinctive feature of levels VII-V is the Ephyrean goblet, which was much rarer in the lower layers. At Asine only a single room produced a sequence spanning LH IIB and the early LH IIIA1 (termed as LH IIB/ LH IIIA1). The floor deposit from Room F (stratum 3) was dated to $\mathrm{LH}$ IIB $^{28}$ but the assemblage was very small. The new excavations in the northern part of the building have demonstrated that the 'LH IIB/LH IIIA1' floor level rested directly on the natural bedrock. ${ }^{29}$ It was on this basis that Barbro Santillo Frizell raised the question of the redefinition and characterisation of LH IIB and LH IIIA1 pottery phases in general. The same problem reappears in Kea where it has been suggested that a real LH IIB level exists in Building A, which would bridge Phase VII and Phase VIII (rooms 7-8, 10-11). However, pure LH IIB deposits are either both rare and small or of uncertain status. They appear in the higher levels of phase VII (VIIc) but are not related to any floors. ${ }^{30}$ Although fragments of Ephyrean goblets occur in these levels, ${ }^{31}$ the type is also present in earlier pottery phases (LH IIA/LH IIB).${ }^{32}$ In the western sector Ephyrean goblets appear in deposits of the VIIb phase and are associated with

25 BLEgEN et al. 1973, 54, 312. - This layer was assigned to the second settlement of the palace. The layer on the top that showed further traces of burning and destruction belongs to the last phase of the palace.

26 Blegen et al. 1973, Figs. 151-152; 155/1-10. - Cf. Mountjoy 1999, Figs. 111/45; 112/58.

27 Dickinson 1972, 103-105.

28 Frizell 1996, 1290.

29 Frizell 1980, 60. - Frizell 1996, 1290.

30 In Room 7 the LH IIB level cannot be readily separated from the destruction deposit of phase VII: Cummer, Schofield 1984, $143-$ 144. - See Cummer, Schofield 1984, 60-61 and Pl. 29/a-I, k-1 for the plain goblets from Room 10 (LH IIB level) and SHOFIELd 2011, 165 for deposit C in Room W.23 in the western sector.

31 Cummer, Schofield 1984, 60 and Pl. 50a (LH IIB level D in Room 10). - The deposit with the plain goblets from Room 11 contained a handle of an Ephyrean goblet but the context is contaminated and it has been dated to LH IIB or LH IIB/IIIA1: Cummer, ScHOFIELD 1984, 62.

32 See Cummer, Schofield 1984, 143, note 12 for the find spots of Ephyrean goblets in the destruction horizon of phase VII and in the LH IIB level. - For a complete example from the Phase VII destruction deposit of Room 21 see Cummer, Schofield 1984, Pl. 75/1161. - For the phases at Ayia Irini see SHofield 2011, viii. 
pottery of LH IIA style, suggesting an earlier beginning for the type. ${ }^{33}$ In addition, vessels with fine stipple pattern occur in the western sector together with LH IIB goblets. ${ }^{34}$ Consequently, an earlier start of the fine version of the stipple pattern in Kea is supported by the material from Korakou where the motif also appears in LH IIB levels, ${ }^{35}$ probably as an innovation. Smaller LH IIB deposits have been identified in the lower town of Tiryns (House D1). ${ }^{36}$

Most of the settlements and contexts described above were occupied during LH IIIA2 but the relevant material does not always come from floor deposits. However, well stratified settlement deposits dating to this phase are known from the Argolid (Mycenae, Tiryns), Tsoungiza, Mitrou and from many funerary contexts around the Aegean. The earliest stage of the phase remains poorly known, particularly with regard to its differentiation from LH IIIA1. Arne Furumark has suggested that the phase should be sub-divided. ${ }^{37}$ Elizabeth French assumed the existence of an intermediate stage between LH IIIA1 and LH IIIA2 but she didn't identify any stratigraphic evidence for this at Mycenae. ${ }^{38}$ The kylix, FS 256, which is difficult to identify when sherds are found amongst fragmented material, is thought to belong to the early part of the phase. ${ }^{39}$ Octopus and whorl shells as well as the kylix FS 257 with a banded stem are all considered to start in LH IIIA2 Late. ${ }^{40}$ The multiple stem (FM 19) is thought to appear as an innovative motif during LH IIIA2 Early, although some sherds have been recorded at Atreus Bothros. ${ }^{41}$ The LH IIIA2 Early phase is mainly known from funerary contexts and from a dump at Tsoungiza. This assemblage was not related to a specific

33 Schofield 2011, 86-87, 96 and Pl. 58/1080 (period VIIb).

34 See also Schofield 2011, 176-177 and Pl. 78/2124, 2133 (Phase VIIb destruction). - Mountjoy dates the material to phase VIIc in LH IIB: MounTJOY 1999, 879 and Fig. 358/52-53.

35 Dickinson 1972, Pl. 33b. - Mountjoy 1999, 214 and Fig. 67/91. - Among the catalogued pottery from House D1 in the lower town of Tiryns there are sherds of mugs with the stipple pattern: Hiesel 1975, 23 and Pl. 24/1/c, f.

36 Hiesel 1975, 18-19, 22-23. - Hiesel mentions also a very small amount of LH IIIA1 pottery amongst the material found on top of the walls and the floor of the building (e.g. fragment of a mug with stipple pattern): Hiesel 1975, 23 and Pl. 24/1.

37 Furumark 1941, 101.

38 French 1965, 160. - According to French 1965, LH IIIA2 Early is represented only by funerary contexts in Mycenae, whereas Late LH IIIA2 is represented by the fill of the terrace houses (terrace on the Atreus ridge and terrace below the House of the Shields), the Petsas House and the fill of the Dromos of Tomb 505.

39 Mountjoy 1999, 28-29.

40 SChÖNFeld 1988, 158. - Thomas 2011a, 224.

41 Thomas 2011a, 225. - See French 1964, 260-261 for earlier examples. floor but was sealed by LH IIIA2 and LH IIIB levels (trench EU9). Because of the rarity of LH IIIA2 Early settlement contexts, the picture is rather more obscure with a tripartite division of the period and the recognition of an even earlier stage within LH IIIA2, which closely resembles LH IIIA1 in style. A tripartite division of LH IIIA2 has been proposed at Nichoria but the early phase is rarely attested stratigraphically. Amongst the new vessel forms are stemmed bowls (although these are very rare), while the rims of goblets and kylikes are more rounded than is the case in LH IIIA1. ${ }^{42} \mathrm{At}$ that time, pattern painted goblets are infrequent. In terms of the tripartite division of LH IIIA2, the decorated kylikes appear in the middle phase of LH IIIA2, which correlates with Furumark's LH IIIA2 Early phase. ${ }^{43}$ The carinated kylikes have a straight upper section with lipless or rounded rims and a straight inner lip. ${ }^{44}$ In the late phase, kylikes FS 257 are common, whereas other differences suggest changes in the proportions of the pottery types present, rather than changes in the style. ${ }^{45}$ The introduction of the deep bowl that is however still rare in LH IIIA2 seems to represent a useful way of separating the early from the latest phases. ${ }^{46}$ According to Cynthia Shelmerdine the material from the terrace on the Atreus ridge represents an even more advanced stage than does the LH IIIA2 Late style in Nichoria with motifs that continue into LH IIIB1, while Guntram Schönfeld re-dated the deposit to LH IIIB Early. ${ }^{47}$ In Area Epsilon at Ayios Stephanos a large group of early LH IIIA2 wares (mostly drinking vessels) has been excavated in a small area in the extension of the trench. ${ }^{48}$ The pottery was not associated with a floor and, given the pronounced elevation of the surface, it has been suggested that it was washed down from elsewhere. Since it was also found above the existing walls, the area must have been out of use when the pottery was washed down. However, the deposit was also partially disturbed. The wash layer was associated stratigraphically with LH IIIC Early sherds, whereas an underlying earth

42 Shelmerdine 1992, 495-497, 586 and Fig. 9-39.

43 Shelmerdine 1992, 496.

44 Shelmerdine 1992, 501, 594 and Fig. 9-47/P3721-P3722.

45 Shelmerdine 1992, 496.

46 French 1965, 184 (one sherd in the Atreus terrace ridge), 194. - Thomas 2011a, 179-180 and Fig. 5/15 (one sherd in stratigraphic units $1576-1579$ of LH IIIA2 Late period in Tsoungiza). According to Thomas the material from stratigraphic units 1576-1579 bridges LH IIIA2 Late with LH IIIB1. - ViTALE 2011, 342 and Tab. 5.

47 SchönfEld 1988. - The deep bowl appears in Nichoria in LH IIIA2/LH IIIB1: SHELMERDINE 1992, 497.

48 Mountjoy 2008, 304-313 and Figs. 6.3-6.9. - TAylour, Janko 2008, 17-19. - Only one kylix was found to the west of this concentration. 
pocket containing pottery was dated to LH IIA. ${ }^{49} \mathrm{~A}$ number of walls dating to LH IIIC or LH IIIA2 also exist, but no associated floors have been identified..$^{50}$ Originally dated to LH IIIA2 Early, ${ }^{51}$ the wash deposit from Area Epsilon has been re-dated by Salvatore Vitale to LH IIIA2 Middle. ${ }^{52}$ A tripartite division of LH IIIA2 has been also applied in Mitrou based on the evidence of sequences from a road. Following this, Vitale has also re-dated the pottery from trench EU9 in Tsoungiza to LH IIIA2 Middle. ${ }^{53}$ The presence of painted stemmed bowls (mainly monochrome but occasionally bearing linear or pattern-painted designs) as in Nichoria has been proposed as main criterion for distinguishing LH IIIA1 from LH IIIA2 Early, ${ }^{54}$ although painted stemmed bowls also appear in even earlier contexts. ${ }^{55}$ Another shape that should begin in LH IIIA2 Early is the painted cup (FS 214), but this is a very rare form. ${ }^{56}$ However, it needs to be stressed that the LH IIIA1 and LH IIIA2 floors were not found in a vertical sequence at the same location. ${ }^{57}$ In addition, the LH IIIA1 material from Mitrou is, in terms of quantity, very restricted and some types are the same as those found in LH IIIA2, (the monochrome goblets with a short base, 'kantharoi', for example), whereas some other open painted forms have short lips, as in LH IIIA2. ${ }^{58}$ A very useful criterion for separating LH IIIA2 early from LH IIIA1 in Mitrou is the decrease of the Aeginetan pottery in the contexts dating to the former period.

\section{Methodology}

The first stage in the classification of the pottery was the identification of the wares represented in the assemblages

49 TAylour, Janko 2008, 13, 15-17, 21 and Figs. 1.3-1.5.

50 An original ash layer and plaster assigned to a LH IIIA2 destruction was found in connection with walls ke and kf: TAYLOUR, JANKO 2008, 18-20 and Figs. 1.6-1.8.

51 Mountjoy 1999, 28. - However, Mountjoy 2008 often refers to the assemblages as LH IIIA2 Middle.

52 See Vitale 2011,341-342 and Tab. 5, although part of the material he dates to LH IIIA2 Late. - See also Thomas 2011a, 224.

53 Vitale 2011, 341.

54 Vitale 2013, 129.

55 MARTIN 1992, 490 reports a goblet with horizontal handles among the LH IIIA1 material from Nichoria. - See also FRENCH 1964, 250 and Fig. 2/6 (Atreus Bothros, with stipple pattern, beginning of handle preserved).

56 Also a small goblet cannot be excluded: Vitale 2011, Fig. 2/1.

57 Vitale 2013, 123. - LH IIIA1 pottery comes from an exterior surface and a pit opened in this surface southeast of Room 1 in Building $\mathrm{H}$.

58 Vitale 2013, Fig. 2/c, e. - The LH IIIA2 goblet with thin line on the exterior and monochrome interior has been suggested by ТномAs 2011a, 196, 225 and Fig. 10 as a marker for the Early LH IIIA2, although in Mitrou the cups (FS 214) have a broader band on the exterior rim: Vitale 2011, Fig. 2/1. and the quantification of all sherds by ware type..$^{59}$ Following this, all of the diagnostic sherds were counted separately (MNI), measured and the percentages of the rims and base diameters calculated in order to establish an accurate basis for the statistical analysis (Tab. 3). ${ }^{60}$ Only a small part of the material was suitable for statistical evaluation ('Floor' 3 and layers sealed by 'Floor' 4 in trench I $18 \alpha / \beta$, see below). As with every pottery study, various practical problems were encountered in the course of the analysis. Notable amongst these were the following: the lack or rarity of reliable stratified contexts from the early Mycenaean phases for comparative purposes; the different approaches taken to the recording and statistical evaluation of the material and, last but not least, the fragmented condition of the assemblages from settlements. The degree of fragmentation often hampers both the exact classification of the ware (slip or burnishing not preserved, etc.) and the identification of the vessel form. The classification of the diagnostic sherds follows Furumark's system wherever possible. As it was apparent that a large part of the material dating from LH II to LH IIIA2 was either monochrome or plain it was decided to expand the study with a rim/base classification system. ${ }^{61}$ This was designed to serve as a further tool in our attempts to understand the extent of continuity and change in the commonest features that characterise the style of each phase, rims being a sensitive chronological feature. ${ }^{62}$ Moreover, this approach provides a fuller overview of the material in cases where not all sherds have been drawn (Tab. 2). Furumark's classification has been followed in the case of the decorative motifs, while Christian Podzuweit's classification has been followed in the case of the linear decoration. ${ }^{63}$ The aim of the recording system is intended to be the development of an internal chronological and typological system that will be bound to the stratigraphic sequence in the palace and will allow synchronisation with other areas.

59 In general RuTTER 1995 is followed. - For a discussion of wares and their defining features see Horejs 2010, 20-23.

60 Orton, Tyres, Vince 1993. - Bader 2010. - See Jung 2010, 146-148 for a discussion of the statistical analysis of the Mycenaean pottery. - However, BADER 2010, 228 stresses that the effort of calculating base EVEs is only worthwhile in sealed contexts.

61 Such an attempt to classify and quantify rim and decoration types of Late Bronze Age pottery has been made by ScHönfeld 1988, Tab. 1 on LH IIIA2 Late - LH IIIB Middle pottery from the Lower Citadel of Tiryns. - See also Stockhammer 2008, 111-114 and Fig. 21-55 for a rim/base/handle/leg typology according to fabric of the sherds from the LH IIIC material from the NE-Lower Town. 62 It has often been pointed out that Furumark's classification system lacks a detailed scheme for rims, bases and handle types, which form the bulk of material in settlement deposits: JUNG 2002, 65. - See also Podzuweit 2007, 18.

63 Podzuweit 2007. - KARdamaki 2013 with few additions regarding pottery of LH IIIB2 and LH IIIC Early 1 sub-phases. 
Finally, a brief note needs to be added concerning the theoretical approach followed for the dating of the pottery. In settlement contexts the study of sealed floor deposits provides the only secure base for developing typological and chronological frameworks for a given site. Such contexts are, however, often missing or poorly preserved and the ceramic expert needs to rely on additional information derived from various different types of settlement deposits (wash deposits, refuse), which may contain pottery from more than one phase. One of the major problems in terms of the study of the floor deposits and the fills overlying them is related to the evaluation of the sherds and their relationship to complete vessels from the same or other contexts. The problem stems from the fact that the precise origin of the fragmentary material cannot always be determined (discarded material on floors, earlier strays within fills, tiles or floors). It may be contemporary with, earlier (residual) or later (intrusive) than the latest use of a floor or structure. However, only the full recording of the pottery can provide the necessary evidence pertaining to site formation processes and the use of floors within a given context. In general, there are two main criteria for dating a floor deposit. The first involves dating the latest material, while the second involves dating the general style of the most frequent diagnostic sherds. In the latter case the latest material is treated as innovative. The early (residual sherds or heirlooms) and the late pottery (innovative) is isolated by the statistical analysis and both groups are statistically recognisable as rare or very rare groups. ${ }^{64}$ This approach allows the reconstruction of a more realistic picture of the pottery consumed in a given sub-phase or period, but in order to provide secure data it requires sequences of well preserved and sealed floor deposits, as found, for example, at Tiryns. ${ }^{65}$ While the pottery from the selected contexts at Ayios Vasileios is being recorded in full, only few of the cases identified to date represent sealed floor levels suitable for a study that considers the aspects of innovation, fading and floruit within the pottery assemblages. Part of the material presented here comes from fills that were not sealed by new floors (the 'Ditch' and the fill above 'Floor' 3 in trench $118 \alpha / \beta$, Room 6 in trench $\mathrm{I} 18 \alpha / \beta$ ), or from underfloor fill terracing (western stoa) and

64 For the discussion see KILIAN 1988 and SCHÖNFELd 1988.

65 For the methodological problem of combining and comparing statistical data resulting from complete vessels (on floors mainly) and sherd material from fills see FRENCH 2011, 67. - It is often assumed that the fully preserved vases, as opposed to the fragmented sherds, deliver a closer dating for the final use of a structure or floor. However, only the full recording of the sherd material allows a complete understanding of the stratigraphy and layer formation and can serve as a basis for statistical and typological comparison. dumps (fresco dump, south-eastern deposit). ${ }^{66}$ In the case of trench $\mathrm{I} 18 \alpha / \beta$ the two highest levels, if they existed at all, were heavily damaged and may be contaminated by later material. The most crucial methodological issue raised here concerns the classification of these fills (south-eastern deposit, 'Floor' 3 in trench $\mathrm{I} 18 \alpha / \beta$, fill under the western stoa) that date to phases, which remain poorly defined. Thus, while the pottery from these contexts appears rather homogeneous, few sherds or vessels belong stylistically to the following phases (the latest LH IIIA1 and early LH IIIA2). Until more material from stratified floor deposits has been excavated at Ayios Vasileios it seems more appropriate in these cases to consider the latest material as indicative of the date of the structures and other events (the final use of a floor or the moment of deposition, for example).

\subsection{The Rim Typology}

In the course of the study, more than 340 different rim types were identified and recorded. They belong to all of the wares, but the majority come from the group of fine pottery and belong to open forms (painted and plain) (Tab. 2). The rim types were classified according to the exact shape, length and thickness of the rim and the orientation of the profile. Other variables, such as the rim diameter, were not considered as in almost all cases similar rim types come from vessels of a similar size and with a similar rim diameter. This method of recording has highlighted the extent of diversity within the material and even within individual vessel types, as represented by the rims. While all of the rim types defined will be presented in full in a future publication, individual rim types that shared similar features have here been aggregated into broader categories in order to provide a clearer picture of the development of the various rim shapes. Corresponding features include similarities in the length, shape or thickness of the rims, or the height of the carination in the case of the carinated kylikes (FS 267).

Table 2 shows the stratigraphic distribution of the most characteristic rim categories as they were identified in trench I18 $\alpha / \beta$ (Tab. 1), the fresco dump and the south-eastern deposit (Tab. 6). ${ }^{67}$ Using these data, it is evident that the distribution of specific rim types has a chronological significance. The first group contains tall everted rims (often thin), tall and slightly everted rims (often thin) and, rims

66 See MounTjoy 1993, 120-121 for a classification of settlement deposits. - In the present work we are mainly dealing with what is called underfloor terracing (under the western stoa), casual tipping (fresco dump) and floor deposits (southern stoa and trench I18 $\alpha / \beta$ ). 67 The rims of the conical cups and Vapheio cups are not included in the table. The rim types shown in Table 2 represent a summary of the individual rim types. 
with a hollowed interior (Tab. 2/1, 3, 5, 11, 17, 23); ${ }^{68}$ the second group contains thicker tall and medium tall rims (Tab. 2/81, 85, 44, 69), the third mainly short everted and short rounded rims (Tab. 2/68, 34, 12, 28, 94, 33, 112, 90). The fourth group covers rims with a carination (kylikes FS 267, bowls FS 295) (Tab. 2/51, 86, 30a, 32, 36, 31, 38, 186, 198, 177, 209, 165, 174, 175, 180, 202, 206, 340, 111, 98, 45). The first obvious change relates to the decrease in the tall rims from the first group after 'Floor' 4 (the lowest pebble surface). Few were found in the south-eastern deposit and they were almost absent from the fresco dump (LH IIIA2). Medium tall rims were common in 'Floor' 3 (the higher pebble surface) (LH IIIA1 - LH IIIA2 early) and they were well represented in the south-eastern deposit. Short everted and short rounded rims, related to the semi-globular kylix such as FS 264-266, 256-257, are typical of LH IIIA2. The short rounded rims (Tab. 2/112) were extremely rare and appeared in secondary or mixed deposits (Fig. 8/124) and in Room 6 (Fig. 10/170-171). A similar rim type was noted on a kylix from the destruction deposit associated with the southern stoa (Fig. 20/318). A few of the carinated kylikes from the fresco dump have a short rounded rim (Tab. 2/180). Another change involves the appearance of the carinated rims from trench $\mathrm{I} 18 \alpha / \beta$ in Building B, something that seems to occur rather suddenly and is associated with 'Floor' 3 (the highest pebble surface). These rims have the carination high on the vessel and they differ from those in the fresco dump (LH IIIA2) and Room 6, which have later profiles with a low carination and rounded or flaring rims. The earlier version of the carinated rims is also known from the south-eastern deposit (Tab. 2/30a, 32, 38). Other rims such as those depicted in Table 2/114, 58, 72, 80, 212, 203 come from small vessels (e.g. cups). Some are very rare, but all are attested at 'Floor' 3 and later in Building B. The stratified material is, however, limited in terms of quantity and many important rim types (such as rims with early features and craters) appear in layers with mixed material ('Ditch', Tab. 2/51). It is hoped that the excavation will eventually produce a sequence of the commonest shapes based on a larger sample derived from well-stratified deposits.

68 The definition 'tall', 'medium tall' rims refers to the material from the contexts presented here. There will be possibly some alterations after material from other phases has been incorporated in the rim chart as rims from earlier phases (e.g. LH IIA) are usually even taller than what we call tall everted in this paper.

\subsection{The Pottery Wares}

In this section the principal wares which have been identified macroscopically will be described. ${ }^{69}$ A broad division based on the size and density of the non-plastic inclusions was used to distinguish between fine, semi-coarse and coarse pottery (Tab. 3). ${ }^{70}$ These three classes were further divided into several sub-groups defined according to the texture of the clay, the surface treatment of the vessels and the presence and quality of the paint. The fine wares consist mainly of fine plain and lustrous painted Mycenaean pottery. Fine to medium-coarse plain and burnished pottery is very rare and probably residual in nature. In terms of the colour of the clay, slip and texture the painted pottery was found in three principle variants. The first group includes sherds with light brown, light grey and, more rarely, light red, well-fired clay with black paint. Many pattern-painted sherds and all of the sherds of Vapheio cups with the ripple pattern belong to this group. Although more data are required in order to confirm this, it seems that this ware-type occurs mainly in the earlier phases (pebble surfaces in trench $I 18 / \beta$ and in the south-eastern deposit in trench B15 (LH IIIA2 Early). The most frequent ware-type consists of sherds with soft to hard-fired pink/red chalky clay and red/brown paint. Occasionally the clay contains a few inclusions. This group consists mainly of monochrome and linear painted vessels, especially goblets and kylikes. It is very common in all of the contexts studied. Another ware-type, found mainly in trench $\mathrm{I} 18 \alpha / \beta$, is represented by monochrome sherds with orange clay and a few sparse inclusions, mainly of a whitish colour. Minor groups are represented by sherds with grey cores, sparse mica inclusions and black paint and mainly take the form of monochrome goblets or kylikes from the higher levels in trench $\mathrm{I} 18 \alpha / \beta$.

A number of different ware-types were also identified within the class of fine plain pottery. One group includes sherds in a red chalky clay, and with slip that is often

69 The wares are defined according to the fabric, colour and texture of the clay, colour, size and density of inclusions, colour and quality of paint, and surface treatment. - See RUTTER 1995, 11-14 for the definition of ten classes of wares on EH III pottery from Lerna IV.The colour of the clay is described according to Munsell Soil Colour Charts. No attempt has been made to identify the non-plastic inclusions, but in a few cases the presence of mica and schistose has been noted.

70 The fine fabric includes sherds without inclusions or with very rare inclusions, although they often contain mica. Medium coarse fabrics include sherds with inclusions up to $4 \mathrm{~mm}$. The coarse fabrics have inclusions larger than $4 \mathrm{~mm}$. For the density of the inclusions the following division is used: 'occasional', 'some', 'many', 'massive amounts'. - See Rutter 1993, 59. - See also Maran 1992, 119. 


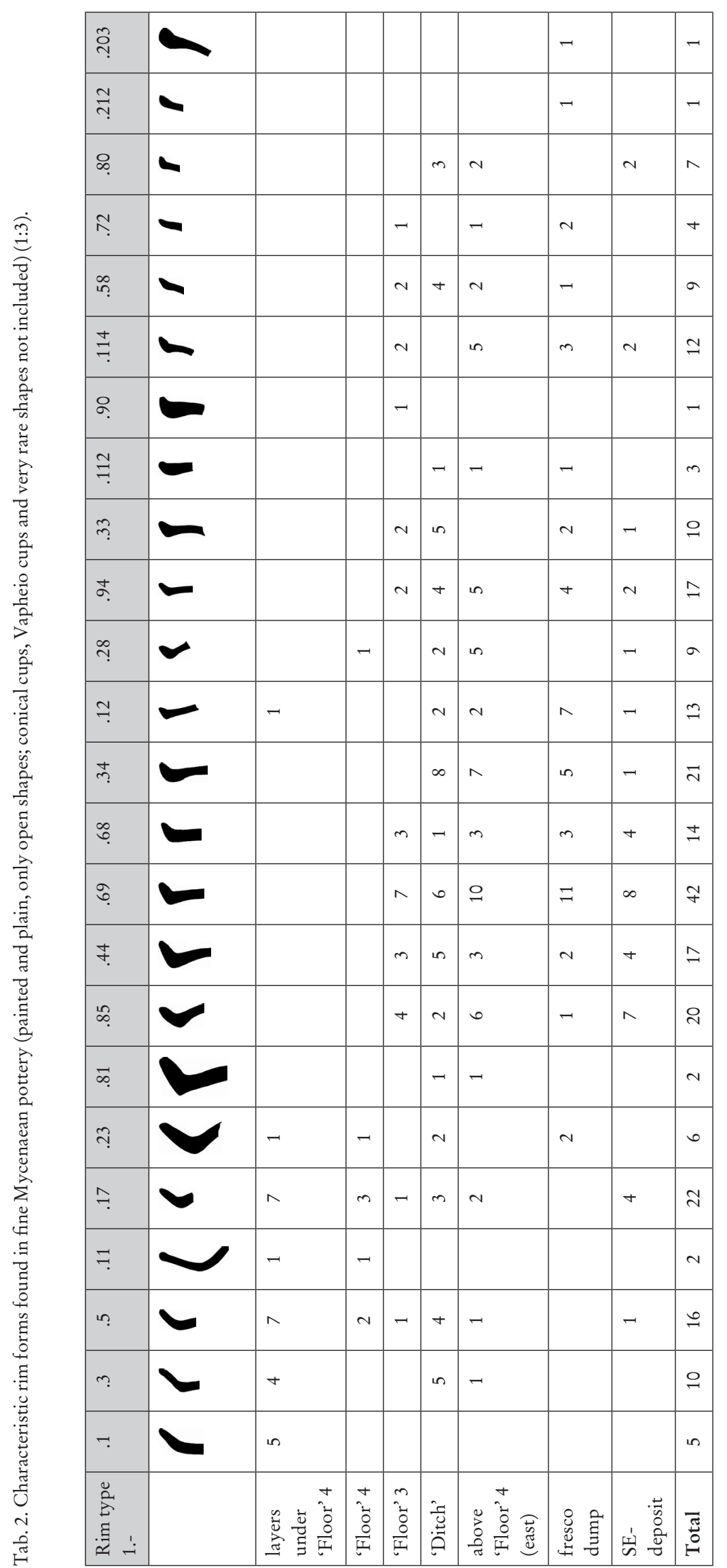




\begin{tabular}{|c|c|c|c|c|c|c|c|c|c|}
\hline हَّ & & $\stackrel{\sim}{\sim}$ & $\infty$ & l & 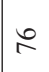 & $\approx$ & $\stackrel{\infty}{=}$ & $i n$ & \\
\hline $\bar{\infty}$ & $\nu$ & & & & & & $m$ & & n \\
\hline$\stackrel{゚}{\beth}$ & & & & & & & 6 & - & $n$ \\
\hline$\stackrel{n}{f}$ & & & & & - & & & - & N \\
\hline$\stackrel{\infty}{\sigma}$ & & & & & - & - & & & $\sim$ \\
\hline$\Xi$ & 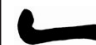 & & & - & & & & & - \\
\hline 离 & & & & & & & - & & - \\
\hline ֻุ & & & & & & & - & & - \\
\hline ชิ & & & & & & & - & & - \\
\hline 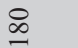 & & & & & & & in & & in \\
\hline$\cong$ & 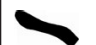 & & & & & & $m$ & & $m$ \\
\hline$\stackrel{ \pm}{I}$ & & & & & & & 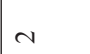 & & $\sim$ \\
\hline$\approx$ & 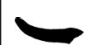 & & & & & & $m$ & & $m$ \\
\hline ิㅗ & - & & & & & & $n$ & & $r$ \\
\hline 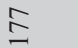 & 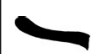 & & & & & & 으 & & 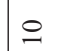 \\
\hline$\stackrel{\wp}{\beth}$ & 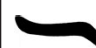 & & & & & & $=$ & & $=$ \\
\hline$\infty$ & 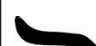 & & & & & & $n$ & & $n$ \\
\hline$\underset{m}{\infty}$ & - & & & & - & - & $m$ & N & $n$ \\
\hline $\bar{m}$ & $\nu$ & & & $\mathrm{N}$ & ナ & $\simeq$ & & $n$ & $\vec{\sim}$ \\
\hline ల) & 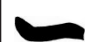 & & & - & t & - & - & - & $\infty$ \\
\hline$\approx$ & $\sim$ & & & $\mathrm{N}$ & in & a & 0 & $r$ & $\approx$ \\
\hline 今ึ & - & & & & - & $m$ & - & N & $r$ \\
\hline$\infty$ & 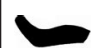 & & & - & & & & & - \\
\hline $\bar{n}$ & $\nu$ & & & & - & & & & - \\
\hline 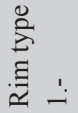 & & 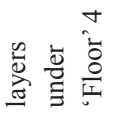 & 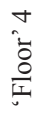 & 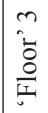 & 递 & 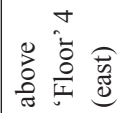 & 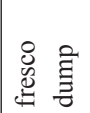 & 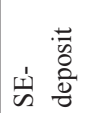 & 吾 \\
\hline
\end{tabular}


abraded. Dust-sized shiny mica inclusions are often visible on the surface of the sherds. Another ware type is distinguished by its well-fired buff/light grey clay. Finally, one ware-type consists of sherds made from a well-fired pink clay with mica inclusions. The majority of the conical cups belong to this fabric group. A few vessels are made of wellfired, greyish clay.

One of the common medium coarse wares has a gritty fabric. The clay is orange to light brown in colour and the inclusions range in density from 'some' to 'occasional' or 'massive' amounts. Sherds of this group have a light slip and in some cases, traces of burnishing are preserved. The character of the inclusions is diverse with the shapes varying from round to angular and the size from small to medium. Colours include black, brown and white, the latter possibly calcite. Shiny platy inclusions (schist?) are also visible. A small number of sherds, which belong to this or to very similar fabrics, have lustrous and, in one case, matt paint. All of the vessels are handmade and the closed vessels from the group have a very distinctive method of handle attachment, which involved cutting a hole through the wall of the vessel. Although the description of the clay and inclusions is not dissimilar to that of the lustrous decorated pottery (a Minoanising class of pottery) identified in considerable quantities at Ayios Stephanos, the distinctive method of attaching the handles has not hitherto been observed in the latter wares.

The hand-made cooking pots (button-based jugs and tripods, the latter rare) are made of a low-fired fabric generally with brown, smoothed surfaces, which are only occasionally burnished. The inclusions are small to medium in size and black, brown and white in colour and include mica. Rare red shiny, platy inclusions are also visible. Sherds of this type were identified in all contexts. One sub-group includes sherds with gritty fabrics and a high density of silvery, shiny, platy inclusions. Another group consists of wheel-made vessels in a micaceous fabric. This type came mainly from the higher levels in trench I18 $\alpha / \beta$ and was also present in the fresco dump. Finally, one cooking-pot fabric includes wheel-made vessels with a hard-fired, red, sandy clay body.

A common and distinctive ware is identified as the red silver mica fabric. The clay varies from red to grey in colour and the surface of the sherds has a high density of mica with rarer medium-sized angular silver platy inclusions. Some of the rims have distinctive impressions similar to those seen on many of the vessels from Ayios Stephanos and Kythera, which might suggest that they were imported from Kythera. Vessel forms include distinctive basins with horizontal strap handles, but other shapes (closed shapes) are also well represented. At present it is unclear whether the rarity of this fabric in the fresco dump (LH IIIA2) is connected with the chronological distribution of the ware. A sub-group of the fabric was used for wheel-made micaceous cooking tripods, which are well known from LH IIIA2 deposits at Kythera. The clay is red to orange in colour and the dustsized sparkling inclusions are not that frequent nor present at such a high density as in the main group. The inclusions are small to medium in size and occur in various colours (white, silver, dark).

Many of the MH wares identified at Ayios Stephanos were absent from the material recovered from the Building B-trench $I 18 \alpha / \beta$. That the lowest levels so far identified in trench $I 18 \alpha / \beta$ are not very early is further indicated by the low quantity of sherds representing the lustrous decorated and sand-tempered pottery. Only one very small sherd with incised decoration belongs to the grey Minyan ware group. The gradual decrease in the hand-made coarse and burnished wares that continued a local $\mathrm{MH}$ tradition, and their replacement by the fine plain pottery, has been observed in several regions in the course of LH II, although local variations also exist. ${ }^{71}$

The main groups and the various sub-groups identified in the pottery assemblages demonstrate the variability of the material and this may be linked with changes in pottery technology and consumption. These aspects will be studied both petrographically and chemically (using NAA) in order to understand the production processes, the distribution of the material and the existence of 'local' versus imported pottery. ${ }^{72}$

\section{Building B}

In trench $\mathrm{I} 18 \alpha / \beta$ an area measuring $1.70 \mathrm{~m} \times 2.40 \mathrm{~m}$ was identified lying between two $1 \mathrm{~m}$ thick walls running in a northwest to south-east direction (walls 42 and 71) (Figs. 2-3). During the excavation a sequence of five levels was identified in the western part of the trench, although for the two higher levels ('Floor' 1 and 'Floor' 2) further investigation is

71 See, for example, the LH IIB/LH IIIA1 wells in Athens: MounTJOY 1981, 74-79. - See RUTTER 2015 for the development of the handmade plain or burnished classes from MH IIIA to LH IIA in Tsoungiza.

72 Although it is too early to propose a definitive answer to the question of pottery production on the site, no wasters have yet been identified amongst the material. It is still not possible to suggest whether the pottery (or part of it) can be characterised as 'local' or 'regional'. Regional pottery is defined by RUTTER 2015 as deriving from areas within a radius of $10 \mathrm{~km}$ around one site. In this case, pottery from the Menelaion or Ayios Stephanos would be classified as supra-regional imports. 


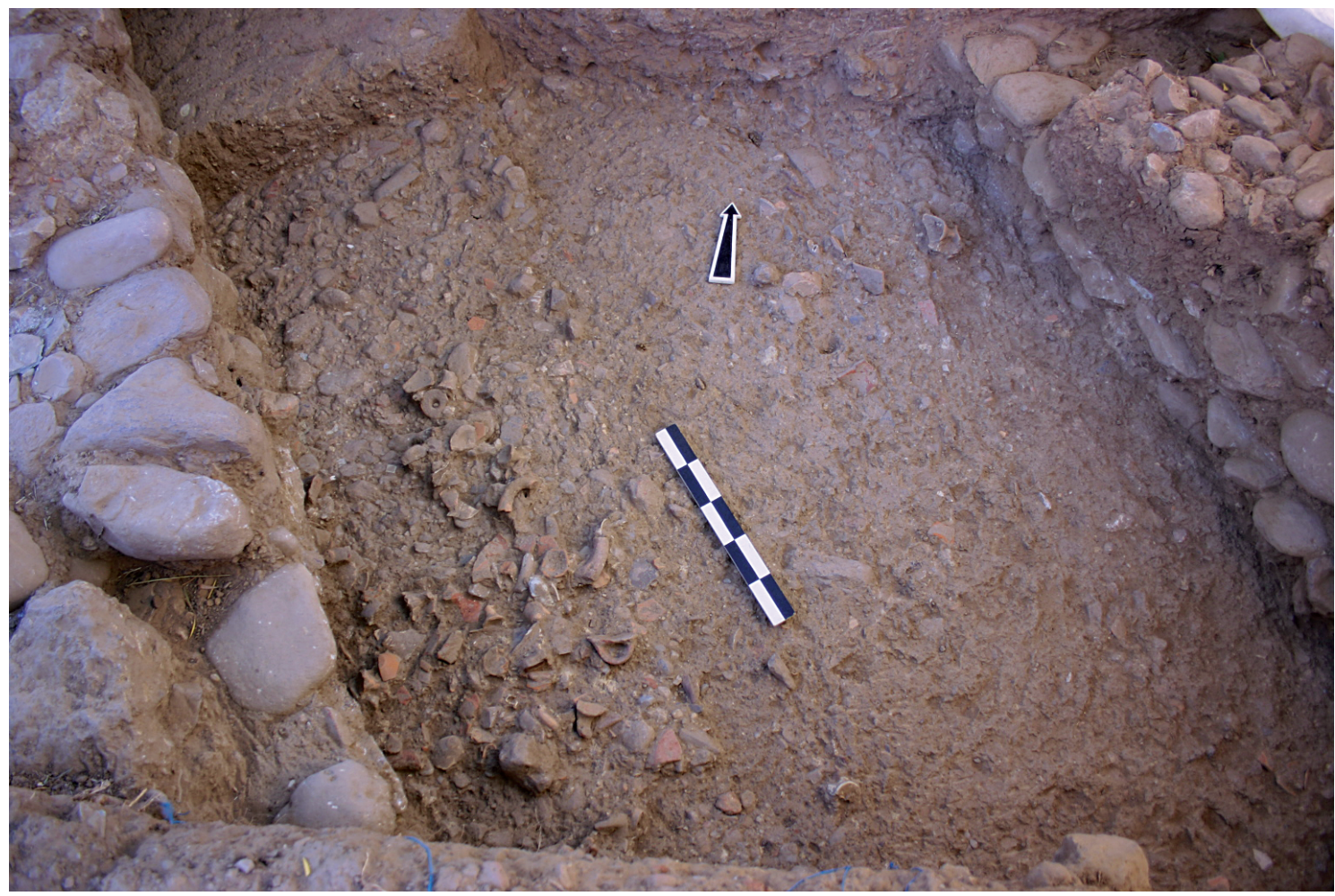

Fig. 2. Building B. Trench I18 $\alpha / \beta$. From left to right: wall 71, 'Floor' 2 (top left), 'Floor' 3 (highest pebble surface) with sherds on top of it, 'Ditch', wall 42 (Photo: E. Kardamaki; courtesy of A. Vasilogamvrou).

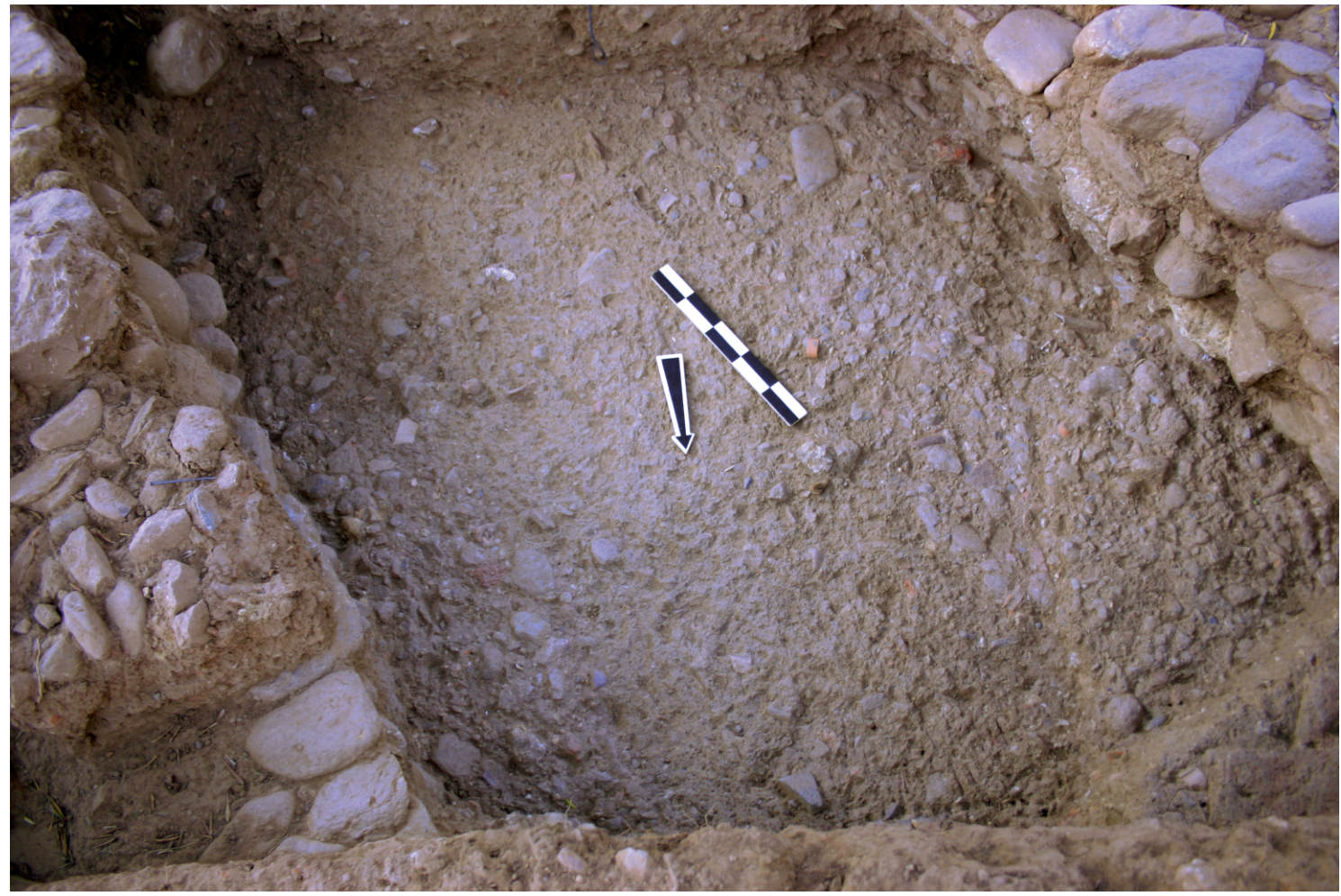

Fig. 3. Building B. Trench I18 $\alpha / \beta$. From left to right: wall 42, 'Floor 4 (lowest pebble surface), 'Ditch', 'Floor' 4 (lowest pebble surface), 'Floor' 3 (highest pebble surface) and 'Floor' 1 (bottom right), wall 71 (Photo: E. Kardamaki; courtesy of A. Vasilogamvrou). 
required in order to confirm this. If these layers represented surfaces then at best they were made of trodden earth and, for the most part, had been destroyed by subsequent activities (Tab. 1). The highest level ('Floor' 1) consisted of red clay and was identified some $30 \mathrm{~cm}$ below the modern surface. At the same level but in the southern part of the trench two stone slabs were found lying horizontally and associated with wall 71 . It has been assumed that they were related to each other, but the red surface was not identified in that area. Between $9 \mathrm{~cm}$ and $13 \mathrm{~cm}$ below 'Floor' 1 lay a hard, yellowish layer which, as it contained small pebbles, was identified as a putative surface - a hypothesis that remains plausible. The pottery in these levels was very fragmented. In general, the yellowish colour and consistency of the soil did not change much from above 'Floor' 1 and under 'Floor' 2 (above 'Floor' 3). In contrast, a sequence of two pebble surfaces ('floors' 3 and 4 ) beneath 'Floor' 2 was well-preserved (Fig. 3). ${ }^{73}$ The first and highest of these, ('Floor' 3) was found to lie some $12 \mathrm{~cm}$ to $18 \mathrm{~cm}$ lower than the stone slabs of 'Floor' 1, whereas the second pebble surface ('Floor' 4) was laid only $12 \mathrm{~cm}$ below the first. Both of the pebble surfaces were well preserved along wall 71 and up to $55 \mathrm{~cm}$ to the east of it and both were interrupted by the 'Ditch' before they reappeared in the eastern part of the trench. The surfaces are related to walls 42 and 71, which showed evidence of at least two building phases. To the east of the 'Ditch' the highest pebble surface ('Floor' 3) was poorly preserved and only the lowest pebble surface was found in a good condition along wall 42 and extending up to $30 \mathrm{~cm}$ to the west of it. The levels under the second pebble surface ('Floor' 4 ) to the west were investigated by means of a small trial trench $(1.00 \times 0.60 \mathrm{~m})$ that was opened adjacent to wall 71 in the south-western corner of the trench. Under a $10 \mathrm{~cm}$ thick fill a new surface ('Floor' 5) was discovered. This was made of hard packed earth and a polished stone lay on its surface. On its western side, and along wall 71, the soil had a different colour and consistency and also contained stones. It has been assumed that it represents the fill of a foundation trench for the building of a wall. This presumed foundation trench continued below the level of the new surface ('Floor' 5). The lowest fill below 'Floor' 5 and above the natural bedrock was $10 \mathrm{~cm}$ thick and contained only a few sherds and stones. 'Floor' 5 was also interrupted by the aforementioned 'Ditch'. The existence of this feature became clear during the excavation of the two pebble floors. It was $70 \mathrm{~cm}$ wide and ran parallel to the walls. However, it

73 The term 'floor' was applied during the excavation (and has been retained here) since the character of the area as an open space was not clear. is unclear whether the so-called 'Ditch' also had the same form in the higher levels above 'Floor' 3. Its relationship to the two highest floors ('floors' 1 and 2), which were poorly preserved to the west and unidentifiable in the eastern part of the trench, is uncertain. However, in terms of pottery typology the material from the 'Ditch' and from 'floors' 1 and 2 (or the soil between them) was the same, whereas the material found directly on 'Floor' 3 (the highest pebble surface) seems to be slightly earlier in date and probably represented the final stage of LH IIIA1 or the earliest phase of LH IIIA2.

The following stratigraphic features are the main source of information for the present study: (i) the deposits lying on the pebble and other surfaces ('floors' 3-5) and the fills above and below them in the western part of the trench; (ii) the 'Ditch' (interrupting the pebble surfaces and the lowest surface dubbed 'Floor' 5); (iii) the pottery from the eastern part of the trench, above the second pebble surface, which was treated as a single unit and probably contained mixed pottery from the uppermost (and largely destroyed) pebble surface ('Floor' 3 ) and other higher levels. Furthermore, the pottery from the 'Ditch' has a mixed character and the latest material provides a terminus post quem for its opening. Only two cross-context pottery joins were identified linking different stratigraphic units. The first of these came from the foundation trench of wall 71 and 'Floor' 5 . The second one consisted of three sherds that came from 'Floor' 5 , the fill above 'Floor' 5 and the lowest pebble surface ('Floor' 4). They probably indicate that material from the earlier fill was used for the construction of the pebble surface. The first may suggest that the foundation trench for the building of the wall interrupted the lowest 'Floor' 5 . It is possible that more material from the foundation trench originally belonged to the level of 'Floor' 5.

The material from all of these stratigraphic units is fragmented and no vessel with a fully preserved profile survived in the small area excavated so far. The 'Ditch' contained a very large number of sherds, fragments of vitrified clay similar to those discovered in the destruction debris of the court and several fresco fragments with decoration. As a result it is possible that a proportion of the material may derive from a room or building that was destroyed by fire at the same time as the court and the west stoa. So far we have no clear evidence for the function of the 'Ditch', but at some point it may have been used as a dump. The material from the pebble surfaces is different. Here, not a single fresco fragment was discovered; a very distinctive feature of these surfaces is the very large number of animal bones discovered lying directly on them. Some of them bear clear cut marks on their surfaces. The density of sherds and animal bones 
was higher closer to wall 71 giving the impression that they had been swept towards the wall. Other finds from the floor deposit include one naturalistic figurine ('Floor' 3), a few bronze tools ('Floor' 3 and fill above 'Floor' 5) and fragments of quartz ('Floor' 3 ). More excavation is required, but the relatively narrow area identified in trench $\mathrm{I} 18 \alpha / \beta$ may have been an open space, probably a road, between rooms or buildings. As a feature, pebble surfaces occur also in other areas of Building B. Directly to the west of wall 71, in trench I18 $\alpha$, where part of a room (Room 6) has been discovered, a layer of pebbles appeared at the same level as the highest pebble surface in trench $\mathrm{I} 18 \alpha / \beta$. This may be a coincidence as the pebbles did not form a proper surface, but it is possible that they once belonged to a floor, which had been disturbed by later activities. If true, this would suggest that such pavements were also used in the interior of the rooms as floors or sub-structures. A similar pebble floor was found during Catling's excavation in Mansion 1. On top of it a group of 133 vessels, many sherds, burnt soil, and numerous animal bones were discovered in situ. In some cases holes or pits were found in the floor, which also contained ceramic vessels. As he conceived of it as inadequate for the floor of a monumental building such as Mansion 1, Catling interpreted it as the sub-floor of the mansion, which had been used as a working surface by the builders of Mansion 2. ${ }^{74}$ A very similar structure was found in Building B at the Aetos South Slope. There too, vessels were found on its surface. ${ }^{75}$

\subsection{The Pottery from Trench I18 $\alpha / \beta$ (Building B)}

The pottery from trench $I 18 \alpha / \beta$ is both highly fragmented and abraded and no complete vessel profiles are fully preserved. Nine hundred diagnostic sherds were recorded from a soil volume of $2.2 \mathrm{~m}^{3} .^{76}$ The open forms are far more frequent than closed forms, totalling $77 \%$ of the feature sherds of the assemblage. Only the diagnostic sherds from the highest pebble surface ('Floor' 3 ) and the levels under the lowest pebble surface as a single separate unit have been statistically evaluated (Tabs. 3-4) as those lying directly on the lowest pebble surface ('Floor' 4) and 'Floor' 5 are too few in number to provide any secure basis for a statistical analysis. Approximately $70 \%$ of the recorded material consists of small sherds, a fact that suggests that a high proportion of the material was part of a fill that may have been brought from elsewhere (especially the 'Ditch' and the fill

74 Catling 2009a, 16.

75 Catling 2009a, 198, 200-201, 203-204.

76 A $0.30 \mathrm{~m}$ thick deposit up to the level of the lowest pebble floor $(1.75 \times 2.40 \mathrm{~m})$, and another $0.30 \mathrm{~cm}$ thick deposit from the trial trench below the lowest pebble floor $(60 \times 80 \mathrm{~cm})$ and the 'Ditch' $(0.70 \times 2.40 \mathrm{~m})$. overlying the highest pebble surface) or that it was discarded during the period of the use of the floors. The pottery found on top of 'Floor' 3 (the uppermost pebble surface) is better preserved and medium sized sherds account for $50 \%$ of the total (Tab. 3). In the following sections the pottery from trench $I 18 \alpha / \beta$ will be described by ware type and within each section the characteristic features of the assemblage as identified in the various stratigraphic units will be discussed. Following this, the pottery from the other contexts (Room 6 in Building B, south-eastern deposit, fresco dump, western and southern stoa) will be described and the chronological aspects of the assemblage will be discussed. The conclusions will be summarised in section 8 .

\subsection{The Fine Pottery}

\subsubsection{The Lustrous-Painted Pottery (Mycenaean)}

\subsubsection{Monochrome Pottery}

\subsection{Goblets}

The monochrome vessels constitute the commonest type of pottery in the assemblage and one, which occurs throughout the stratigraphic units defined in trench $I 18 \alpha / \beta$. The most frequent vessel shape appears to be the goblet, but our wider understanding of its typological development during the periods LH II and LH IIIA is hindered by the high degree of fragmentation and the scarcity of large, high quality, stratified and published assemblages from these periods. A number of features including the length and thickness of the (i) stem, (ii) the rim, and (iii) the handle appear to be chronologically sensitive, but there is also a high degree of variability and some early features (such as the low stem) may continue into later periods. Monochrome goblets occur frequently during LH IIIA $1^{77}$ and probably evolved into the monochrome kylix (FS 264) during LH IIIA2, a form which is very characteristic for this period. ${ }^{78}$ Monochrome goblets continue to exist, but they probably constitute a

77 Cf. Martin 1992, 490, 572 and Fig. 9-25. - Vitale 2013, Tab. 1. - In the case of important LH IIIA1 deposits that were excavated earlier in the last century, monochrome sherds were not always kept. This is the case at Atreus Bothros where the pattern painted pottery is predominant amongst the published material, although the monochrome goblets or kylikes were probably common throughout the deposit: French 1964, 254, note 47a based on a statement of STUBBINGS 1947, 28 who saw the material prior to the culling of the monochrome sherds. - See also Thomas 2011a, 198.

78 Podzuweit 2007, 104 correctly stresses the similarity between kylikes and goblets, arguing that they actually represent two variants of the same vessel form. However, this refers rather to the early phases of LH IIIA. - MARTIN 1992, 489 proposes a close link between the LH IIIA1 kylix and the shallow cup. 
Tab. 3. Trench I18 $\alpha / \beta$. Diagnostic sherds belonging to the most frequent pottery wares and the percentages of rims and bases in the layers sealed by 'Floor' 4 (lowest pebble surface) $\left(144 \mathrm{~m}^{3}\right)$ and on top of 'Floor' 3 (highest pebble surface). Where no numeric value appears for rim and base EVEs, the diagnostic sherds were too small to allow the diameter to be measured. Actual sherd sizes (see STOCкHAMmER 2008): small $(<5 \mathrm{~cm})$, medium $(5-10 \mathrm{~cm})$, big $(>10 \mathrm{~cm})$.

\begin{tabular}{|c|c|c|c|c|c|c|c|c|c|c|c|c|}
\hline & $\begin{array}{l}\text { Layers } \\
\text { under } \\
\text { 'Floor' } 4\end{array}$ & $\begin{array}{l}\text { Actual } \\
\text { sherd size }\end{array}$ & Rims & $\begin{array}{l}\text { Rim } \\
\text { EVEs }\end{array}$ & Bases & $\begin{array}{l}\text { Base } \\
\text { EVEs }\end{array}$ & 'Floor' 3 & $\begin{array}{l}\text { Actual } \\
\text { sherd } \\
\text { size }\end{array}$ & Rims & $\begin{array}{l}\text { Rim } \\
\text { EVEs }\end{array}$ & Bases & $\begin{array}{l}\text { Base } \\
\text { EVEs }\end{array}$ \\
\hline $\begin{array}{l}\text { fine lustrous } \\
\text { (Mycenaean) }\end{array}$ & $\begin{array}{l}53 \\
(39.2 \%)\end{array}$ & $\begin{array}{l}<5 \mathrm{~cm}: 43 \\
5-10 \\
\mathrm{~cm}: 9 \\
>10 \mathrm{~cm}: 1\end{array}$ & 20 & $44.0 \%$ & 9 & $107.0 \%$ & $\begin{array}{l}44 \\
(31.4 \%)\end{array}$ & $\begin{array}{l}<5 \mathrm{~cm}: \\
30 \\
5-10 \mathrm{~cm}: \\
12 \\
>10 \\
\mathrm{~cm}: 2\end{array}$ & 22 & $128.0 \%$ & 7 & $72.0 \%$ \\
\hline fine plain & $\begin{array}{l}40 \\
(29.6 \%)\end{array}$ & $\begin{array}{l}<5 \mathrm{~cm}: 34 \\
5-10 \\
\mathrm{~cm}: 6\end{array}$ & 6 & $40.0 \%$ & 15 & $204.0 \%$ & $\begin{array}{l}62 \\
(42.3 \%)\end{array}$ & $\begin{array}{l}<5 \mathrm{~cm}: \\
26 \\
5-10 \mathrm{~cm}: \\
36\end{array}$ & 25 & $87.0 \%$ & 11 & $398.0 \%$ \\
\hline $\begin{array}{l}\text { medium } \\
\text { coarse gritty } \\
\text { (handmade) }\end{array}$ & $\begin{array}{l}18 \\
(13.3 \%)\end{array}$ & $\begin{array}{l}<5 \mathrm{cm:} 7 \\
5-10 \mathrm{~cm}: \\
10 \\
>10 \mathrm{~cm}: 1\end{array}$ & 4 & $10 \%$ & 6 & $110 \%$ & $\begin{array}{l}6 \\
(4.3 \%)\end{array}$ & $\begin{array}{l}<5 \mathrm{~cm}: 2 \\
5-10 \\
\mathrm{~cm}: 4\end{array}$ & 1 & - & 2 & $27.0 \%$ \\
\hline $\begin{array}{l}\text { cooking } \\
\text { pottery with } \\
\text { schistose } \\
\text { (handmade) }\end{array}$ & $\begin{array}{l}5 \\
(3.7 \%)\end{array}$ & $\begin{array}{l}<5 \mathrm{~cm}: 3 \\
5-10 \\
\mathrm{~cm}: 2\end{array}$ & 1 & $3.0 \%$ & 2 & $200 \%$ & $\begin{array}{l}8 \\
(5.7 \%)\end{array}$ & $\begin{array}{l}<5 \mathrm{~cm}: 4 \\
5-10 \\
\mathrm{~cm}: 4\end{array}$ & 1 & $6.0 \%$ & 3 & $59.0 \%$ \\
\hline $\begin{array}{l}\text { red/orange } \\
\text { cooking } \\
\text { (?) pottery, } \\
\text { sandy with } \\
\text { schistose (?) }\end{array}$ & $\begin{array}{l}7 \\
(52 \%)\end{array}$ & $\begin{array}{l}<5 \mathrm{~cm}: 3 \\
5-10 \\
\mathrm{~cm}: 4\end{array}$ & 2 & $9.0 \%$ & 1 & $17.0 \%$ & $\begin{array}{l}14 \\
(10.0 \%)\end{array}$ & $\begin{array}{l}<5 \mathrm{~cm}: 4 \\
5-10 \mathrm{~cm}: \\
10\end{array}$ & 5 & $28.0 \%$ & 3 & $9.0 \%$ \\
\hline $\begin{array}{l}\text { red silver } \\
\text { mica fabric }\end{array}$ & $\begin{array}{l}1 \\
(07 \%)\end{array}$ & $\begin{array}{l}5-10 \\
\mathrm{~cm}: 1\end{array}$ & - & - & 1 & $17.0 \%$ & $\begin{array}{l}3 \\
(2.1 \%)\end{array}$ & $\begin{array}{l}5-10 \\
\mathrm{~cm}: 2 \\
>10 \\
\mathrm{~cm}: 1\end{array}$ & 1 & - & - & - \\
\hline $\begin{array}{l}\text { fine bur- } \\
\text { nished } \\
\text { (handmade?) }\end{array}$ & $\begin{array}{l}11 \\
(81 \%)\end{array}$ & $\begin{array}{l}<5 \mathrm{cm:} 7 \\
5-10 \\
\mathrm{cm:} 3 \\
>10 \mathrm{cm:} 1\end{array}$ & 3 & - & 2 & $9.0 \%$ & $\begin{array}{l}2 \\
(1.4 \%)\end{array}$ & $<5 \mathrm{~cm}: 2$ & - & - & - & - \\
\hline $\begin{array}{l}\text { medium } \\
\text { coarse } \\
\text { (pithoi) }\end{array}$ & - & - & - & - & - & - & $\begin{array}{l}1 \\
(0.7 \%)\end{array}$ & $\begin{array}{l}\text { 5-10 } \\
\mathrm{cm}: 1\end{array}$ & - & - & - & - \\
\hline Total & $\begin{array}{l}135 \\
(100 \%)\end{array}$ & $\begin{array}{l}<5 \mathrm{cm:} 97 \\
(71.8 \%) \\
5-10 \mathrm{~cm}: \\
35 \\
(26.0 \%) \\
>10 \mathrm{~cm}: 3 \\
(22 \%)\end{array}$ & 36 & $106.0 \%$ & 36 & $664.0 \%$ & $\begin{array}{l}140 \\
(100 \%)\end{array}$ & $\begin{array}{l}<5 \mathrm{~cm}: \\
68 \\
(47 . \%) \\
5-10 \mathrm{~cm}: \\
69 \\
(50.0 \%) \\
>10 \\
\mathrm{cm:} 3 \\
(2.2 \%)\end{array}$ & 55 & $249.0 \%$ & 26 & $565.0 \%$ \\
\hline
\end{tabular}


Tab. 4. 'Floor' 3 (highest pebble surface). I18 $\alpha / \beta$. Fine lustrous (Mycenean) and plain pottery, diagnostic sherds. The majority of the painted pottery belongs to monochrome and linear decorated sherds.

\begin{tabular}{|c|c|c|c|c|c|c|}
\hline Fine lustrous & Rims & Bases & Handles & Stems & $\begin{array}{l}\text { Wall sherds } \\
\text { with features }\end{array}$ & Total \\
\hline goblet FS 263 & 8 & 2 & 2 & 1 & & 13 \\
\hline kylix FS 264 & 3 & & & & & 3 \\
\hline kylix/goblet & 4 & 1 & 2 & 2 & & 9 \\
\hline crater FS 7-10 & & & 1 & & & 1 \\
\hline stemmed bowl? FS 304 & 1 & & & & & 1 \\
\hline conical bowl FS300/301 & & 1 & & & & 1 \\
\hline Vapheio cup FS 224 & 1 & 1 & & & 1 & 3 \\
\hline unidentifiable open vessels & 4 & 2 & 2 & & 3 & 11 \\
\hline closed vessels & 1 & & & & 2 & 3 \\
\hline Total & 22 & 7 & 7 & 3 & 6 & 45 \\
\hline Fine plain & Rims & Bases & Handles & Stems & $\begin{array}{c}\text { Wall sherds } \\
\text { with features }\end{array}$ & Total \\
\hline carinated kylix FS 267 & 3 & & & & & 3 \\
\hline carinated kylix/carinated bowl & 3 & & & & & 3 \\
\hline carinated bowl FS 295 & 1 & & & & & 1 \\
\hline goblet & & 1 & 1 & 1 & & 3 \\
\hline goblet/kylix & 3 & 3 & 1 & 1 & & 8 \\
\hline kylix & 1 & 2 & & 12 & & 15 \\
\hline kylix with high swung handle FS 272 & 1 & & & & & 1 \\
\hline cup FS 219/220 & 2 & & & & & 2 \\
\hline basin FS 294 & 1 & & & & & 1 \\
\hline unidentifiable open vessels & 9 & 4 & 6 & & 1 & 20 \\
\hline closed vessels & 1 & 1 & 3 & & & 5 \\
\hline Total & 25 & 11 & 11 & 14 & 1 & 65 \\
\hline
\end{tabular}

smaller proportion of the total. ${ }^{79}$ This is a difficult matter to assess as the similarity of the kylikes and goblets in terms

79 Shelmerdine 1992, Fig. 9-42/P3675, 3677. - Mountjoy 2008, Fig. 6.6/3067-3076 (Ayios Stephanos, wash deposits in Area Epsilon). - According to Podzuweit 2007, 56 and the evidence from Tiryns, monochrome goblets appear in reduced numbers even up to the late stages of LH IIIB. Unfortunately it is not always easy to say whether the fragments discussed by Podzuweit come from goblets or kylikes, although one example has a tall, thin stem and probably comes from a kylix: PoDzuweIt 2007, Pl. 22/5. - Schönfeld discusses stemmed bowls together with goblets and suggests the continuity of the monochrome goblet up to LH IIIA2 and LH IIIB, although the rim type shown as a characteristic example of many LH IIIA2 goblets is short and could come from a kylix: SCHÖNFELD 1988, 158 and Tab. 1, No. 6. of the rims, stems, and the overall size of the vessels during LH IIIA2 makes the exact identification of vessel forms very difficult. ${ }^{80}$ The majority of the fragments identified in Building B belong to the goblet FS 263. There is no evidence of the goblet with high swung handles (FS 270). Although the material is quite scrappy there seems to be a distinction

80 See Thomas 2011a, 198-200 and Figs. 12-13 for LH IIIA2 early kylikes FS 264. - Cf. the LH IIIA1 and LH IIIA2 rim fragments from Ayios Stephanos assigned to kylikes FS 264 or goblets FS 263 respectively: MounTJOY 2008, Figs. 6.6/3070-3071; 6.20/3309 (the LH IIIA1 fragment comes from Area Beta, Floor 1). Intermediate types also exist. - Cf. MounTJoy 1999, Fig. 402/16 for a LH IIIA1 monochrome kylix FS 264 from Rhodes with short fat stem and short rim identified as a shape that 'falls between a goblet and a kylix'. 
between the layers below and above or on top of 'Floor' 3 (the highest pebble surface). The goblets from the former all have short stems (Figs. 5/41-42; 6/84). ${ }^{81}$ One monochrome ring base seems, on account of its size, to have belonged to a similar form rather than a bowl (Fig. 4/1). ${ }^{82}$ If it is indeed from a goblet then it would closely resemble the so-called 'truncated goblets', for which the best published parallels belong to LH IIB. ${ }^{83}$

Medium tall monochrome stems can be securely identified only on 'Floor' 3 , in the 'Ditch' and in the layers above 'Floor' 4 (east) (Figs. 7/101; 8/122; 9/155). ${ }^{84}$ Pattern painted goblets (FS 255) with tall stems are considered to be typical of LH IIIA1, but published examples of monochrome or linear painted goblets (FS 263) with the same features are either absent or rare. ${ }^{85}$ This may be due to the fact that sherds are not always fully illustrated. As a result, it is impossible to determine whether the medium tall monochrome stems from the higher levels belong to goblets (FS 263) or kylikes (FS 264). They are slightly thicker than the usual stems of

81 Cf. Mountjoy 2008, Fig. 6.1/3007 for monochrome goblets with short, thin stems (Ayios Stephanos, LH IIA). The stem from the lowest pebble surface (Fig. 6/84) resembles bases from stemmed bowls (FS 304), but it is narrower: cf. Thomas 2011a, 204 and Fig. 16/168170 (Tsoungiza, LH IIIA2 early). It probably comes from a goblet with a short stem and a more sharply articulated high dome: cf. Tномаs 2011a, 196 and Fig. 10/79 (Tsoungiza, LH IIIA2 early, linear painted goblet).

82 For monochrome bowls and cups cf. Mountjoy 2008, Figs. 6.1/3008 (Area Epsilon, LH IIA); 6.17/3271-3272 (Area Beta). - For similar bases identified as bowls see Frizell 1980, 59 and Fig. 10/220 (base with concave underside, Asine, LH IIB/LH IIIA1) and Mountjoy 1981, Figs. 31/431 (monochrome cup with concave underside, Well H, Acropolis, LH IIB/LH IIIA1); 25/342 (ring base of a monochrome (?) bowl, Well Z on the Acropolis, LH IIB/ LH IIIA1). - A similar base from the construction fill at the Menelaion is identified as an unusual base from a monochrome goblet; Catling 2009a, 89. - Catling 2009b, Fig. 92/ET65 (East Terrace). 83 MounTJor 1999, 214 and Fig. 67/87-88 (Galataki and Korakou, LH IIB, pattern painted). - This type of base must not be confused with the low stems of the so-called monochrome 'kantharoi' which are found in LH IIIA1 contexts: CaTLIng 2009b, Fig. 92/ET64. Vitale 2013, Fig. 2/c: Mitrou (LH IIIA1, 'Kantharos'). - According to Mountjoy 1999, 332 and Fig. 112/58 the kantharoi represent a feature of the early stages of LH IIIA1.

84 Mountjoy 1999, Fig. 23/134-137; 332 and Fig. 111/53. - For a monochrome kylix the stem would be thick $(2.7 \mathrm{~cm})$ and in general shorter. - Cf. MounTJoy 2008, Fig. 6.6/3069 (LH IIIA2) and TномAs 2011a, 200 and Fig. 13/132-135 (LH IIIA2 early).

85 Martin 1992, 490 notes that the majority of goblets dating to LH IIIA1 in Nichoria have low stems, but no examples have been illustrated. - In Pylos two monochrome goblets from the south-west corner have low bases: Blegen et al. 1973, Fig. 155/5-6. - Linear painted goblets with tall stems are securely identified among the in situ material from Mansion 1: CATLING 2009b, Fig. 135/VII23. kylikes, but the exact identification of the sherds remains an open question. Few other features noted in the material from the layers sealed under 'Floor' 4 are considered to be early. Firstly, the preserved bases are not sharply articulated underneath as they often are during LH IIB and LH IIIA1 and some bases are painted underneath (Figs. 4/10; 5/43). ${ }^{86}$ The latter feature occurs only rarely after $\mathrm{LH} \mathrm{IIB}^{87}$ and such bases are not amongst the material from the pebble surfaces. Secondly, several rims are tall, slightly everted and occasionally have slightly hollowed interiors, whereas the handles tend to be wide and thin (Fig. 5/37-40). ${ }^{88}$ Some or all of these features are common during LH IIA, as is evident in the assemblages from Area Epsilon at Ayios Stephanos and in Korakou. ${ }^{89}$ Goblets with tall and slightly everted rims or short stems also appear on the pebble surfaces (Figs. 6/83$\left.84 ; 7 / 99^{90}-100\right)$. One rim from 'Floor' 4 is slightly thickened (Fig. 6/83). This feature is also seen on a goblet from the foundation trench (Fig. 5/37), but as it has a rim diameter of over $25 \mathrm{~cm}$ it probably belongs to a crater. ${ }^{91}$ Sherds with

86 Cf. Rutter 1993, Fig. 6/20 (Tsoungiza, LH IIA). - Mountjoy 2008, Figs. 6.1/3007 (Area Epsilon, LH IIA); 6.18/3291 (burial 28, LH IIB); 6.37/3667 (LH IIA but unstratified). - For the low monochrome stem cf. Mountjoy 2008, Fig. 6.37/3674 (goblet, dated to LH IIB).

87 Mountjoy 2008, Fig. 6.20/3308 (Area Beta, LH IIIA1 floor). 88 Cf. Mountjoy 2008, 328 and Fig. 6.1./3006-3007. - Monochrome goblets with tall but slightly everted rims and conical bases with painted undersides are found also in other contexts at Ayios Stephanos. Few pieces from Area Beta are dated to LH IIA, but they come from a context that also included LH IIB pottery: MounTJOY 2008, Fig. 6.17/3270, 3268.

89 Dickinson 1972, 106. - Mountjoy 1999, 206, 208 and Fig. 64/3034. - MounTJoy 2008, Fig. 6.1./3002-3004. - Pattern painted goblets with everted rims and hollowed interiors are also found in the construction fill of Mansion 2: CATLING 2009b, Fig. 107/ST41.

90 For similar stems cf. CATLING 2009b, Fig. 94, ET75-ET76 (construction fill). - Similar bases, however, may occur also among LH IIIA2 stemmed bowls (ThomAs 2011a, 204 and Fig. 16/172), but these are more sharply articulated underneath the base. - For the later phases, vases with a rim diameter over $25 \mathrm{~cm}$ (FRENCH 1964. - WARDLE 1973) or 20/23 cm (STOCKHAMMER 2008, 109) are conventionally classified as craters. Here, the classification based on the border of $25 \mathrm{~cm}$ is followed, due to the fact that goblets and craters in LH IIB and LH IIIA1 may have very similar profiles. Later craters with a rim diameter of even $20 \mathrm{~cm}$ and a distinct rim profile may occur. - Cf. however CATLING 2009b, Fig. 89/ET25 with Fig. 93/ET69 with rim diameters $25.4 \mathrm{~cm}$ and $25.6 \mathrm{~cm}$ respectively. The former is a crater and the latter a goblet: CATLING 2009a, 88-89.

91 Mountjoy 2008, Fig. 6.17/3267 for a goblet with similar profile, but the exterior of the lip is not rounded (Area Beta, LH IIA). The pottery comes from a floor deposit that also contained later material. - Cf. Taylour, Janko 2008, Fig. 1.39. - See also Catling 2009b, Fig. 93/ET 69 for large goblets. 
more advanced features appeared in the higher levels. Medium tall rims from open vessels (Tab. 2/44, 85) are present only in the 'Floor' 3 context, in the 'Ditch', and in the fill above 'Floor' 4 (east) (Figs. 7/97-98, 103, 105; 8/119-120; 9/149-150), the latter two containing mixed pottery from various levels. Another rim type that seems to appear for the first time in 'Floor' 3 has a straight inner lip (Tab. 2/69; Fig. $7 / 97,102) .{ }^{92}$ For some of the medium tall or shorter rims from the same context, from the 'Ditch' and from the fill in the east, a kylix (FS 264) may be an alternative identification (Figs. 7/98,102; 8/123; 9/151-152). ${ }^{93}$ Finally, the majority of the rim fragments from the layers above 'Floor' 3 seem to belong to small and medium sized goblets or to kylikes with a diameter between 12 and $14 \mathrm{~cm}$, although they may also belong to smaller vessels such as bowls. ${ }^{94}$

The general tendency seen in the material from trench I18 $\alpha / \beta$ suggests a gradual decrease in and eventually the abandonment of, monochrome goblets with tall rims (often large vessels) (Fig. 5/37-38). The introduction of the medium tall stemmed vessels (Fig. 7/101) coincides with the prevalence of medium tall everted rims. This is probably of chronological significance and may mark a change in the pottery styles, although other early features may well continue to appear (low stemmed goblets). ${ }^{95}$ These developments may be related to the introduction of the monochrome kylix (FS 264) from the period represented by 'Floor' 3 onwards. In the earlier levels, only one sherd from the foundation trench seems to belong to this form (Fig. 5/44). It has been suggested (on the basis of evidence from Ayios Stephanos) that another type of rim, in my opinion often distinguished by its straight inner lip, is characteristic of LH IIIA2 Early. ${ }^{96}$

92 Cf. MountJoy 2008, 308 and Fig. 6.6/3070-3071 (LH IIIA2 early-mid). This type of rim is usually termed 'fine everted' by MountJoy 2008, 303, 305, 307. It is also similar to the triangular rim from Nichoria. At the latter site it has been observed that, during LH IIIA1, the goblets have two different types of rims: long everted rims and short triangular rims, the latter being rarer: MARTIN 1992, 490, 571 and Figs. 9-24/P3556-3563(long); 9-24/3557; 9-25/P3575, 3577 (short triangular), whereas the monochrome goblets tend to have longer rims: MARTIN 1992, 490, 572 and Fig. 9-25.

93 Cf. Mountjoy 2008, Fig. 6.6.

94 Cf. Mountjoy 2008, Fig. 6.32/3573 for cups (LH IIIA2 wash deposit).

95 Catling 2009b, Figs. 107/ST46, 49-50 (construction fill); 146/ NB50). - A small goblet (FS 270) with a similar short stem was found in the LH IIB/LH IIIA1 fill of well E but has been dated to LH IIB: Mountjoy 1981, 31 and Fig. 16/183. - Goblets with short stems occur also in LH IIIA2: MounTJoy 2008, Fig. 6.6/3067 (LH IIIA2). See also MounTJoy 1999, Fig. 112/58 for a monochrome goblet from Pylos with a short base similar to a kantharos (LH IIIA1) but found together with goblets that have taller stems.

96 Mountjoy 2008, 304-308.
On the other hand, the appearance of this rim type in LH IIIA1 seems possible. ${ }^{97}$ This observation is also supported by material from other regions. ${ }^{98}$

The material from 'Floor' 3 shows a strong connection with the LH IIIA1 pottery tradition (goblets), but the kylix fragments and one stemmed bowl (FS 264, FS 304; Fig. 7/102-103), even though rare, are features, which seem to be diagnostic of the beginning of LH IIIA2 Early at Mitrou and Nichoria. Strong LH IIIA1 elements have also been detected in the LH IIIA2 Early material from Tsoungiza. The large number of goblets from 'Floor' 3 (in comparison to the aforementioned sites) suggests either a slightly earlier date or a regionally-specific variation. With regard to the layers under 'Floor' 4, a date in LH IIB is most likely, as indicated by the short stems and the presence of a monochrome truncated goblet and the pendent rock pattern (Figs. 4/1; 5/37-38, 41-42, 47. See also below). Mixing with earlier (LH IIA) material is also possible (bases with painted undersides and eventually the fragments of Vapheio cups with ripple pattern, Figs. 4/10, 18-19;5/43, 51-53). The date of the final use of 'Floor' 4 during LH IIIA1 has to remain open until the excavation in the area is resumed, but the diagnostic pottery recovered to date has good parallels at the floor of Mansion 1 at the Menelaion (LH IIIA1).

\subsection{Other Shapes}

Another shape identified amongst the monochrome pottery is the kylix, FS 269, with handles attached under the rim, one example of which was found in the 'Ditch' (Fig. 8/124). This particular type of kylix appears in LH IIIA1 and continues into LH IIIA2. ${ }^{99}$ The fragment from the 'Ditch' has a short rounded rim, which is very characteristic for LH IIIA2. The short rims and some of the medium tall rims probably

97 Construction fill: Catling 2009b, Figs. 92/ET59 (decorated goblet); 92/ET63 (monochrome); 96/ET109; 98/ET132 (plain carinated kylikes), 137 (kylix/goblet); 117/CLO19 (monochrome goblet). The monochrome goblets from Mansion 1 with a straight lip on the interior seem to come mainly from the construction fill (mainly LH IIIA1).

98 Martin 1992, 572 and Fig. 9-25/P3569, P3573, P3575, P3577 (monochrome goblets, LH IIIA1; wash deposit, L23Sq). The goblet with the net pattern and the triangular rim probably comes from a higher level with mixed material: MARTIN 1992, 571 and Fig. 9-24/ P3557. - Cf. Martin 1992, 534 (catalogue entry) with AschenBrenNER et al. 1992, 436 and Fig. 7-60/a-b with section. - Level 6 is probably close to the surface and contains mixed pottery.

99 Furumark 1941. - Mountjoy 1999, Fig. 112/59 (Rizomylo: LH IIIA1). - Mountjoy 2008, Fig. 6.21/3325 (Area Beta, Ayios Stephanos; the kylix has been dated to LH IIIA2, although it was found in a medieval context). 
belong to kylikes FS 264. The monochrome medium tall stems could come from the latter shape or from goblets (Fig. 9/155). Others are thinner and should almost certainly be assigned to kylikes (Fig. 8/125).

One monochrome flaring rim with a thickened lip found in 'Floor' 3 comes from a crater (Fig. 6/83). The monochrome stemmed bowl, FS 304, may be represented by a single example: a rim from 'Floor' 3 (Figs. 7/103), which has the beginning of a horizontal handle. This shape is considered to originate in LH IIIA2 ${ }^{100}$ One hand-made monochrome example with tall, slightly everted rim was found in the construction fill of Mansion 2 at the Menelaion (LH IIIA1 - LH IIIA2 Early) ${ }^{101}$ and one goblet with horizontal loop handles has been reported amongst the LH IIIA1 material from Nichoria. ${ }^{102}$ This may be an early example of the stemmed bowl. LH IIIA1 pattern-painted versions have been reported from the Atreus Bothros in Mycenae. ${ }^{103}$ The rim of the vessel from 'Floor' 3 is of the medium tall everted type, which is known in both LH IIIA1 ${ }^{104}$ and LH IIIA2 Early ${ }^{105}$ contexts and would be more appropriate for a goblet. This might be seen as further evidence of an early example of a form that has not yet adopted the more typical shorter rim form. A round horizontal handle from the 'Ditch' (Fig. 8/126) has dimensions that are more typical of craters than of stemmed bowls. Evidence for craters (FS 281) in LH IIIA2 is sparse. ${ }^{106}$

100 Cf. Shelmerdine 1992, 495, 586 and Fig. 9-39/P3649 for a monochrome example with similar profile. In Nichoria the earliest example is assigned to LH IIIA2 Early. - No stemmed bowls have been identified in the LH IIIA1 deposit from Mitrou: VitAle 2013, Tab. 3 .

101 Catling 2009a, 95, 354. - CATLing 2009b, Fig. 107/ST46 (construction fill). - Another stemmed bowl comes from the construction level of Mansion 2, but a contamination with LH IIIB2 material has been reported from the site: CATLING 2009a, 99. - Cf. CATLING 2009b, Fig. 117/CLO20. - Large monochrome stemmed bowls appear in the wash level: CATLing 2009b, Fig. 166/WN49-50. At Ayios Stephanos MounTJoy 2008, 355 and Fig. 6.30/3524 notes the presence of a possible stemmed bowl in a much earlier, LH IIA, context. It has a broad band around the rim and a splash around the handle. 102 Martin 1992, 490. The fragment is not illustrated.

103 French 1964, 250 and Fig. 2/6.

104 French 1964, Fig. 2/1, 5. - Martin 1992, 572 and Fig. 9-25/ P3571 (goblet). - Shelmerdine 1992, 495, 586 and Fig. 9-39/P3649 (stemmed bowl). - CatLing 2009b, Fig. 94/ET74 (linear painted goblet).

105 One monochrome stemmed bowl and another with a monochrome exterior from Tsoungiza have tall everted rims but with straight inner lips: Thomas 2011a, 204 and Fig. 16/165-166. - One example with a wavy band has a similar rim: Tномаs 2011a, 203 and Fig. 15/156.

106 Mountjoy 1999, 128 and Fig. 29/209. The crater from Berbati is dated to LH IIIA2 on the evidence of the diagonal shells.
The base of a monochrome mug (FS 225) was found in the layers above 'Floor' 4 (east) (Fig. 9/156). It has a cylindrical lower section that supports a slightly flared upper section. Monochrome mugs with similar shape are known from Ayios Stephanos in LH IIIA2. ${ }^{107}$ As the upper part of the vessel is not preserved it cannot be confirmed whether it belongs to the wide cylindrical type with the handle springing from the rim (FS 227) as identified by Mountjoy at Ayios Stephanos. ${ }^{108}$ The mug from the 'Ditch' is smaller, but it has a bevelled base similar to the example from Ayios Stephanos. This may be a feature derived from early cups and from Vapheio cups. ${ }^{109}$ Monochrome mugs (FS 225-226) were probably in use by LH IIIA1. ${ }^{110}$

Finally, there are fragments from monochrome bowls or basins amongst the material from the lower levels (Fig. 4/12). The rim of a monochrome basin was found in the layers above 'Floor' 4 (east) (Fig. 9/157). Monochrome basins prior to LH IIIA2 are scarce, but linear versions of the shape have been reported (LH IIIA1). ${ }^{111}$

Amongst the closed vessels one shoulder fragment from 'Floor' 3 has a ridge at the base of the neck (Fig. 7/104). Monochrome closed shapes occur in LH IIIA $2^{112}$ contexts, but they are also present in the earlier phases. ${ }^{113}$ The ridge at the base of the neck is a frequent feature. ${ }^{114}$

\subsubsection{The Linear Painted Pottery}

The linear painted pottery is, in general, rarer than the monochrome pottery. The material is in a highly fragmented condition and some pieces may be earlier strays (residual). The most common shape is the goblet (FS 263) with a monochrome interior and plain exterior. Most fragments

107 Mountjoy 2008, Fig. 6.3/3035 (Area Epsilon, wash deposit). 108 Cf. Mountjoy 2008, Fig. 6.3/3037 (Area Epsilon, wash deposit). 109 Also the pictorial mug FS 225.7 from Ialysos, which has been dated by MounTJor 2013, 136-138 and Fig. 1 (A846) to LH IIIA2 Late or LH IIIB, has a bevelled base.

110 Vitale 2013, Tab. 3 reports mug bases FS 225 that are monochrome outside. - Catling 2009b, Fig. 134/VII7 (construction fill, identified by CATLING 2009a, 108 as an ?alabastron) (LH IIIA1LH IIIA2 early).

111 Catling 2009a, 90. - Catling 2009b, Fig. 94/ET84 (in situ). Vitale 2013, Tab. 3.

112 Mountjoy 1986, 74 and Fig. 85/1-3. - Thomas 2011a, 193 and Fig. 8/46-47 (LH IIIA2 early Tsoungiza).

113 Mountjoy 1986, 60 and Fig. 69/2 (feeding bottle). - One large monochrome vessel (Hydria) is present in the construction fill of Mansion 2: CATLing 2009b, Fig. 95/ET93. - Cf. Mountjoy 1981, 42 and Fig. 24/317-318 (bases from large monochrome vessels, Acropolis wells). - For smaller vessels like jars and jugs see CaTLING 2009b, Figs. 106/ST20;116/CLO9-CLO10 (construction fill); 130/V5 (in situ). - At Atreus Bothros very few monochrome closed vessels have been reported from LH IIIA1: FRENCH 1964, 260.

114 FRENCH 1964, Pl. 71d/1, 5 (Atreus Bothros, pattern painted). 
belong to vessels with tall, slightly everted or medium tall rims (Figs. 4/15; 6/72-73, 85-86; 7/105), ${ }^{115}$ occasionally with slightly hollowed interiors ${ }^{116}$ (Figs. 4/14; 5/46) but very rarely with short rims and interior straight lips (Fig. 4/13). ${ }^{117}$ Fragments of goblets with monochrome interior surfaces seem to be concentrated in the fill between 'Floor' 5 and 'Floor' 4, whereas they were infrequent in 'Floor' 3 (Fig. 7/105-106) and in the 'Ditch' (Fig. 8/127).

The majority of the sherds with measurable diameters come from small or medium sized vessels with rim diameters ranging between $10 \mathrm{~cm}$ and $14 \mathrm{~cm}$; only one example comes from a larger vessel $(16 \mathrm{~cm}$, Fig. 8/127). It is possible that some of these fragments belong to cups ${ }^{118}$ or small goblets. Small goblets were present in either primary or secondary contexts at the Menelaion. ${ }^{119}$ However, the absence of larger versions of the linear painted goblets like the ones known from the Menelaion is noteworthy. ${ }^{120}$

Goblets with solidly painted interior and plain exterior are thought to represent a pottery type that was popular during LH IIB. ${ }^{121}$ Although absent from, or very rare in, major LH IIIA1 deposits (Atreus Bothros, the Acropolis wells ${ }^{122}$ the evidence from Tsoungiza suggests that in some regions the linear painted goblets may have continued as late

115 Cf. Catling 2009b, Fig. 93/ET70 (fill), ET71 (in situ).

116 Cf. Catling 2009b, Fig. 108/ST51 but with a high handle (construction fill, LH IIIA1-LH IIIA2 early).

117 It resembles the triangular rim type identified in Nichoria: MARTIN 1992, 490, 571 and Fig. 9-24/P3557. Probably a mixed context (see note above). - CATLING 2009b, Fig. 93/ET68 (monochrome; fill).

118 Catling 2009b, Fig. 135/VII24 (construction fill; identified as a goblet but a cup, FS 214, would be also possible).

119 Catling 2009b, Figs. 95/ET72, ET76 (construction fill), ET74 (in situ); 108/ST56, ST59 (construction fill); 135/VII23 (in situ, 15.6 $\mathrm{cm})$.

120 In Atreus Bothros the average rim diameter of the goblets is 18$20 \mathrm{~cm}$ and the minimum is $12 \mathrm{~cm}$ : FRENCH 1964, 249. - In Nichoria the rim diameters of LH IIIA1 goblets range from 14 to $22 \mathrm{~cm}$ : MARTIN 1992, 490.

121 Frizell 1980, 68 and Fig. 11/248 (Asine, layer 3, Room F). - Cummer, Schofield 1984, 103 and Pl. 75/1162 (Building A, Room 21, phase VII destruction deposit). - In the western sector at Kea rare examples also occur in phase VIIb (Room. W23, deposit B). This is a mixed deposit that may date to LH IIB or earlier: SCHOFIELD 2011, 165 and Pl. 81/2500.

122 French 1964, 249, 254, 261 mentions a 'number of fragments painted on the inside mainly from goblets and cups'. Only one example from the wells on the Acropolis has been published: MountJor 1981, 45 and Fig. 25/357 (well Z, LH IIB/LH IIIA1). - See also Asine: FRIZELL 1980, 23, 32 and Fig. 4/48(floor layer 2 of Room C; one geometric sherd, the rest LH IIB/LH IIIA1); 34, 47 and Fig. 7/136-138 (layer 2, Room D, LH IIB/LH IIIA1). Only monochrome and decorated goblets from the Megaron at Nichoria have been published: MarTin 1992, 571-572 and Figs. 9-24-9-25. - Amongst the decorations listed examples of LH IIIA1, goblets with coated interior are mentioned: MARTIN 1992, 490. as LH IIIA2 Early. ${ }^{123}$ The type is, however, securely identified on the floor of Mansion 1 and it has been reported in LH IIIA1 deposits from Mitrou. ${ }^{124}$ One very interesting suggestion was made by Patrick Thomas, who identified the thin line on the exterior of the rim as a chronological marker for separating LH IIIA1 from LH IIIA2 Early goblets with monochrome interior. ${ }^{125}$ At the Menelaion, however, goblets with lines on the exterior rim were found in situ in the pebble floor of Mansion 1 and they also appeared in the floor deposit of Building B at the Aetos South Slope. ${ }^{126}$ In trench $\mathrm{I} 18 \alpha / \beta$ at Ayios Vasileios all of the fragments from below 'Floor' 4 (the lowest pebble surface) except for one very small example (Fig. 4/15) lack the line on their exterior rims. This may suggest a date in LH IIB for these levels. The version with the exterior painted rim was very scarce in trench $\mathrm{I} 18 \alpha / \beta$. One example came from the 'Ditch', which contained mixed material. A few further fragments of the latter type are clearly associated with the late LH IIIA1 to early LH IIIA2 pottery, which was found in the fill under the floor of the stoa and in the south-eastern deposit (Figs. 15/249-254; 20/315). The rims from below the floor of the stoa are of the tall everted type and have good parallels in the Mansion 1 floor deposit, ${ }^{127}$ whereas a few goblets from the south-eastern deposit are shorter and resemble LH IIIA2 examples from Tsoungiza (Fig. 15/252-253). In summarising the evidence from Ayios Vasileios and the Menelaion one may argue that the goblets with plain exterior and solidly painted interior are characteristic of LH IIB, whereas those with the painted exterior rim appear more often in LH IIIA1 and also continue to LH IIIA2.

\subsubsection{Pattern Painted Pottery}

Pattern painted pottery was very rare in all levels in trench I $18 \alpha / \beta$. It was also virtually absent from Room 6 in trench I18 $\alpha$ (Fig. 10) and from the fresco dump (Fig. 12), both of which can be dated to LH IIIA2. The picture is different in the south-eastern deposit, which dates to LH IIIA1 or to early LH IIIA2 and where pattern painted pottery is well represented. The evidence suggests that the decorated pottery may not have had distribution in all areas of the palace during the LHIIB and LH IIIA2 Early periods.

123 Thomas 2011a, 195-196 and Fig. 10

124 CATLING 2009b, Figs. 93/ET 69-71; 107/ST52; 108/ST53-55. The rims from the Mansion 1 floor deposit are occasionally slightly hollowed in the interior like some of the rims from trench $\mathrm{I} 18 \alpha / \beta$. For Mitrou see Vitale 2013, Tab. 3.

125 Thomas 2011a, 195-196 and Fig. 10.

126 Catling 2009b, Figs. 108/ST53, 55; 254/AB19.

127 CATLing 2009b, Figs. 93/71; 72/74. All in situ. 


\subsection{Goblets}

It is possible that the very low percentage of pattern painted goblets in trench I18 $\alpha / \beta$ may be due to the small size of the excavated area. The few examples identified came from the layers under 'Floor' 4 and their date ranges lay between LH IIB and LH IIIA1. Two small fragments from 'Floor' 5 may also belong to this form. The first example has the remains of a running spiral with a blob on the exterior line (Fig. 4/17). ${ }^{128}$ The second fragment carries a horizontally placed floral motif with a filling of multiple parallel lines, which is reminiscent of a papyrus (FM11) motif (Fig. 4/16). This latter design is usually dated to LH IIIA1 and the decoration resembles Minoan motifs. ${ }^{129}$ It is known from three vessels from the Menelaion, a basket of Minoan type and a closed vessel. Both vessels were found in the construction fill of Mansion 2. ${ }^{130}$ The papyrus rises vertically from the basket but is combined with two horizontally-orientated bivalve shells that have the same filling. The third fragment belongs to a goblet with a monochrome interior and diagonally orientated papyrus, which was excavated by Dawkins in 1909; its exact stratigraphic location is uncertain. ${ }^{131}$ The papyrus represents a motif of Minoan inspiration and Catling did not deny the possibility that the basket from the construction fill was a real LM IIIA1 import. ${ }^{132}$ In terms of fabric, the fragment from Ayios Vasileios does not differ from the rest of the painted pottery and it may be of local origin. To date it has not been possible to identify this motif in any context pre-dating LH IIIA1. ${ }^{133}$ Only one LH IIB goblet from Korakou may have a vertically-orientated papyrus with a filling of angular lines. ${ }^{134}$ However, as the motif was common in Crete from LM IB onwards the possibility of an earlier date than LH IIIA1 on the mainland cannot be dismissed. ${ }^{135}$

128 Mountjoy 1986, 49 and Fig. 54/12 (NSC, unstratified). - CATLING 2009a, 90, 123. - CATLING 2009b, Figs. 96/ET101 (characterised as Argonaut; construction fill); 126/III8 (but in the connection line not on spiral; construction fill); 164/WN15 (crater; wash levels, stylistically dated to LH IIIA1). - Also in closed shapes: MounTJOY 1986, 59 and Fig. 67/4 (the blobs are much longer; Acropolis wells). - Catling 2009b, Fig. 134/VII8 (construction fill).

129 Mountjoy 1999, Fig. 21/120 (Mycenae, Kalkani). - See Andreadaki-Vlazaki, Papadopoulou 1997, Fig. 7/П1525B (Chamalevri Crete, LM IIIA1). - HATZAKI 2003, Fig. 4.15/14 (Knossos, Little Palace).

130 Catling 1996. - Catling 2009a, 96, 106. - Catling 2009b, Figs. 108/ST74; 128/IV11 and P1. 75/IV11.

131 Dawrins 1910, 9 and Fig. 4/a. - Mountjoy dates the goblet to LH IIIA1: MounTJoy 1999, 264 and Fig. 86/71.

132 Catling 2009a, 96, 106.

133 One ewer from a tomb in the Agora is decorated on the shoulder with a papyrus with a filling of parallel lines, but the dating ranges between LH IIB and LH IIIA1: ImMERwAHR 1971, 218-219 and Pl. 51 (XXIII-2).

134 Dickinson 1972, Pl. 34e (first row, right). 135 WARREN 2011, 188 and Fig. 4/P1575.
The pendent rock motif appears twice, once on a goblet and once on a mug (Figs. 5/47; 8/130). The fragment of the goblet came from the foundation trench sealed by the floor. Goblets with pendent rock pattern are found in situ on the floor of Mansion $1^{136}$ and the motif is typical of LH IIB and LH IIIA1. ${ }^{137}$ The painted bases of two goblets, probably decorated with a broad band on the exterior surface, were recovered from the foundation trench (Fig. 5/48-49). They belong to a type of goblet with a short base (FS 254), which was common in LH IIA and LH IIB. ${ }^{138}$ One painted rim from 'Floor' 4 may also belong to a pattern painted goblet (Fig. 6/87).

\subsection{Craters}

The first securely identified fragment of a crater (FS 7-10), a handle decorated with diagonal stripes, derives from 'Floor' 4 (Fig. 6/88). ${ }^{139}$ Two further fragments, one showing possible traces of stemmed spirals and dating to LH IIIA1, come from the 'Ditch' (Fig. 8/132). ${ }^{140}$ At the Menelaion in Mansion 1, craters (FS 7) were well represented in the floor deposit $^{141}$ and in the construction fill. ${ }^{142} \mathrm{~A}$ crater with horizontal handles (FS 279) and decorated with an Argonaut in the fashion of Ephyrean goblets ${ }^{143}$ was amongst the material found in situ. The evidence from the Menelaion suggests that by the time of the final use of the floor of Mansion 1 (during LH IIIA1) craters with both vertical and horizontal handles were already an integral part of the pottery assemblage. ${ }^{144}$ This recalls the well-known group of craters excavated by Dawkins, which have been dated by Furumark to LH IIIB. ${ }^{145}$ On the basis of their elaborate decoration Mountjoy re-dated the craters to LH IIIA2, noting, however, that they include later features such as short rims and

136 CatLing 2009b, Fig. 91/ET50. - For goblets with the pendent rock pattern from the construction fill see CATLING 2009b, Figs. 91/ ET51-53 (LH IIB-LH IIIA1); 107/ST41. - For earlier pottery with pendent rock pattern see MounTJOy 1999, 96 and Fig. 16/65.

137 Dickinson 1972, Pl. 33 (left row, middle; Korakou, LH IIB). - See also Schofield 2011, 165, 185 and Pl. 82/2516-2517 (West Sector, Room W.23, deposit C, LH IIB).

138 For goblets with short bases, FS 254, and a broad band on the exterior dating to LH IIA see MountJoy 2008, 355-356 and Fig. 3522-3523.

139 For the handle decoration cf. CATLING 2009b, Figs. 90/ET28 (in situ); 91/ET32 (hole in pebble floor LH IIIA1); 145/NB34 (LH II). 140 Martin 1992, 573 and Fig. 9-26a.

141 Catling 2009b, Figs. 89/ET 25; 90/ET28.

142 Catling 2009b, Figs. 90/ET27, ET30-ET31; 91/ET32; 115/ CLI6; 117/CLO11; 122/I4; 124/II15; 135/VII10-11; 141/VIII3.

143 Catling 2009a, 106. - Catling 2009b, Fig. 130/V6. - Mountjoy dates it to LH IIIA1: MounTJOY 1999, 264 and Fig. 87/75.

144 According to MounTJOy 1986, 51 the appearance of a crater and large goblets is characteristic of LH IIIA1. - MARTIN 1992, 573-574 and Fig. 9-26a-9-26b (Nichoria).

145 Dawkins 1910, 9 and Pl. 1. - Furumark 1941. 
piriform lower bodies. On the other hand, craters with piriform lower bodies are known from LH IIIA1 contexts in Messenia. ${ }^{146}$ Moreover, craters from Messenia with slightly shorter everted rims also appear in LH IIIA1 and are also attested in the construction fill of Mansion 2 at the Menelaion (LH IIIA1 to LH IIIA2 Early). ${ }^{147}$ It is suggested here that these craters date to a late stage of LH IIIA1 or early LH IIIA2, the evidence for this being the decorative motifs which consist of Argonauts, elaborate ivy and running spirals that would fit very well in an LH IIIA1 style. However, their ambiguous stratigraphic position precludes a definite conclusion on this point, although an earlier date than LH IIIB, as proposed by Furumark, is possible. ${ }^{148}$

\subsection{Mugs}

The mug is a rare form and the best preserved examples come from contexts containing mixed assemblages. One mug (FS 225) is decorated with the pendent rock pattern and two parallel contour lines, while a group of wavy lines is located further down the decorative zone (Fig. 8/130). This was a very popular decorative theme, which is frequently seen on goblets, cups and craters during LH IIB and especially during LH IIIA1. Its first occurrence, however, is during LH IIA. ${ }^{149}$ It has many variations and a wide distribution. There may be two rather than one contour lines and the wavy lines on the lower body may be omitted, but these variations do not seem to have any obvious chronological significance. ${ }^{150}$

\subsection{Vapheio Cups}

Almost all of the fragments of Vapheio cups (FS 224) have been illustrated. The sherds are all small and decorated either with ripple patterns (FM 78; Figs. 4/18; 5/52-53) or a more schematic version of the motif, e.g. vertical bars (Fig. 4/19). The fragments appeared in almost all stratigraphic units from the lowest fill of the 'Ditch' with one

146 Blegen et al. 1973, Fig. 155/10. - Mountjoy 1999, 328, 331 and Figs. 110/43; 111/45.

147 Catling 2009b, Figs. 90/ET30; 117/CLO11; 124/II16.

148 The Messenian craters all have loops below the handles, whereas the decoration of the Dawkins craters ends in tails.

149 Mountjoy 1999, Fig. 16/66 LH IIA (Mycenae, PCC).

150 Catling 2009b, Fig. 90/ET31; 120 and Fig. 124/II13, 15 (construction fill, single and double contour lines under the pendent rock pattern). - Mountjoy 1986, 46 and Fig. 53/4 (LH IIB, Ayia Irini, pendent rock pattern and wavy line). - Frizell 1980, Fig. 6/107 (dated to LHIIB but discovered in a LH IIB/LH IIIA1 layer). - MounTJOY 1999, 113 and Fig. 23/134 (goblet, Prosymna, LH IIIA1, pendent rock pattern and wavy line). See also MountJoy 1981, Fig. 15/180 (goblet, LH IIB/IIIA1, Athens). - MARTIN 1992, 575 and Fig. 9-27/ P3584 (Nichoria, L23Sq, LH IIIA1, wash dump). base found lying directly on 'Floor' 3 (fig. 7/107). Another base came from the 'Ditch' (Fig. 8/131). One rim from the foundation trench sealed by 'Floor' 4 may have belonged to a Vapheio cup with monochrome interior and a broad rim band on exterior (Fig. 5/51). The deep exterior rim band is reminiscent of early LMIA Vapheio cups from Kythera, ${ }^{151}$ but the monochrome interior as a feature derives from Crete and is absent at Kythera (LMIA - LMIB) except where it appears on imported vessels. ${ }^{152}$

Because of the fragmentary condition of the assemblage it is impossible to distinguish between sherds from Type II and sherds from Type III cups as most examples combine features typical of both types, including bases with cut edges, incurving lower walls (Type III. Fig. 8/131), and unslipped interiors (Type II). ${ }^{153}$ Vapheio cups of Type III are thought to have developed during LH I Late, ${ }^{154}$ but at the same time it seems that the specimens with tangent spirals may be earlier in date. According to Dickinson (a view followed by Lindblom and Manning) Vapheio cups with the ripple pattern on the Greek mainland are dominant at a later stage of LH I. This is based on the evidence from Nichoria and Lerna. ${ }^{155}$ In early LHI deposits foliate bands and tangent spirals are more frequent than is the ripple pattern. ${ }^{156} \mathrm{At}$ Asine, Vapheio cups with the ripple pattern are not present in LH I. ${ }^{157}$

151 Coldstream, Huxley 1972, 289, 291 and Pl. 25/8-9, 11, 29/1, 14, 18, 19. - See also Mountjoy 2008.

152 Coldstream, Huxley 1972, 113 and Fig. 39/120; Pl. 28/120, 123 (deposit $\zeta$, LMIA, but it has no rim band on the exterior); 284, 289. 153 Coldstream, Huxley 1972. - At Nichoria the Vapheio cups usually have cut bases and Vapheio cups with unsmoothed interiors continue: Dickinson 1992, 481, 552 and Fig. 9-5/P3179-3180. - In the Area IV SW LH IIA(1) deposit they reach $25 \%$ of LH decorated fabrics.

154 Dickinson 1992, 474 argues against the deep rim band being an early feature. Moreover, he stresses that the bevelled bases are as frequent as the straight edged bases.

155 The fragment of a Vapheio cup with a simpler version of the ripple pattern comes from a mixed context in Area V in Nichoria: Dickinson 1992, 473 and Pl. 9-1. - Dickinson 2014. - See ColdSTREAM, HuXLEY 1972 for Kythera where cups with ripple pattern are frequent.

156 Dickinson 1992, 475. - The hatched loop that is present in Area IV SW is a later feature (LHII). Regarding the deposit in Area IV SW in Nichoria, which included a wide variety of LH I shapes, Dickinson suggests that it was mixed with LH II material, the evidence being the motifs on the closed shapes, the rarity of added white paint and the frequency of Vapheio cups with the ripple pattern. All these connect this context to the local LH IIA rather than the LH I style: DickiNson 1992, 473, 475 and Pl. 9-5. - Vapheio cups with foliate bands, added white paint, as attested in VDL in the Akrotiri and Lerna shaft graves are typical of LH I: LindBLom, MANNing 2011, 141. 157 Dietz 1980. 
The Vapheio cups with the ripple pattern range in date from LH I Late to LH IIA, but they also continue into LH IIB. ${ }^{158}$ It is possible that the fragments from trench I1 $\alpha \alpha / \beta$ are of an early date, probably LH IIA, as pottery from this period has been found in other parts of the settlement.

Conversely, two very well preserved Type III Vapheio cups with the ripple pattern were found in situ on the floor of Mansion $1 .{ }^{159}$ These were dated by Catling to LH II, but they may have been in use until the final abandonment of the pebble floor of Mansion 1. ${ }^{160}$ The almost total lack of Vapheio cups with the schematic foliate band (FM 64) from Laconia is also noteworthy, particularly as they were a very popular type in the Argolid and Corinth during LH IIB. ${ }^{161}$ This is further evidence for the existence of regional styles during LH IIB.

\subsection{Cups}

One sherd from the foundation trench beneath 'Floor' 4 belongs to a shallow cup (FS 219-220). It is decorated with curved stripes (FM 67; Fig. 5/50). Cups with similar decoration date mainly from LH IIA to LH IIB, ${ }^{162}$ although they also appear in LH IIIA1 contexts. ${ }^{163}$

\subsection{Closed Vessels}

Painted sherds from closed vessels are far rarer than those from open vessels and those sherds that have been identified are all very small, which rendered the identification of the motifs difficult. A few fragments come from the lower levels, 'Floor' 4 and the 'Ditch'.

158 Dickinson 1972, Pl. 34 (lowest row, left). - Mountjoy 1999, 212 and Fig. 66/71-72 (Korakou).

159 Catling 2009a, 88, 95. - Catling 2009b, Fig. 89/ET24 (according to the catalogue the interior of the cup is described as reserved, but it is not clear whether this means that the surface is unslipped), 106/ST25; Pl. 71/ST25. - Some fragments may belong to Type II: Catling 2009b, Fig. 202/MI9.

160 Catling 2009a, 341 dates Vapheio cups in LH IIA, but a later date is also possible.

161 Dickinson 1972, Pl. 34/j (bottom, right). - Frizell 1980.

162 LH IIA: Mountoy 1999, 506-508 and Fig. 180/32, 36, 41 (Athens; 36 is from a museum collection, 41 from a Tomb in Demetrakopoulou). - LH IIB: Dickinson 1972, Pl. 33/e (middle and lower row, left). - MounTJoy 1999, 101 and Fig. 18/87 (Prosymna; Mountjoy does not exclude an earlier date on account of the shape).

163 French 1964, 254 and Pl. 70b/1. - Martin 1992, Fig. 9-28/ P3591 (small handmade bowl). - For the motif in general and cups with wavy lines from the Acropolis wells see MounTJor 1981, 28, 29, 42-43, 50-51 and Figs. 13/137, 14/154, 24/314, 25/325-326 (cups, motif identified as dashes), 31/421, 439 (the latter identified by Mountjoy as a goblet). Most pieces are dated by Mountjoy to LH II and LH IIB. - See also Catling 2009b, Fig. 124/II10 (construction fill, identified as a floral or unknown motif).
One sherd that was found in 'Floor' 5 (Fig. 4/20) may be of LH IIA or LH IIB date. It probably has the remains of a rock pattern or an ogival canopy, but the fragment is too small for any exact identification. Another very small body sherd from 'Floor' 4 carries the remains of what may have been a stemmed ivy design (FM 12; Fig. 6/89), ${ }^{164}$ a popular motif during LH IIA - LH IIIA1. Another fragment from the 'Ditch' decorated with curved stripes and a zone of dots on the neck (Fig. 8/133) may also be of an early date. ${ }^{165}$ Other closed vessel sherds from the foundation trench and the 'Ditch' probably carries curved stripes (FM67), ${ }^{166}$ possibly a foliate band and diagonal lines, an elaborate ivy design, and spirals (Figs. 5/54-56; 8/134). All of these fragments could date from LH IIA to LH IIIA1, ${ }^{167}$ but a closer identification is impossible due to the fragmented state of the assemblage. Some sherds seem to come from handmade vessels (Fig. 5/55-56).

\subsection{Fine Plain Pottery}

The fine plain pottery is, generally speaking, common. It was at its rarest in the lowest fill, under 'Floor' 5 (Fig. 4/3), but the quantities of all types of pottery from this context were so low that no generally applicable conclusions can safely be drawn from it. No diagnostic sherds from fine closed vessels have been identified under 'Floor' 4. Some bases and a few rim sherds were found in the 'Ditch' and one fragment in 'Floor' 3. The majority of fragments from trench $I 18 \alpha / \beta$ are made of fine clay. The surfaces of the sherds were rarely polished, although the wheel marks had been wiped away. It should be stressed, however, that the sherds are often badly preserved and this precludes any closer identification of the surface treatment. Plain burnished pottery is very rare and it is probable that it had fallen out of use by the time of the phases represented in trench $I 18 \alpha / \beta$. One rim sherd, found in the fill beneath 'Floor' 5, appears to be similar in terms of its colour and the texture of the fabric to one described by Zerner from Ayios Stephanos as

164 Dickinson 1972, Pl. 34/b (upper row, middle). - Amongst LH IIA and LH IIB pottery from Korakou the stemmed ivy design is very popular on goblets and cups: FRENCH 1964, Pl. 71b/1-2 (LH IIIA1, Mycenae). - Dickinson 1972, Pl. 32/e. - MountJoy 1999, 206, 208 and Figs. 63/24; 64/35 (LH IIA).

165 For the motif cf. MountJoy 1999, Fig. 15/53-54 (LH IIA Rhyta).

166 At the Menelaion the vertical stripes are rare and the following pieces are not certain: CATLING 2009b, Figs. 147/NB70 (identified as ripple pattern); 163/WN2 (possibly curved stripes); 167/WN83 (? curved stripes); 205/NS18. - See also MounTJOy 2008, Fig. 6.16/3245 (Area Beta at Ayios Stephanos; vertical stripes with dots dated to LH IIA, but the context also contains LH IIB material).

167 Cf. Frizell 1980,22 and Fig. 1/10 (layer 2-3, House B. LH IIIA1). 
fine yellow Minyan ware. ${ }^{168}$ This sherd belongs to either a cup or a goblet and has a rim that is characteristic of the MH III period (Fig. 4/4). ${ }^{169}$ Rims with similar profiles have been identified in LH IIA contexts from Ayios Stephanos (e.g. in Area Lambda). ${ }^{170}$

\subsubsection{Goblets}

Goblets are amongst the forms identified in trench $\mathrm{I} 18 \alpha / \beta$, although the material is very fragmented. The sherds from the lower levels beneath 'Floor' 4 include tall or medium tall everted rims, which are occasionally slightly hollowed on the interior side (Figs. 4/21; 6/75-77). This feature appears relatively rarely on the plain and painted goblets from the Menelaion, ${ }^{171}$ and the peak of its popularity is usually placed during LH I and LH IIA. ${ }^{172}$ The rims with small diameters may also derive from cups (Fig. 6/75). One goblet base was securely identified in the lowest fill beneath 'Floor' 5 (Fig. 4/3). More fragments from stems and disc bases were found in the lower levels. In the rare cases where the bases are better preserved, their undersides are not sharply articulated as was common from LH IIB onwards (Figs. 4/22; 5/57). ${ }^{173}$ Many of the disc bases have a flat base ${ }^{174}$ (Fig. 5/59), although others are more conical/concave (Fig. 4/22). ${ }^{175}$ The

168 ZERNER 2008, 196.

169 Howell 1992, Figs. 3-33/P2414 (MH II Minyan, Nichoria); 3-77/P2833 (MH III, coarse; Nichoria).

170 According to the stratigraphic assignment the layers include mixed LH I - LH IIA material and occasionally medieval or LH III pottery: Taylour, Janko 2008, Figs. 1.50-1.52. - Zerner 2008, Fig. 5.26/1549-1551. - Cf. Maran 1992, 10, 13 and Pl. 1/35 (red Aeginetan, Kiapha Thiti, deposit containing mainly LH IIA). Such rims are absent from the published material from the Menelaion.

171 Cf. Catling 2009b, Figs. 109/ST82 (in situ, floor of Mansion 1); 148/NB82 (North Building, LH IIA - LH IIIA1); TH37 (LH IIA?, cf. CATLing 2009a, 65-66 for pottery from baulk K21/L21 with predominately LH IIA pottery); 157/TH41 (LH IIB-LH IIIA1).

172 See Mountjoy 2008, Figs. 6.17/3275-3276, 3279 (Ayios Stephanos, Area Beta, dated to LH IIA, but the deposit also contains LH IIB pottery); 6.25/3382-3383, 3386 (Ayios Stephanos, yellow Minyan ware from a LH I context).

173 In Nichoria most of the LH II goblets have bases that are not sharply articulated underneath: DickINSON 1992, 559 and Fig. 9-12/ P3346-3352; 555 and Fig. 9-8/P3262-3270 (Area IV, SW, LH IIA); 568 and Fig. 9-21/P3523-3527, 9-22/P3472, P3552-3554 (washy coated ware, LH II). - RUTTER 1993, 67 and Fig. 7/23, 26 (Tsoungiza, LH IIA). - For goblets with sharply articulated bases underneath see Dickinson 1992, 556 and Fig. 9-9/P3309 (Area IV, SW, mixed LH IIA); 566 and Fig. 9-19/P3494 (but Dickinson does not exclude a date in LH IIIA1). - For LH IIIA1 examples see: MounTJOY 1981, Fig. 10/85 (Athens wells, LH IIB/LH IIIA1). - CATling 2009b, Fig. 136/VII37, VII39, VII40 (Mansion 1, in situ).

174 Cf. Dickinson 1992, 559 and Fig. 9-12/P3348 (Area IV, SE, LH IIA); 568 and Fig. 9-21/P3527 (trial trench M22-II, level 6, LH II).

175 Cf. Dickinson 1992, 556 and Fig. 9-9/P3306 (LH IIA mixed deposit) for similar base. version with double sharp or shallow curves on the underside (which is typical for LH IIA) has not been securely identified in the assemblage. ${ }^{176}$ Only one base may belong to this type (Fig. 4/22). The majority of the stems from below 'Floor' 4 are short (Fig. 4/25-28), and as such, characteristic of LH II. These stems are also relatively thin, a somewhat unusual feature. ${ }^{177}$ In the pebble surfaces there were several stems and rims that could come from goblets. The stems belong to both the short as well as the medium tall versions (Fig. 6/90-91). Of the two goblet stems from 'Floor' 3, one is notable as its very high dome has an almost exact parallel from the Menelaion (Fig. $7 / 110$ ). ${ }^{178}$ The very high dome is a feature known from Crete during LM IIIA1. ${ }^{179}$

One specific problem concerns the first appearance of the kylix, in both its globular and carinated forms. Relative evidence comes from 'Floor' 3 (Tab. 2/86, 32, 36, 31), from 'Floor' 4 (Fig. 6/92) and probably from the lower levels (Fig. 4/23-24, 29). Although LH IIIA1 is considered to be the period during which the plain kylix emerged as the dominant shape,${ }^{180}$ the high or medium stemmed globular kylix does not appear to be very common on the pebble surfaces. This may be because of the fact that goblets and kylikes cannot be easily distinguished in a highly fragmented assemblage. ${ }^{181}$ Rim fragments assignable to kylikes FS 267 are attested in 'Floor' 3. No kylix with a high stem of the type known from other LH IIIA1 contexts has been identified

176 Rutter 1993, 67 and Fig. 7/23, 25-27; 81 (Tsoungiza). - Cf. Dickinson 1992, 559 and Fig. 9-12/P3350-3351 (Nichoria, Area IV, NE). - Mountjoy 2008, Fig. 6.17/3283-3284. - The material comes from Area Beta but it is mixed with LH IIB pottery: MounTJOY 2008, 326. - See also Taylour, Janko 2008, Figs. 1.24-1.25). - At the Menelaion this is rarely attested: CATLING 2009b, Fig. 109/ST85, construction fill.

177 Cf. Dickinson 1992, 559 and Fig. 9-12/P3349.3350.3352 (Area IV, NE, LH IIA); 568 and Fig. 9-21/P3526-3527 (Nichoria LHII). - But see also Catling 2009b, Figs. 109/ST82 (in situ, Mansion 1, LH IIIA1); 125/II22 (construction fill) for later parallels. Two stems from Ayios Vasileios (Fig. 4/26.28) are slightly thinner than the examples cited from Nichoria and the Menelaion. - See also CatLing 2009b, Fig. 125/II22 (construction fill).

178 Catling 2009b, Fig. 93/ET69 (in situ, in pebble floor of Mansion 1 , monochrome interior). - The very high dome is a feature characteristic in Crete: cf. HatZaKi 2005, 131, 141 and Fig. 4.6/15.

179 See Andreadaki-Vlazaki, Papadopoulou 1997, 118 and Fig. 16/П15242.

180 In Nichoria the kylix with medium high stem is far more common than the goblet and both shapes often have the same type of rims with a 'sharp inner angle': MARTin 1992, 493-494, 579 and Fig. 9-31/ P3614, 3617.

181 In LH IIB/LH IIIA1 contexts from Asine there is no clear example of a kylix, although types FS 263-264 are treated together as a single group that is supposed to be very common. However most of the pieces presented have rather long rims for kylikes FS 264: FrIZELL 1980, 110-111 and Fig. 8/155-161. 
with any certainty on the floor of Mansion 1 at the Menelaion and the same is also true for other LH IIIA1 deposits such as Mitrou. ${ }^{182}$ The majority of the plain open vessels are goblets, ${ }^{183}$ although some sherds may come from kylikes, while others are more likely to be from carinated kylikes. ${ }^{184}$ Carinated kylikes are well represented in the holes that cut the sub-floor of Mansion 1 at the Menelaion with three examples, all of which have early rim types, whereas examples of the form dating to LH IIB are well represented at Tsoungiza. ${ }^{185}$ One type, intermediate between the one-handle goblet and the kylix, was recovered from one of the holes. ${ }^{186}$

With the evidence available at present it is not possible to determine when, in stratigraphic terms, the globular kylix first appeared at Ayios Vasileios. Stems that may have come from tall (but not necessarily high) or medium tall stemmed vessels were found in 'Floor' 5 and in 'Floor' 3 (Fig. 4/29; 7/111), but some of these could come from carinated kylikes (FS 267). This is a difficult issue to resolve as there is an overlap between the stems and handles of goblets and kylikes during the LH IIB and LH IIIA1 phases, which makes the exact identification of individual sherds difficult. Some of the vessels from Nichoria and the Menelaion may serve as examples. A goblet that was found in situ on the pebble subfloor of Mansion 1 is similar to vessels identified as kylikes in the LH IIIA1 levels in Nichoria. ${ }^{187}$ Many goblets at the Menelaion have medium tall, thin stems of the type usually found on globular kylikes, ${ }^{188}$ while in other cases they have the short, thin stems typical of the carinated kylikes. ${ }^{189} \mathrm{~A}$ good way to distinguish a globular kylix from a goblet (at least during LH IIIA1 when both forms are present) is to identify the shallower shape of the former, ${ }^{190}$ although this

182 See Vitale 2013, Tab. 5 where there are ambiguous examples of kylikes with high stems.

183 Goblets: CATLING 2009b, Figs. 96/ET109; 97/ET112 (stem with high dome); 109/ST78, 80, 82; 131/V18; 136/VII30, 37, 39, 40.

184 Catling 2009a, 92, 106. - CATling 2009b, Figs. 96/ET111; 129/

IV16.

185 Thomas 2011b, 302.

186 CATLING 2009b, Figs. 110/ST89; 137/VII49-VII50, VII52, VII55 (for VII50 there is no detailed information).

187 In terms of the thickness of the stem and the width of the handle, see MARTIN 1992, 579 and Fig. 9-31/P3616 and CATLING 2009b, Fig. 136/VII30 (in situ). The thickness of the stem and the width of the handle are the same. The kylix is deeper than the goblet.

188 CATLING 2009b, Figs. 96/ET110 (construction fill); 97/ET116 (in situ, floor of Mansion 1).

189 Cf. the stems in: CATlling 2009a, 115. - CAtling 2009b, Figs. 148/NB94; 149/NB99-100; Pl. 80/a-b (identified as early carinated kylikes, North Building, LH IIA-LH IIIA1) with CATLING 2009b, Fig. 96/ET110 (goblet, construction fill). - See especially the carinated kylix from CATLING 2009b, Fig. 137/VII55 with unusual short stem and deep body (construction fill).

190 Cf. MARTIN 1992. distinction is difficult to make when dealing with highly fragmented material. ${ }^{191}$

\subsubsection{Carinated Kylikes}

Considerable efforts were made to try to understand whether the carinated kylix (FS 267) was present in the lowest levels of the trench. The stems of the carinated kylikes are often up to $2 \mathrm{~cm}$ thick. ${ }^{192}$ Two bases and a stem from 'Floor' 5 may be of this form (Fig. 4/23-24, 29) ${ }^{193}$ and the same is true for one stem from 'Floor' 4 (Fig. 6/92). ${ }^{194}$ As there is an overlap in shape with the stems of goblets (Fig. 4/27), ${ }^{195}$ the presence of rim fragments showing the carination, remains the only secure criterion for identifying the form amongst the fragmented material. As a result, the earliest secure evidence for the form comes from 'Floor' 3, which can be dated to the final stage of LH IIIA1 or LH IIIA2 Early (Tab. 2/86, 32, $36,31)$. Some thin stems may also come from the same type of vessel (Fig. 7/108). ${ }^{196}$ The rims are medium tall or short and everted, occasionally with a straight interior lip. They all share a common feature in the form of a carination that is set high up on the vessel, close to the rim. Kylikes with these features (carination high up on the vessel and the straight interior lip) are considered to be characteristic of LH IIIA1 ${ }^{197}$ and are well known from Nichoria, although the shape is still uncommon. ${ }^{198}$ Some examples have been identified at the Menelaion where they occur amongst the material found in situ (e.g. in the holes that cut the floor). ${ }^{199}$ Another very useful criterion for the identification of LH IIIA1 rims was put forward by Mountjoy who observed that the LH IIIA1 rims from carinated kylikes are thin and everted, whereas

191 But see CATLing 2009b, Fig. 109/ST79-81 for goblets that probably have a more shallow body. - Cf. MARTin 1992, Fig. 9-31/P36163617.

192 But see Hiesel 1975, 23 and Fig. 7/2 (House D1 Tiryns) (stem $3 \mathrm{~cm}$ thick).

193 But see Mountjoy 2008, Fig. 6.1/3006 (monochrome goblet from Ayios Stephanos, LH IIA).

194 Cf. Catling 2009b, Figs. 96/ET110 (construction fill); 97/ ET 116 (goblet with high handles, in situ).

195 Catling 2009b, Figs. 136/VII30, 34, 37 (only VII30, VII 37 in situ, floor of Mansion 1); 137/VII50-VII51; 147/NB81.

196 Cf. Catling 2009b, Fig. 98/ET136 (construction fill).

197 One kylix with a low carination and a medium tall everted rim from Area Lambda at Ayios Stephanos has been dated to LH IIIA1, but it doesn't come from a stratified deposit of this period: MounTJOY 2008, Fig. 6.31/3557.

198 Martin 1992, 493, 580 and Fig. 9-32/P3621-3622 (L23Sq, LH IIIA1 wash deposit).

199 CATLINg 2009b, Fig. 97/ET121 (construction fill). - In situ: CATLING 2009b, Figs. 97/ET124 (the interior lip is longer than the examples from Ayios Vasileios); 137/VII50 (the interior rim is not straight cut). 
their LH IIIA2 equivalents are thicker. ${ }^{200}$ The carinated kylix with a medium tall or tall everted rim and a very high carination on the body (the early version of the form) was very rare amongst the stratified material from trench $\mathrm{I} 18 \alpha / \beta$. One example was found in 'Floor' 3 (Tab. 2/86), while a few rims derive from contexts containing mixed material (Tab. 2/51). One kylix of this type was found amongst the vessels from the floor of House D1 at Tiryns, which are dated to LH IIB. ${ }^{201}$ At the Menelaion, similar carinated kylikes were found in the construction fill of Mansion $2^{202}$ and, although they did not appear in the floor deposit of Mansion 1 , two well preserved examples were found in the interior of a pit that cut through the floor. ${ }^{203}$ Although LH IIIA1 kylikes show a high degree of variation and occasionally include the early features described above, the kylix with the tall everted rim and the high carination is probably most characteristic of LH IIB. Thus the question of whether the shape appears at Ayios Vasileios during LH IIB, as has been argued for the north-easternPeloponnese, has to remain open. ${ }^{204}$ During LH IIIA1 it was certainly present at Ayios Vasileios and in the Mansion 1 floor deposits, but it may not be as common as it is elsewhere (Argolid, Mitrou). ${ }^{205}$

More developed rim types have been identified in the 'Ditch' and in the layers above 'Floor' 4 (east) (Figs. 8/137; 9/159). Carinated kylikes dating to LH IIIA2 are well represented in Room 6 (trench I18 $\alpha$ ) and in the fresco dump in the western sector. In the latter feature, the kylikes often have a rounded or simple flaring rim and the carination is lower on the body, resulting in a straight/vertical or slightly in-curving upper section (Figs. 10/173-175; 13/201-203). Occasionally rim fragments and even some of the complete vessels from the fresco dump exhibit early features, including angular rims, rims with a straight interior lip, and the high carination

200 Mountjoy 1995, Fig. 39/6. - Mountjoy 1996, 50-52 and Fig. 4/58 (poorly stratified). - See also IMMERWAHR 1971, Pl. 35/6 for the example cited by MounTjoy 1995.

201 Hiesel 1975, 23 and Fig. 7/2.

202 Cf. Catling 2009b, Fig. 97/ET117-120 (construction fill).

203 Cf. Catling 2009b, Fig. 137/VII49, VII52.

204 In Tsoungiza it is the second most common shape after the goblet during LH IIB: Thomas 2011b, 302. - In Nichoria there is no evidence of kylikes in the LH II material: Dickinson 1992, 486 relates goblets to FS 263, FS 268. - One fragment of a carinated kylix from Ayios Stephanos with the carination high on the vessel has been dated by Mountjoy to LH I-II. However, the fragment comes from an unstratified deposit and as it has the interior cut lip, it may date to LH IIIA1: MounTJOy 2008, 301 and Fig. 6.2/3019.

205 Catling 2009b, Figs. 97/ET124; 110/ST89; 136/VII50 (FS 267). - In the wells in the Acropolis there is only one fine plain kylix. Mountjoy 1981, 25 and Fig. 10/100 identifies the vessel as a goblet (FS 272).
(Tab. 2/32, 36, 38; Fig. 13/200). It is possible that some of these fragments are residual as the deposit was not sealed by a floor. Alternatively, it may be that some vessel types, represented by well-preserved vases, continued at Ayios Vasileios from LH IIIA2 Early into the latest part of the phase. The evidence from Tsoungiza suggests that kylikes with a wider range of profiles, which show a lack of standardisation, are characteristic of the early part of LH IIIA2. ${ }^{206}$ Early rim types are present in the south-eastern deposit, which may date to the early stage of LH IIIA2. Finally, it should be noted that several carinated kylikes from the construction fill of Mansion 2 at the Menelaion belong to types, which are better known from the fresco dump (LH IIIA2) at Ayios Vasileios. ${ }^{207}$

\subsubsection{Angular Bowls}

The angular bowl (FS 295) is closely linked typologically with the carinated kylix and both forms may be part of the same set. The material from the Menelaion provides valuable information regarding the development of the shape, which is slightly different than that of the carinated kylix. Several bowls with strap handles, ${ }^{208}$ most of them carinated, were found in the construction fills of Mansion 2, ${ }^{209}$ but only one was found in situ on the pebble sub-floor of Mansion 1. ${ }^{210}$ This example has a tall everted rim with a carination high on the body. Catling separates the angular bowls from the construction fill into early and late variants. The early angular bowls tend to be larger vessels (Catling's group I) with an average rim diameter of $25 \mathrm{~cm}$. ${ }^{211}$ Some vessels may also have had three handles. Similar large bowls with a carination high on the body were found at Nichoria. ${ }^{212}$ This type either disappeared entirely during LH IIIA2 or became very rare.

No definite examples of the form were identified in the levels under 'Floor' 3 in trench $\mathrm{I} 18 \alpha / \beta$ (Tab. 2). One rim from 'Floor' 3 has a rounded overhanging lip, which is characteristic for the shape. In comparison to the carinated

206 Thomas 2011a, 213-215 and Fig. 22/246.

207 Cf. Catling 2009b, Figs. 97/ET125-127; 98/ET128-132.

208 Catling 2009a, 408-409, 413-414. - Catling 2009b, Fig. 99/ ET146-150.

209 Catling 2009b, Fig. 99/ET147-148.

210 Catling 2009b, Fig. 138/VII70.

211 Catling 2009a, 408-409.

212 MARTin 1992, 493, 580 and Fig. 9-32/P3625-3626. - The average rim diameter of the angular bowls in Nichoria is $24 \mathrm{~cm}$. Amongst the examples shown, the carination is set very high on the vessel. - At the Menelaion the carination is generally slightly lower on the body than at Nichoria (cf. CATLING 2009b, 95 and Figs. 99/ET148; 138/VII67VII70) but rarely very low (CATLING 2009b, 95 and Fig. 99/ET147, construction fill). - FRIZELL 1980, Figs. 4/58-59 (LH IIB/LH IIIA1, no handles), 9/170-175. 
kylikes identified in the same layer, the carination of the vessel is lower on the body (Tab. 2/111). ${ }^{213}$ More fragments came from the 'Ditch' and from the layers above 'Floor' 4 (east) (Figs. 8/139-140; 9/160). All but one of these has the carination low on the body and seems to be later in date than the examples from Mansion 1.214

The rim from 'Floor' 3 belongs to a medium-sized vessel, but the south-eastern deposit contained examples of larger bowls (Fig. 20/303-304). The latter are typologically similar to the vessels from the Menelaion and often have a carination high on the body, although their rim diameter does not exceed $20 \mathrm{~cm}$. Furthermore, the version with the three handles identified at the Menelaion and in Nichoria is absent at Ayios Vasileios. ${ }^{215}$

Regarding the development of the form at Ayios Vasileios, the next recognisable stage is represented by the material from the fresco dump, which can be dated to LH IIIA2 (Figs. 14/217-218), and the destruction deposit of the southern stoa (Fig. 20/320). In the fresco dump the majority of the bowls belong to smaller vessels with rounded and flaring rims and a carination that may also be lower on the vessel. A few vessels also exhibit early LH IIIA2 features. ${ }^{216}$

\subsubsection{Other Kylikes and Dippers}

The evidence for kylix types other than FS 267 is sparse in the material from trench $I 18 \alpha / \beta$. In general, the rims of the fine plain group identified in 'Floor' 3 are of tall to medium-tall everted forms and the majority probably comes from goblets with only a few from kylikes (Tab. 2/85, 94). One fragment with short rounded rims (Tab. 2/ 90) was found on 'Floor' 3. This strongly resembles the rim of the kylix from Room 6 dating to LH IIIA $2^{217}$ while another vessel has an everted rim and a shallow profile (Tab. 2/33). The first form occurs very rarely prior to LH IIIA2, while the second represents a rare but well known LH IIIA1 kylix variant and has a good parallel in the form of a fragment

213 Cf. Catling 2009b, Fig. 138/VII68. - The large bowls from the floor deposit tend to have the carination higher on the vessel: cf. CATLING 2009b, Fig. 138/VII70.

214 Catling 2009b, Fig. 99/ET147. - See also Frizell 1980, Fig. 9/172 for one angular bowl with a carination lower in the body from Asine (LH IIB/LH IIIA1).

215 One similar angular bowl with a large rim diameter $(22.7 \mathrm{~cm})$ was found in Room 20 in Pylos (Blegen's shape 5): see Blegen, Rawson 1966, 356-357, Fig. 350/shape No.5. - The vessel is slightly deeper than the examples from Mansion 1/2 and south-eastern deposit from Ayios Vasileios.

216 Cf. Thomas 2011a, 215-216.

217 Cf. Thomas 2011a, 210 and Fig. 19,206 (dipper) for the rim type (LH IIIA2 early, Tsoungiza). from the south-eastern deposit (LH IIIA1 - LH IIIA2 Early) (Fig. 16/267). ${ }^{218}$

More short rims from semi-globular kylikes were found in the 'Ditch' and the layers above 'Floor' 4 (east) (Tab. 2/34, 28, 112; Fig. 9/161-162). ${ }^{219}$ These probably date to LH IIIA2. The kylix with high swung handles (FS 272) has also been identified in the 'Ditch' and the fresco dump (Figs. 9/161; 13/206). The latter shape is much commoner during LH IIIA1, but its short rim fits well in LH IIIA2. The plain conical kylix (FS 274) that first appears in LH IIIB was absent from trench $118 \alpha / \beta$. One very small fragment was found in the fresco dump (Fig. 13/207). Dippers (FS 236) are very rare, although one fully preserved example was found in Room 6 together with kylikes and a cooking tripod (Fig. 10/179, see below).

\subsubsection{Conical Cups}

Fragments of conical cups (FS 204) were present from the earliest levels of trench I18 $\alpha / \beta$ onwards. Most of the sherds are made from a similar red fabric, which contains moderate to abundant quantities of silver mica, although one rim from the foundation trench under 'Floor' 4 is made of a red gritty clay. ${ }^{220}$ The majority of the bases have cut marks on the underside, ${ }^{221}$ while a few rims from the lower levels have a thickened inner lip (Fig. 4/31). Others have a straight lipless or in-curving rim (Figs. 5/61; 8/143). Those with a more pronounced in-curving lip appeared mainly in contexts overlying 'Floor' 4. It has not proved possible to draw any conclusions about the frequency of the form during the phases represented in trench $118 \alpha / \beta$. It is also not possible to reach any conclusions concerning the increase or decrease in subsequent phases owing to the limited quantities of material. Conical cups are very well represented in early Mycenaean contexts. At Nichoria they constitute a relatively large proportion of the plain pottery and are already present in LH I. ${ }^{222}$ The form is also very well

218 See also Thomas 2011a, 212 and Fig. 21/30 for a similar rim (LH IIIA2, Tsoungiza).

219 Cf. Shelmerdine 1992, 594 and Fig. 9-47/P3723 (LH IIIA2 middle-late). - Thomas 2011a, 211 and Fig. 20/215, 217.

220 At Nichoria many conical cups have rough surfaces, but examples with smoothed surfaces are present as well: Dickinson 1992, 486, 570 fig. 9-23/P3373. - No conical cups have been mentioned in connection with the LH IIIA1 deposits on the site.

221 Bases with cut marks that have not been smoothed are a very common feature of LH IIIB carinated kylikes (FS 267), angular bowls (FS 295), and small cups (FS 220). Hruby 2006 sees this as evidence for large-scale mass production.

222 Dickinson 1992, 478, 553 and Fig. 9-6/P3195. 
represented at the Menelaion, ${ }^{223}$ but is conspicuously rare at Ayios Stephanos. ${ }^{224}$ The high number of the conical cups in the fresco dump (LH IIIA2. Fig. 14/220-221) contrasts with the total absence of the type in Room 6 even though the contexts are broadly contemporary. In contrast to Nichoria there is no evidence that they were used as lamps at Ayios Vasileios. ${ }^{225}$

\subsection{The Coarse Wares}

\subsubsection{The Gritty Fabric}

Although represented by highly fragmented sherds, the gritty fabric is a constant feature in all stratigraphic units from the lowest fill up to 'Floor' 3 (Tab. 3). It was also found in the fresco dump (LH IIIA2) although in very small quantities (Fig. 14/226). The gritty ware that continued from the $\mathrm{MH}$ period is represented by two principal shapes: goblets and closed vessels such as jugs, jars, and hydrias. The range of vessel forms and the character of the fabric at the macroscopic level link it with the gritty fabrics that are found in Laconia during MH III. The so-called gritty yellow Minyan pottery with burnished surfaces (and matt paint) became very common at Ayios Stephanos during the latest stages of MH III and continued up to LH IIA. ${ }^{226}$ The popularity of this fabric may have been the result of contacts with the northern Peloponnese. ${ }^{227}$ Evidence for the burnishing of the surfaces is rare in the assemblage from trench I18 $\alpha / \beta$, but this is mainly due to the poor preservation of the sherds. One common feature linking the gritty yellow Minyan ware from Ayios Stephanos and Ayios Vasileios is the method of attaching the handles by cutting a hole in the wall of the vessel (Figs. 5/63; 7/112-113). This very distinctive method of manufacture was also used on the MH I-II dull painted pottery from Ayios Stephanos but has not been reported by Zerner from the northern Peloponnese. At Ayios Vasileios this type of handle attachment is present only at closed vessels and the same seems to be true at Ayios Stephanos. However, one vessel belonging to the red silver mica fabric has a similar handle attachment (Fig. 7/118). Despite the results of the petrographic analyses, the provenance of the gritty

223 Catling 2009b, Figs. 99/ET140-ET145 (all but 141 from construction fill, 141 in situ in the pebble floor of Mansion 1); 110/ST96ST103 (construction fill).

224 Mountjoy 2008, Fig. 6.9/3112.

225 Dickinson 1992, 478. - See Wiener 2011 for Minoan cups and French, TomLinson 1999 for the shape during the Mycenaean period on the Greek mainland.

226 See Zerner 2008, 182-187, 197 for a description of the gritty fabric at Ayios Stephanos. - Yellow Minyan ware is termed by RutTeR, RUTTER 1976 gritty yellow Minyan ware.

227 Zerner 2008, 183. yellow Minyan ware at Ayios Stephanos is still uncertain, ${ }^{228}$ although the distinctive details of its manufacture (notably the handle attachment), which do not occur elsewhere, have allowed Zerner to suggest a southern Peloponnesian origin for the fabric. ${ }^{229}$ As a result a local origin for the gritty fabric from Ayios Vasileios (which exhibits the same features as the pottery from Ayios Stephanos) is very likely and the petrographic analysis will establish whether there is a close connection between the fabrics from both areas or if they even derive from a common workshop. The shape repertoire from trench I18 $\alpha / \beta$ seems to be much more restricted than at Ayios Stephanos, which probably reflects a later stage of the development of the type.

The fragments from trench I18 $\alpha / \beta$ described below, all have good typological parallels in the MH III Late-LH II, and LH IIA deposits at Ayios Stephanos. Fragments assigned to goblets are represented by bases and handles, although some of the rims could belong either to widemouthed jars or to goblets. Bases are concave underneath with a spreading foot (Fig. 4/5, 34; 5/68; 6/80). ${ }^{230}$ Two of the bases have a distinct ridge on their exterior (Fig. 6/80), a feature that occurs in a gritty goblet from Ayios Stephanos dating to LH IIA (although it came from a rather mixed context). ${ }^{231}$ The few handles identified in I1 $8 \alpha / \beta$ are wide and flat or have an oval section (Figs. 5/65; 6/93). ${ }^{232}$ One of the handles from 'Floor' 5 has a slight double trough, which is often found on kantharoi. ${ }^{233}$ Various fragments from closed vessels were also identified (Figs. 4/8; 5/62-64; $6 / 81-82 ; 7 / 112-113)$. One rim with a handle may belong to a wide-mouthed jar (Fig. 4/32), ${ }^{234}$ but other rims cannot be more closely identified and may derive from either widemouthed jars or goblets (Fig. 5/66). Most of the handles are horizontal and probably come from hydrias. ${ }^{235}$ They are round in section and were attached to the vessel by a hole

228 Whitbread, Jones 2008, CD-94, 112-113. - The fracture has 'quartz and microfossils of coarse sand-size'. It belongs to set 3, class 1 at Ayios Stephanos.

229 Zerner 2008, 197. - The chemical analysis by Jones 2008, 115 suggests a probable local origin (AAS).

230 Cf. Mountjoy 2008, Fig. 6.25/3404-3407 (Area Lambda 3/4, LH I/IIA context). - Zerner 2008, Fig. 5.27/1567 (Area Lambda 1973-7, LH IIA pottery, fine yellow Minyan ware).

231 Cf. Zerner 2008, Fig. 5.28/1614 (Area Lambda 1973-7, MH III/ LH I/IIA context).

232 Cf. Zerner 2008, Fig. 5.27/1563 (Area Lambda 1973-7, LH IIA pottery, fine yellow Minyan ware). - MounTJoy 2008, Fig. 6.25/3403 (Area Lambda 3/4, LH I/IIA context).

233 Cf. Zerner 2008, Fig. 5.27/1559-1560 (Area Lambda 1973-7, LH IIA pottery, fine yellow Minyan ware).

234 ZERNER 2008, Fig. 5.25/1512 (MH III).

235 Cf. Zerner 2008, Fig. 5.28/1626 (yellow Minyan gritty ware, Area Lambda 1973-7, LH IIA pottery identified as a jar). 
through the wall, as described above (Fig. 5/63). One fragment that was found in the foundation trench and sealed by 'Floor' 4 bears traces of paint (Fig. 5/69). It belongs to the neck of a closed, handmade vessel. As the paint is only preserved as a shadow, it cannot be definitely identified as either matt or lustrous, ${ }^{236}$ although a rim from the 'Ditch' bears traces of lustrous paint (Fig. 9/144).

Although the material is highly fragmented there is no reason to believe that the gritty goblets and closed vessels described above do not relate to the period of use of 'Floor' 5 and possibly also of 'floors' 3 and 4. At the Menelaion a group of large hand-made closed vessels, dubbed 'handmade water pots' were produced in fine to coarse and gritty fabrics and occasionally have burnished surfaces. ${ }^{237}$ Three such vessels were found in situ on the floor of Mansion $1 .^{238}$ The interior surface of these vessels is distinctly rough. Vases with similar surface treatment on the interior were identified only rarely in trench $\mathrm{I} 18 \alpha / \beta$, although the handle attachment of the handmade water pots at the Menelaion is identical, involving the cutting of a hole through the wall of the vessel. ${ }^{239}$ One difference between Ayios Vasileios and the Menelaion is the fact that the burnished and coarse fabrics from the Menelaion were only rarely used for open vessels such as basins and were never used for goblets. ${ }^{240}$ Regardless of these differences, the material from both sites clearly demonstrates that the coarse and medium coarse hand-made and burnished closed vessels in the $\mathrm{MH}$ tradition continued in use until LH IIIA1. Catling clearly states that during the early phases of the settlement at the Menelaion the hand-made water pots are much more frequent than the fine wheel made vessels. ${ }^{241}$ The floor deposits in Mansion 1 and Building B at the Aetos South Slope produced only a few small or medium sized wheel-made plain pots, specifically one jug with vertical flat handles and one amphora. ${ }^{242}$ Large wheel-made plain jugs were found mainly in the construction fill of Mansion 2 at the Menelaion that probably contained also some LH IIIA2 material. ${ }^{243}$ Coarse and medium-coarse handmade and burnished vessels, both closed and open forms, continued to be made and used in

236 See ZERnER 2008, Fig. 5.30/1680-1683 for matt-painted necks of the gritty fabric (Area Lambda 1973-7, LH IIA pottery).

237 CATLING 2009a, 422.

238 CATling 2009b, Figs. 102/ET179; 111/ST116; 119/CLO54.

239 Catling 2009a, 119, 160, 422. - Catling 2009b, Figs. 159/ TH85; 209/NS91-93.

240 Catling 2009a, 423. - Catling 2009b, Figs. 222/NW53; 257/

AB78.

241 Catling 2009a, 416.

242 CATling 2009b, Figs. 131/V25; 139/VII73.

243 Catling 2009a, 417. - Catling 2009b, Fig. 100/ET154. other parts of the Greek mainland as late as LH IIIA1. In the wells at the south slope of the Athenian Acropolis the plain gritty or burnished jars represent the only storage jars. ${ }^{244}$ In the north-east Peloponnese the situation is rather different. Large quantities of semi-coarse storage jars, mainly imported from Aegina, disappear after LH IIA. ${ }^{245}$ In Messenia similar fabrics are still present until the end of the LH II period. ${ }^{246}$ With regard to the small plain and closed wheelmade vessels, the first evidence from Ayios Vasileios was found in the higher levels above the highest pebble surface, although they do occur together with sherds of the gritty fabric (Tab. 3-4).

\subsubsection{The Handmade Cooking Pot Fabric}

Handmade cooking pots with smoothed brown/red surfaces and with a fabric containing schist are common in all stratigraphic units and many bear traces of burning from use (Tab. 3). The most frequent shape is the button-based cooking jug. The latter is common throughout the $\mathrm{MH}$ and early Mycenaean periods. ${ }^{247}$ According to Zerner, bases with a concave underside appear during the MH III at

244 See MountJoy 1981, 70-73 and Tab. I-III for the fabrics attested in Well $\mathrm{Z}$ at the south slope of the Acropolis. In the table provided for Well Z one category termed 'unburnished' contains exclusively closed shapes such as hydrias and many fragments whose shape cannot be identified due to the fragmentation of the material. The shapes are similar to those of the burnished wares and their fracture is gritty: MountJoy 1981, 56 and Fig. 5. - Closed shapes produced in plain wheel-made fine fabrics are very rare and represented only by few sherds. Of the 751 sherds/vessels of the plain pottery type, only eight sherds are of the polished and standard quality: MounTJOY 1981, 14, 71 and Tab. I.

245 Tsoungiza EU10: RUTTER 1993, 88. - RUTTER 2015.

246 At Nichoria the LH IIB and LH IIA layers cannot be easily distinguished, but by LH IIIA1 there are coarse jars and basins (including one found next to the hearth of the Megaron) apparently in wheelmade fabrics: MARTin 1992, 494, 584-585 and Fig. 9-36/P3640, 9-37, 9-38/P3644. - During LH II the dull painted pottery which consists of hand-made coarse (light and dark grit) vessels (closed vessels and bowls) is very common. The heavier plain pottery, also handmade, is present (together with miscellaneous categories decorated in a MH style), but the general impression is that the coarser fabrics that were very popular during MH III and LH I gradually disappear in the course of LH II in favour of fine plain pottery. However, the burnished pottery and the washy-coated wares are common during LH IIA. During LH IIA burnished pottery comprises one third of the total of the plain pottery, although the quantity declines in later phases: Dickinson 1992, 472, 481, 485, 486 and Tab. 9-2. - In Area IV, NE the material includes LH IIA and LH IIB pottery. In the table we see the decrease in the $\mathrm{MH}$ pottery styles (dull painted, miscellaneous, coarse) towards LH IIB, but the quantity of burnished pottery is not distinguished in the table.

247 Rutter 1993. - Mountjoy 2008, Fig. 6.27/3452-3453. 
Ayios Stephanos. ${ }^{248}$ One such example was found in the fill under 'Floor' 5 (Fig. 4/7). Other bases are flat (Fig. 5/70) and have good parallels amongst the LH I/IIA material from Ayios Stephanos. ${ }^{249}$ The preserved handles are troughed ${ }^{250}$ and the rims are of the tall everted form (Figs. 4/35; 7/114). Few everted rims were found in the 'Ditch' and the pebble floor. ${ }^{251}$

Cooking tripods were also produced in the same (or a very similar) fabric and the leg of one such tripod was found on 'Floor' 4. ${ }^{252}$ The leg has a double troughed section, which is characteristic of the local tripods at the Menelaion (Fig. 6/95) and was attached to the body by cutting a hole through the wall of the vessel. A fragment with a round-sectioned handle was found on the highest pebble surface and may well belong to a vessel of this type (Fig. 7/115). Although the largest part of the neck is not preserved, it is clear that the handle was set on the shoulder, or the juncture of the neck and the shoulder and not under the rim. The position of the handle on the shoulder is considered to be an early feature, ${ }^{253}$ but at the Menelaion both versions are present, one with the handle starting from the shoulder and the other with the handle starting from the neck. ${ }^{254}$ The first type probably continued until the end of LH IIIA1. ${ }^{255}$ In the Athenian wells, on the other hand, the only type of cooking pot recorded has the handles on the shoulder. ${ }^{256}$ No cooking pots in this fabric were identified in the LH IIIA2 deposit in Room 6 to the west of the pebble surfaces of trench $I 18 \alpha / \beta$ (see below). Although the assemblage is small, it may suggest that this fabric was rarely used at Ayios Vasileios after LH IIIA1 and LH IIIA2 Early.

248 ZERNER 2008, 185 and Fig. 5.50/2193.

249 Zerner 2008, Fig. 5.36/1818, 1821, 1823, 1825. - Cf. Catling 2009b, 97 and Fig. 101/ET165, ET168-ET169.

250 Cf. CATLing 2009a, 92. - CATLING 2009b, 98 and Fig. 102/ET172 for a cooking pot that has a handle with a similar section (in situ in floor of Mansion 1). The handle is thicker. In the catalogue entry there is no specification of the construction method of the vessels and this probably implies that the tripod was wheel-made.

251 Mountjoy 2008, Fig. 6.27/3449 (Area Lambda 3/4, LH I).

252 At Nichoria there are legs of tripods in LHI layers: DicKINSON 1992, 480, 551 and Fig. 9-4/P3169. - Evidence for first tripods at Ayios Stephanos occurs during MH III-LH I: Zerner 2008, 185.

253 MARAN 1992,144-146 suggests that cooking pots of this category continue into LH II.

254 Catling 2009b, Figs. 160/TH101; 131/V26 (in situ); 132/V27 (identified as a tripod by Catling). - Other tripods with similar handle placements are wheel-made: CATLing 2009b, 108 and Figs. 112/ ST125; 152/NB135.

255 In Tsoungiza, during LH IIIA2 Early, the cooking tripods have handles attached under the rim: THOMAs 2011a, 217 and Fig. 25/279280, 286, 288.

256 Mountjoy 1981, Fig. 6/27-32.
In rare cases, cooking pots in the same or a very similar fabric were wheel-made. One base comes from the 'Ditch', which contained pottery dating to the LH II to LH IIIA2 periods. Wheel-made button-based jugs and tripods are also known from the Menelaion. ${ }^{257}$ Finally, only one sherd belongs to an open form, a handmade basin (Fig. 9/146).

Some sherds in rare fabrics were recovered from layers sealed by 'Floor' 4. One tripod leg has medium sized inclusions and light surfaces, but no schist is visible, at least at the macroscopic level (Fig. 6/96). A second leg came from 'Floor' 5 and has a light to pale red fabric with smoothed surfaces and many inclusions (Fig. 4/6). It has a rectangular section, which does not resemble the much broader troughed legs from the Menelaion. ${ }^{258}$

\subsubsection{The Red Sandy Cooking Fabric}

The red sandy wheel-made fabric was used for closed and, very occasionally, open vessels. The fabric was not represented in the fill beneath 'Floor' 5 , but this may be due to the small amount of pottery in that specific context. Three fragments were found in the lower levels sealed by 'Floor' 4 (Fig. 5/71) and these belong to closed vessels with thin walls and vertical handles with a round cross-section. The example from the foundation trench has a handle beginning under the rim, a later feature of hand-made vessels (button-based jugs) in the coarse fabric. A conical cup in the same fabric $^{259}$ (Fig. 5/61) is heavily burnt on the interior, perhaps indicating that it had been used as a lamp. One wheel-made cooking pot, found in situ on the sub-floor of Mansion 1, is described as being made of red clay, but the section of the handle is square and the rim is short. ${ }^{260}$

\subsubsection{The Red Silver Mica Fabric}

Sherds in a micaceous fabric appeared in all layers in trench I $18 \alpha / \beta$. Two main sub-groups can be distinguished. The first consists of vessels with a very high density of silver mica and the second of cooking pots with a lower density of silver mica.

257 Catling notes in the catalogue that one fragment is handmade, which probably suggests that some button-based jugs are, at least during LH IIB/LH IIIA1, partially or wholly wheel-made: cf. CATLING 2009a, 120. - CATLING 2009b, 155 and Fig. 159/TH98-99.

258 Cf. Catling 2009b, 108 and Fig. 112/ST125. - One leg from the erosion deposit on the south hill has a smaller and square section: Catling 2009b, 206 and Fig. 210/NS113.

259 Cf. Frizell 1980, 249 and Fig. 12/249 (layer 3, Room F, LH IIB) for a conical cup described as having a coarse fabric and brick red fracture but also buff slip.

260 Catling 2009b, 98 and Fig. 102/ET171. 
The first sub-group includes large basins, occasional cooking pots and other closed shapes. The base of a cooking pot was found in the fill above 'Floor' 5. It is handmade with traces of burning on the exterior surface (Fig. 4/36). The sherd probably represents the red silver mica or micaceous Minoan cooking jars identified at Ayios Stephanos and Kythera, although at Kythera the same fabric was also used to make cooking tripods. ${ }^{261}$ While the fragment from beneath 'Floor' 4 is small and there is no evidence of a leg, it may belong to a cooking tripod with a flat base, a wellknown Minoan type common at Kastri. At Ayios Stephanos several rims from cooking tripods have been identified but, to date, just one leg. ${ }^{262}$ Overall, however, the material from Ayios Stephanos shows a greater degree of variability in terms of form and decoration ${ }^{263}$ and some cooking vessels are also occasionally painted. ${ }^{264}$ The micaceous cooking vessels from Ayios Stephanos and Ayios Vasileios are probably imports from Kythera. ${ }^{265}$ The same fabric is also known from the Menelaion where there are no tripods but, according to Catling, some of the vessels had been exposed to heat. ${ }^{266}$ One fully preserved vat with a spout was found in situ on the floor of Building B at the Aetos South Slope. ${ }^{267}$ Rims with impressed decoration are common at all three major sites (Ayios Stephanos, Ayios Vasileios, and the Menelaion). The handle of one basin was attached by cutting a hole in the vessel (Fig. 7/118), ${ }^{268}$ which probably suggests that this technique was also used at Kythera and not only in Laconia for closed vessels made in gritty fabric (see above, Fig. 5/63). The bases of the basins are flat and there is no evidence of paint (e.g. light on dark decoration) while the cooking pots and other closed vessels are wheel-made, the same is not immediately apparent in the case of the basins. Further fragments were found on 'Floor' 3 and include small round and square rims from closed vessels (Fig. 7/116-117).

The second group within the micaceous fabric class consists of cooking pots, a category that includes tripod legs

261 The red silver mica fabric appears in Kythera from MMIB onwards: Coldstream, Huxley 1972.

262 Zerner 2008, 207. - See also Rutter, Rutter 1976, 58 and Plate $\mathrm{XVI} / 972$.

263 Cf. Zerner 2008, Fig. 5.34/1776-1779 for different kinds of rims in micaceous Minoan fabrics.

264 Zerner 2008, 206. - At Kastri also the cooking pots are occasionally painted: Coldstream, Huxley 1972.

265 For the base cf. Zerner 2008, Fig. 5.34/1780. - See Whitbread, JoNes 2008. - For a recent discussion of the red mica fabric from Kythera see KIRIATZI 2010.

266 CATLing 2009a, 438-439.

267 Catling 2009b, Fig. 259.

268 For the handle cf. Zerner 2008, Fig. 5.2/1031 and Catling 2009b, Fig. 259 (LH IIB/LH IIIA1, in situ, Building B). and bases. The majority of the sherds were found in the 'Ditch' and only one rim was found under 'Floor' 4. Most of the vessels appear to be wheel-made. One fully preserved wheel-made tripod with a flat base was found in Room 6 to the west of wall 71 and the pebble surfaces in trench I18 $\alpha / \beta$ (Fig. 11/180. see below). This confirms the presence of micaceous cooking pots and tripods, probably imports from Kythera, up to LH IIIA2. The petrographic analysis of the material will shed more light on the technology and provenance of this group.

\section{Building B - Room 6}

To the west of Trench I $18 \alpha / \beta$, part of a room was excavated. Although it is probable that a sequence of floors once existed within this room, they are poorly preserved. At approximately the same level as the highest pebble surface from I $18 \alpha / \beta$, a layer consisting of loosely scattered pebbles was identified, but it is unclear whether it represents a similar type of feature. Above this, part of one floor was found in the north-eastern corner of the trench with a dipper lying upside down on top of it beneath a pile of fallen stones (Fig. 10/179). This floor is approximately $20 \mathrm{~cm}$ higher than the surface of 'Floor' 3 in trench $I 18 \alpha / \beta$. A kylix was recovered from a context at the same level but without any surviving trace of the floor (Fig. 10/171). Approximately $20 \mathrm{~cm}$ higher than the floor and the dipper was a group of vessels, which consists mainly of carinated kylikes and a cooking tripod. It remains uncertain as to whether these vessels belong to the floor with the dipper identified under the stones or another, which has not survived. The area had been badly disturbed by the tree roots and these may have moved the vessels from their original position. The leg of the tripod, for example, was found $15 \mathrm{~cm}$ higher than the vessel itself (Fig. 11/180) and the same is true of a semi-globular kylix (Fig. 10/170).

The majority of the fine vessels are plain, although two fragments from monochrome kylikes were also identified (Fig. 10/167-168). Based on the rim typology, the plain kylikes and the dipper represent a later phase than does the pottery from the pebble surfaces in $\mathrm{I} 18 \alpha / \beta$, although they may be contemporary with the latest pieces in the 'Ditch' (cf. Figs. 8/137; 9/159). The kylikes from Room 6 are also similar to those from the fresco dump (Fig. 13/201-206), particularly the carinated kylix, which has a simple flaring rim (Fig. 10,174). Two semi-globular kylikes with short rounded lips were also found (Fig. 10/170-171) and this rim type is characteristic of LH IIIA2. The dipper also has a simple, slightly rounded, rim (Fig. 10/179). The cooking tripod has a wide neck with a slightly flaring rim (Fig. 11/180). It is wheel-made with a flat base and a handle that is attached 
to the juncture of the neck and the shoulder but possibly slightly higher than in the fragment from 'Floor' 3 in trench I18 $\alpha / \beta$ (Fig. 7/115). ${ }^{269}$ A feature shared with the cooking pots from the Menelaion is the wide neck with a flaring rim. It should be noted, however, that the majority of the tripods discovered in situ in Mansion 1 and in the construction fill of Mansion 2 have handles attached to the shoulder. ${ }^{270}$ Moreover, the cooking pots from the Menelaion never have flat bases. ${ }^{271}$ When comparing the tripods from LH IIIA2 contexts it would seem that the differences in detail reflect the development of various local traditions. In Tsoungiza the LH IIIA2 Early tripods have sharply angled necks and vertical or tall everted rims, while tripods with shorter rims appear during the LH IIIA2 Late period. ${ }^{272}$ Generally speaking there seems to be a variety of forms amongst the published examples from the LH IIB - LH IIIA1 periods. ${ }^{273}$ The tripod from Room 6 is made of red gritty clay with white inclusions and mica. Although the density of mica is not as high as was the case with the basins in the red silver mica fabric (Fig. 7/118), this vessel may also be an import from Kythera. Flat bases are a common feature of Minoan cooking pots and in Kastri this type of cooking pot, made of a red micaceous clay, is present as early as the MMIB, ${ }^{274}$ while cooking tripods in the same fabric are also known from the later phases at Kastri. However, the majority of the tripods from Kythera have legs, which are round in cross-section ${ }^{275}$ rather than oval or troughed as is the case with the cooking tripod from Ayios Vasileios/Room 6. Apart from the different profiles of the legs, the rims of the LH IIIA2 cooking

269 CAtling 2009a, 425-426. - Cf. also Mountjoy 1981, 58 and Fig. 6/25 (LH IIB-LH IIIA1, Athens, tripod with a flat base). The method of manufacture (hand- or wheel-made) is not stated. - At Nichoria one flat based tripod from LH IIIA2 Middle has been reported, but it is not clear whether it has a conical upper section like other tripods from the site or an everted rim: SHELMERDINE 1992, 502. 270 CATLING 2009b, Figs. 102/ET172; 112/ST125 (hole in pebble floor), ST126 (in situ); 131/V26.

271 Catling 2009b, Figs. 102/ET172; 112/ST125; 120/CLO57 (in situ, Mansion 1); 152/NB13.

272 Thomas 2011a, 217-218 and Fig. 25/285-287. - In the LH IIIA2 early dump at Tsoungiza the bases of the tripods are either rounded or smaller and much thicker: THOмAs 2011a, 217 and Fig. 25/282283.

273 See Martin 1992, 494, 583 and Fig. 9-35 for barrel-shaped tripods with incurving upper part.

274 Coldstream, Huxley 1972, $133-134$ and Fig. 43/56-57; Pl. 35/56-57, 59-60 (deposit $\mathrm{m}$ ) for LMIB examples. - Legs in a coarse 'oatmeal' fabric and oval section are also recorded: CoLDStream, Huxley 1972, 98 and Pl. 22/59 (deposit $\delta$ ).

275 Coldstream, Huxley 1972, 158 and Fig. 47/51-53; Pl. 43/5154. Most of them are made of red micaceous fabric. No. 52 is also decorated (deposit $\rho$. LH IIIA2-IIIB1). pots from Kastri are also very different. They tend to have a vertical neck or a tall-everted rim with a lipless or small rounded lip. ${ }^{276}$ While the LM III cooking tripods also have wide necks with everted rims ${ }^{277}$ when compared to examples with tall or medium-tall everted rims, ${ }^{278}$ they differ from the vessel from Ayios Vasileios in that their flat bases are almost as wide as the rims. They also have horizontal handles and legs with round cross-sections. ${ }^{279}$

\section{Trench B15ס and D6d}

The south-eastern deposit and the fresco dump were not sealed contexts and the presence of earlier and later material within them is to be expected. Most of the pottery is highly fragmented, but there are also many large sherds and some vessels that are fully restorable. In both cases the material seems to have been dumped in a single action and there is no evidence for stratification within the deposits. The fresco dump in the western sector may have resulted from the cleaning of a room or building as it also included a large number of well-preserved frescos. A selection of the material is presented in the following paragraphs in order to elucidate the periods discussed here.

\subsection{Trench $\Delta 6 \delta$. Fresco Dump West to the Court}

Patterned or linear painted pottery is rare and highly fragmented (11\%) and the majority of the diagnostic fragments belong to monochrome vessels. There are rims that are of the medium tall everted form and may belong to monochrome goblets (Fig. 12/182-184). Some of the bases may also belong to the same form (Fig. 12/187). The sherds representing these vessels may be residual in character. Fragments of vessels with shorter lips are also present and seem to be commoner than they were in the 'Floor' 3 contexts in trench $\mathrm{I} 18 \alpha / \beta$ (Fig. 12/185-186; Tab. 2) ${ }^{280}$ Some of the linear painted convex bases may belong to LH IIIA2 semi-globular kylikes (FS 256/257), a pottery type that is not well represented among the LH IIIA2 contexts discussed so far (Fig. 12/192-193). ${ }^{281}$ In addition, there is one shallow cup

276 See Coldstream, Huxley 1972, 158 and Fig. 47/51-53; Pl. 43/51-53. No. 53 has sandy greyish fracture and less mica.

277 Betancourt 1980, Fig. 1/A.C45 (LM IIIB). - See also Watrous 1992, Fig. 62/1654. - RutTER 2006, 1161 and Pl. 3.68/59/16 (LM IIIB). 278 Watrous 1992, Fig. 50/1346 (LM IIIB, Kommos deposit 78).

279 Although cooking pots with narrow bases appear at Kastri: Coldstream, Huxley 1972, Fig. 43/56-57.

280 The short everted rim is a feature assigned by Mountjoy to kylikes FS 256 of Group II. Mountjoy considers this type of rim to be characteristic of the LM IIIA1 kylikes: MounTJoy 2008, Fig. 6.5. Thomas 2011a.

281 Mountjoy 2008, Fig. 6.4/3047. - Thomas 2011a, 197 and Fig. 11/88 (reserved edge). 
decorated with a schematic foliate band (Fig. 12/197). This type of decoration starts in LH IIIA1 but becomes very popular during LH IIIA2. ${ }^{282}$ The handle of one crater is decorated with multiple diagonal stripes (Fig. 12/198). Among other sherds of note, is the disc from a small stirrup jar with concentric circles (Fig. 12/199). This shape has not been attested amongst the material from Building B or from the south-eastern deposit. Finally, one fragment with part of a horizontal handle may belong to a monochrome stemmed bowl (Fig. 12/188) (Tab. 5).

The plain pottery from this deposit closely resembles the pottery from Room 6 in Building B and can be dated to LH IIIA2. The commonest shape is the carinated kylix (Fig. 13/200-203), followed by the conical cup (Fig. 14/220-221). Angular bowls are also well represented in the assemblage (Fig. 14/217-219). The conical cups almost always display cut marks on their bases. The carinated kylikes have short rounded or flaring rims. Some have the carination high on the body or have rims with a straight interior lip, but these are much rarer than in Building $\mathrm{B}$, trench $\mathrm{I} 18 \alpha / \beta$ or in the southern sector (Tab. $2 / 30,36,174$ ). Also typical of the LH IIIA2 phase is the fact that the angular bowls are rarely represented by large vessels. ${ }^{283}$ Six out of seven fragments with evidence of a handle have a diameter of between $8 \mathrm{~cm}$ and $14 \mathrm{~cm}$. The rim fragments that were assigned to the semi-globular kylix are short, rounded or flaring (Fig. 13/204-206). Goblets are very rare. One of the latest sherds is a fragment with a handle that belongs to a conical kylix (FS 274), a shape that was introduced in the LH IIIB1 period (Fig. 13/207). ${ }^{284}$

\subsection{Trench B15ס. South-Eastern Deposit}

This feature contained many complete fine plain vessels. Several others are represented by large fragments, which consist of the vessel profile and more than $15 \%$ of the original rim diameter. A small part of the assemblage can be dated to LH IIA on stylistical grounds. The rest appears to be of LH IIIA1 or of LH IIIA2 Early date.

Some small and medium sized sherds of closed shapes of 'palatial' style, ${ }^{285}$ possibly piriform jars or alabastra, comprise part of the early group of LH IIA pottery. These sherds are

282 At Tsoungiza it was not identified amongst open forms dating to the LH IIIA2 Early dump but only in the closed forms: THомas 2011a, 189-190 and Tab. 3-4. - Foliate bands of the abstract type also appear on closed forms from LH IIIA1 contexts: MounTJOY 1981, Fig. 13/147.

283 CATLING 2009b, 95 and Fig. 99/ET147-148 (construction fill). 284 FRENCh 1965, 159.

285 See Dickinson 1972 for the division of the LH IIA material into palatial and domestic shapes. The palatial style consists of shapes and decorations that derive from Crete. decorated in the marine style (Fig. 14/227), ${ }^{286}$ while others show the remains of crocus (FM10) designs with dots on either side of three parallel lines (Fig. 14/228), ${ }^{287}$ horizontal ivy (FM12) with the stone pattern (Fig. 14/229), and the rock pattern I (FM32; Fig. 14/230). On one sherd the urchin (FM22) appears as a fill motif combined with a spiraloid decoration (Fig. 14/231). ${ }^{288}$ Another sherd may show the traces of a hatched loop (FM 63; Fig. 14/233). ${ }^{289}$ One conical rim of a large vessel belongs to an in-and-out bowl decorated with a foliate band (FM 64) on the exterior surface and zigzag (FM61) on the interior surface (Fig. 14/234). Most of the published examples of the shape date to LH IIA, ${ }^{290} \mathrm{a}$ period into which the foliate band would fit well.

The bulk of the pottery has good parallels amongst the assemblages from the Menelaion, including finds from the floor deposit in Mansion 1. However, one major difference between the two is the fact that monochrome pottery is very well represented at Ayios Vasileios. The rims of the goblets are medium tall and rarely tall everted (Tab. 2; Fig. 15/235238), while some have a straight interior lip (Fig. 15/239), a feature which is here considered to have appeared in LH IIIA1. Some of the bases (those which are painted underneath and are not sharply articulated) may be of an earlier date (LH IIA - LH IIB) (Fig. 15/242) as these features appear only rarely in later periods. ${ }^{291}$ Amongst the other forms may be the semi-globular kylix (FS 264; Fig. 15/243-245) and the kylix with the shallow body, which is more characteristic of LH IIIA1 (Fig. 15/246). Finally, the group includes the neck of a monochrome semi-coarse closed vessel (Fig. 15/248). The character of the fabric suggests that it may be an import. It closely resembles the LH IIIA1 hand-made water pots from the Menelaion and has a very characteristic ridge on the exterior lip. ${ }^{292}$

Several other goblets rims bear linear and pattern-painted designs. For those with a monochrome interior and an exterior rim line (Fig. 15/249-254), it has been suggested that they represent a useful chronological marker for distinguishing the LH IIIA1 from LH IIIA2 goblets. ${ }^{293}$ Two of the examples found in situ on the floor in Mansion 1, however, belong to this type (LH IIIA1). ${ }^{294}$ Some of the goblets have a

286 Mountjoy 2008, Figs. 6.16/3246; 6.29/3506-3507.

287 Cf. Mountjoy 1986, 23-24 and Fig. 18/1 (Ayia Irini, alabastron). 288 Cf. Catling 2009b, 124 and Fig. 128/IV13.

289 DiCKINSON 1972, 106-107.

290 Mountjoy 1999.

291 Mountjoy 2008, Figs. 6.18/3291 (LH IIB burial, Ayios Stephanos); 6.20/3308 (Area Beta, LH IIIA1, Ayios Stephanos).

292 CATLing 2009b, 98 and Fig. 102/ET179.

293 Thomas 2005, 195-196 and Fig. 10/76-79.

294 CATLing 2009b, 104 and Fig. 108/ST53, 55. - The example from Asine also includes LH IIIA1 pottery. 
Tab. 5. Fresco dump west of the court. Fine lustrous (Mycenaean) and plain pottery, diagnostic sherds (“'FS 171 etc.' corresponds specifically to FS 171, 173-175, which are difficult to separate when dealing with fragmentary sherds, see SтоскнамMER 2008, 160-161).

\begin{tabular}{|c|c|c|c|c|c|c|c|}
\hline Fine lustrous & Rims & Bases & Handles & Stems & $\begin{array}{l}\text { Wall sherds } \\
\text { with features }\end{array}$ & Other & Total \\
\hline goblet FS 263 & 5 & 3 & 3 & 1 & & & 12 \\
\hline goblet/crater & & & 1 & & & & 1 \\
\hline kylix FS 264 & 1 & 2 & & & & & 3 \\
\hline kylix FS 256-257? & 3 & 2 & 2 & & & & 7 \\
\hline goblet/kylix & 2 & 2 & & & & & 4 \\
\hline cup FS 237 & 1 & & & & & & 1 \\
\hline mug FS 225 & & & & & 1 & & 1 \\
\hline stemmed bowl FS 304 & & & 1 & & 1 & & 2 \\
\hline unidentifiable open vessel & 4 & 1 & & & & & 5 \\
\hline closed shape & 3 & & & & 1 & & 4 \\
\hline stirrup jar FS 171, etc.* & & & & & & 1 & 1 \\
\hline Total & 19 & 10 & 7 & 1 & 3 & 1 & 41 \\
\hline Fine plain & Rims & Bases & Handles & Stems & $\begin{array}{l}\text { Wall sherds } \\
\text { with features }\end{array}$ & Other & Total \\
\hline carinated kylix FS267 & 8 & 2 & & & & & \\
\hline goblet & 2 & 2 & 2 & & & & \\
\hline goblet/kylix & 2 & 4 & & & & & \\
\hline carinated kylix/carinated bowl & 76 & & & & & & \\
\hline kylix rounded & 15 & 40 & 1 & 13 & & & \\
\hline conical kylix FS 274 & 1 & & & & & & \\
\hline \multicolumn{8}{|c|}{ kylix with high swung handle FS 272} \\
\hline crater FS 7-10 & 1 & & & & & & \\
\hline carinated bowl FS 295 & 11 & 1 & 1 & & & & \\
\hline conical cup FS 204 & 24 & 1 & & & & & \\
\hline cup & 8 & & & & & & \\
\hline basin FS 294 & 3 & & & & & & \\
\hline unidentifiable & 44 & 14 & 8 & 3 & & & \\
\hline closed vessels & & 1 & & & & & \\
\hline Total & 195 & 65 & 12 & 16 & & & \\
\hline
\end{tabular}

tall rim (Fig. 15/249-251), a feature which is virtually absent amongst the material from Tsoungiza. ${ }^{295}$ Those with medium tall rims, however, closely resemble the goblets from Tsoungiza and could date to LH IIIA2 Early or LH IIIA1 Late. ${ }^{296}$ Some of the goblets from the south-eastern deposit

295 Thomas 2011a, 196 and Fig. 10.

296 Cf. Mountjoy 2008, Fig. 6.6/3070 and Vitale 2011, Fig. 2/2 (identified as LH IIIA2 early FS 264). come from small vessels and could belong to one-handle goblets or cups - another feature shared with the vessels from Tsoungiza (Fig. 15/254). ${ }^{297}$

The most frequent decorative motifs amongst the group of pattern-painted goblets is the pendent rock

297 See Thomas 2011a. - The goblet with the monochrome interior appears during LH IIIA1: Podzuweit 1977, 133 and Fig. 8/6. 
pattern (FM32), occasionally followed by contour lines (Fig. 16/262-264), Argonaut (FM22; Fig. 16/265), running spirals (FM46; ${ }^{298}$ Fig. 16/258), curve-stemmed spirals (FM49; ${ }^{299}$ Fig. 16/259-260), and lily (FM9; Fig. 16/256). Of these, only the stemmed spiral seems to be confined to LH IIIA1, ${ }^{300}$ whereas all of the others continued from LH IIB. Amongst the material found in the floor deposit in Mansion 1, the goblet with the pendent rock pattern is well represented ${ }^{301}$ and the same is true of the other goblet types. ${ }^{302}$ The Ephyrean goblet has not been securely identified, but it should be emphasised that this type is, in general, much rarer in Laconia than it is in the Argolid. ${ }^{303}$

Another shape represented in the assemblage is the cup (FS 219). Two examples, one base and one rim, are decorated with a stipple pattern (FM77; Fig. 17/272-273) and one mug (FS 225) carries the same motif (Fig. 17/270). The fine version of the stipple pattern is considered to be a 'type fossil' for LH IIIA $1^{304}$ and vases with this decoration are well

298 Cf. Blegen et al. 1973, Fig. 151 for rim fragments with running spirals (south corner, LH IIIA1 Pylos, floor deposit).

299 A wavy line is not to be excluded. - Cf. Frizell 1980, Fig. 7/126 (stratum 2, House D, LH IIB-LH IIIA1).

300 French 1964, Pl. 71/c. - The curve-stemmed spiral continues into LH IIIA2: Thomas 2011a, 197-198 and Fig. 11/93, 95. - For the other motifs in LH IIB deposits see: - Lilies: FRIZELL 1980, 268 and Fig. 11/247 (identified as spiral, the stamens are different). - HieseL 1975, 21 pl. 28, 1 right (floor of house D1 in Tiryns). - Argonaut: FRIZELL 1980, and Fig. 11/246. - Hiesel 1975, 22-23 and Pl. 27/1, 28/1 left, 29/1 lower row right and left (floor of house D1 in Tiryns, Ephyrean goblets). - CATLING 2009b, Figs. 91/ET50; 130/V11 (goblet with pendent rock pattern, in situ). - And for the motifs in LH IIIA1 see: Cf. Frizell 1980, Fig. 1/10 (stratum 2-3 in House B, Asine, predominately LH IIIA1 pottery). - For goblets with running spirals see Mountjoy 1981, Fig. 25/349 (well Z). - CATLIng 2009b, Fig. 107/ ST40 (goblet with Argonaut; construction fill).

301 Catling 2009b, Figs. 91/ET50 (in situ); 107/ST4 (construction fill).

302 Curve-stemmed spirals: CATLING 2009b, Fig. 128/IV8 (mug, in situ). - CATLING 2009b, Fig. 135/VII17. - Goblets with running spirals are also rare: CATLING 2009b, Fig. 146/NB46, LH IIBLH IIIA1). - See also French 1964, Pl. 72b/4 (Atreus Bothros). Argonaut: CATLING 2009b, Fig. 107/ST40 (construction fill).

303 Cf. Frizell 1980, 11 and Fig. 2/46-247, 3/32-34 (stratum 2, Room B, LH IIB-LH IIIA1), 6/90-96 (stratum 2, Room D, LH IIB- LH IIIA1). - See also MounTJOY 1981, Fig. 15/177-178 for the type in Athens (well 7). - CATLING 2009b, Fig. 254/AB7-AB9, $\mathrm{AB} 14$ ( $\mathrm{AB} 7$ in situ). - In Mansion 1 there were very rare fragments, but they were not found in situ: CATLING 2009b, Figs. 122/I6; 124/ II11. - One crater found in situ in Mansion 1 is decorated in the Ephyrean style: CATLIng 2009b, Fig. 130/V6, with lily. - For other unstratified fragments see CATLING 2009b, Fig. 165/WN39. - MARTIN 1992.

304 French 1964, Fig. 2/12-13, 17; Pl. 72a. - Other forms decorated with stipple pattern at Atreus Bothros include goblets and a stemmed bowl. The latter form, decorated with stipple pattern, is very well represented at Atreus Bothros: FRENCH 1964, 250, 255. represented amongst the material found in situ in Mansion 1 at the Menelaion. ${ }^{305}$ However, its earlier origin is indicated by a number of pieces of evidence. It has, for example, been identified amongst the material from House D1 at Tiryns, ${ }^{306}$ at Korakou, and at Ayia Irini. ${ }^{307}$ The motif is well represented in contexts dating to the early stages of LH IIIA2. ${ }^{308}$ The early, LH IIA - LH IIB, version of the motif is attested only in one case: a single piriform jar (FS 28?), the neck of which is decorated with vertical lines (Fig. 17/282). ${ }^{309}$

Some painted kylikes from the south-eastern deposit resemble LH IIIA1 shapes (Fig. 16/267-268). ${ }^{310}$ The rims identified here are all shorter than those known from the few (but well preserved) examples of the form. One rim is decorated in a typical LH IIB ${ }^{311}$ and LH IIIA1 fashion, with the pendent rock design followed by two contour lines and horizontal wavy lines or zig-zags on the body (Fig. 16/267). ${ }^{312}$ The same decorative theme appears on a mug from the 'Ditch' in Building B (Fig. 8/130) and is also well attested at the Menelaion. ${ }^{313}$ However, the mug from the 'Ditch' and the craters from the Menelaion all have deep and broad pendent rock designs, whereas that on the kylix from the south-eastern deposit is similar to the pendent rock pattern often found on the shoulder of the LH IIA - LH IIIA1 jugs and jars. ${ }^{314}$ Very few bases from kylikes have been identified (Fig. 16/269). They have broad bands on the stems, a legacy from the goblets, and they probably belong to the same

305 CATLING 2009b, Figs. 89/ET15; 91/ET34-35; 106/ST17. - Mugs with the stipple pattern are known only from unstratified contexts: Catling 2009b, Figs. 165/WN37-38; 184/PD20).

306 Hiesel 1975, Pl. 29/1 upper row right.

307 FRIZELl 1980, Figs. 3/25-26 (stratum 2 from Room B however was not sealed by another floor and the layer also included one geometric sherd: FRIZELL 1980, 23); 6/84 (cup); 89 (mug) (stratum 2 from Room D was not sealed by another floor: Frizell 1980, 34). MountJoy 1981, Fig. 15/167-168 (well E).

308 See Thomas 2011a.

309 Cf. Dickinson 1972, Pl. 32/f (layer VI): see also Mountjoy 1999, 208 and Fig. 64/39. - For the lines at neck cf. CATLING 2009b, Fig. 254/AB5. - Cf. Also Karantzali 2001.

310 Cf. Mountjoy 1981. - Catling 2009b.

311 Mountjoy 1986, 39 and Fig. 39/1 (filling motif in the neck of a jar from Asine, LH IIB).

312 Similar wavy lines appear decorating the body of an open shape in Nichoria (LH IIIA1): MARTIN 1992, 492, 578 and Fig. 9-30/P3607. 313 Catling 2009b, Fig. 90/ET31 (crater in situ) and in a simpler version: CATLING 2009b, Fig. 124/II13, II15. - One goblet from Ayia Eirini has a pendent rock pattern without contour line but has a wavy line in the body: Mountjoy 1986, 46 and Fig. 53/4. - Frizell 1980, Fig. 6/107 (dated by Frizell 1980, 45 in LHIIB but occur in LH IIB/ LH IIIA1 layer). - MountJoy 1999, 113 and Fig. 23/134. - See also MounTJOy 1981, Fig. 15/180 (LH IIB/IIIA1, Athens, re-dated to LH IIB in MounTJOY 1999). - Earlier versions with similar decoration are known also from the Argolid: MounTJOy 1999, Fig. 16/66 LH IIA. 314 Mountjoy 1999, 96 and Fig. 16/69 (Asine, LH IIB). 
form. The LH IIIA2 kylix with the monochrome stem and the reserved lines identified at Ayios Stephanos, which may reflect Cretan influence (Mountjoy's Group II from Ayios Stephanos), has not been identified amongst the material from the south-eastern deposit. ${ }^{315}$

Examples of the shallow cup (FS 220) have also been found. Two of the bases had an internal depression in the centre, which is characteristic of the LH IIIA1 phase (Fig. 17/275, 277). ${ }^{316}$ The cups are decorated with multiple angular stems (FM19; Fig. 17/277), isolated wavy bands (Fig. 17/274), vertical wavy lines (FM53; Fig. 17/275), and horizontal curved-stemmed ivy (FM12; Fig. 17/276). The angular stems become very common during LH IIIA2, ${ }^{317}$ but they also occur in earlier contexts. ${ }^{318}$ The rest, and particularly the isolated wavy lines (FM53) and what may be the remains of a horizontal curved-stemmed ivy (FM12), would not be out of place in a LH IIIA1 context. Moreover, the ivy design on one cup seems to reflect Cretan traditions that continue from the LM IB. ${ }^{319}$ The short rims would be more typical of LH IIIA2.

Other rare open forms include a basin decorated with a wavy band on the lip and body (Fig. 17/279), a single-handled cup (FS 283) with ridges on the rim, and a decorative spiral motif (Fig. 17/271). Both forms are found mainly in contexts that date to LH IIIA2, ${ }^{320}$ while the wavy band decoration is very common during this period. ${ }^{321}$

Conical rhyta are represented by two examples. One of them bears a group of lines and multiple hooked-stems (FM19; Fig. 17/281), the latter being one of the most characteristic motifs of the LH IIIA2 period. ${ }^{322}$ The second rhyton

315 MounTjoy 2008, Fig. 6.5/3064-3066. But Mountjoy notes that there are similar stems from kylikes that do not belong to this type, e.g. Rhodes and Attica.

316 The distinction between sunken and grooved interior (LH IIIA2) bases is difficult to identify from the published drawings: cf. MounTJOY 1986, 63 and Fig. 72/6; 84 and Fig. 100/1-3. - See also Vitale 2013, Fig. 2/g (very small depression resembling LH IIIA2 bases).

317 Vertical wavy lines. - But see also MounTjoy 1999, 332 and Fig. 112/60 for the same motif on the interior of a bowl with handles on the rim (Pylos, LH IIIA1). According to Mountjoy this is a Minoan motif.

318 Thomas 2011a, 225.

319 See Andreadaki-Vlazaki 2011, Figs. 11/c; 16/d for the motif (LM IB Chania).

320 Cf. Mountjoy 1999, 1009 and Fig. 409/65 (Rhodes, LH IIIA2). - Mountjoy classifies the cup from Rhodes and another from Karpathos as FS 208/283 since the shape also resembles the shallow handless bowl (FS 208). A parallel from Pellana does not have ridges on the rim: Mountjoy 1999, 274 and Fig. 91/134.

321 Thomas 2011a, 225.

322 The fragment of a conical rhyton with multiple stems of triangular form should come from a mixed context: MARTIN 1992, 491. is decorated with multiple alternating thin and thick lines (Fig. 17/280) and lacks the groups of fine lines known from vessels dating to LH IIIA2. ${ }^{323}$

Among the vessels of closed form there are vessels with curved stripes (FM 67; Fig. 18/288-289) and alabastra with rock pattern (FM 32; Fig. 17/283) and curve-stemmed ivy (FM12; Fig. 17/284). Most of these motifs are consistent with LH IIB and LH IIIA1 dates. ${ }^{324} \mathrm{~A}$ small piriform jar (FS 45) with vertical chevrons on the shoulder may be somewhat later, with a probable date in LH IIIA2 (Fig. 18/285). Another sherd has a hatched motif that resembles a stirrup jar from Deposit $\rho$ in Kastri, also dated to LH IIIA2 (Fig. 18/286). ${ }^{325}$

The character of the plain pottery reflects its intermediate position between the LH IIIA1 and LH IIIA2 phases, something that is also reflected in other parts of the pottery assemblage, notably the coexistence of pattern painted goblets and monochrome kylikes (FS 264). The range of vessel forms is dominated by goblets, including some very large examples (Fig. 19/299-300), carinated kylikes (Fig. 18/290296), angular bowls (Fig. 20/303-305), craters (Fig. 19/301302), and conical cups (Fig. 20/306-312). A carinated goblet with a potters mark on the underside of the base is worthy of particular note (Fig. 18/297). Carinated goblets are not unknown in LH II, although they are very rare and follow the $\mathrm{MH}$ tradition in terms of the shape. This is an example of the move towards a fine plain fabric from the MH III - LH I/ LH II tradition of burnished fabrics, in which the shape occurs more commonly. ${ }^{326}$ Two fine plain craters are present, one of which preserves its horizontal handles (Fig. 19/301). An almost exact parallel from the Menelaion was described as a goblet with an unusually tall body. ${ }^{327}$ Its shape resembles that of the craters discovered by Dawkins in Mansion 1. The second crater from Ayios Vasileios has the same shape as the LH IIIA1 craters (FS 7) from Pylos (Fig. 19/302). An almost identical shape was documented in the case of the LH IIB

323 Mountjoy 1986, 82-83 and Fig. 98/3 (identified as the third type of decoration that is quite common).

324 Curve-stemmed ivy in LH IIIA1: MounTJoy 1986, 55, 57 and Figs. 60/1; 64/1-2, 6. - In LH IIB: Frizell 1980, Fig. 5/69 (closed shape with sacral ivy with triple stem), 11/238 (alabastron with ivy and a double stem). - One alabastron with a triple ivy design was found at the Menelaion in situ on the sub-floor of Room V: CATLING 2009b, Fig. 130/V1 (but with linear decoration instead of rock pattern).

325 Coldstream, Huxley 1972, 157 and Pl. 43/48.

326 See MounTJoy 2008, Figs. 6.17/3268; 6.30/3528, 3532 (LH IIA monochrome carinated goblets from Ayios Stephanos). - For MH examples see Zerner 2008, Figs. 5.14/1237; 5.24/1482.

327 Catling 2009a, 91. - Catling 2009b, Fig. 96/ET107 (construction fill). 


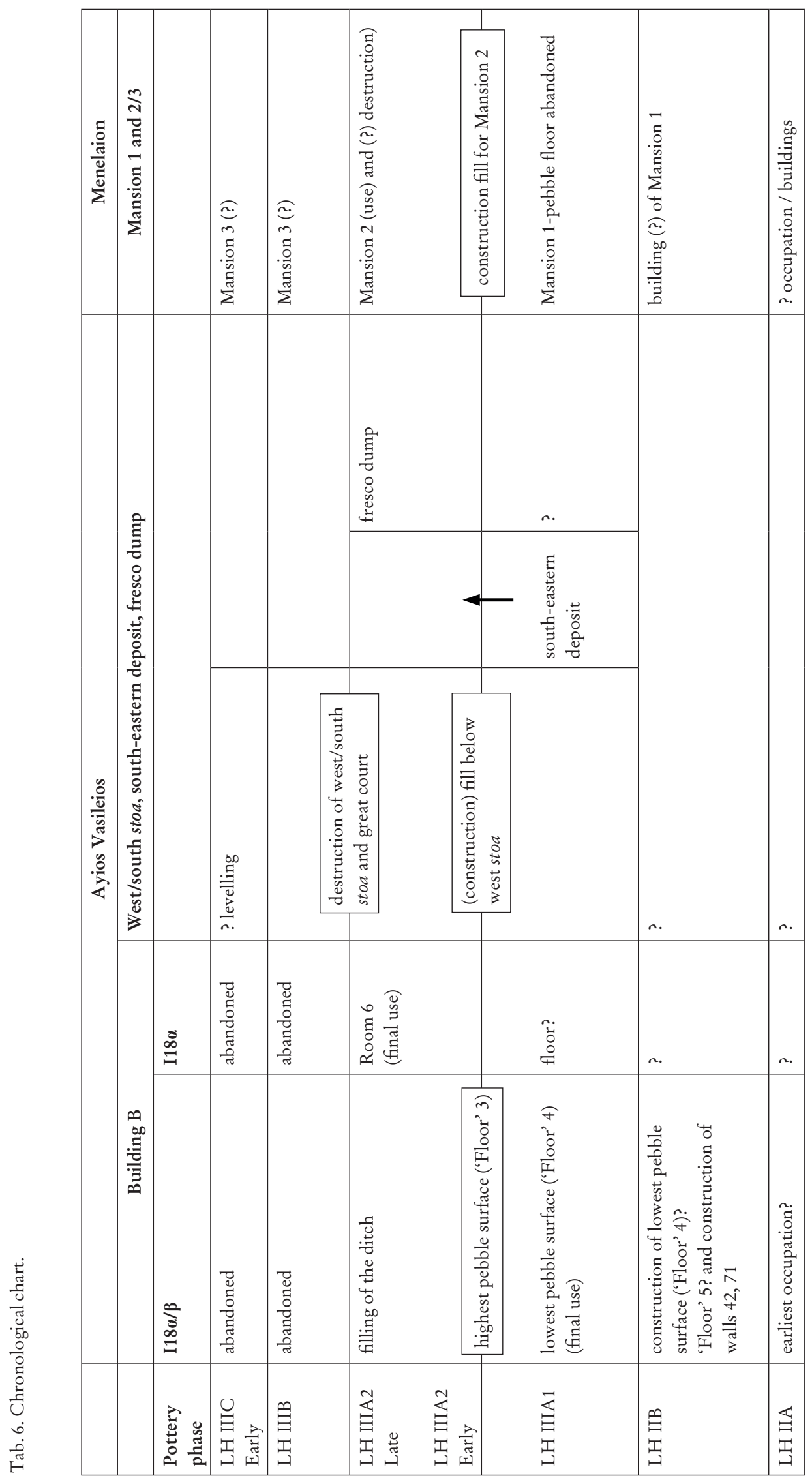


floor deposit in House F at Asine. ${ }^{328}$ The carinated kylikes are also well represented and, based on their rim typology, they seem to represent an earlier stage than the kylikes from the fresco dump and Room 6 in I18 $\alpha / \beta$ (Building B). Compared to the LH IIIA2 and LH IIIB examples their carination is still high and close to the rim (Fig. 18/291-293, 295). The globular kylix with a high stem (well-represented in some LH IIIA1 or early LH IIIA2 contexts) is rare. ${ }^{329}$ One rim fragment may belong to a kylix with a high swung handle (Fig. 18/298).

\section{Western and Southern Stoa}

In the profile of a deep Byzantine pit a deposit was recognised that consisted of three discrete layers (differentiated by their colour). The deposit was sealed by the floor of the western stoa. A concentration of pottery sherds was found some $20 \mathrm{~cm}$ beneath the floor of the stoa, but this did not relate to a specific floor. The deposit probably represents the fill of a terrace on top of which the floor of the stoa was laid. ${ }^{330}$ Amongst the painted pottery sherds, there are goblets (Fig. 20/313-314) or one-handle goblets/cups (Fig. 20/315) with a painted linear design, a monochrome interior, and a thin band on the exterior rim (Fig. 20/313315). Although the sample is very small it does not seem to post-date the pottery from 'Floor' 4 in trench $I 18 \alpha / \beta$. The goblets have the tall and medium-tall everted rims, which are also common amongst the pottery from 'Floor' 4 and below in trench $I 18 \alpha / \beta$ and which also occur occasionally in the south-eastern deposit (cf. Figs. 6/85-86; 15/249-251). Goblets with monochrome interiors and lines on the exterior of the rim were present in the floor deposit of Mansion 1 and seem to represent a common type dating to LH IIIA1 in Laconia. However, one base from the fill under the floor of the west stoa comes from a monochrome stemmed bowl (FS 304) and is not amongst the shapes/types recovered from the floor of Mansion 1. A fragment of a closed vessel, probably a piriform jar, carries a scale pattern (FM 70) on the upper part of the body (Fig. 20/316). Its decoration stops above the belly of the vessel, a feature more characteristic of LH IIIA2 rather than LH IIIA1. ${ }^{331}$ Amongst the unpainted pottery the rim of a carinated kylix with a thin lip and high carination was particularly notable as being commoner in

328 Frizell 1980, 68 and Fig. 12/253 (approximate diameter $20 \mathrm{~cm}$ ). 329 Blegen et al. 1973, Fig. 155/16 (Pylos Trench LT1).

330 The detailed analysis of the stratigraphy and pottery of the area of the western stoa and the archive will be the subject of a separate study.

331 However, piriform jars in LH IIIA1 may have also a narrow decorative zone: MounTJoy 1999, 104 and Fig. 20/104 (Tomb 11.15 in Prosymna).
'Floor' 3 and in trench I18 $\alpha / \beta$ (Fig. 20/317. Tab. 1/31). It seems to be more typical of LH IIIA1, but it continues to the next phase. The deposit was sealed by the court of the western stoa and contained pottery similar to that from the floor of Mansion 1 at the Menelaion, but the latest material was probably contemporary with that from 'Floor' 3 in trench I1 $\alpha \alpha / \beta$ in Building B. It can be dated to the earliest phase of LH IIIA2 (or the latest phase of LH IIIA1).

A few vessels were found in situ in the floor of the southern $s t o a^{332}$. These are almost all heavily burnt as a result of the destruction of the building by fire. Their dating is based in part on their stratigraphic position as almost all vessels are plain and, as such, very difficult to date. The majority of the vessels and sherds represent types typical for the LH IIIA1 and LH IIIA2 Early phases. The carinated kylikes still have a short upper body, while the medium sized angular bowls have thin rims (Fig. 20/319-320). One semi-globular kylix has a short everted rim (Fig. 20/318), which is similar to the rounded rims from Room 6 in Building B and the fresco dump (it appeared only once in 'Floor' 3 in trench I18 $\alpha / \beta$ ). It can be dated in a more advanced stage of LH IIIA2. It was also present in the fill of the 'Ditch' that probably dates to the latter period (Fig. 9/161), although this vessel does not have the typical LH IIIA2 deep body. A date in a later stage than the south-eastern deposit (LH IIIA2 Early) is suggested by the absence or rarity of the plain goblets.

The vitrified floor of the western stoa was sealed by a red layer on top of which was the floor of the upper storey with the Archive. In other cases, fragments of the upper floor were found directly on the floor of the western stoa. ${ }^{333}$ The majority of the sherds from this fill date to the LH IIIA1 and LH IIIA2 phases, but a very small number of the vessels would fit better in LH IIIB1 (e.g. one dipper with a dotted rim). Thus, the destruction of the Archive may have taken place in the latter phase, but the study of this material is still in progress.

\section{Conclusions}

On the basis of the previous discussion it would seem that Ayios Vasileios saw a major building program, which was completed at the beginning of LH IIIA2 (the fill under the western stoa).

The analysis presented in this article is one element of a larger project, which aims to elucidate the occupation

332 A substantial quantity of sherds and vessels excavated during the 2016 campaign was added to the assemblage of pottery discovered on the floor of the southern stoa. This material will be presented in a separate work which is currently in preparation.

333 Vasilogamvrou 2015b, 107. 
history of the palace at Ayios Vasileios. Its main goals are the establishment of a pottery sequence, the dating of the various building phases, and the comparison of the local ceramic repertoire with those from other sites and particularly from the Menelaion, which lies some $15 \mathrm{~km}$ to the north. To achieve this, an attempt has been made to identify sealed and stratified deposits from the area occupied by the palace directly to the south of the North Cemetery. ${ }^{334}$ This has proved to be a difficult task as extensive sealed strata remain unexcavated (e.g. under the floor of the court), while in other cases the floors were either poorly preserved or were not preserved at all (e.g. the largest part of Building B). Only in trench I18 $\alpha / \beta$ (Building B) a small area with a sequence of floors was discovered. However, the bulk of the pottery recovered consisted of very small and fragmented sherds. Two external occupation surfaces consisting of pebbles ('floors' 3 and 4) were probably part of a road and apparently also used for the dumping of pottery and food remains from activities in adjacent buildings. Beneath the lowest pebble surface (and sealed by it), the foundation trench of the $1 \mathrm{~m}$ thick wall 71 was identified and may have disturbed another older level. To the west of the road, part of a room was excavated (Room 6). This contained well preserved vessels, although the floors themselves were very poorly preserved. In addition, some material from other areas was used for comparative purposes (fresco dump, south-eastern deposit, pottery from beneath the western stoa), but only in one case was the pottery recovered from a sealed context (the pottery assemblage from beneath the western stoa). The preliminary results of this study suggest a relatively close correlation between the Menelaion and Ayios Vasileios in terms of the building and destruction horizons, although more data are required in order to confirm this.

There is no evidence for LH I - LH IIA occupation in the lower levels of trench $I 18 \alpha / \beta$, which were sealed by 'Floor' 4 (the lowest pebble surface). It seems that these phases saw only very restricted occupation - mainly located close to the area of the North Cemetery ${ }^{335}$ and Building A. LH I and LH IIA Vapheio cups are represented by a few sherds from trench I1 $\alpha / \beta$ as well as from other areas of the palace, but these were most probably either residual in later contexts or reflect the continued production of some early types (such as the Vapheio cup with the ripple pattern). The characteristic features of typical LH I and LH IIA pottery assemblages are notable by their absence. The broad range of fabrics that continue into LH IIA (often in large

334 For the pottery from the North Cemetery see Hachtmann forthcoming.

335 HaChTMANN forthcoming. quantities) from MH III and LH I (dark and pale burnished types, matt painted pottery, lustrous decorated fine, and medium coarse wares) ${ }^{336}$ were either absent from (or were very rare in) trench I18 $\alpha / \beta$, whereas the Mycenaean pottery (lustrous painted wares) was very common. ${ }^{337}$

The material from trench I1 $\alpha \alpha / \beta$ suggests that some of the earlier fabrics and shapes continue to be used in later periods. These include button-based cooking jars, ${ }^{338}$ gritty plain and burnished goblets, and hand-made closed jars (water pots) (Tab. 3). ${ }^{339}$ The vessels in the red silver mica fabric may well be imports from Kythera. ${ }^{340}$ The layers sealed by the lowest pebble surface ('Floor' 4) probably date to LH IIB, although part of the assemblage may possibly be earlier in date (LH IIA). The fine painted pottery is dominated by low stemmed monochrome, linear painted, and plain goblets (Fig. 4/1, 9-10, 13-15, 21-22, 25-28; 5/37-46; $6 / 72-78)$. The pattern-painted pottery is rare but includes some distinctive motifs (Fig. 5/47). The monochrome goblets with tall, slightly everted rims, which were well represented in the foundation trench of wall 71 (Fig. 5/37-38),

336 Jones, Rutter 1977. - Zerner 2008, Fig. 5.32/1704, 1706, 1709 1710, 1735-1737. - Minoanising classes of pottery are rare in LH I contexts at Nichoria, although there are some imports or imitations of Minoan pottery types: Dickinson 1992, 473. - At Nichoria sand tempered pottery occurs mainly in the MH II-III levels. It is described by DiCKINson 1992, 476, as a gritted fabric similar to the oatmeal Minoanising wares from Ayios Stephanos. - For LH I/LH IIA pottery in Area Lambda 3/4 (Floor 6) at Ayios Stephanos (especially Baskets 86 and 89 ) see JANKo 2008, Fig. 1.3 (the LH IIA layer is not sealed by a floor). - One layer combines the floor and a second the fill above the floor (layers 5 and 6): JANкo 2008, Fig. 1.52. - See also MounTJoY 2008, 344-350 and ZerNER 2008, Figs. 5.24/1475; 5.26/1515, 1518, 1521, 1536, 1540-1541, 1544, 1546-1549, 1553; 5.27/1554-1555, 1557-1558, 1562-1563, 1565-1566, 1569, 1572, 1574, 1576, 1581, 1588 (fine matt painted); 5.28/1607, 1612, 1616-1617, 1630-1631, $1633 ; 5.29 / 1651,1656 ; 5.30 / 1660-1661,1666,1669,1674,1676-1680$, 1688; 5.31/1691-1692 (gritty matt painted); 5.33/1745-1746, 1749; $5.35 / 1785,1794$

337 Very few fragments of Mycenaean pottery are present on Floor 6 in Area Lambda 3/4: MounTJoy 2008. - The Vapheio cup form constitutes $30 \%$ of the decorated sherds in Area IV SW (LH I) at Nichoria, although some material may be of LH II date: DiCKINSON 1992, 474-480. - In Area IV NE (LH IIA) dark-surfaced highly burnished pottery makes up a high percentage of the material. The percentage of the plain pottery there is very high ( $60 \%$ plain, $12 \%$ decorated): Dickinson 1992, 472.

338 Zerner 2008, Figs. 5.34/1797, 1799 (bowls), 1802; 5.36/18151816 (wide-mouthed jars).

339 Although the burnished pottery continues in LH IIB, at Nichoria it is reduced: Dickinson 1992, 486. - On the other hand at Tsoungiza EU10 (LH IIA) the fine polished pottery is already a significant part of the material and there is no evidence for fine burnished pottery: RUTTER 1993, 58 and Tab. 1; Fig. 7.

340 Zerner 2008, Fig. 5.34/1770, 1777. 
seem to continue a LH IIA tradition. The latter type occurs frequently beneath the lowest pebble surface but is rare in other significant LH IIA and LH IIB contexts. ${ }^{341}$ At the Menelaion monochrome goblets were absent from the assemblages discovered in the floor deposits of Mansion 1 and they appeared only once in the holes that cut through the pebble floor. ${ }^{342}$ They were mainly found in the construction fill of Mansion 2. It was only in Building B at the Aetos Stone Mound site that one monochrome goblet exhibiting early features was found in situ. This vessel was discovered together with two Ephyrean goblets and one goblet with a monochrome interior and a rim painted on the exterior. The extreme rarity of the latter type (only one very small fragment was found on 'Floor' 5) probably suggests that the lowest levels sealed by the 'Floor' 4 in trench $118 \alpha / \beta$ are earlier than the final phase of the Mansion 1 pebble floor and the horizon sealed by the floor of the court (Fig. 20/315). Regional differences within LH IIB are suggested by the absence of the Ephyrean goblets and the Vapheio cups with foliate bands. ${ }^{343}$ Both types are generally rare in Laconia. At Ayios Stephanos no sealed deposit dating to LH IIB has survived. During the LH IIB phase 'Floor' 5 was in use, the foundation trench of the $1 \mathrm{~m}$-thick wall 42 was excavated and the lowest pebble floor ('Floor' 4) was laid down.

The pottery found on top of the lowest pebble surface in trench $I 18 \alpha / \beta$ is, in many respects, similar to that from the lower levels but owing to the limited quantity of material and the small size of the excavated area, exact identification and dating is difficult. However, one stem may belong to a carinated kylix, a very rare shape during the LH IIB and LH IIIA1 phases (Fig. 6/92).

A more advanced pottery style is represented by the material found on top of the highest pebble surface ('Floor' 3). This material is characterised by the appearance of medium tall-stemmed monochrome open vessels,

341 Mountjoy 2008, 299-300. - Monochrome goblets are absent in Area Lambda 3/4. The fine plain pottery from the latter context is burnished (described as fine yellow Minyan ware): MounTJoy 2008, Fig. 6.25. - Moreover monochrome goblets are absent from Tsoungiza: RUTTER 1993, 88. - At Nichoria there is no evidence for solidly lustrous painted goblets. A category described as 'washy coated' includes goblets and cups, but the slip/paint is not glossy as in later periods: Dickinson 1992, 485, 563 and Fig. 9-16/3453-3454; 569 and Fig. 9-22/P3552-3553; 570 and Fig. 9-23/P3551.

342 Catling 2009b, Fig. 135/VII20.

343 Dickinson 1972. - Frizell 1980, 67 and Fig. 11/241-243 (House F, Stratum 3. LH IIB). - The type is also present in the Athenian wells: MounTJOY 1981, Fig. 25/331. - Only one fragment of a Vapheio cup with a foliate band was discovered at the Menelaion: Catling 2009b, Fig. 163/WN12. - For Ayios Stephanos see MounTJoY 2008, Figs. 6.2/3024; 6.19/3294 (Area Beta). plain carinated kylikes, and angular bowls. On the other hand, the semi-globular monochrome kylikes are rare, although their identification is secure (Fig. 7/101-102). A few of the rims may belong to the LH IIIA1 shallow kylix (Tab. 2/33). The majority of the painted sherds come from monochrome low-stemmed monochrome goblets and goblets with monochrome interiors (Fig. 7/99-100, 105-106), which continue from the earlier phase. On the basis of the evidence available at present, it is difficult to correlate the final phases of the pebble floors from trench I1 $8 \alpha / \beta$ with the floor deposit from Mansion 1 at the Menelaion. The absence of the medium tall-stemmed monochrome goblets and the monochrome semi-globular kylikes from the floor deposit in Mansion 1 may suggest a slightly earlier date for that deposit when compared with the final phase of the highest pebble surface in trench $I 18 \alpha / \beta$. On the other hand, some monochrome stems and rims from the construction fill of Mansion 2 at the Menelaion seem to belong rather to kylikes FS 264 or to goblets FS 263 with medium tall rims. ${ }^{344}$ This fact may suggest that the final deposition of the construction fill of the building took place in LH IIIA2 Early.

The following sequence is proposed on the basis of this evidence. The pottery from the floor of Mansion 1 at the Menelaion offers good parallels with that from the lower levels and the final use of the lowest pebble surface ('Floor' 4) in trench $\mathrm{I} 18 \alpha / \beta$. Common to both of these deposits are the goblets with tall everted rims, monochrome interiors, and occasional thin lines on the exterior of the rim, whereas the carinated kylix and angular bowl remain rare. The horizon sealed by the floor of the western stoa probably belongs to the same - or due to the presence of a stemmed bowl FS 304 slightly later (LH IIIA2 Early) - phase, but more material from the latter deposit is required in order to confirm this. The highest pebble surface in trench I $18 \alpha / \beta$ ('Floor' 3 ) is slightly later in date and, in terms of pottery style, it may be contemporary with some of the latest material from the construction fill of Mansion 2 at the Menelaion. It should be stressed that at the Menelaion there is a vague indication of another level above the floor of Mansion 1 and below the now lost (but postulated) floor of Mansion 2. ${ }^{345}$ The monochrome and linear painted goblets are still frequent and the plain or monochrome semi-globular kylikes are rare, while the plain carinated kylikes are of the early type with a high carination. ${ }^{346}$ The south-eastern deposit at Ayios Vasileios

344 CATling 2009b, Fig. 92/ET 62-ET 63.

345 Catling 2009a, 42-43.

346 However, some of the carinated kylikes from the construction fill have rim types that belong to a more advanced stage of LH IIIA2: Catling 2009b, Figs. 97/125-127; 98/ET132. 
does not represent a closed context and as a result it may contain pottery from various phases. The latest material from this seems to correlate with that from the highest pebble surface in trench I1 $\alpha \alpha / \beta$ ('Floor' 3 ). The dominant forms are the monochrome, linear painted and pattern painted goblets, and the earlier type of plain carinated kylikes. The semi-globular plain kylix is rare as is the monochrome kylix (FS 264; Fig. 15/243-245). A few of the vessels, including the shallow cups, one rhyton, and a few of the closed forms could date to LH IIIA2 (Fig. 17/273-277.281; 18/285-286).

The next ceramic phase is connected with the deposition of the fresco dump (to the west of the court). In trench I1 $\alpha / \beta$ at least two floors may have existed above the pebble surfaces. They were heavily disturbed and the material was mixed. The latest material from the 'Ditch' that interrupted the pebble surfaces and the lower levels includes similar material and dates to LH IIIA2. The latter period is also represented by the material from Room 6, west of trench I18 $\alpha / \beta$. During this phase the repertoire is dominated by monochrome and plain vessels. Plain angular bowls and kylikes are very frequent and the plain and monochrome semi-globular kylikes are also present, but the goblets virtually disappear. Their very rare occurrence may indicate the presence of early strays. The rarity of the pattern-painted pottery, which contrasts strongly with the situation in the Argolid and Corinthia may be due to regional differences. The pattern painted semi-globular kylikes (FS 256/257) are rarer than they are at Ayios Stephanos. ${ }^{347}$

The absence or rarity of the pattern painted kylix (FS 256) poses a number of problems as this is a chronological marker for the beginning of LH IIIA2. Five bases from the fresco dump could come from this type of vessel (Fig. 12/192-193). The same is also true for one base from the south-eastern deposit (Fig. 16/269). The material from the highest pebble surface in trench $I 18 \alpha / \beta$ and part of the material from the south-eastern deposit includes characteristics that have recently been suggested as being typical of LH IIIA2 Early. ${ }^{348}$ These mainly relate to the presence of the monochrome semi-globular kylikes and goblets and the absence of the painted kylix (FS 256). Other diagnostic forms, such as the painted semi-globular cup (FS 214), are more difficult to identify amongst fragmented assemblages as the relevant rims could come from small goblets. As a result, it is suggested here that there is a ceramic sub-phase that resembles LH IIIA2 Early, in which monochrome and pattern painted goblets (FS 263, 254/255), monochrome semi-globular kylikes (FS 264) and shallow painted kylikes

347 For the early phase of LH IIIA2 in Mitrou see ViTAle 2011.

348 ViTALE 2011 has re-dated Tsoungiza and the wash deposit from Area Epsilon at Ayios Stephanos to LH IIIA2 Middle. appear together (highest pebble surface and south-eastern deposit), although the two latter forms are rarer. This phase is clearly connected with a late LH IIIA1 style as is evident in the assemblage from the south-eastern deposit in which features of the next phase have already appeared. Although this may turn out to be a question of terminology (LH IIIA1 Late and LH IIIA2 Early) more published material from vertical sequences of settlement contexts could clarify the issue. Consequently, the LH IIIA2 material identified in the fresco dump and Room 6 could belong to a later stage of the phase (in which kylix FS 257 is still absent or very rare and deep bowls FS 284 are absent). ${ }^{349}$ The future investigation of Building B and other contexts may provide valuable information in terms of both the stratigraphy and the pottery typology and may allow a further sub-division of the LH IIIA1 and LH IIIA2 phases.

The previous discussion suggests the existence of at least three pottery sub-phases at Ayios Vasileios lying between LH IIA and LH IIIA2 Late. During these phases a large part of the palace was built and rebuilt before its destruction by fire. LH IIB is most probably the period during which thick walls were constructed and it may be that it was during a late stage of LH IIIA1 or LH IIIA2 Early that the buildings represented by the western stoa at Ayios Vasileios and Mansion 2 at the Menelaion were erected.

The refurbishment of the latter phase led to huge changes and, as far as can be determined, this was the first time that the rooms were adorned with wall paintings. In trench I1 $\alpha \alpha / \beta$ the fresco fragments appear only in the 'Ditch' and in the higher layer that contained pottery dating to LH IIIA2. Painted fresco fragments at the Menelaion were also mainly found in the construction fill and were not found among the floor deposits of Mansion 1.

The palace at Ayios Vasileios was largely destroyed by a catastrophic fire, an event which is evident in all of the excavated areas and especially in the court and the stoas. While LH IIIB2/LH IIIC Early sherds are well represented in secondary deposits, pottery of LH IIIB1 style is very rare. Despite this, a few sherds discovered in layers related to the destruction of the floor of the Archive could date to this phase. The scarcity of LH IIIB1 pottery is a general phenomenon in Laconia and may, in part, be related to the different pottery traditions which, in Laconia, continue from LH IIIA2 but which may also have other historical causes. It is expected that the ongoing excavation and evaluation of the material from the site will allow a clearer dating of the events that led to the destruction of the palace.

349 Vitale 2011. 

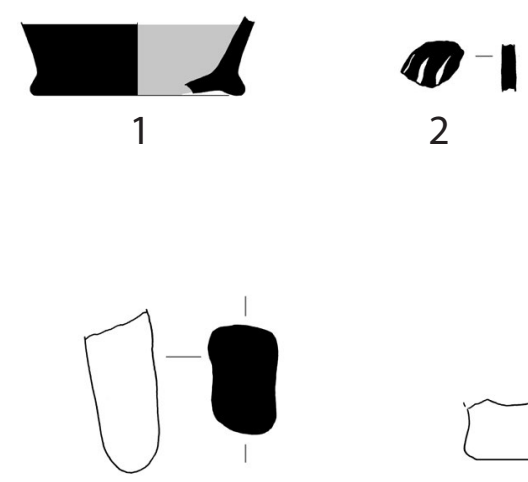

6

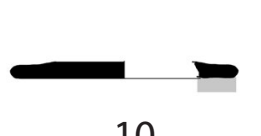

10

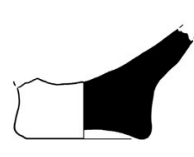

7
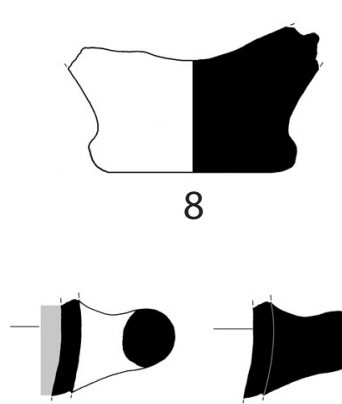

12

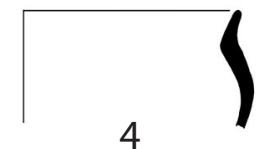

4
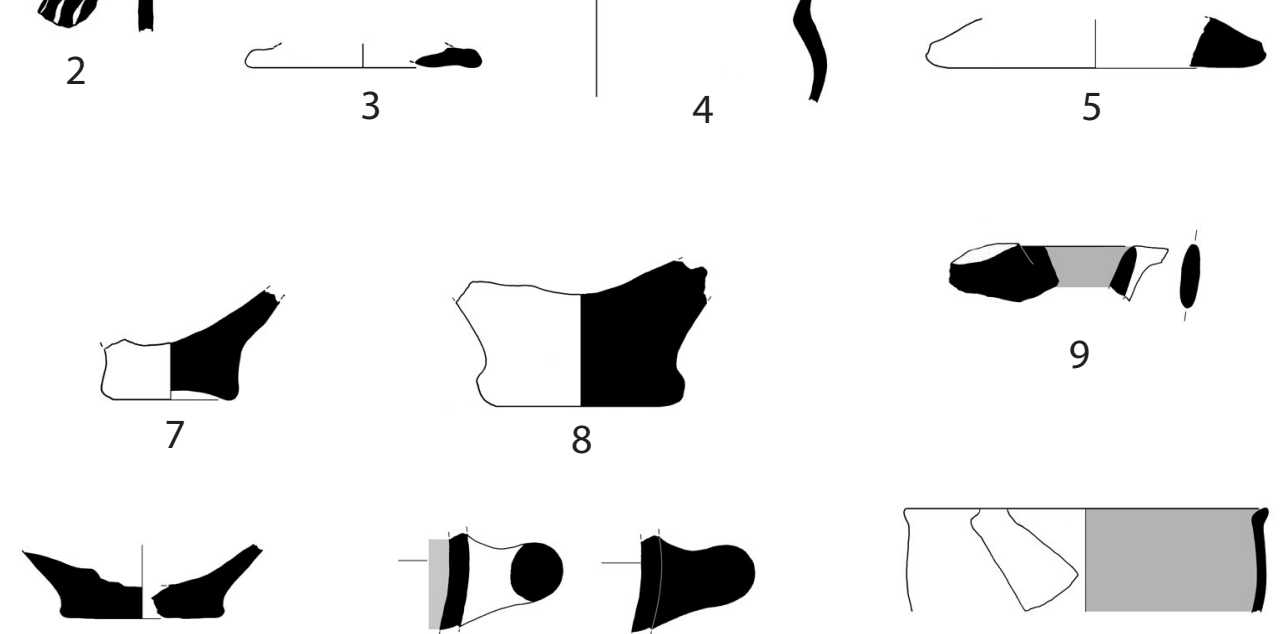

11

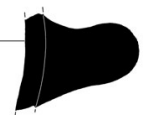

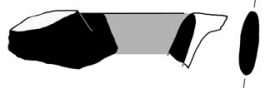

9

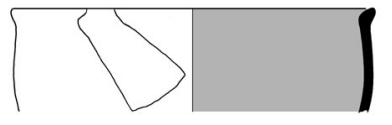

13

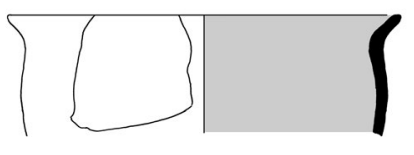

14

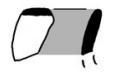

15

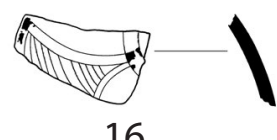

16
\& 1

17

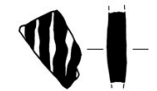

18

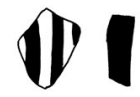

19
(1)

20

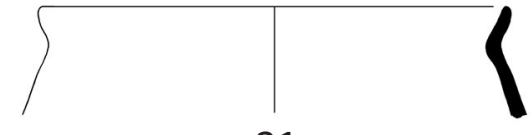

21
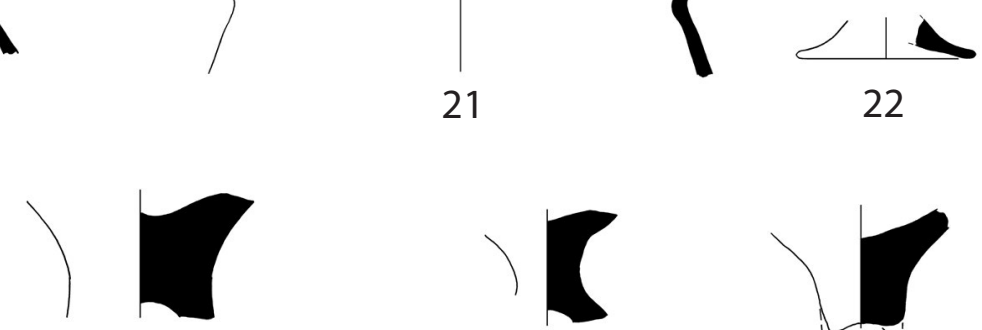

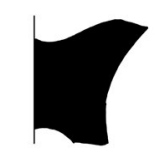

25

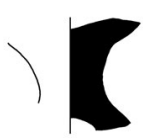

26

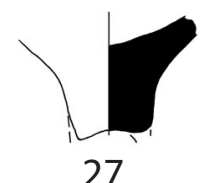

27
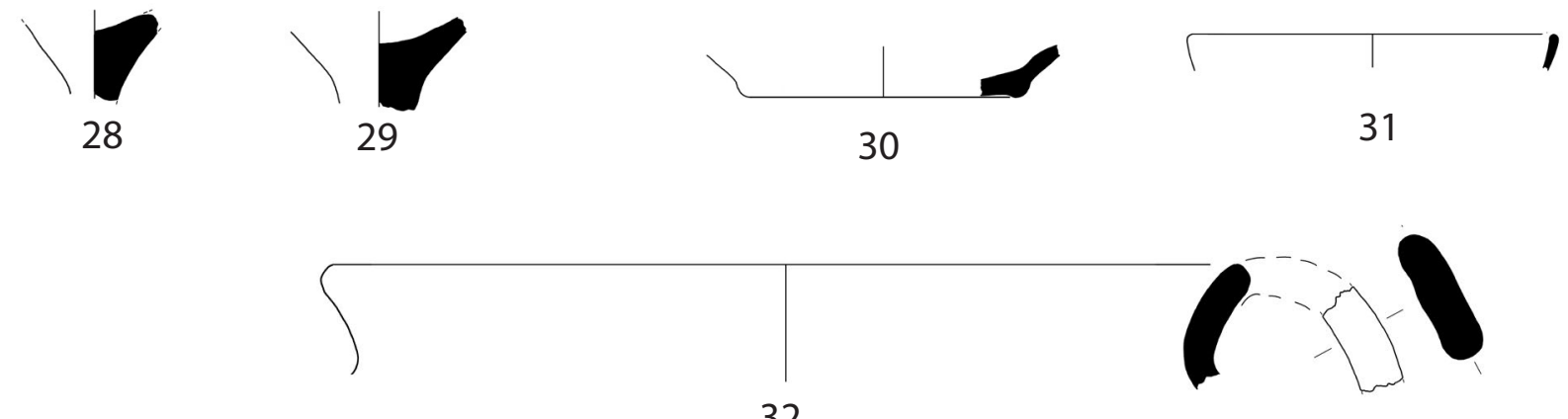

32

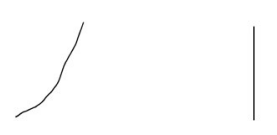

33

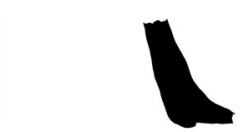

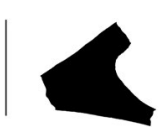

34

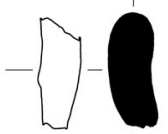

35

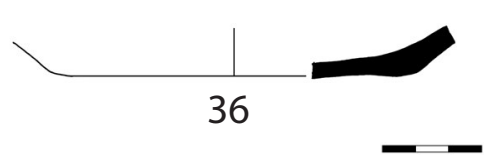

Fig. 4. Below ‘Floor’ 5 (1-8), ‘Floor’ 5 and above ‘Floor’ 5 (9-36) (Drawings: A. Poelstra). 

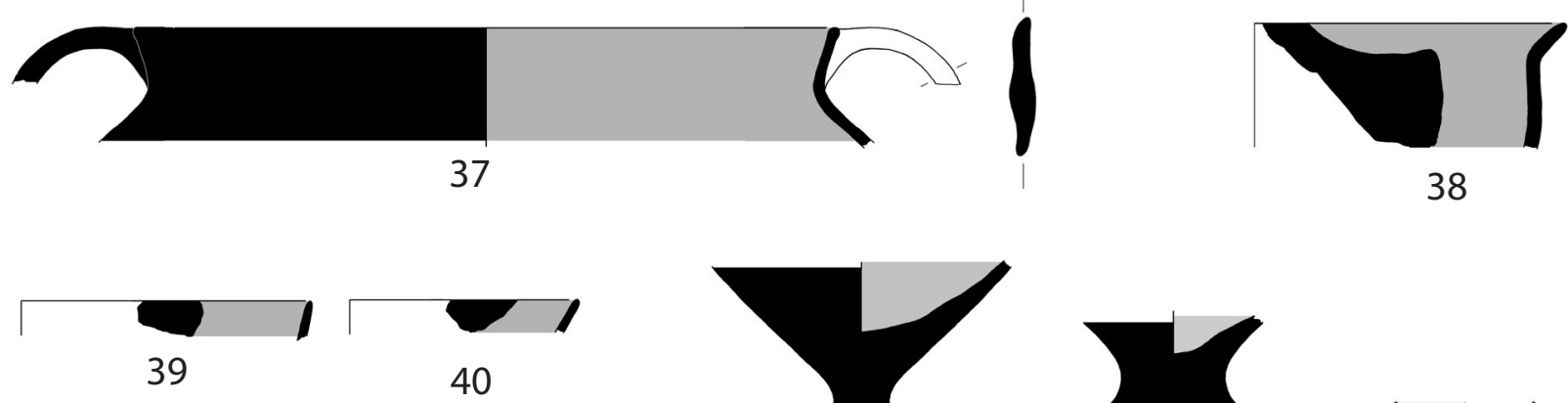

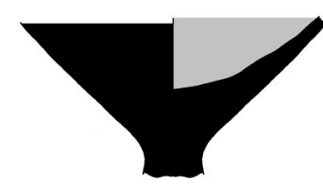

41

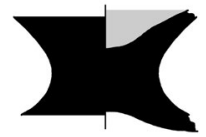

42
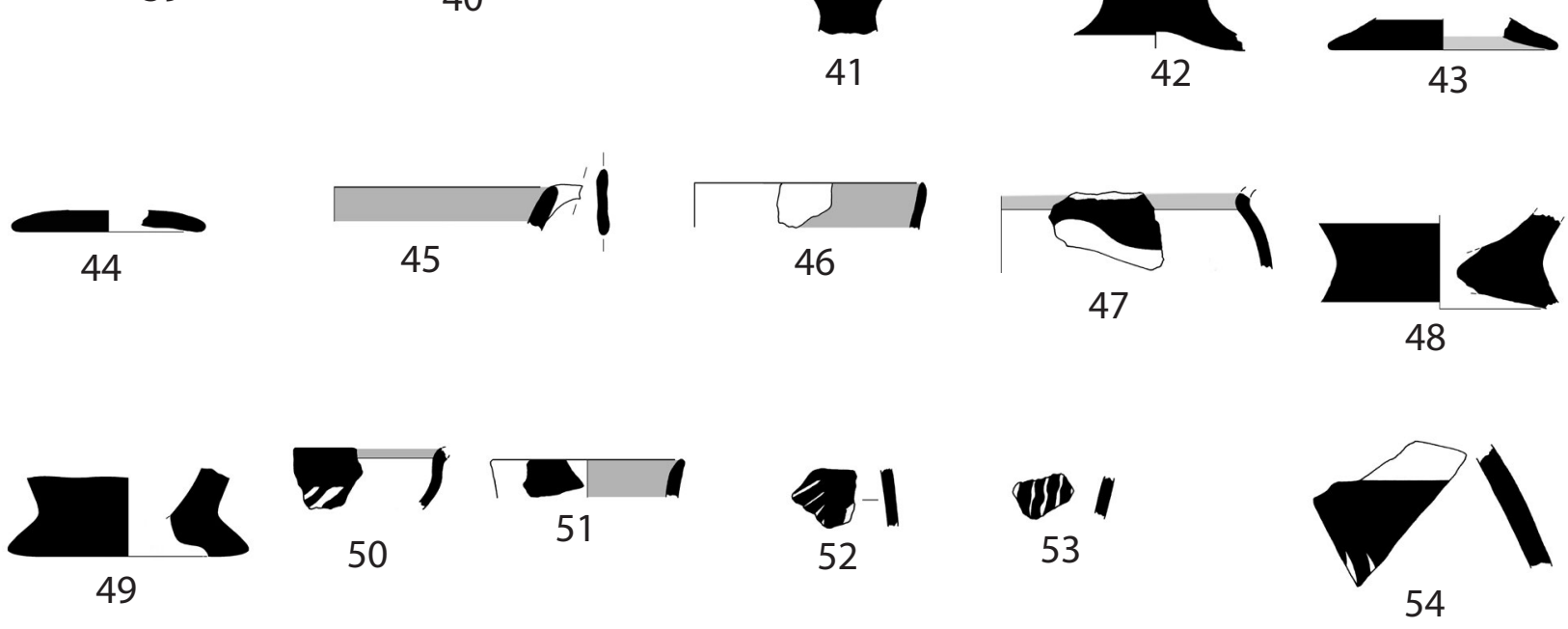

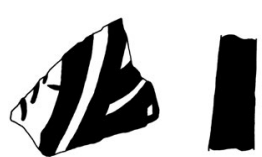

55
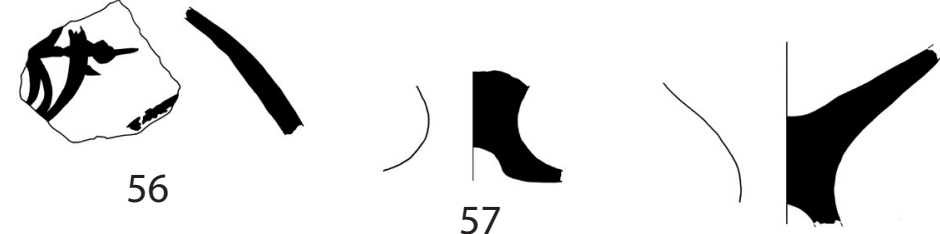

58

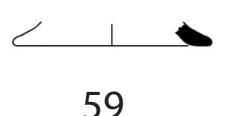

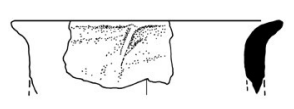

60

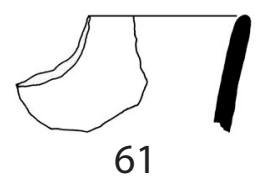

61

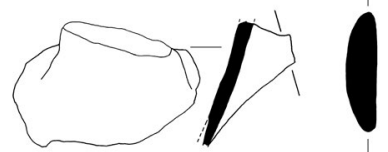

65

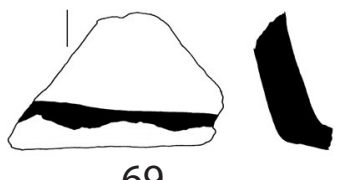

68

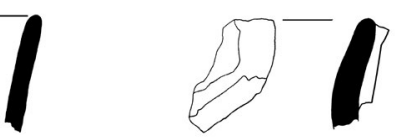

62

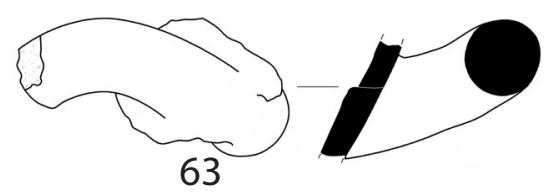

66
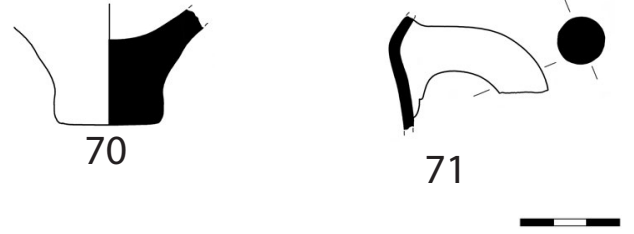

Fig. 5. Foundation trench of wall 71 (37-71) (Drawings: A. Poelstra). 


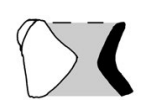

72

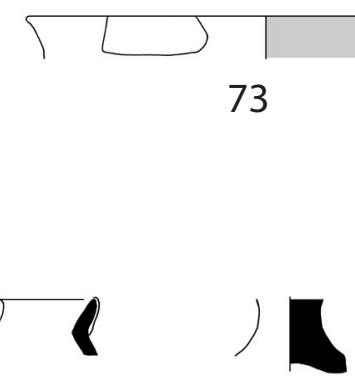

77

78
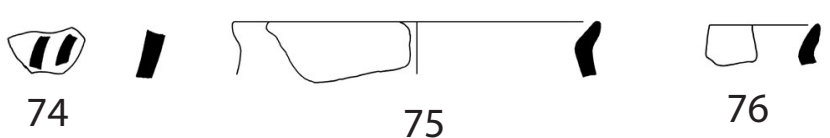

76

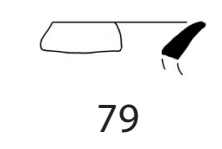

79

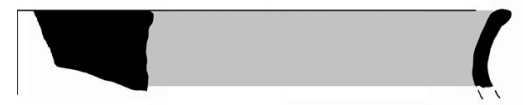

83

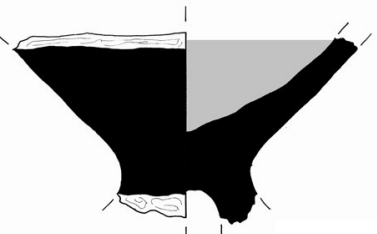

84

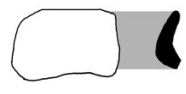

85

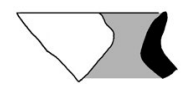

86

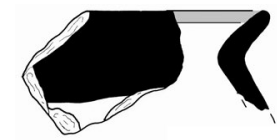

87

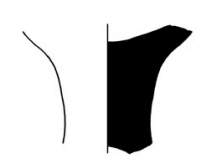

91

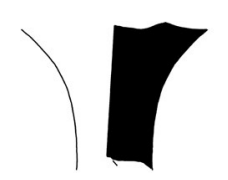

92

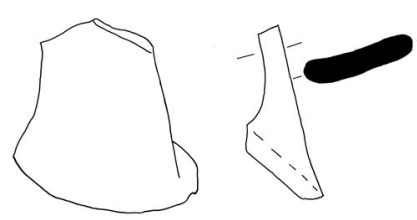

93
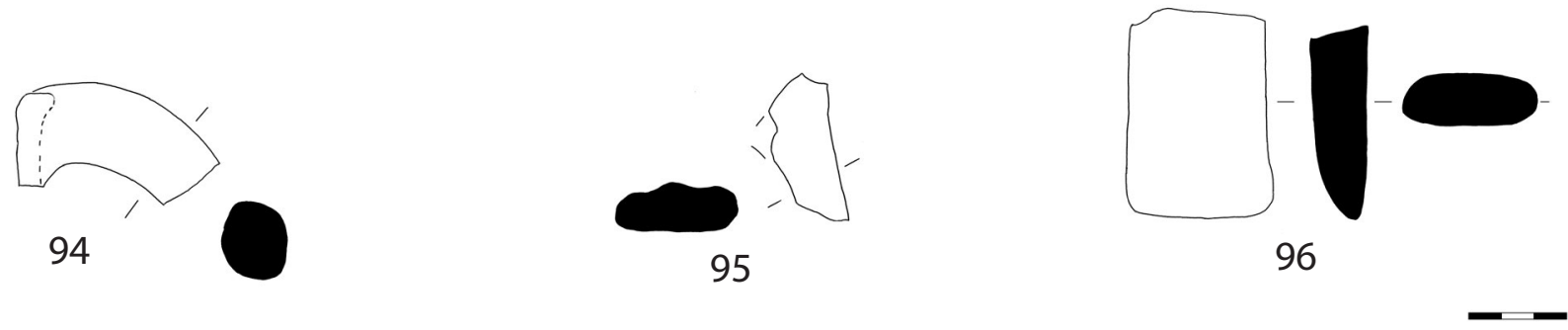

Fig. 6. Below 'Floor' 4 (lowest pebble surface (72-82); 'Floor’ 4 (lowest pebble surface (83-96) (Drawings: A. Poelstra). 


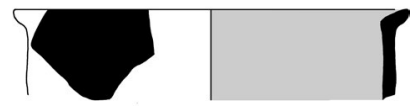

97

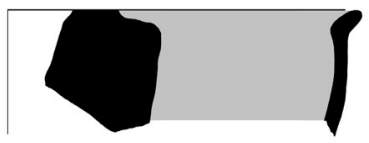

98

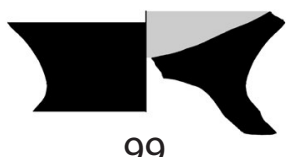

99

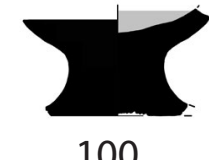

100

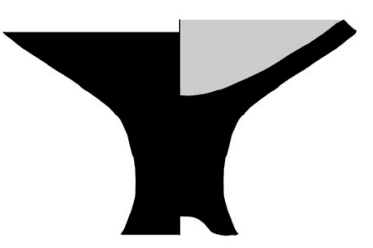

101
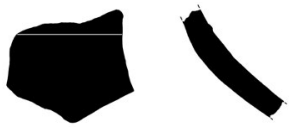

104
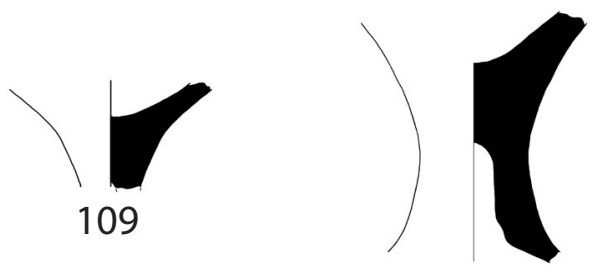

110

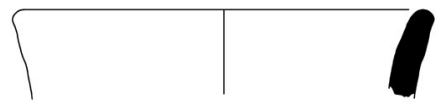

114

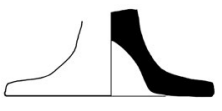

111

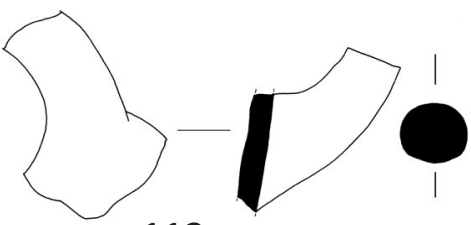

112

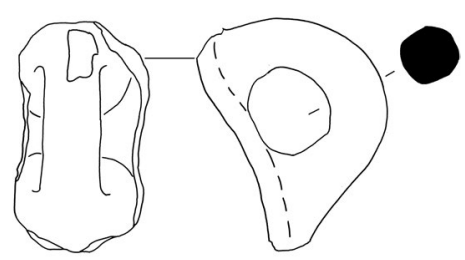

115

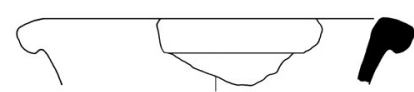

116

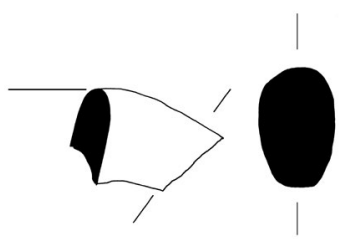

117
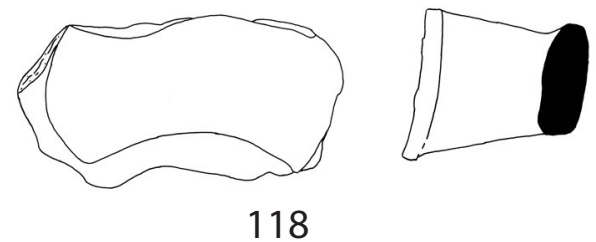

$-$

Fig. 7. 'Floor' 3 (highest pebble surface) (Drawings: A. Poelstra). 


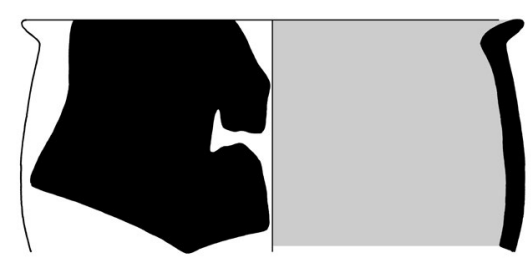

119

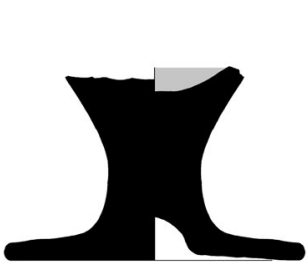

122

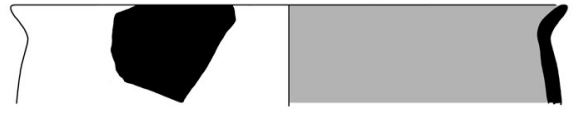

120

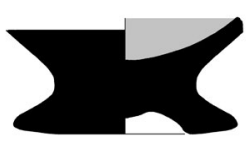

121

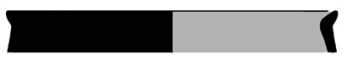

123

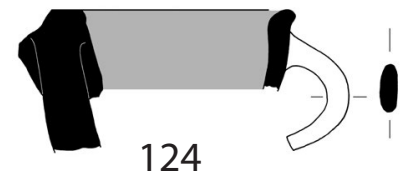

124
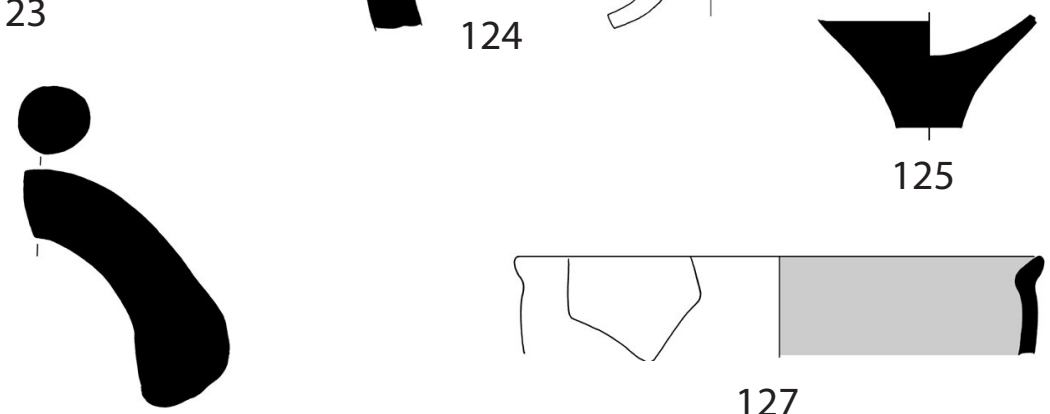

125

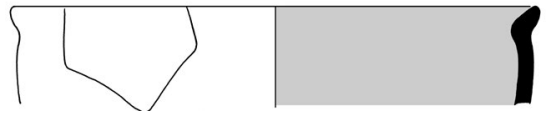

127

126

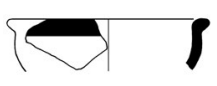

128

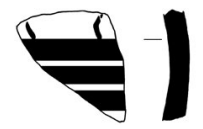

132

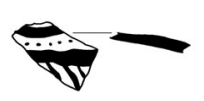

133

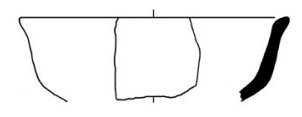

137

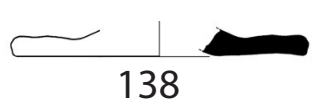

136

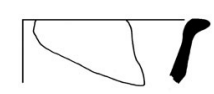

140

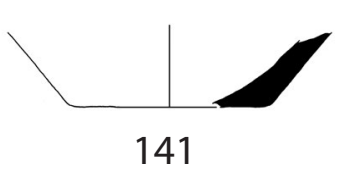

141

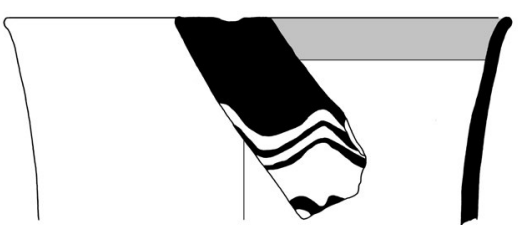

130

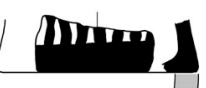

131

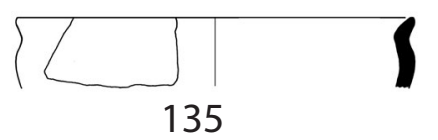

134

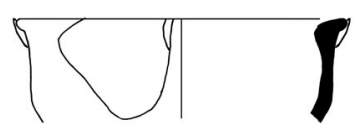

139
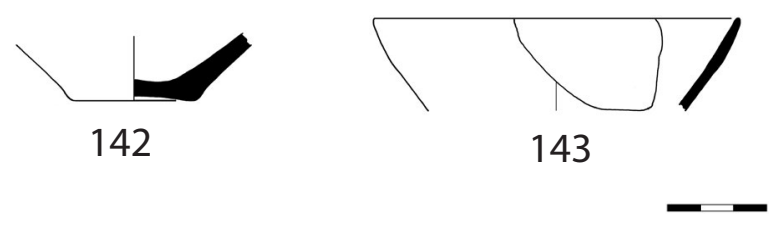

Fig. 8. 'Ditch' (Drawings: A. Poelstra). 

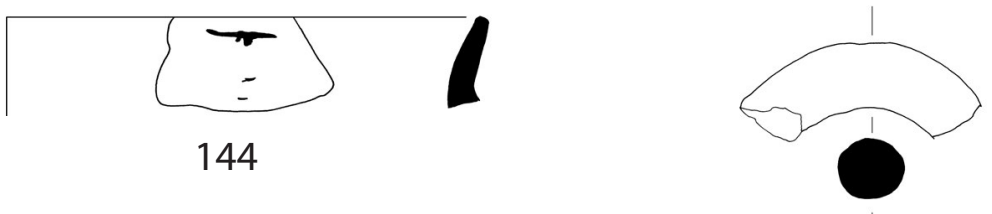

$145^{\prime}$

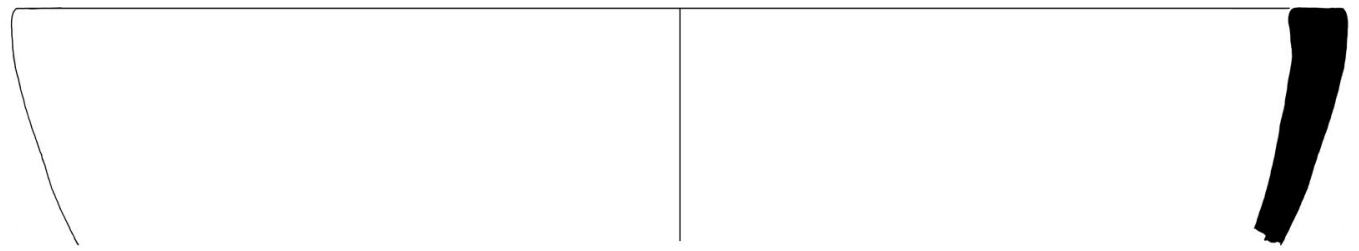

146

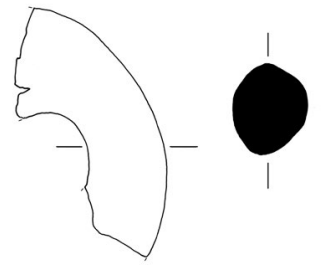

147

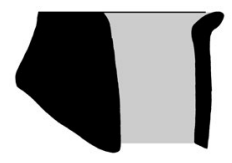

150

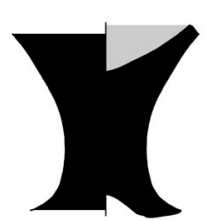

155

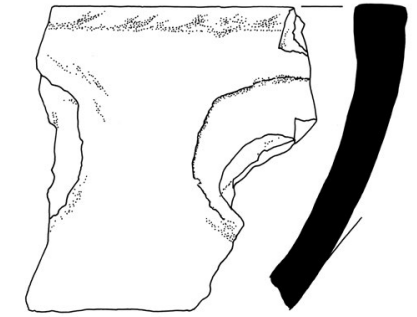

148

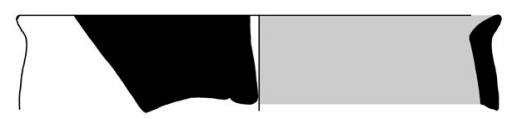

151

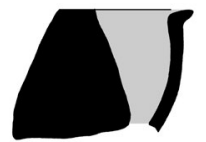

153

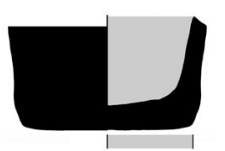

156

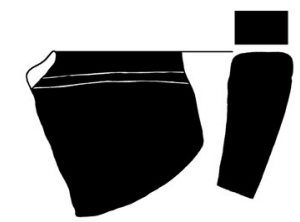

157

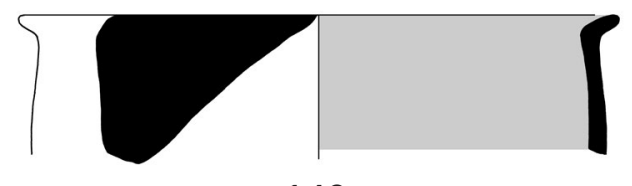

149

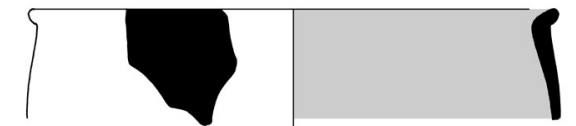

152

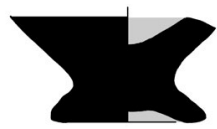

154

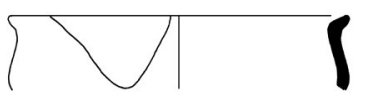

158

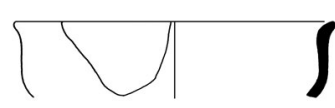

159

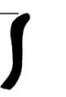

$-$

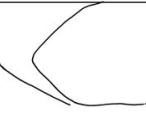

160

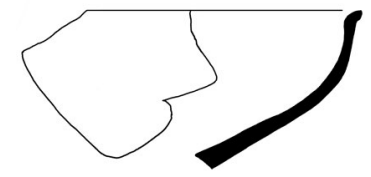

162

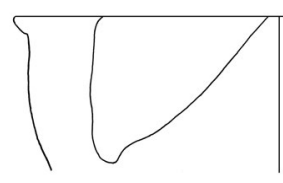

163

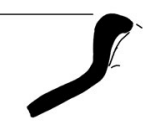

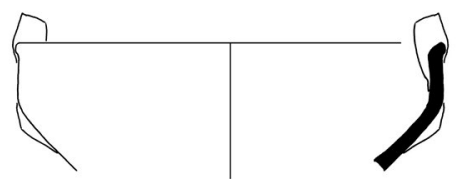

161
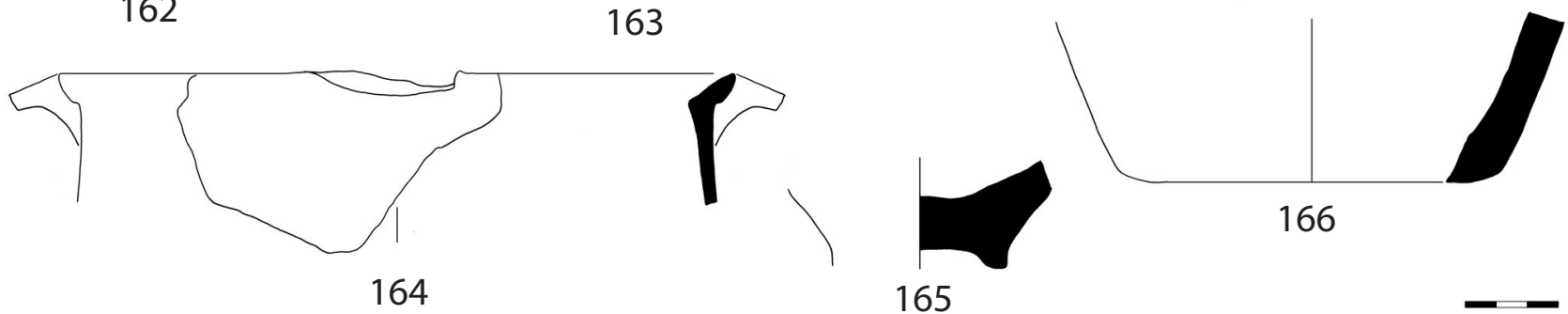

Fig. 9. 'Ditch' (144-148); Above 'Floor' 4 (east) (149-166) (Drawings: A. Poelstra). 


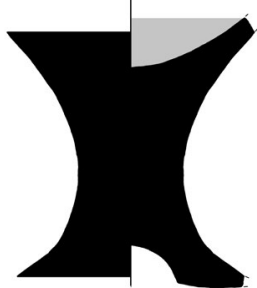

167

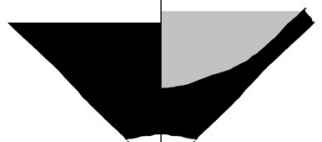

168

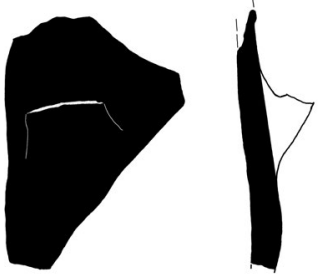

169

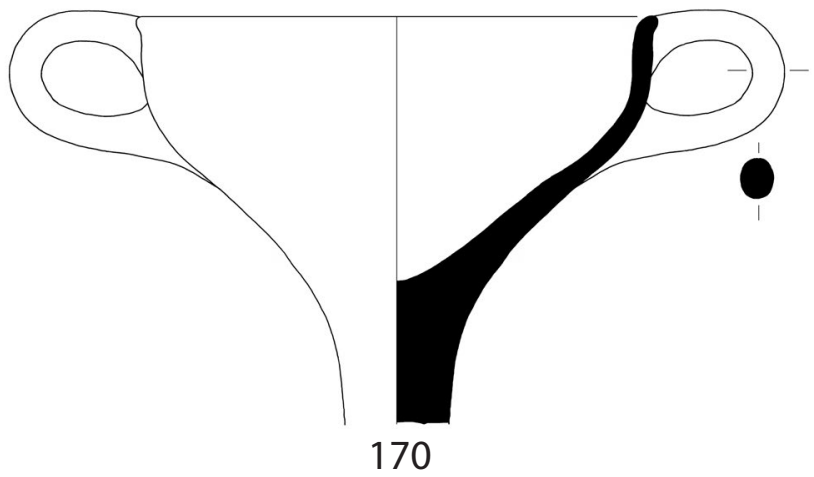

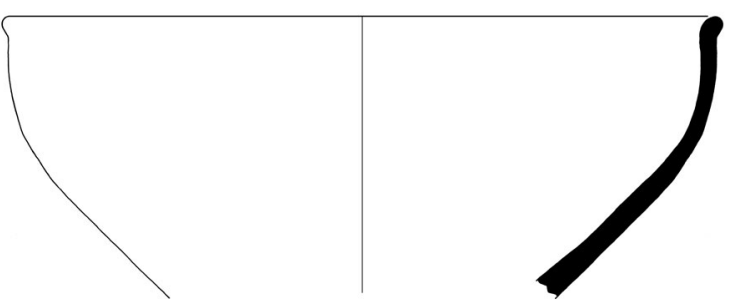

171
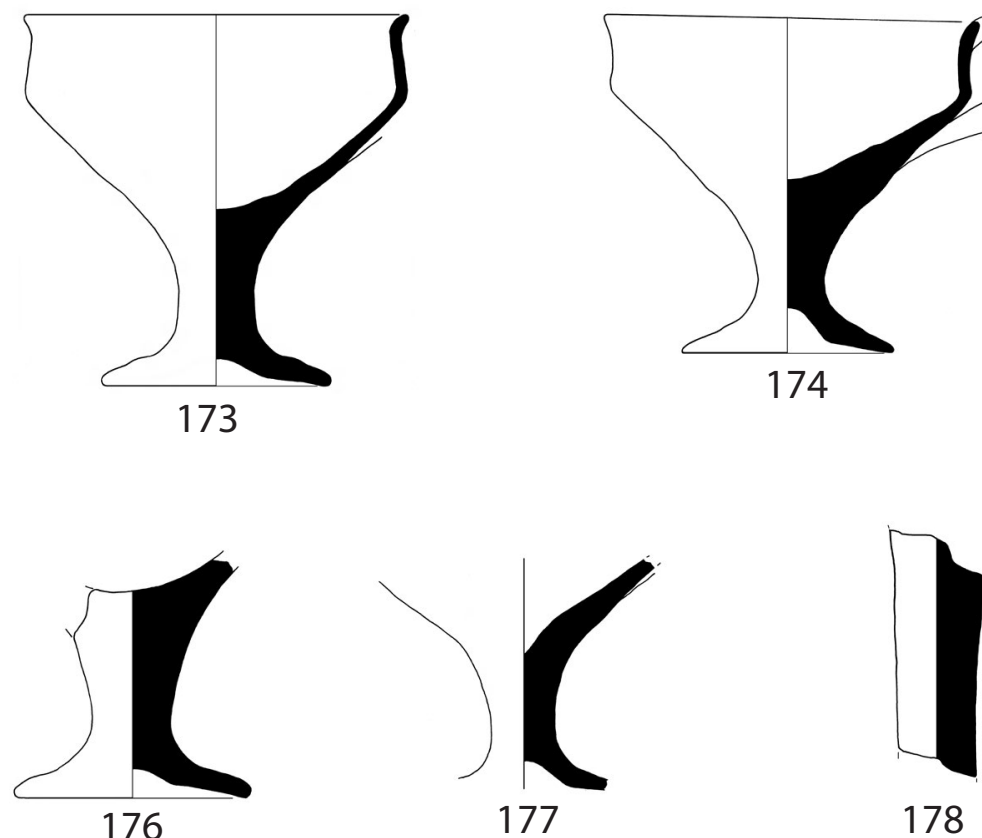

178

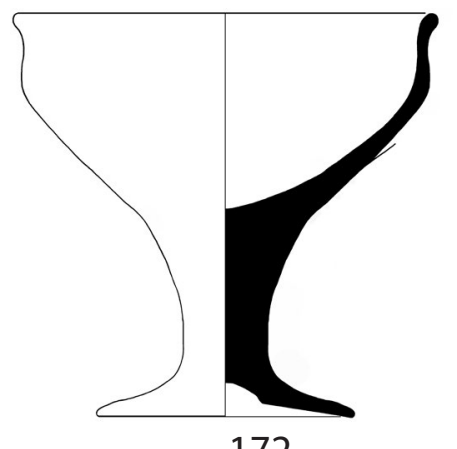

172

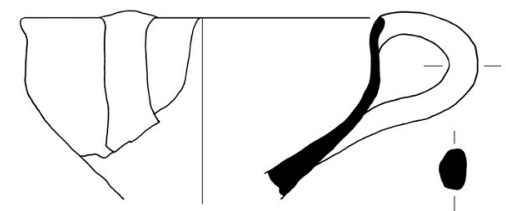

175

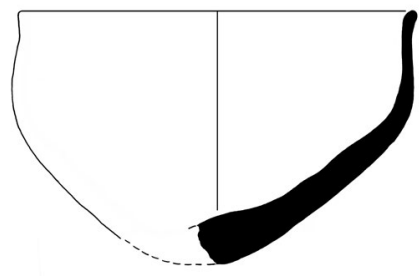

179

Fig. 10. Room 6 (Trench I18 $\alpha$ ) (Drawings: A. Poelstra). 


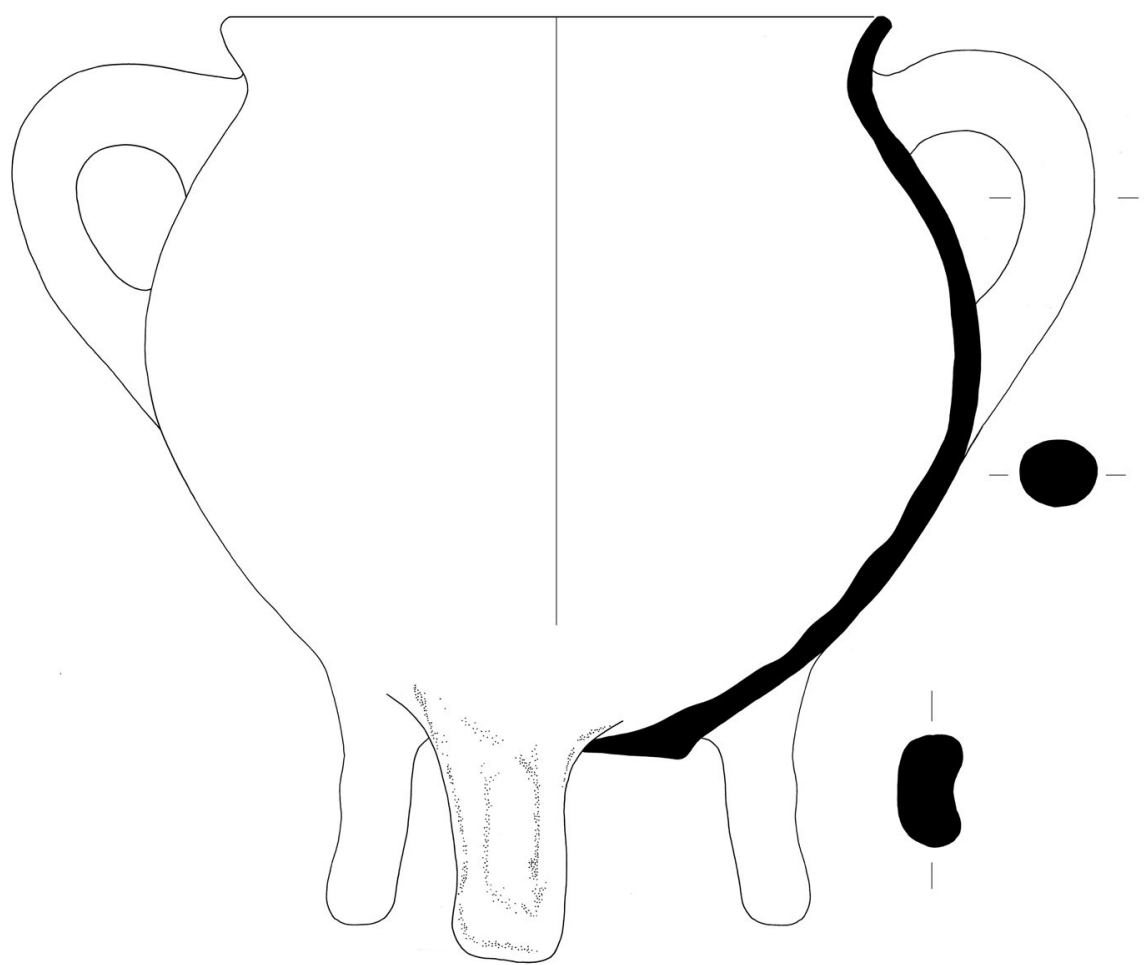

180

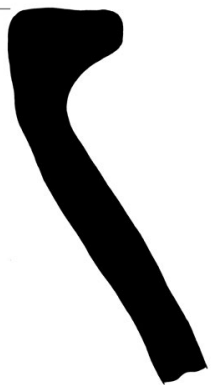

Fig. 11. Room 6 (Trench I18 $\alpha$ ) (Drawings: A. Poelstra). 


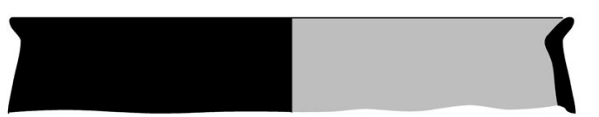

182

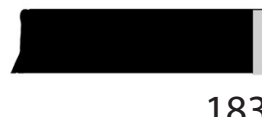

183
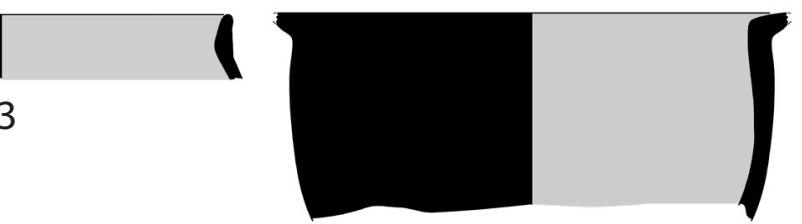

184

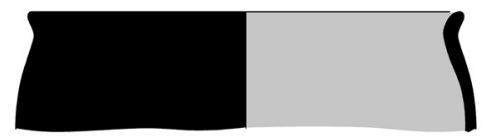

186

185

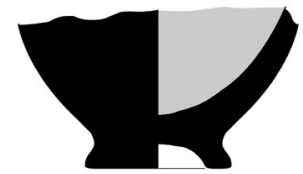

187

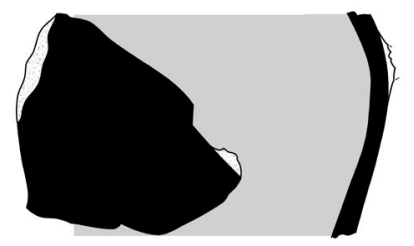

188

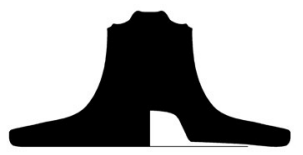

189

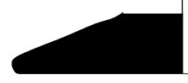

190

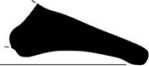

191

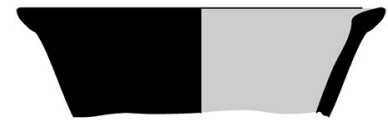

192

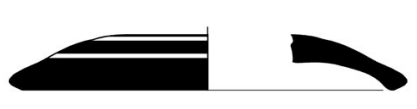

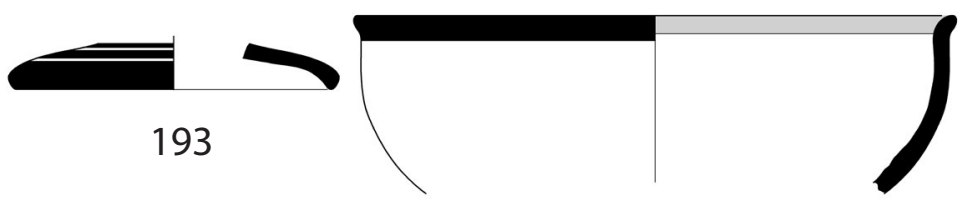

194

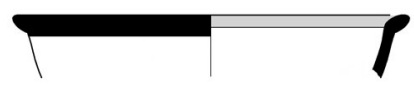

196

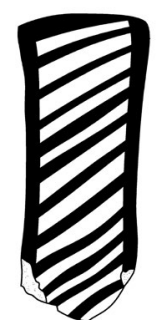

198

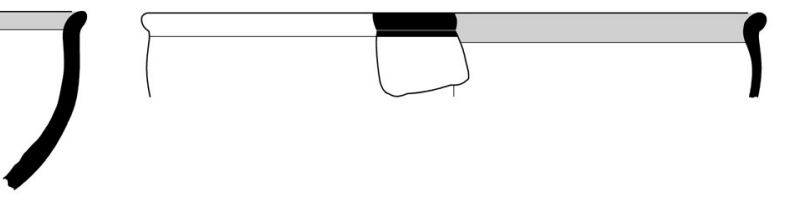

195

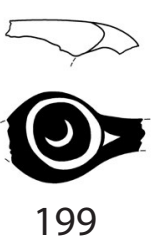

Fig. 12. Fresco dump (Trench $\Delta 6 \delta$ ) (Drawings: A. Poelstra). 

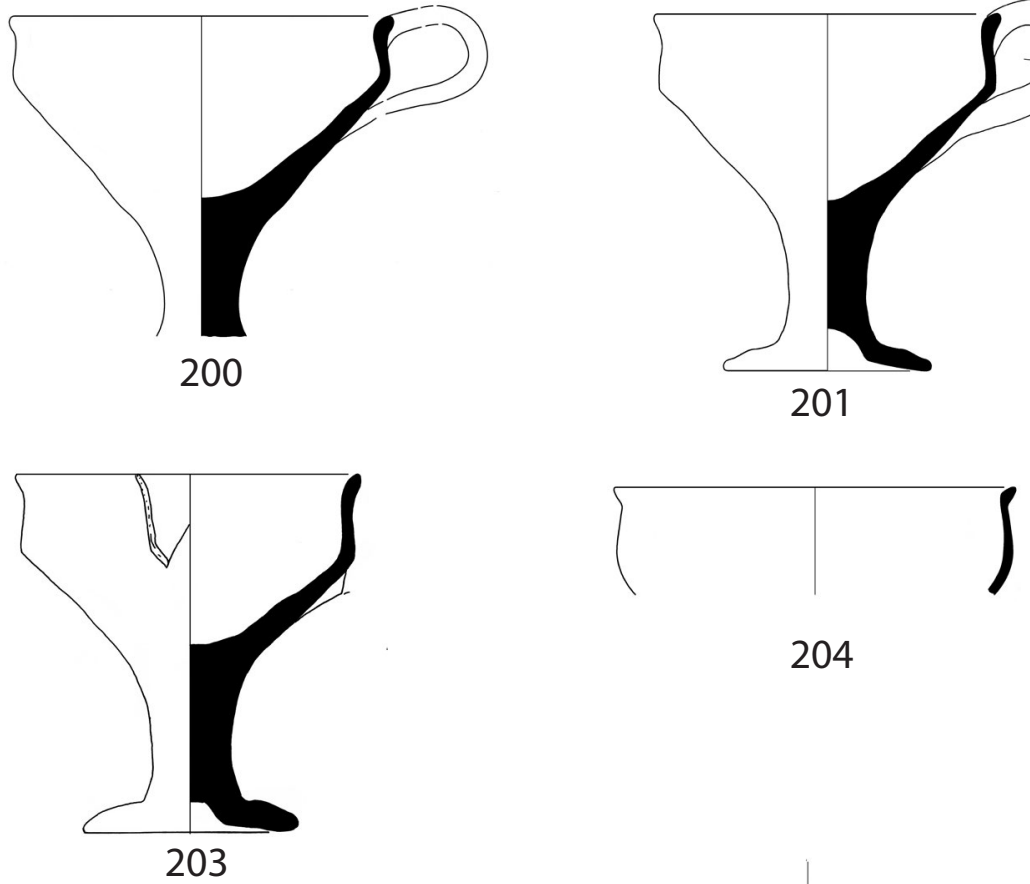

204

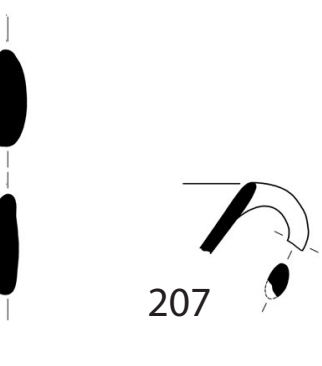

206
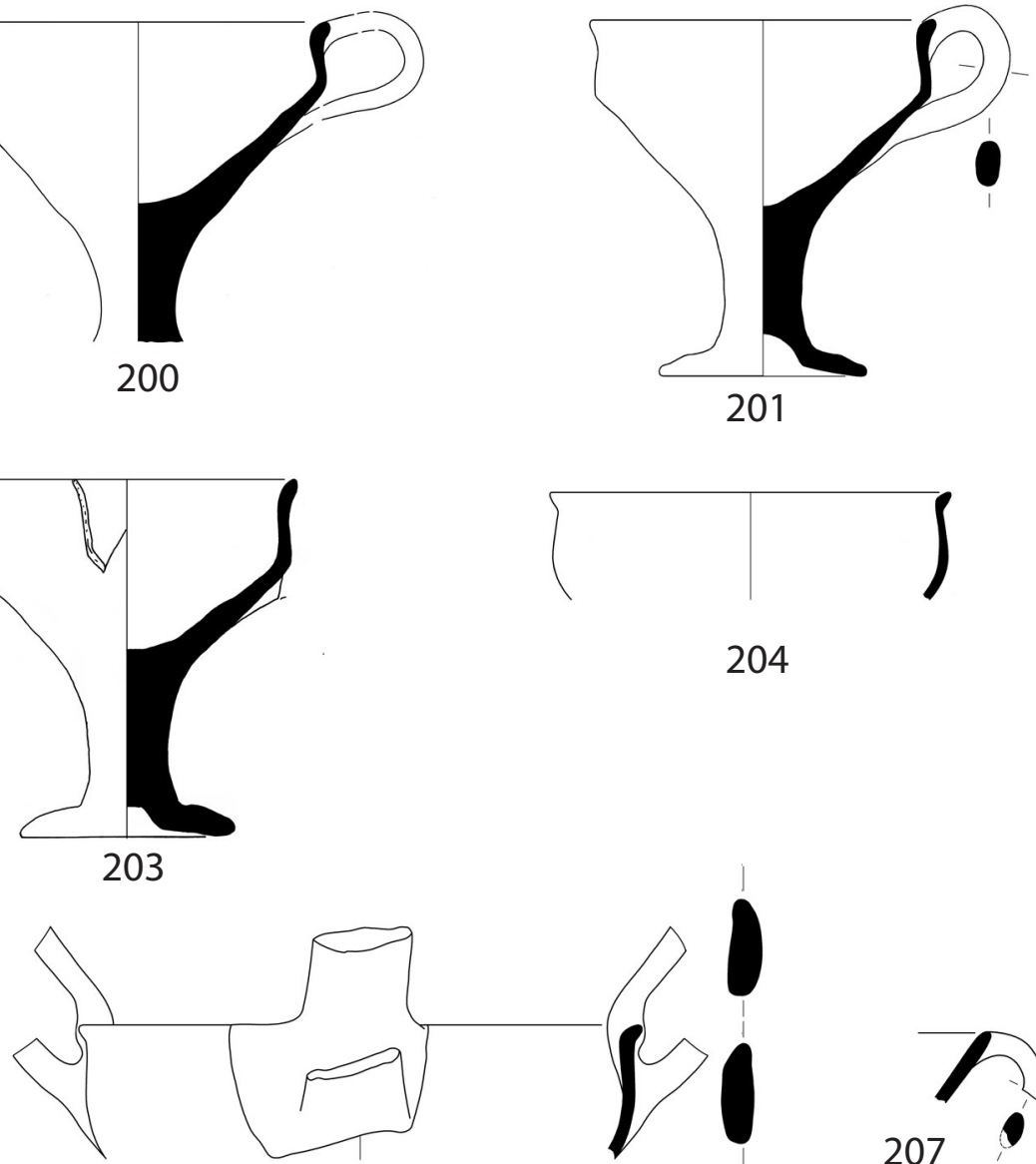
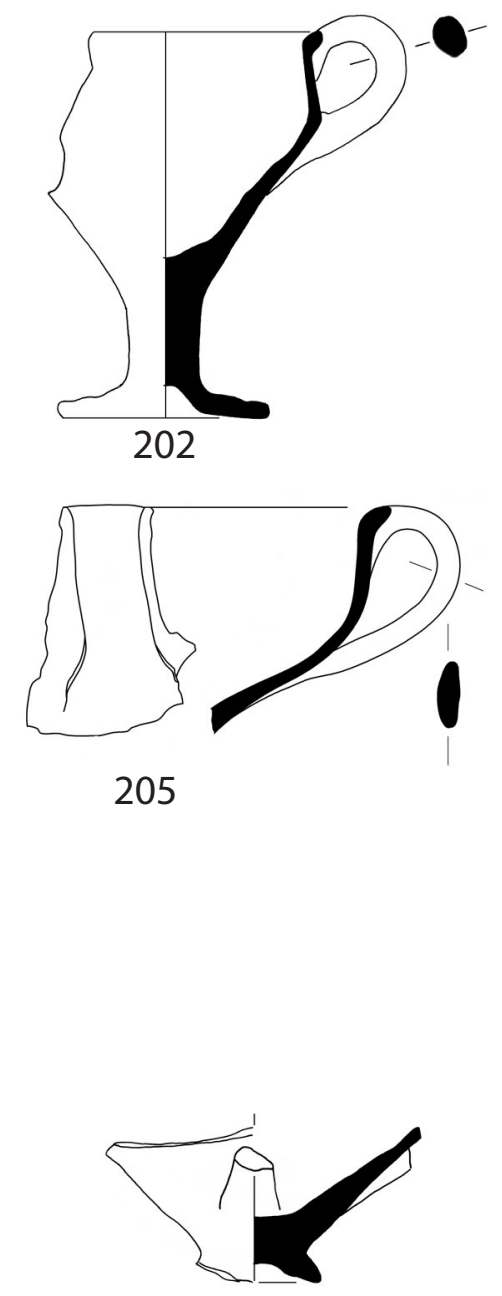

208
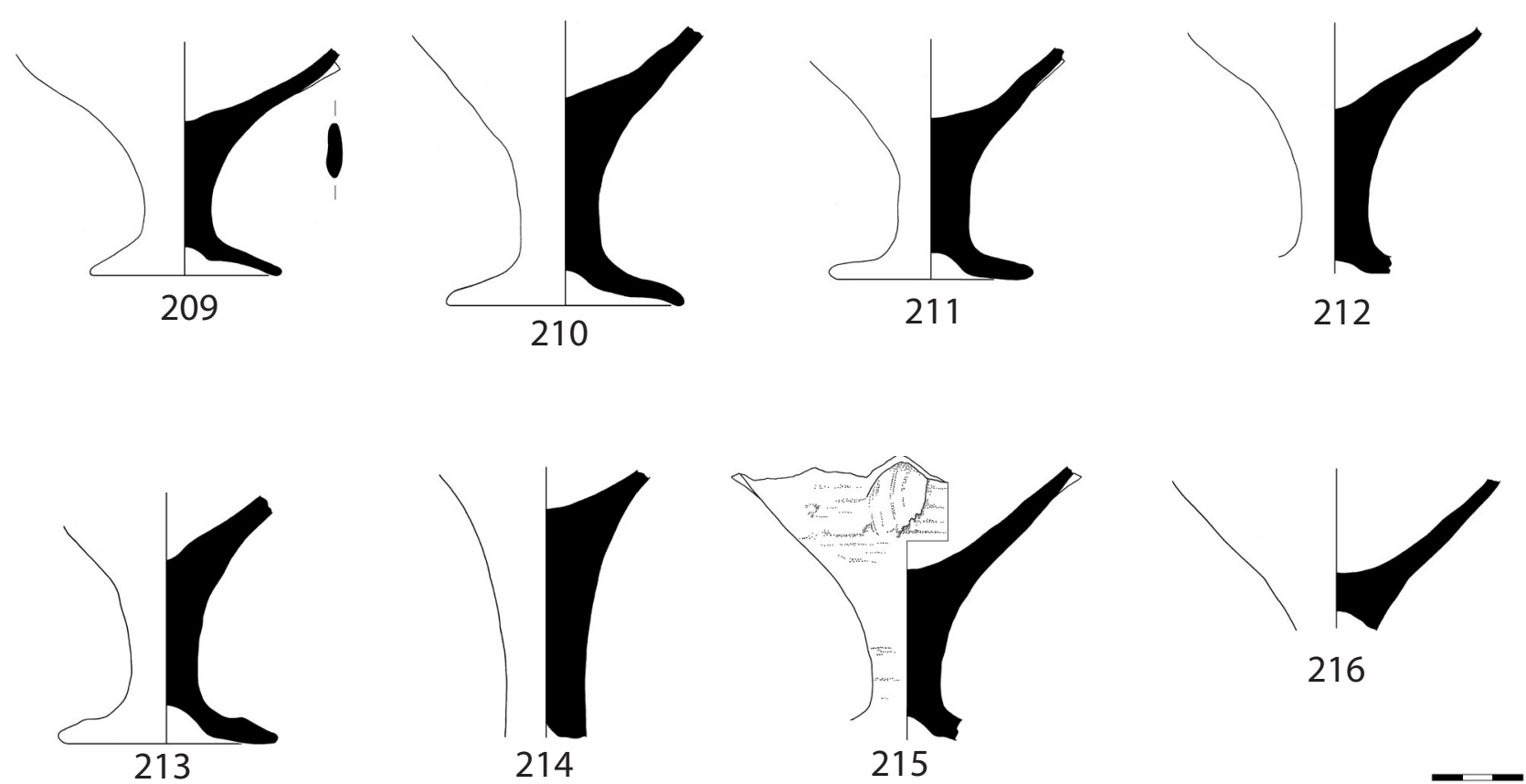

Fig. 13. Fresco dump (Trench $\Delta 68$ ) (Drawings: R. Jung [202-203, 208], A. Poelstra [201, 204-207, 209-216]) 


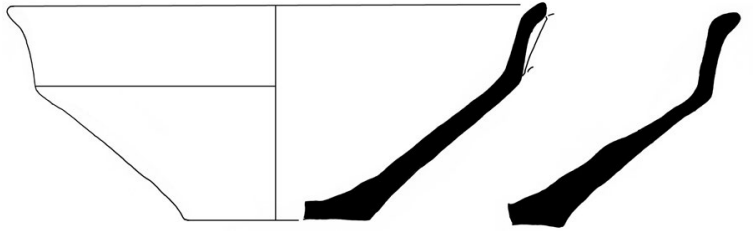

217

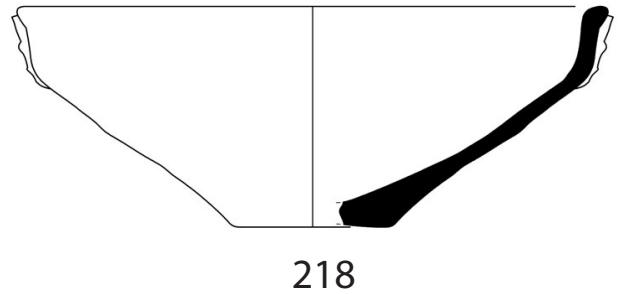

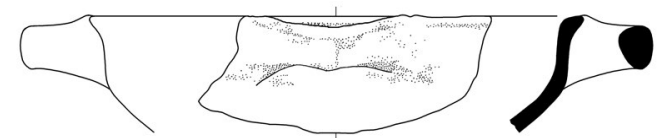

219

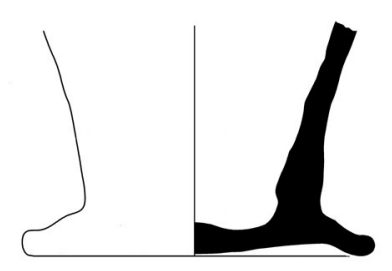

222

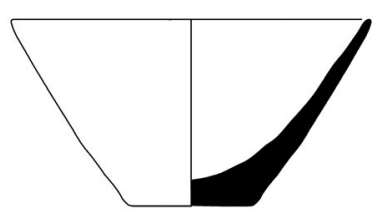

220
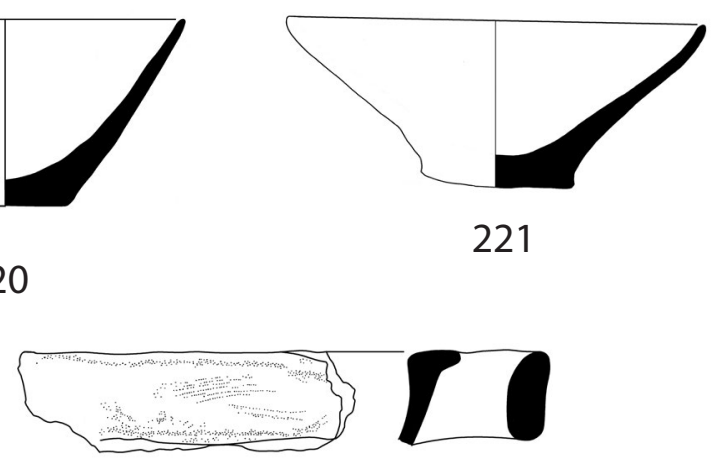

223

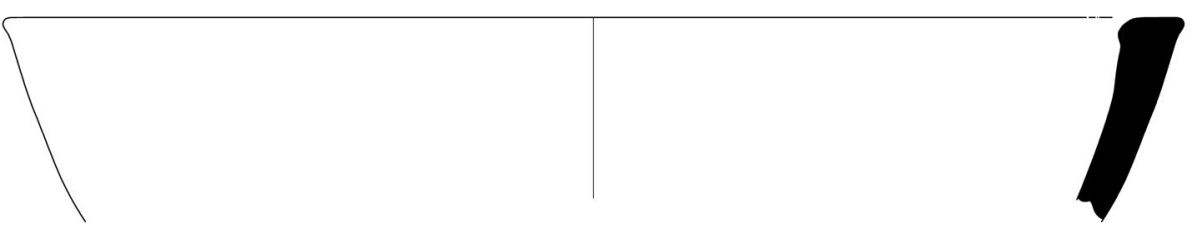

224

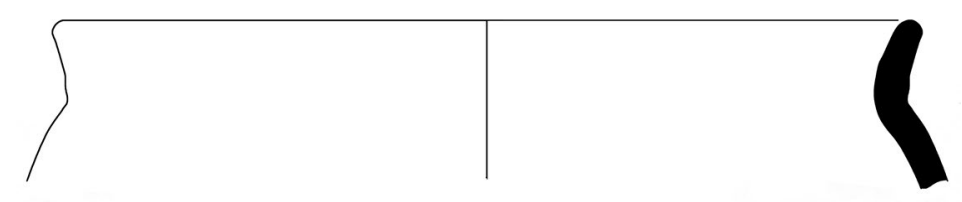

225

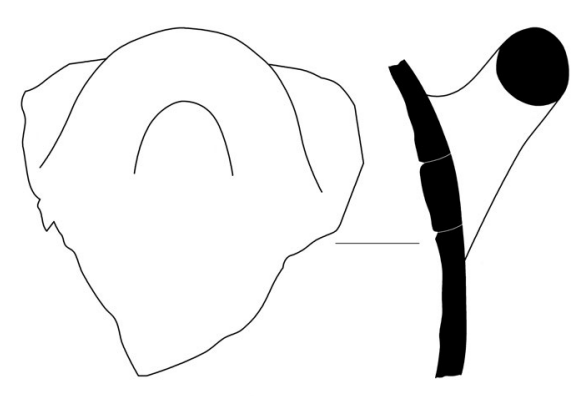

226

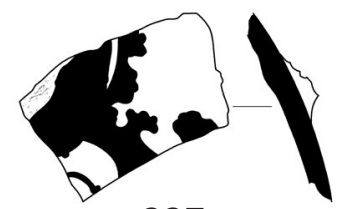

227

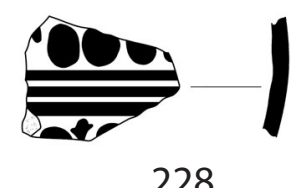

228
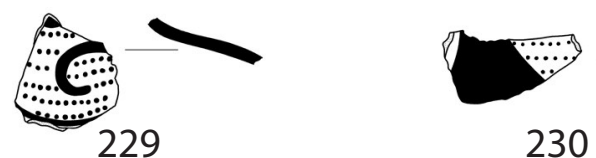

230

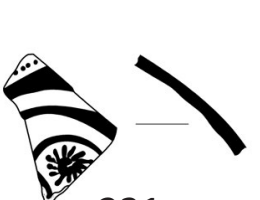

231

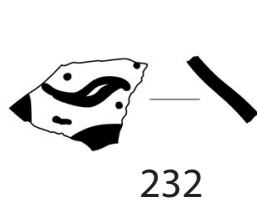

232

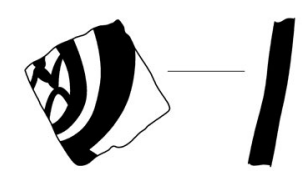

233

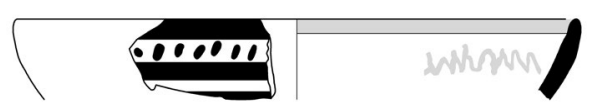

234

Fig. 14. Fresco dump (217-226); south-eastern deposit (227-234) (Drawings: R. Jung [217], A. Poelstra [218-234]). 

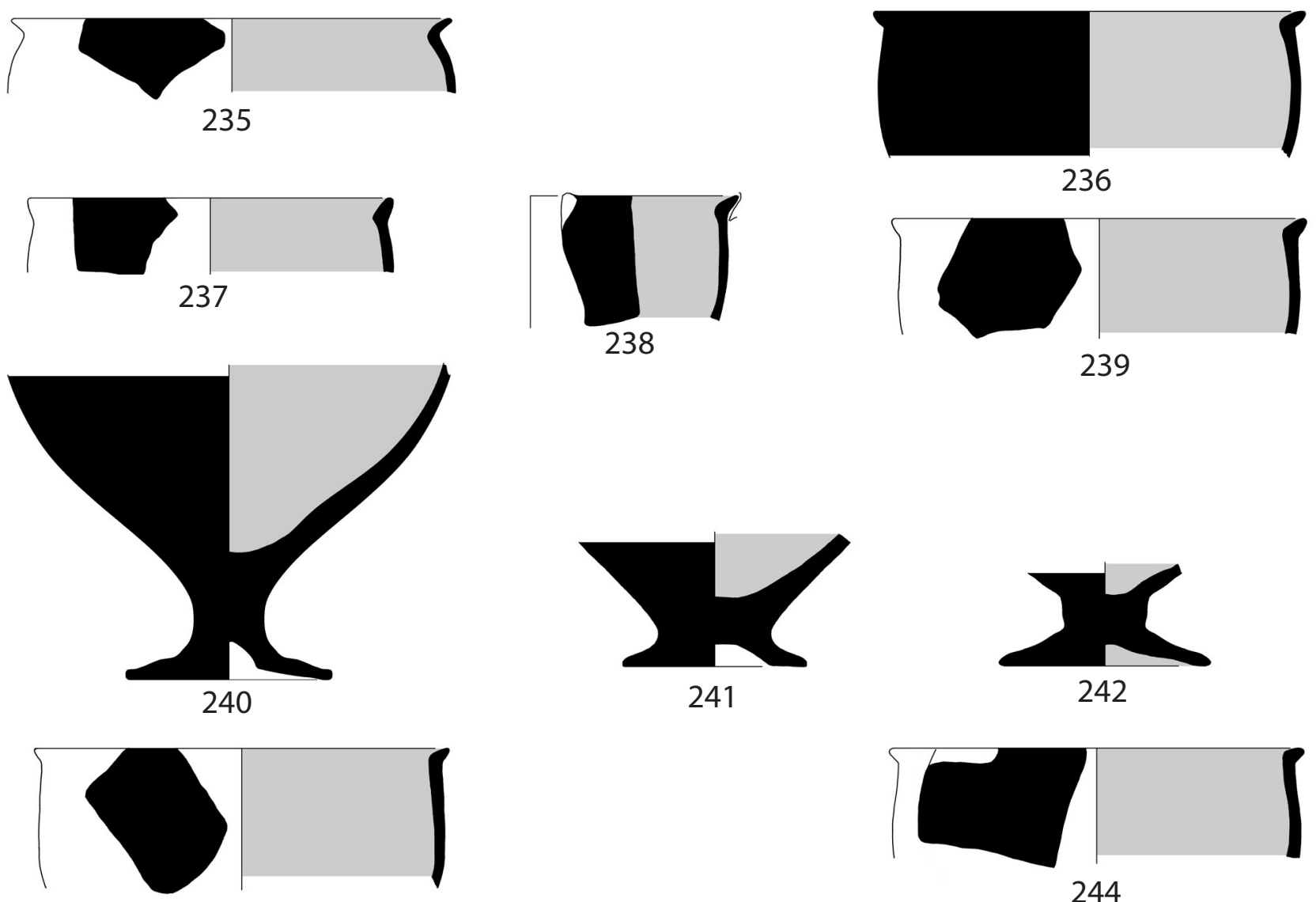

243
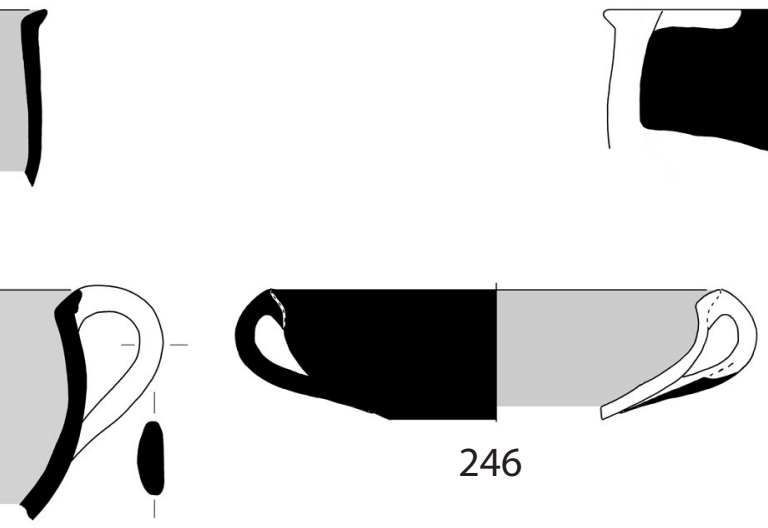

246
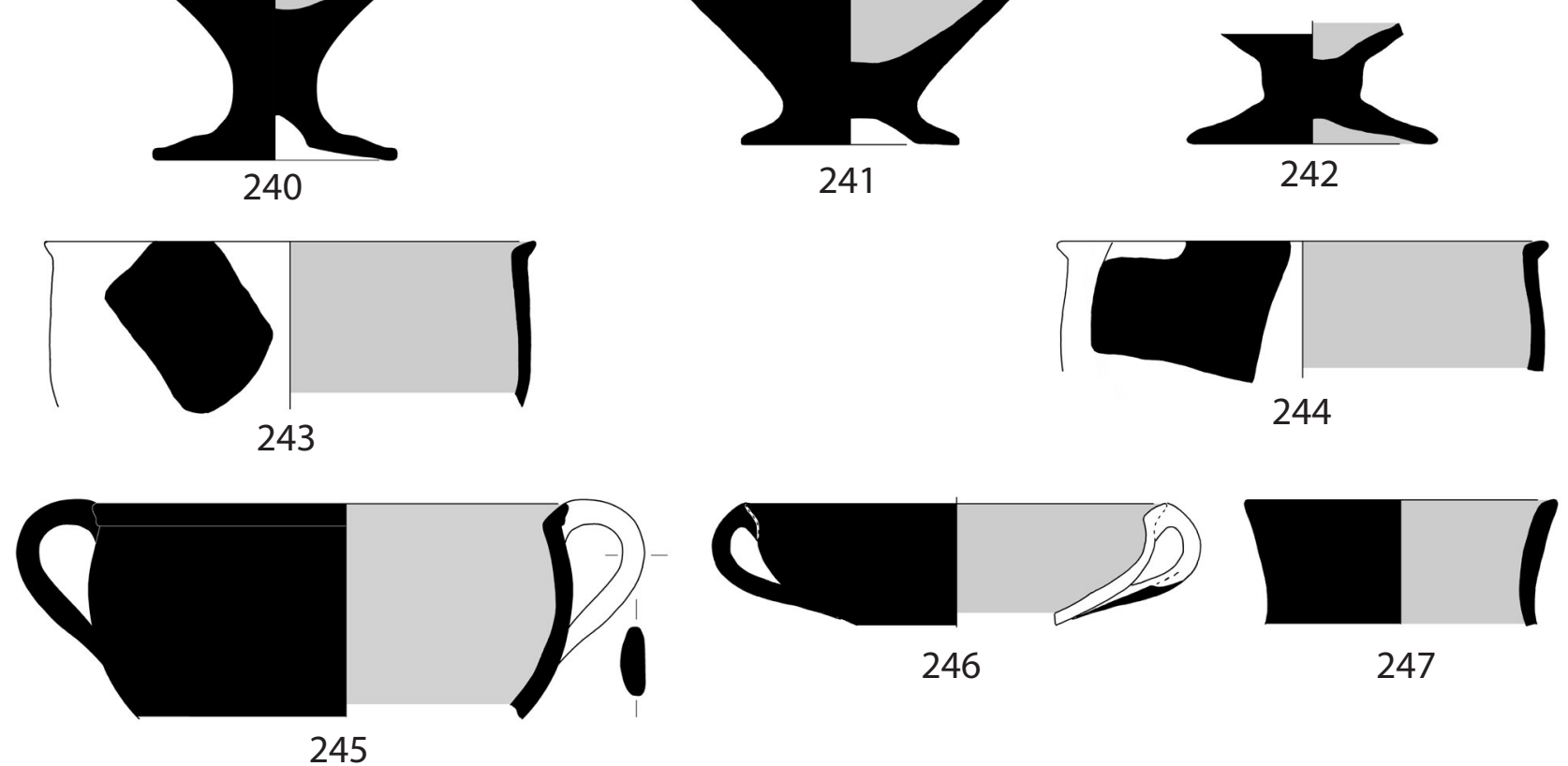

245
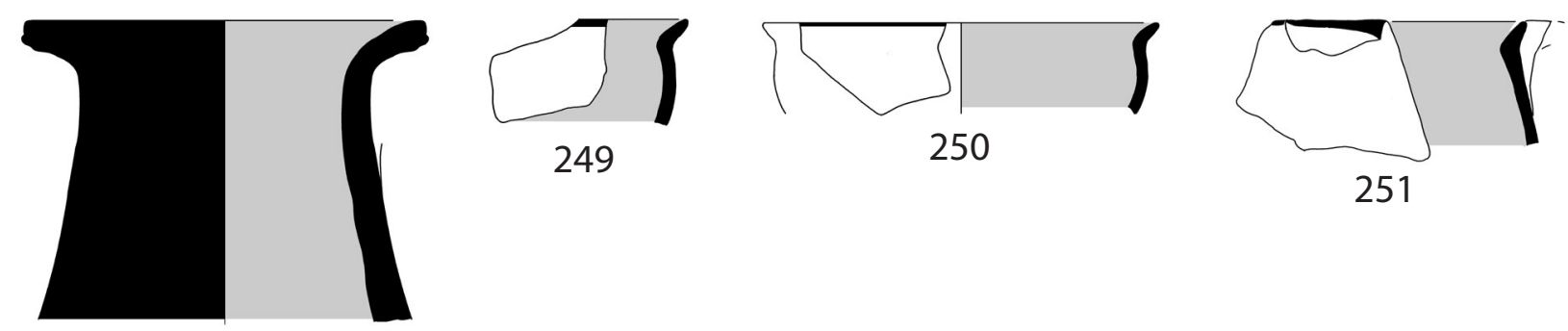

248
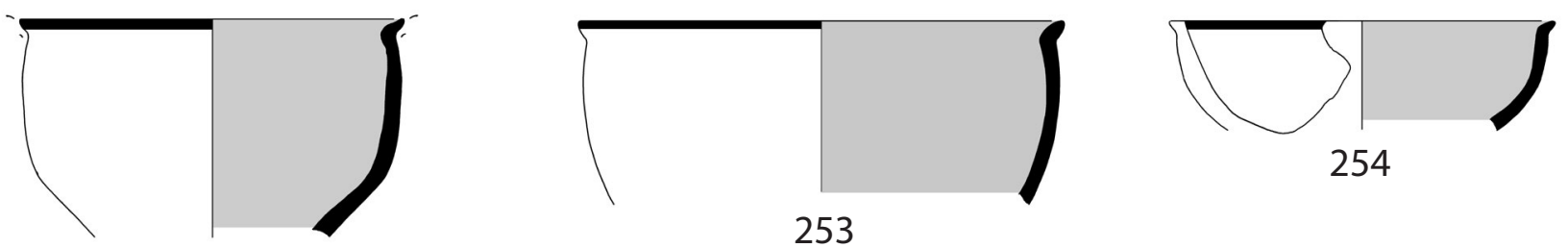

252

Fig. 15. South-eastern deposit (Drawings: A. Poelstra). 

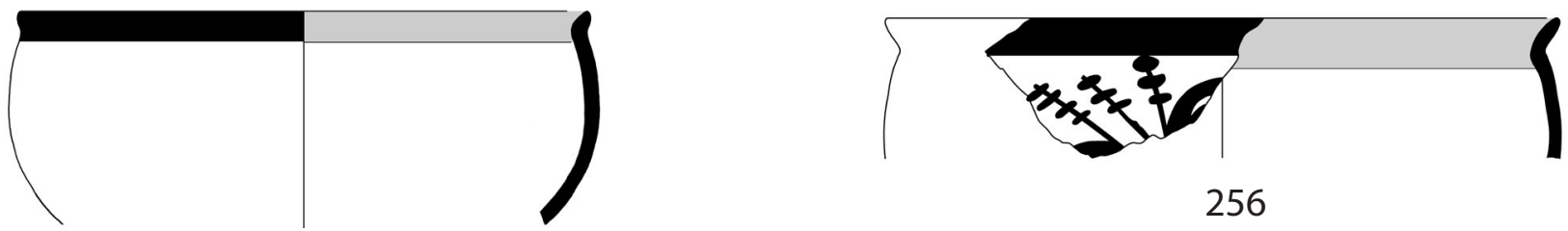

255

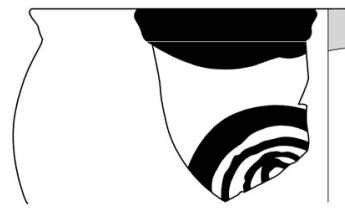

257

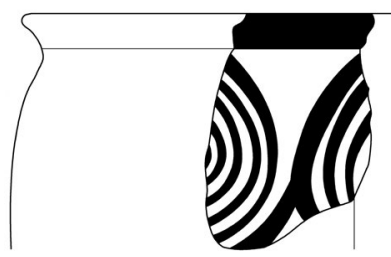

258

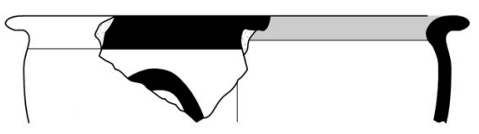

260

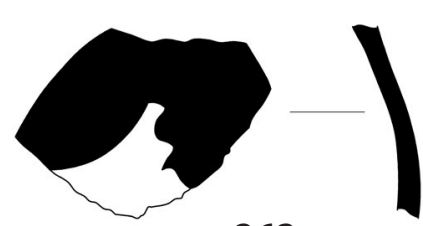

263

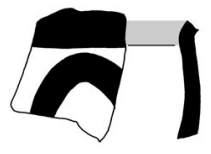

261

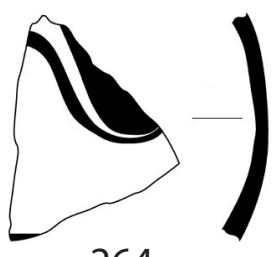

264

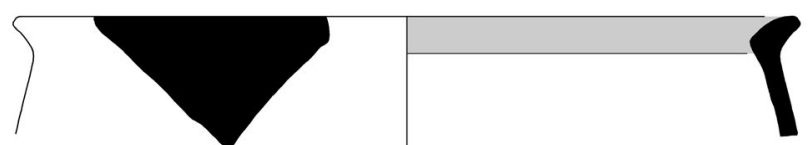

266
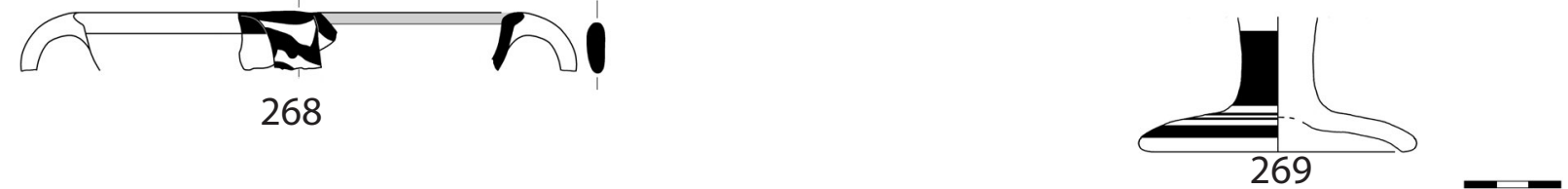

Fig. 16. South-eastern deposit (Drawings: A. Poelstra). 

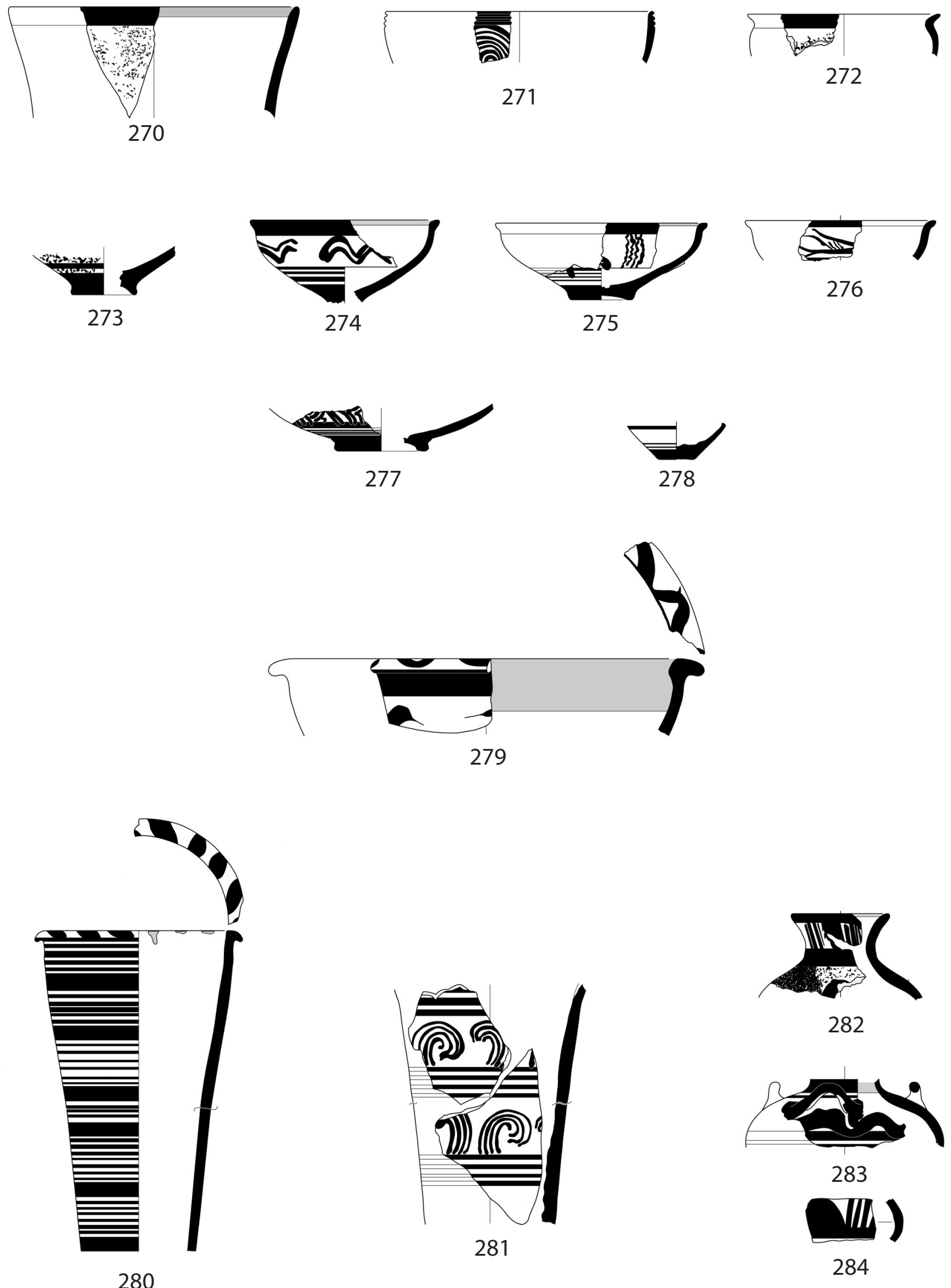

284

Fig. 17. South-eastern deposit (Drawings: A. Poelstra). 

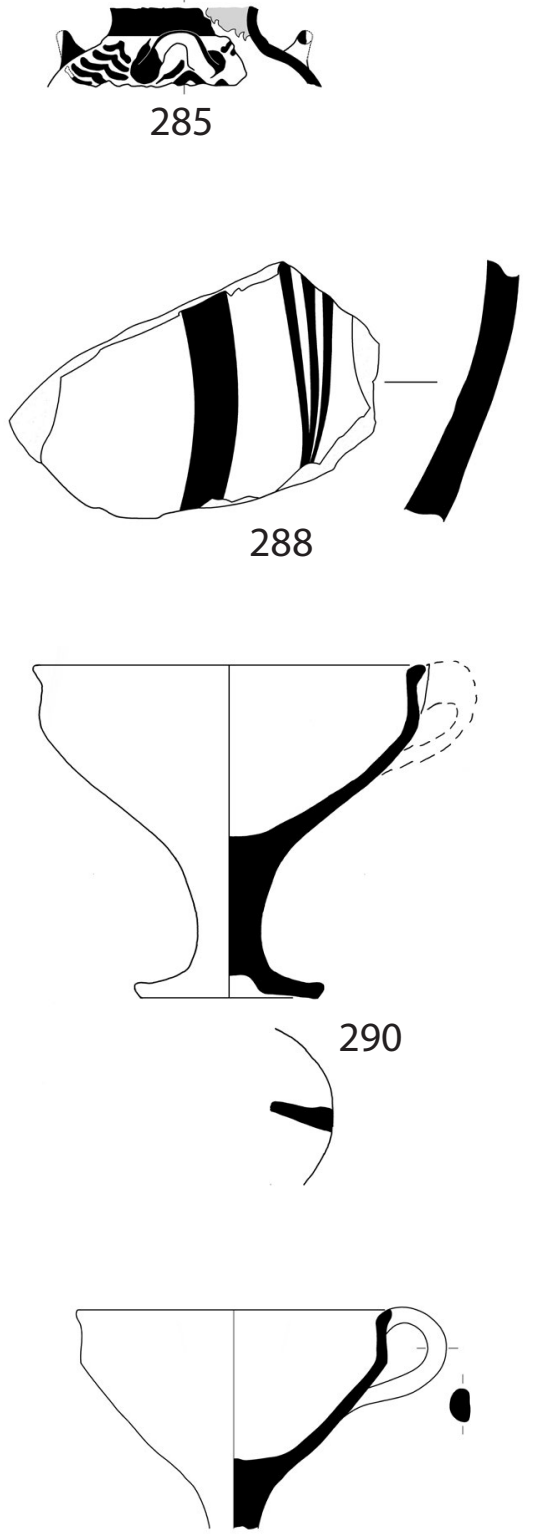

293

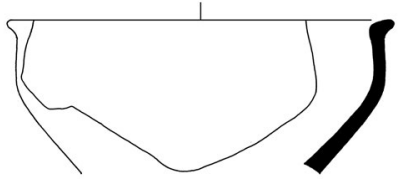

296
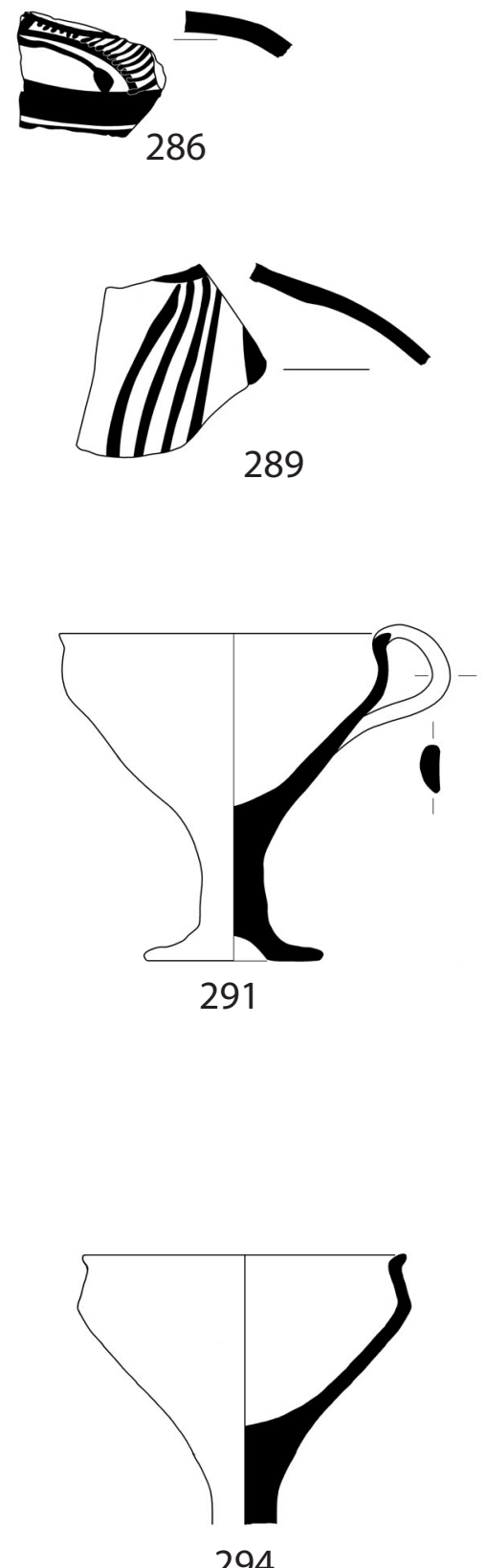

294
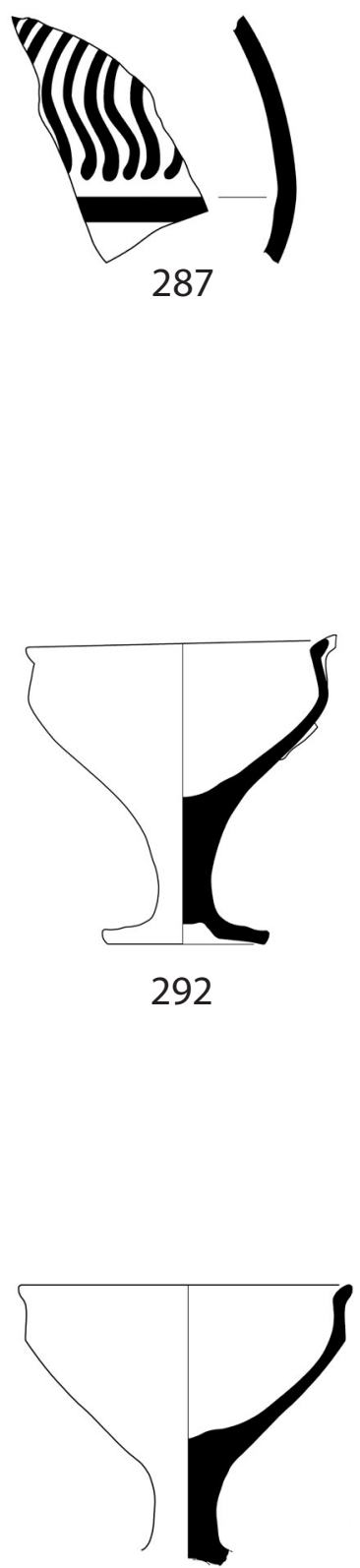

295
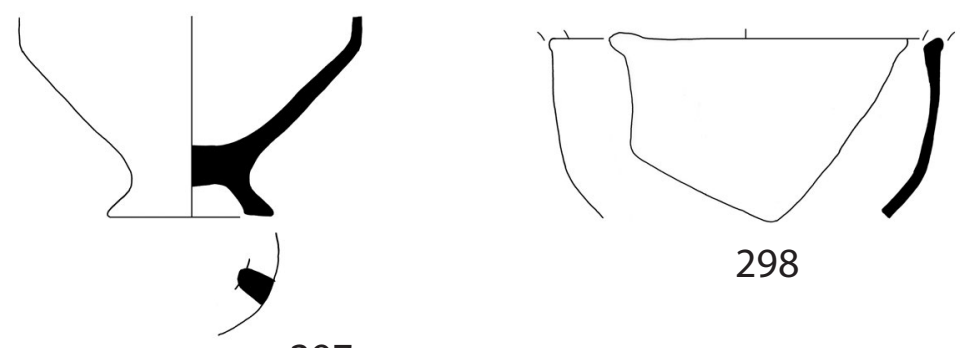

298

297

Fig. 18. South-eastern deposit (Drawings: A. Poelstra). 

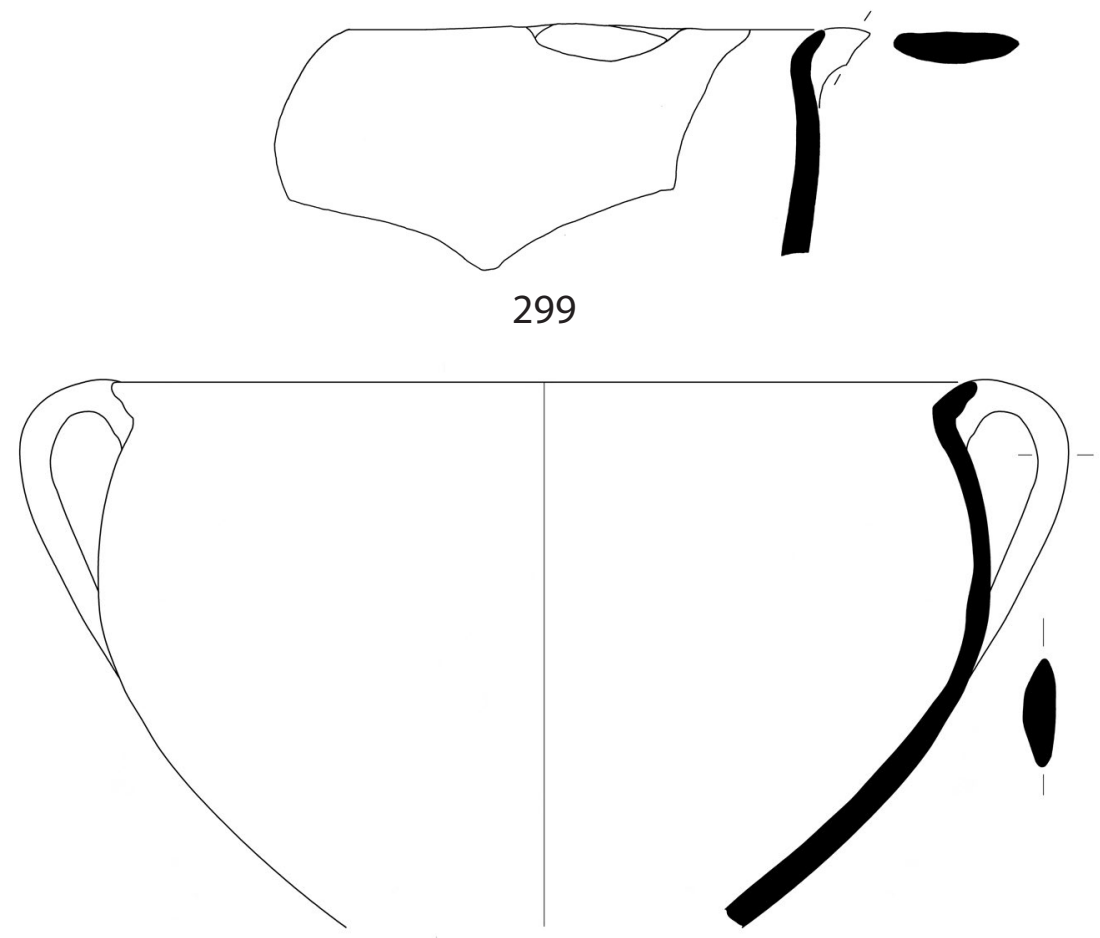

300
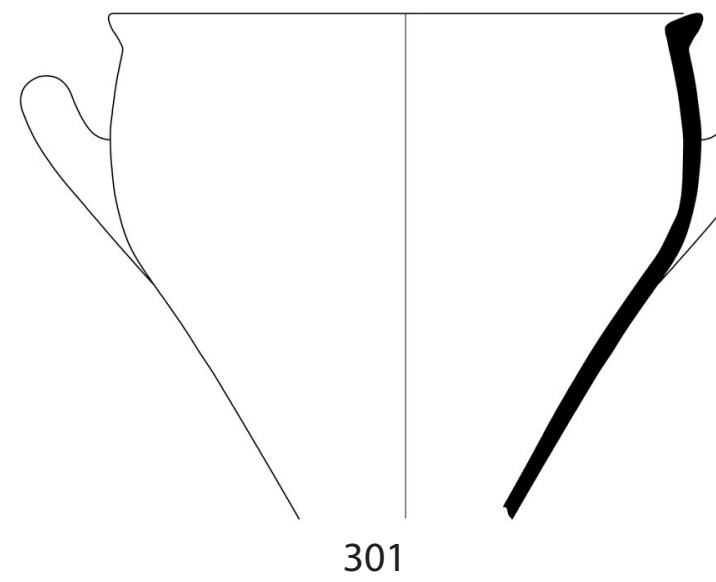

301

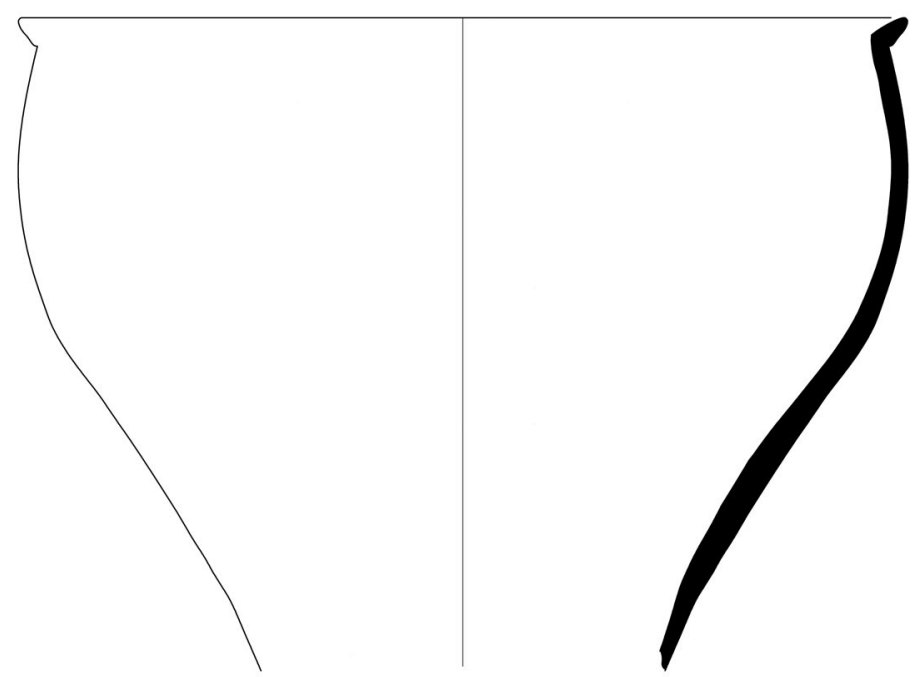

Fig. 19. South-eastern deposit (Drawings: A. Poelstra). 


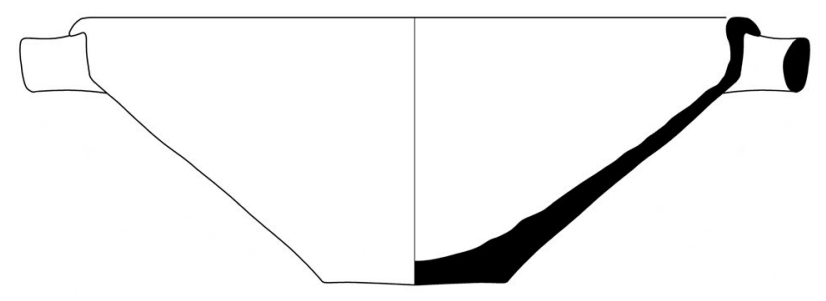

303

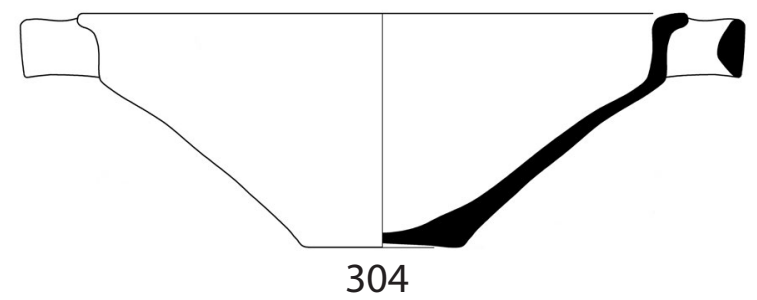

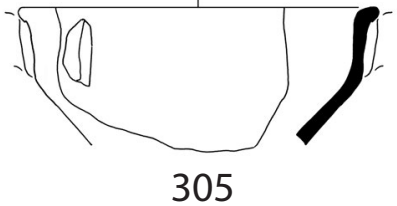

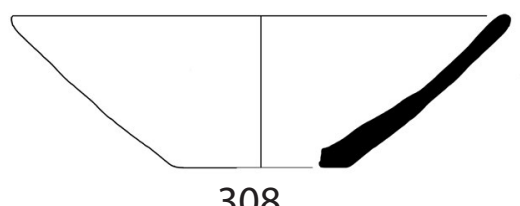

308

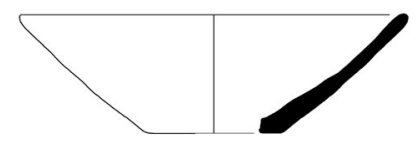

311

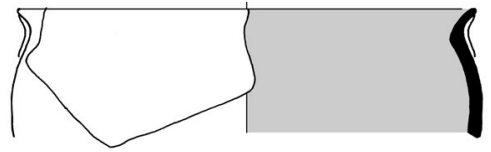

314

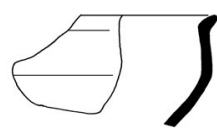

317

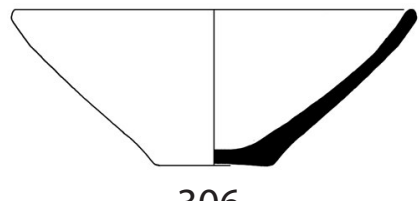

306

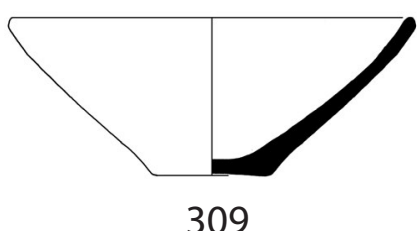

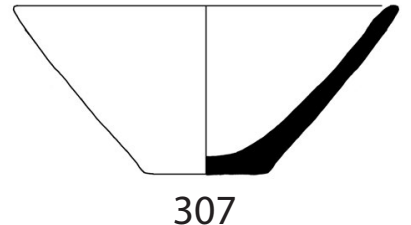
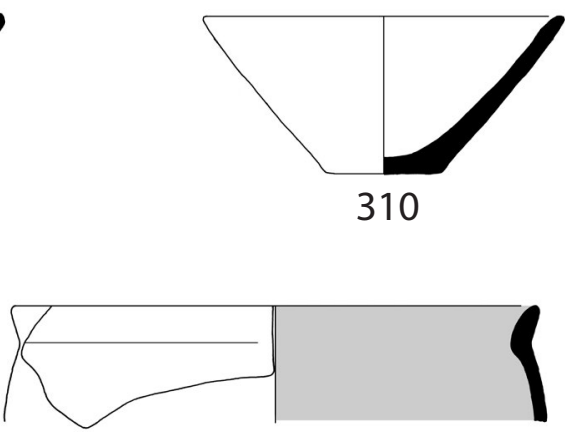

313
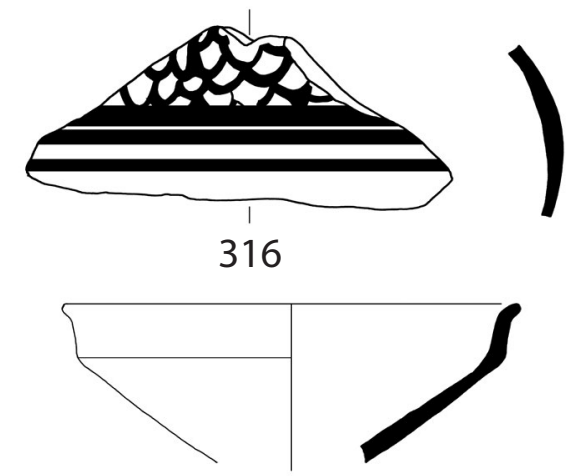

319

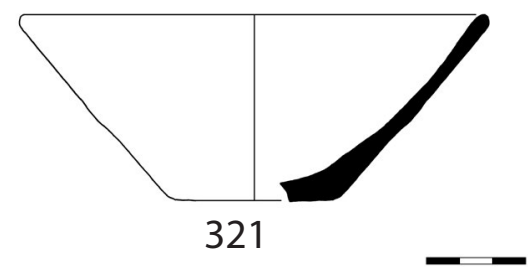

Fig. 20. South-eastern deposit (303-312); below floor of west stoa (313-317); floor of south stoa (318-321) (Drawings: A. Poelstra [303-312], E. Kardamaki [313-321]. 


\section{Pottery Catalogue}

The size of the sherds is classified as small $(<5 \mathrm{~cm})$, medium $(5-10 \mathrm{~cm})$ and big $(>10 \mathrm{~cm}) .{ }^{350}$ The number of the pottery groups represents unique units, assigned during the excavation. ${ }^{351}$ The base and rim forms of sherds not appearing in the catalogue entry will be illustrated in detail in the final publication of the material. For rim types discussed in the present article, see Table 2. Unless otherwise stated, Munsell colour refers to the exterior surface and fracture (core and near surfaces) of the sherd. ${ }^{352}$

Fig. 4. Lower levels trench $I 18 \alpha / \beta .-1$. base, medium, fine lustrous, goblet FS 263, diam. $5.8 \mathrm{~cm}$ (31\%), monochrome (linear decoration 11.0), surface 2.5YR 7/8, fracture 2.5YR 7/8 (pottery group 6319). -2 . wall sherd, small, fine lustrous, Vapheio Cup FS 224, ripple pattern FM 78 (pottery group 6319). - 3. base, small, fine plain (burnished/ polished?), diam. $6 \mathrm{~cm}$ (14\%), goblet, surface 7.5YR 8/4, fracture 2.5YR 7/6 (pottery group 6319). - 4. rim, small, fine plain, goblet, diam. body c. $12 \mathrm{~cm}$, surface $7.5 \mathrm{YR} 7 / 6$, fracture 10YR $7 / 2$ (pottery group 6319 ). -5 . base, small, medium coarse gritty, goblet, diam. $10 \mathrm{~cm}(13 \%)$, surface 7.5YR 8/4, fracture/core Gley $17 / \mathrm{N}$, fracture/ near surfaces $2.5 \mathrm{YR} 7 / 6$, handmade (pottery group 6319). -6 . leg, small, medium coarse, tripod (?), surface $10 \mathrm{YR} 8 / 1$, fracture/core 2.5YR 6/1, fracture/near surfaces 2.5YR 7/6 (pottery group 6319). - 7. base, medium, medium coarse, burnished, button-based jug, diam. $4 \mathrm{~cm}(100 \%)$, handmade, secondary burnt, surface 2.5YR 7/4, fracture 2.5YR 5/6 (pottery group 6319). - 8. base, medium, medium coarse, gritty, closed shape, diam. $6.5 \mathrm{~cm}(17 \%)$, handmade surface 2.5YR 5/6, fracture 10R 5/6 (pottery group 6319). - 9. rim/beginning of handle, small, fine lustrous, goblet FS 263, vertical strap handle, monochrome (linear decoration 11.0), secondary burnt (pottery group 6315). - 10. base, small, fine lustrous, goblet FS 263, diam. 7 (9\%), monochrome (linear decoration 11.0), painted underneath, fracture 2.5YR 6/8, paint red (pottery group 6315). - 11. base, medium, fine lustrous, open shape, diam. 5 (34\%), monochrome out (?), surface 5YR 7/6, fracture 5YR 7/6, paint red (pottery group 6317). - 12. wall/handle, medium, basin (?), fine lustrous (?), horizontal handle, round section, monochrome (linear decoration 11.0), fracture/core 2.5YR 6/6, fracture/near surfaces 7.5YR 7/4, paint black/ brown (pottery group 6315). - 13. rim, small, fine lustrous, goblet/ cup, diam. c. $12 \mathrm{~cm}$, monochrome interior (linear decoration 15), surface $7.5 \mathrm{YR} 7 / 4$, fracture $5 \mathrm{YR} 7 / 4$, paint red, rim type 1.12 (pottery group 6317). - 14. rim, small, goblet/cup, fine lustrous, diam. $12 \mathrm{~cm} \mathrm{(9 \% ),} \mathrm{monochrome} \mathrm{interior} \mathrm{(linear} \mathrm{decoration} \mathrm{15),} \mathrm{surface}$ 5 YR $7 / 6$, fracture 5 YR 6/8, paint red, rim type 1.6 (pottery group 6312). - 15. rim, small, goblet, fine lustrous, monochrome interior (linear decoration 15), slip worn off, surface 7.5YR 7/1, fracture 2.5R 6/8, paint dark red, rim type 1.6 (?) (pottery group 6312). - 16. wall sherd, small, fine lustrous, goblet FS 254 (?), papyrus FM 11, surface 10YR 8/3, paint black (pottery group 6317). - 17. wall sherd, small, fine lustrous, goblet (?), spiral, surface 7.5YR 7/4, paint brown (pottery group 6312). - 18. wall sherd, small, fine lustrous, Vapheio cup

350 See Stockhammer 2008, 70.

351 For the linear decoration see Podzuweit 2007 and Kardamaki 2013.

352 See Rutter 1993, 60 and Tab. 2.
FS 224, ripple pattern FM 78, surface 10YR 8/2, fracture 10YR 7/3, paint black (pottery group 6315). - 19. wall sherd, small, Vapheio cup FS 224, ripple pattern FM 78, surface 10YR 8/3, fracture 7.5YR 7/4, paint black (pottery group 6312). -20 . wall sherd, small, fine lustrous, closed shape, ogival canopy (?) surface 10YR 8/3, fracture 10YR 8/3, paint black (pottery group 6315). - 21. rim, medium, fine plain (polished?), goblet, diam. $14 \mathrm{~cm}(11 \%)$, surface $2.5 \mathrm{YR} 7 / 6$, fracture $2.5 \mathrm{YR}$ $6 / 8$, rim type 1.3 (pottery group 6315). -22 . base, small, fine plain, goblet, diam. $5 \mathrm{~cm}(59 \%$ ), surface 5 YR $7 / 6$, fracture 5 YR $7 / 6$ (pottery group 6312). - 23. base, small, fine plain, goblet/kylix, diam. $6 \mathrm{~cm}$ (11\%), surface 5 YR 7/4-7/6, fracture/core Gley $17 / \mathrm{N}$, fracture/near surfaces 5 YR 7/6(pottery group 6315). - 24. base, small, fine plain, goblet/kylix, diam. $6 \mathrm{~cm}(11 \%)$ (pottery group 6315). - 25. stem, medium, fine plain, goblet, surface 7.5YR $8 / 3$, fracture Gley $16 / \mathrm{N}$ (pottery group 6312). - 26. stem, small, fine plain, goblet, surface $5 \mathrm{YR}$ $7 / 6$, fracture 5 YR $7 / 4$ (pottery group 6312). -27 . stem, part of dome preserved, medium, fine plain, goblet, surface $2.5 \mathrm{YR} 7 / 8$, fracture 2.5YR 6/8 (pottery group 6315). - 28. stem, small, fine plain, goblet, surface $5 Y R$ 7/4-7/6, fracture/core Gley $17 / \mathrm{N}$, fracture/near surfaces 2.5YR 7/6 (pottery group 6315). - 29. stem, small, fine plain, goblet/kylix, surface 5YR 7/8, fracture 5YR 7/8 (pottery group 6315). - 30. base, small, fine plain, open shape, diam. $8 \mathrm{~cm}(7 \%)$, surface 5YR 7/4-7/6, fracture 5YR 6/6 (pottery group 6315). - 31. rim, small, fine plain, conical cup, diam. $11 \mathrm{~cm}(7 \%)$, surface $7.5 \mathrm{YR} 8 / 4$, fracture 7.5YR 8/4, rim type 1.14 (pottery group 6315). -32 . rim/handle, medium, medium coarse, gritty, burnished, wide-mouthed jar, diam. 28 (4\%), oval-trough handle, surface 10YR 8/1, fracture/core Gley $16 / \mathrm{N}$, fracture/near surfaces $2.5 \mathrm{YR} 7 / 6$, rim type 1.13 , handmade (pottery group 6315). - 33. neck, big, medium coarse (burnished?), closed shape, neck diam. c. $12 \mathrm{~cm}$, handmade, surface 7.5YR 7/4-7/6, fracture Gley $17 / \mathrm{N}$ (pottery group 6315, 6316). - 34. stem, small, medium coarse gritty, goblet, diam. stem c. $5 \mathrm{~cm}$, handmade, surface 7.5YR 8/4-7/4, fracture 5YR 6/1 (pottery group 6317). -35 . handle, small, medium coarse, burnished, cooking pot, vertical, trough-handle, surface $7.5 Y R ~ 8 / 2-7 / 3$, fracture 7.5YR 5/3 (pottery group 6315). - 36. base, small, medium coarse, red silver mica fabric, cooking pot (?), diam. $11 \mathrm{~cm}(17 \%)$, secondary burnt on the exterior, handmade, surface 2.5YR 5/6, fracture 2.5YR 5/8 (pottery group 6312)

Fig. 5. Foundation trench of wall 71. Trench I18 $\alpha / \beta .-37$. rim/handle, big, finelustrous, goblet FS 263, diam. $23 \mathrm{~cm}(14 \%)$, monochrome(linear decoration 11.0), vertical handle, grooved, rim type 1.11, fracture/ core 5 YR 5/6, fracture/near surfaces Gley $16 / \mathrm{N}$ and 5YR 6/2, paint black, mended from very small sherds (pottery group 6320). -38 . rim, medium, fine lustrous, goblet FS 263 , int. body diam. c. $16 \mathrm{~cm}$, monochrome (linear decoration 11.0), rim type 1.1, surface 5YR 6/6, fracture 5 YR $6 / 3$, black paint (pottery group 6322). -39 . rim, small, fine lustrous, goblet FS 263, diam. $18 \mathrm{~cm}$ (3\%), monochrome (linear decoration 11.0), fracture/core 5YR 7/1, fracture/near surfaces 5 YR 7/6, paint brown/red, rim type 1.8 ? (pottery group 6318 ). -40 . rim, small, fine lustrous, goblet/cup, diam. $14 \mathrm{~cm}(6 \%)$, monochrome (linear decoration 11.0), fracture/core 5YR 6/1, fracture/near surfaces $5 \mathrm{YR}$ $6 / 3$, rim type 1.1 ? (pottery group 6322). -41 . stem, medium, fine lustrous, goblet FS 263, monochrome (linear decoration 11.0), surface $5 Y R 7 / 4$, fracture 5YR 6/1, red paint (pottery group 6320). -42 . stem, medium, fine lustrous, goblet FS 263, monochrome (linear decoration 11.0) handmade, surface 5YR 7/6, fracture 7.5YR 7/1, orange, red paint (pottery group 6320). - 43. base, small, fine lustrous (?dull painted?), goblet FS 263, diam. $7 \mathrm{~cm}(11 \%)$, monochrome (linear 
decoration 11.0), painted underneath, surface 7.5YR 7/4, fracture 7.5YR 6/2, brown paint (pottery group 6320). -44 . base, small, kylix, diam. $6 \mathrm{~cm}(11 \%)$, monochrome? (linear decoration 11.0), secondary burnt (pottery group 6322). -45 . rim/beginning of handle, small, fine lustrous, goblet FS 263, monochrome (linear decoration 11.0), fracture/core 7.5YR 6/1, fracture/near surfaces $7.5 \mathrm{YR} 7 / 4$, paint black, rim type 1.1/1.8? (pottery group 6320). - 46. rim, small, fine lustrous, goblet FS 263, diam. $14 \mathrm{~cm}(4 \%)$, monochrome interior (linear decoration 15), rim type 1.3 (pottery group 6318). -47 . wall sherd, small, fine lustrous, goblet FS 254, int. body diam. c. $16 \mathrm{~cm}$, pendent rock pendant FM 32, band on interior rim, surface 10YR $8 / 2-8 / 3$, fracture 10YR 7/2, paint black (pottery group 6322). -48 . stem, medium, fine lustrous, goblet FS 254, monochrome base exterior, surface 7.5YR $8 / 4$, fracture/core 5YR 7/2, fracture/near surfaces 5 YR 7/6, paint red (pottery group 6318). - 49. base, medium, fine lustrous, goblet FS 254, diam. $7 \mathrm{~cm}$ (10\%), monochrome base exterior, fracture/core Gley $17 / \mathrm{N}$, fracture/near surfaces 2.5YR 7/4-7/6, surface 7.5YR 8/4, paint red (pottery group 6316,6318 ). -50 . wall sherd, small, fine lustrous, cup FS 219, band on exterior/interior rim (linear decoration 1.0), vertical stripes FM 67, surface 7.5YR 7/4, fracture 2.5YR 6/6, paint red (pottery group 6320). - 51. rim, small, fine lustrous, Vapheio cup FS 224, diam. c. $6 \mathrm{~cm}$ (10\%), deep rim band? Fracture 5YR $8 / 4-7 / 4$, paint red (pottery group 6322). -52 . wall sherd, small, fine lustrous, Vapheio cup FS 224, ripple pattern FM 78/vertical stripes FM 67, vertical band (handle decoration?), fracture 10YR 7/4, surface 10YR 8/2, paint black (pottery group 6320). - 53. wall sherd, small, fine lustrous, Vapheio cup FS 224, ripple pattern FM 78, fracture 2.5YR 7/6, surface 7.5YR 8/4, paint black (pottery group 6320). -54. wall sherd, medium, fine lustrous, closed shape, vertical stripes FM 67, fracture 10YR 7/4, surface 10YR 8/2, paint black (pottery group 6322). - 55. wall sherd, small, fine lustrous, closed shape, foliate band, diagonal lines, handmade, secondary burnt, fracture Gley $16 / \mathrm{N}$, surface 10YR 8/2-8/3, paint red (pottery group 6320). -56 . wall sherd, medium, medium coarse lustrous painted, closed shape, ivy FM 12, handmade, surface 10YR 8/2-7/3, paint brown, red (pottery group 6318$).-57$. stem, medium, fine plain, goblet, secondary burnt, fracture 5YR 6/6, surface 5YR 7/6 (pottery group 6320). - 58 . stem, medium, fine plain, goblet, fracture Gley $16 / \mathrm{N}$, surface $5 \mathrm{YR}$ 6/6 (pottery group 6320). -59 . base, small, fine plain, goblet, diam. $6 \mathrm{~cm}(11 \%)$, surface 10YR 7/2, fracture Gley $17 / \mathrm{N}$ (pottery group 6320). - 60. rim/beginning of handle (horizontal strap handle), small, fine plain (burnished?), bowl, diam. $8 \mathrm{~cm}(11 \%$ ), fracture 2.5YR 7/6, surface 7.5YR 7/4, rim type 1/47? (pottery group 6318). - 61. rim, small, medium fine gritty, conical cup?, fracture $2.5 \mathrm{YR} 6 / 8$, surface 2.5YR 5/8 (pottery group 6320). - 62. rim/beginning of handle, medium, medium coarse, gritty, burnished, closed shape, handmade surface 7.5YR 7/4, fracture/core Gley $17 / \mathrm{N}$, fracture/near surfaces 2.5 YR $7 / 6$ (pottery group 6320). -63 . handle, medium, medium coarse, gritty, hydria, horizontal, round section, hole for attachment of handle, handmade, fracture 10 YR $7 / 1$, surface $7.5 \mathrm{YR} 7 / 3-7 / 4$ (pottery group 6316). - 64. base, medium, medium coarse, gritty, closed shape, diam. $5.8 \mathrm{~cm}(100 \%)$, handmade, fracture $5 Y R$ 7/6, surface 7.5YR 7/3 (pottery group 6316). - 65. handle, medium, medium coarse, gritty, goblet, handmade, fracture 7.5YR 6/1, surface 7.5YR 7/6 (pottery group 6322). - 66. rim, small, medium coarse, gritty, closed shape/goblet, handmade, fracture $2.5 \mathrm{YR} 6 / 8$, surface 10YR $8 / 3$, rim type 2.1 (pottery group 6322). -67 . neck/handle, medium, medium coarse, burnished, closed shape, slip worn off, surface 10YR 8/3-7/3, fracture/core 7.5YR 6/1, fracture/near surfaces 7.5YR 6/4, handmade (pottery group 6320). - 68. base, small, medium coarse, gritty, goblet, diam. $10 \mathrm{~cm}(4 \%)$, fracture Gley $18 / \mathrm{N}$, surface 10YR 8/1 (pottery group 6322). -69 . neck, medium, medium coarse, gritty, burnished, matt painted (?), closed shape, diameter at the beginning of neck c. $16 \mathrm{~cm}$, band at the beginning of neck, handmade, fracture 7.5YR 6/2, surface 10YR 8/3, paint black (pottery group 6320). - 70 . base, medium, medium coarse, burnished, button-based cooking jar, diam. $3.2 \mathrm{~cm}(100 \%)$, handmade, secondary burnt (pottery group 6316). -71. handle, medium, red medium coarse, sandy, closed shape, vertical, round section, medium, fracture $5 \mathrm{YR} 7 / 8$, surface $5 \mathrm{YR} 7 / 8$ (pottery group 6316).

Fig. 6. Fill below lowest pebble surface ('Floor' 4). Trench I18 $\alpha / \beta$. - 72. rim, small, fine lustrous, goblet FS 263, monochrome interior (linear decoration 15), surface 7.5YR 8/4, fracture 10YR 6/4, paint black, rim type 1.18 (pottery group 6311). - 73. rim, small, fine lustrous, goblet FS 263, monochrome interior (linear decoration 15), diam. $14 \mathrm{~cm} \mathrm{(3 \% ),} \mathrm{surface} \mathrm{7.5YR} \mathrm{8/4-7/4,} \mathrm{fracture} \mathrm{2.5YR} \mathrm{7/6,} \mathrm{paint}$ black, rim type 1.15 (pottery group 6311). -74 . wall sherd, small, fine lustrous, open shape, spiral (pottery group 6311). -75 . rim, small, fine plain (polished? burnished?), goblet/cup, diam. $11 \mathrm{~cm}(11 \%)$, surface 7.5YR 8/4-7/4, fracture 7.5YR 6/3, rim type 1.2 (slightly hollowed in) (pottery group 6310). - 76. rim, small, fine plain (polished), goblet/cup, surface 10YR 8/3, rim type 1.16 (pottery group 6311). - 77 . rim/beginning of handle, small, fine plain, goblet, diam. $16 \mathrm{~cm} \mathrm{(5 \% ),}$ surface 2.5YR 7/8, fracture 2.5YR 7/8, rim type 1.17 (pottery group 6311). - 78. stem, small, fine plain, goblet, surface 7.5 YR $8 / 3$, fracture 7.5YR 7/3-6/3 (pottery group 6311). - 79. rim, small, fine plain burnished (?), goblet, surface 5 YR 7/6, fracture Gley $16 / \mathrm{N}$, rim type 1.15 (pottery group 6310). - 80. base, small, medium coarse, gritty, goblet, diam. $16 \mathrm{~cm}(6.16 \%)$, handmade, fracture Gley $17 / \mathrm{N}$, surface 10YR 8/3-7/3 (pottery group 6310). - 81. handle, medium, medium coarse, gritty, Hydria, horizontal, round, surface $7.5 \mathrm{YR} 8 / 3$, fracture/core 5 YR $7 / 1$, fracture/near surfaces $5 Y R 7 / 4$, handmade (pottery group 6311). - 82. handle, medium, medium coarse, red gritty, closed shape, vertical, round, fracture 2.5YR 6/8 (pottery group 6310).

Lowest pebble surface ('Floor' 4). Trench I18 $\alpha / \beta$. - 83. rim, small, fine lustrous, goblet/crater, diam. $30 \mathrm{~cm} \mathrm{(4 \% ),} \mathrm{monochrome} \mathrm{(linear}$ decoration 11.0 ), rim type 1.21 , fracture Gley $17 / \mathrm{N}$, surface $2.5 \mathrm{YR}$ 7/8, red paint (pottery group 6309). - 84. stem, medium, fine lustrous, goblet FS 263, monochrome (linear decoration 11.0), fracture $5 \mathrm{YR}$ 6/2, surface 10YR /2, black paint (pottery group 6309). - 85. rim, small, fine lustrous, goblet, monochrome interior (linear decoration 15), surface 7.5YR 8/3, fracture 2.5YR 6/8, paint black, rim type 1.16 (pottery group 6309). - 86. rim, small, fine lustrous, goblet, monochrome interior (linear decoration 15), surface 10YR 8/2, fracture 2.5YR 7/6, paint red, rim type 1.16 (pottery group 6309). - 87. rim, small, fine lustrous, goblet/crater, rim band (linear decoration 1.0), rim type 1.23 , fracture/core Gley $18 / \mathrm{N}$, fracture/near surfaces $5 \mathrm{YR}$ 7/4, surface 10YR 7/3, paint brown, red (pottery group 6309). -88 . handle, medium, fine lustrous, goblet/crater, diagonal lines framed, fracture/core Grey $17 / \mathrm{N}$, fracture/near surfaces $10 \mathrm{YR} 7 / 4$, surface 10YR 7/3-7/4, paint brown, black (pottery group 6255). - 89. wall sherd, small, fine lustrous, closed shape, ivy FM 12, slip worn off, surface $7.5 \mathrm{YR} 7 / 2$, fracture $2.5 \mathrm{YR} 7 / 4$, paint black (pottery group 6309). - 90. stem/beginning of handle, medium, fine plain, goblet, fracture $5 Y R 7 / 6$, surface $5 Y R 7 / 4$, (pottery group 6255). - 91. stem, medium, fine plain, goblet, fracture $2.5 \mathrm{YR} 7 / 8$, surface $2.5 \mathrm{YR} 7 / 8$ (pottery group 6309). - 92. stem, medium, fine plain, goblet/kylix, 
fracture 2.5YR 7/8, surface 7.5YR 8/4-7/4, (pottery group 6309). 93. handle, medium, medium coarse, burnished, goblet, vertical, oval, medium, handmade, secondary burnt, fracture 2.5YR 6/6, (pottery group 6255). - 94. rim/handle, medium, medium coarse, gritty, closed shape, wheel made (?), secondary burnt, fracture/near exterior surface $2.5 \mathrm{YR} 5 / 8$, fracture/near interior surface Gley $15 / \mathrm{N}$ (pottery group 6255). - 95. leg, medium, medium coarse, burnished (?), cooking tripod, troughed, handmade, hole for attachment of leg, secondary burnt, fracture 2.5YR 6/6 (pottery group 6255). - 96. leg, medium, medium coarse, cooking tripod, handmade, secondary burnt, fracture/core 2.5YR 6/1, fracture/near surfaces $2.5 \mathrm{YR} 7 / 8$, surface $2.5 \mathrm{YR}$ 6/6 (pottery group 6309)

Fig. 7. Highest pebble surface ('Floor' 3). - 97. rim, small, fine lustrous, goblet/kylix, diam. $12 \mathrm{~cm}$ (6\%), monochrome (linear decoration 11.0), fracture 2.5YR 6/6, paint red, rim type 1.69 (pottery group 6229). - 98. rim, small, fine lustrous, goblet/kylix, body diam. c. $20 \mathrm{~cm}$, monochrome (linear decoration 11.0), fracture/core Gley $16 / \mathrm{N}$, fracture/near surfaces $2.5 \mathrm{YR} 7 / 6$, paint red, rim type 1.42 (pottery group 6233). - 99. stem, big, fine lustrous, goblet FS 263, monochrome (linear decoration 11.0), fracture Grey $17 / \mathrm{N}$, surface 5 YR $7 / 6$, paint black (pottery group 6229). - 100. stem, small, fine lustrous, goblet FS 263, monochrome (linear decoration 11.0), fracture 5YR 7/4, paint black (pottery group 6229). - 101. stem, medium, fine lustrous, goblet/kylix, monochrome (linear decoration 11.0), fracture 2.5YR 7/8, paint red (pottery group 6229). - 102. rim, small, fine lustrous, kylix FS 264, diam. $9 \mathrm{~cm}(12 \%)$, monochrome (linear decoration 11.0), fracture 2.5YR 7/8, paint red and brown, rim type 1.68, (pottery group 6229). -103 . rim with beginning of horizontal (?) handle, big, fine lustrous, stemmed bowl FS 304, diam. $20 \mathrm{~cm}$ (23\%), monochrome? (linear decoration 11.0?), paint almost entirely worn off, fracture 5 Y $8 / 3$, surface 5 YR $8 / 3$, paint black? rim type 1.40 (pottery group 6229$)$. - 104. wall sherd, medium, fine lustrous, closed shape, monochrome (linear decoration 11.0), fracture/near exterior surface $2.5 \mathrm{YR} 6 / 8$, fracture/near interior surface $2.5 \mathrm{YR} 6 / 2$, paint red, handmade? (pottery group 6233). - 105. rim, small, fine lustrous, goblet FS 263, diam. $14 \mathrm{~cm}$ (12\%), monochrome interior (linear decoration 15), surface 7.5YR 7/4, fracture 2.5YR 6/6, paint black and red (pottery group 6236). - 106. base, medium, fine lustrous, goblet FS 263, diam. $5.8 \mathrm{~cm}$, monochrome interior (linear decoration 15), surface 10YR 8/3, fracture 7.5YR 6/4, paint red (pottery group 6236). - 107. base, small, fine lustrous, Vapheio cup FS 224, diam. $4.8 \mathrm{~cm}$ (22\%), ripple pattern FM 78, painted base underneath, fracture Gley $17 / \mathrm{N}$, paint black (pottery group 6229 ). -108 . stem, small, fine plain, kylix, surface/fracture 2.5YR 5/6 (pottery group 6233). - 109. stem, small, fine plain, kylix, surface/fracture 2.5YR 6/8 (pottery group 6233). - 110. stem, medium, fine plain, goblet/kylix, surface 10YR $8 / 3$, fracture/core 10YR 6/2, fracture/near surfaces 10YR $8 / 3$ (pottery group 6233). - 111. base, medium, fine plain, kylix, diam. $6.3 \mathrm{~cm}$ (78\%), fracture 5YR 7/6, surface 5YR 7/6 (pottery group 6233). - 112. handle, medium, medium coarse, gritty, hydria, horizontal, round, handmade, secondary burnt, hole for the attachment of the handle, fracture/core Gley $16 / \mathrm{N}$, fracture/near surfaces 7.5YR 7/6, surface 7.5YR 7/6 (pottery group 6233). - 113. handle, medium, medium coarse, gritty, closed shape, vertical, round, handmade, hole for the attachment of the handle, fracture/core 10YR 6/3, fracture/near surfaces 5 YR 5/6, surface 10YR 8/3 (pottery group 6233). - 114. rim, small, medium coarse, burnished, cooking pot, diam. $12 \mathrm{~cm} \mathrm{(6 \% ),}$ rim type 1.62, handmade, fracture 10YR 5/2 (pottery group 6233).
- 115. wall/handle, medium, medium coarse, burnished, cooking pot, handmade ? fracture 2.5YR 6/6, surface 5YR 6/4 (pottery group 6233). - 116. rim, medium, medium coarse, red mica fabric, closed

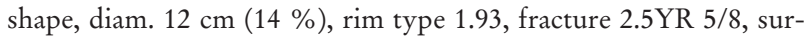
face 2.5 YR $6 / 8$ (pottery group 6233). - 117. rim/beginning of handle, medium, medium coarse, red mica fabric, closed shape, fracture/ core Gley $14 / \mathrm{N}$, fracture/near surfaces 2.5 YR 5/8, surface 2.5YR 5/8 (pottery group 6233). - 118. wall/handle, big, medium coarse, red mica fabric, basin, handmade, hole for the attachment of the handle, fracture 2.5YR 5/6, surface 2.5YR 6/6 (pottery group 6233)

Fig. 8. 'Ditch'. Trench I18 $\alpha / \beta$. - 119. rim, big, fine lustrous, goblet FS 263, diam. $15 \mathrm{~cm}$ (12\%), monochrome (linear decoration 11.0), rim type 1.40 , fracture Grey $17 / \mathrm{N}$, paint black (pottery group 6266,6197). -120. rim, small, fine lustrous, goblet FS 263, diam. $17 \mathrm{~cm}$ (6\%), monochrome (linear decoration 11.0), fracture 2.5YR 6/8, paint red, rim type 1.6 (pottery group 6270 ). - 121. base, medium, fine lustrous, goblet FS 263, diam. $7 \mathrm{~cm}$ (22\%), monochrome (linear decoration 11.0), fracture/core 2.5YR 7/1, fracture/near surfaces $2.5 \mathrm{YR}$ $7 / 8$, paint red (pottery group 6269). - 122. base, medium, fine lustrous, goblet/kylix, diam. $8.8 \mathrm{~cm}$ (39\%), monochrome (linear decoration 11.0), fracture 2.5YR 6/8, paint red (pottery group 6269). -123 . rim, small, fine lustrous, kylix/cup, diam. $10 \mathrm{~cm}(11 \%)$, monochrome (linear decoration 11.0), fracture 2.5YR 5/8, paint red, rim type 1.191 (pottery group 6269). - 124. rim/handle, small, fine lustrous, kylix FS 269, monochrome (linear decoration 11.0), rim type 1.90/1.112 (in the table 1 appears as 1.112), fracture 2.5YR 6/6, paint (pottery group 6259). - 125 stem, medium, fine lustrous, kylix, monochrome (linear decoration 11.0), fracture/near exterior surface 2.5YR 7/6, fracture/ near interior surface Gley $17 / 10 Y$, paint red (pottery group 6270). 126. handle, medium, fine lustrous, basin/crater, horizontal, round, monochrome (linear decoration 11.0), fracture/core Grey $16 / \mathrm{N}$, fracture/near surfaces 2.5YR 7/8, paint red (pottery group 6266). 127. rim, medium, fine lustrous, goblet FS 263, diam. $16 \mathrm{~cm}(7 \%)$, monochrome interior (linear decoration 15 ), fracture $2.5 \mathrm{Y} 8 / 2$, surface $2.5 Y$ 8/2, paint red, rim type 1.42 (pottery group 6269). - 128 . rim, small, fine lustrous, cup (FS 219/237?), exterior body diameter c. $7 \mathrm{~cm}$, band on exterior rim (linear decoration 1.0), surface 10YR $8 / 3$, fracture 10YR $8 / 3$, paint black, rim type 1.59 (pottery group 6270). - 129. rim, small, fine lustrous, cup (FS 219/237?), diam. $10 \mathrm{~cm}$ $(6 \%)$, band on exterior rim (linear decoration 1.0), surface 7.5YR 7/4, fracture 7.5YR 7/4, paint brown, rim type 1.49 (pottery group 6266). - 130. rim, medium, fine lustrous, mug FS 225, diam. $14 \mathrm{~cm} \mathrm{(6 \% ),}$ band on interior rim, pendent rock pattern FM 32 on exterior rim, followed by double contour line, zig zag, rim type 1.97, fracture/core 2.5YR 7/1, fracture/near surfaces 2.5 YR 7/6, surface 10YR 8/3, paint red (pottery group 6259). - 131. base, small, fine lustrous, Vapheio cup FS 224, diam. $6 \mathrm{~cm}(13 \%)$, ripple pattern FM 78, painted base underneath, fracture 5YR 6/6, surface 10YR 8/3, paint brown and red (pottery group 6254). - 132. wall sherd, medium, fine lustrous, crater, curtailed spiral FM 49, three bands, paint brown, surface 7.5YR 7/4, fracture 2.5 YR 7/6 (pottery group 6242). - 133. wall sherd, small, fine lustrous, closed shape, dots, vertical stripes FM 67, two bands, surface 10YR 8/2, fracture 10YR 8/2, paint black (pottery group 6270). -134 . wall sherd, small, fine lustrous, closed shape, spiral, band, fracture 10YR $8 / 2$, surface 10YR $8 / 2$, paint brown (pottery group 6266). 135. rim, small, fine plain, carinated kylix FS 267, diam. $12 \mathrm{~cm}$ (9\%), surface $7.5 \mathrm{YR} 7 / 4$, fracture $7.5 \mathrm{YR} 7 / 4$, rim type 1.54 (pottery group 6270). - 136. rim, small, fine plain, carinated kylix FS 267, diam. $9.6 \mathrm{~cm}$ 
(8\%), fracture 2.5YR 6/8, surface 5YR 7/6, rim type 1.182 (pottery group 6269). - 137. rim, small, fine plain, carinated kylix FS 267, diam. $9 \mathrm{~cm}(6 \%)$, surface 7.5YR 7/4-7/6, fracture 7.5YR 7/4, rim type 1.55 (pottery group 6270). -138 . base, small, fine plain, kylix, diam. $8.8 \mathrm{~cm}$ (13\%), surface 10YR 8/4-7/4, fracture 2.5YR 7/6 (pottery group 6269). - 139. rim/beginning of handle, small, fine plain, angular bowl FS 295, diam. $10 \mathrm{~cm}(8 \%)$, rim type 1.45 , fracture $2.5 \mathrm{Y} 8 / 2$, surface $2.5 \mathrm{Y} 7 / 1$ (pottery group 6266). - 140. rim, small, fine plain, angular bowl FS 295, diam. $12 \mathrm{~cm}(7 \%)$, surface $2.5 \mathrm{Y} 8 / 2,2.5 \mathrm{Y} 7 / 2$, rim type 1.172 (pottery group 6270). -141 . base, small, fine plain, open shape, diam. $6 \mathrm{~cm}(28 \%)$, base type 1.13, fracture 7.5YR 7/4, surface 10YR $8 / 4$ (pottery group 6269). -142 . base, small, fine plain, open shape, diam. $3.3 \mathrm{~cm}(70 \%)$, fracture/surface $2.5 \mathrm{YR} 7 / 6$, cut marks at the base (pottery group 6242). - 143. rim, small, medium coarse, red gritty, conical cup, diam. $11 \mathrm{~cm}(14 \%)$, rim type 1.64, surface 2.5YR 6/6, fracture 2.5YR 6/6, secondary burnt? (pottery group 6270).

Fig. 9. 'Ditch'. Trench I18 $\alpha / \beta$. - 144. rim, medium, medium fine, gritty, matt painted, goblet, diam. $28 \mathrm{~cm} \mathrm{(4 \% ),} \mathrm{handmade,} \mathrm{paint} \mathrm{worn}$ off, fracture/core Gley $17 / \mathrm{N}$, fracture/near surfaces 5 YR $7 / 4$, surface 7.5YR 7/4-7/6 (pottery group 6266). -145 . handle, medium, medium coarse, gritty, burnished, hydria? Surface 7.5YR 7/4, fracture 7.5YR $6 / 2$ (pottery group 6270). - 146. rim, medium, medium coarse, basin, diam. c. $40 \mathrm{~cm} \mathrm{(3 \% ),} \mathrm{rim} \mathrm{type} 1.53$, surface $2.5 \mathrm{YR} 7 / 6$, fracture/ core 5 YR 5/4, fracture/near surfaces 2.5 YR 5/6, handmade (pottery group 6270). - 147. handle, medium, medium coarse, cooking pot, handmade, secondary burnt (pottery group 6270). - 148. rim, big, medium coarse, red silver mica fabric, basin, surface 7.5YR 7/4-6, fracture 10YR 6/2, handmade, hole for attachment of handle (pottery group 6242).

Fill above disturbed highest pebble surface, east. Trench I1 $\alpha \alpha / \beta$. -149. rim, medium, fine lustrous, goblet FS 263, diam. $18 \mathrm{~cm}$ (20\%), monochrome (linear decoration 11.0), fracture 2.5YR 6/6, paint red, rim type 1.40 (pottery group 6224). - 150. rim, small, fine lustrous, goblet/kylix, monochrome (linear decoration 11.0), fracture 2.5YR $7 / 8$, paint red, rim type 1.61 (pottery group 6224). - 151. rim, medium, fine lustrous, kylix FS 264, diam. $14 \mathrm{~cm}$ (11\%), monochrome (linear decoration 11.0), fracture 2.5YR 6/6, paint red, rim type 1.68 (pottery group 6224). - 152. rim, small, fine lustrous, kylix FS 264, diam. $16 \mathrm{~cm} \mathrm{(6 \% ),} \mathrm{monochrome} \mathrm{(linear} \mathrm{decoration} \mathrm{11.0),} \mathrm{fracture}$ 2.5YR 6/8, paint red, rim type 1.34 (pottery group 6104). - 153. rim, small, fine lustrous, kylix FS 264, monochrome (linear decoration 11.0), fracture/core 5 YR $7 / 4$, fracture/near surfaces 10 YR $8 / 2$, paint dark brown, red, rim type 1.94 (pottery group 6104). - 154. base, medium, fine lustrous, goblet FS 263, diam. $4.5 \mathrm{~cm}$ (100 \%), monochrome (linear decoration 11.0), base painted underneath, fracture 2.5YR 6/8, paint red (pottery group 6104). -155 . stem, medium, fine lustrous, kylix FS 264, monochrome (linear decoration 11.0), fracture Gley $17 / \mathrm{N}$, paint red (pottery group 6224). - 156. base, medium, fine lustrous, mug FS 225, diam. $5 \mathrm{~cm}$ (41\%), monochrome (linear decoration 11.0), base painted underneath, fracture 10YR 6/2, paint black (pottery group 6104). - 157. rim, medium, medium coarse lustrous, basin, monochrome (?) (linear decoration 11.0), fracture/core 5YR 6/1, fracture/near surfaces 5YR 6/4, paint black? rim type 1.147 (pottery group 6104). - 158. rim, small, fine plain, polished, carinated kylix FS 267, diam. $10 \mathrm{~cm}$ (11\%), surface 10YR 8/4, fracture 2.5YR $6 / 6$, rim type 1.31 (pottery group 6104). -159 . rim, small, fine plain, polished, carinated kylix FS 267, diam. $9.8 \mathrm{~cm}$ (12\%), 7.5YR 7/4, fracture 5YR 7/6, rim type 1.166 (pottery group 6224). - 160. rim/ beginning of handle, medium, fine plain, polished, angular bowl FS 295, diam. $14 \mathrm{~cm} \mathrm{(6 \% ),} \mathrm{surface} 2.5$ Y 8/2-7/2, fracture $2.5 \mathrm{Y} 6 / 2$, rim type 1.98 (pottery group 6224). - 161. rim, medium, fine plain, kylix with high swung handles FS 272, diam. $13 \mathrm{~cm}$ (14\%), medium, surface 7.5YR 7/4, fracture 5YR 7/4, rim type 1.146 (pottery group 6104). - 162. rim, small, fine plain, kylix, surface 7.5 YR 7/4-7/6, fracture 2.5YR 6/8, rim type 1.146 (pottery group 6104). - 163. rim, medium, fine plain, kylix, diam. $16 \mathrm{~cm}(11 \%)$, surface 5 YR 7/6, fracture 5YR 6/6, rim type 1.69 (pottery group 6104). - 164. rim, big, fine plain, goblet, diam. $22 \mathrm{~cm}(11 \%)$, surface $5 \mathrm{Y} 8 / 2-8 / 3$, fracture $5 \mathrm{Y}$ $8 / 2-8 / 3$, rim type 1.81 (pottery group 6104 ). -165 . stem, medium, fine plain, goblet, diam. $10 \mathrm{~cm}(6 \%)$, surface 7.5YR 8/4-7/4, fracture 2.5YR 7/6 (pottery group 6224). -166 . base, medium, medium coarse, red silver mica fabric, closed shape, diam. 12-14 cm (6\%), surface 2.5YR 5/4, fracture 2.5YR 5/2, handmade (pottery group 6224).

Fig. 10. Room 6. Building B. Trench I18 $\alpha .-167$. stem, medium, fine lustrous, kylix FS 264, monochrome (linear decoration 11.0) paint almost completely worn off, surface 5YR 7/6, fracture/core 2.5YR 6/4, fracture/near exterior surface $5 Y R$ 7/6, fracture/near interior surface 5YR 7/1, paint red (pottery group 6156). - 168. stem, medium, fine lustrous, kylix FS 264, monochrome (linear decoration 11.0) fracture 5YR 7/6, paint red (pottery group 6172). - 169. wall/beginning of handle, medium, fine lustrous, mug (?) FS 225, interior body diam. $13 \mathrm{~cm}$, monochrome exterior (?), paint almost entirely worn off, surface $7.5 \mathrm{YR} 7 / 4$, fracture/near exterior surface $2.5 \mathrm{YR} 7 / 6$, fracture/ near interior surface 7.5YR 7/4, paint red (pottery group 6172). -170 . $\mathrm{rim} / \mathrm{handles} / \mathrm{stem}$, big, fine plain, kylix FS 265/266, diam. $15,2 \mathrm{~cm}$ (100\%), rim type 1.112 , surface $5 \mathrm{Y} 8 / 1$, fracture/core $2.5 \mathrm{Y} 7 / 3$, fracture/near surfaces $5 Y$ 8/1 (pottery group 6138). -171 . rim, big, fine plain, kylix, diam. $22 \mathrm{~cm}(10 \%)$, surface 10YR 8/4, fracture 2.5YR 7/4-7/6, rim type 1.112 (pottery group 6276). - 172. rim/beginning of handle-base, big, carinated kylix FS 267, diam. rim $12 \mathrm{~cm}$, diam. b $7 \mathrm{~cm} \mathrm{(19 \% ,} \mathrm{B:100 \% ),} \mathrm{surface} \mathrm{10YR} \mathrm{8/1,} \mathrm{fracture} \mathrm{10YR} \mathrm{7/3-6/3,}$ rim type 1.177 (pottery group 6172). - 173. rim/base/beginning of handle, big, carinated kylix FS 267, diam. rim $11 \mathrm{~cm}$, diam. base $7 \mathrm{~cm}$, height $10.50 \mathrm{~cm}$ (rim $15 \%$, base $90 \%$ ), surface 5 Y $8 / 2$, fracture $5 Y$ 7/2-7/3, misfired? Rim type 1.186 (pottery group 6172). - 174. rimbase, big, carinated kylix FS 267, diam. rim $11 \mathrm{~cm}$, diam. base $6 \mathrm{~cm}$, height $9.50 \mathrm{~cm}$ (rim $35 \%$, base $30 \%$ ), surface $2.5 \mathrm{Y} 8 / 2$, fracture $2.5 \mathrm{Y}$ $7 / 2$, painted potters mark underneath the base, rim type 1.340 (pottery group 6221). - 175. rim/handle, big, fine plain, carinated kylix FS 267, diam. $11 \mathrm{~cm}(30 \%)$, surface 10YR 8/2-8/3, fracture/core 7.5YR 7/4, fracture/near surfaces 10YR $8 / 3$, rim type 1.209 (pottery group 6172). - 176. base, medium, fine plain carinated kylix FS 267, diam. $6.9 \mathrm{~cm}$ (base $60 \%$ ), surface 2.5 Y 8/2, fracture 10YR $8 / 3$ (pottery group 6172). -177 . base/stem/beginning of handle at lower part of wall, medium, fine plain, carinated kylix FS 267, surface 5Y 8/2, fracture 5 Y $8 / 2$ (pottery group 6172). - 178. stem, medium, fine plain, kylix FS 264/265/266/272, surface 10YR 8/3, fracture 7.5YR 7/4 (pottery group 6156). - 179. rim, big, fine plain, dipper FS 236, diam. rim $12.2 \mathrm{~cm}(90 \%)$, surface 10YR 8/4, fracture 2.5YR 6/8, rim type 1.120 (not included in table 1) (pottery group 6314).

Fig. 11. Room 6. Building B. Trench I18 $\alpha$ - 180. rim/base, big, red medium coarse, gritty micaceous, cooking tripod, diam. $20.4 \mathrm{~cm}$ (100\%), height (with legs) $29 \mathrm{~cm}$, surface $2.5 \mathrm{YR} 6 / 8$, fracture/core 2.5YR 5/1, fracture/near surfaces 2.5 YR $6 / 8$, almost fully preserved 
(pottery group 6172, 6155). - 181. rim, big, medium coarse, gritty micaceous, pithos, surface 2.5 YR $7 / 8$, fracture/core $5 Y R$ 6/4, fracture/near surfaces 2.5 YR 6/8, handmade? (pottery group 6172).

Fig. 12. Trench $\Delta 6 \delta$. Fresco dump. - 182. rim, small, fine lustrous, goblet FS 263, diam. $16.5 \mathrm{~cm}$ c. (6 \%), monochrome (linear decoration 11.0), fracture 7.5YR 6/2, paint black, rim type 1.69 (pottery group 370). - 183. rim, small, fine lustrous, goblet FS 263 , diam. $14 \mathrm{~cm}$ (9\%), monochrome (linear decoration 11.0), fracture 7.5YR 7/4, paint black, rim type 1.213 (pottery group 305). - 184. rim, medium, fine lustrous, goblet FS 263, monochrome (linear decoration 11.0), fracture/core 5YR 6/1, fracture/near surfaces 5 YR 6/6, paint red, rim type 1.69 (pottery group 366). - 185. rim, medium, fine lustrous, kylix FS 264, diam. $17 \mathrm{~cm}$ (8\%), monochrome (linear decoration 11.0), fracture 7.5YR 6/2, paint brown and black, rim type 1.46 (pottery group 374). - 186. rim, small, fine lustrous, kylix FS 264, diam. $13 \mathrm{~cm}$ (6\%), monochrome (linear decoration 11.0), fracture 10YR 6/1, paint black, rim type 1.176 (pottery group 306). -187 . base, medium, fine lustrous, goblet FS 263, diam. $4.3 \mathrm{~cm}$ (100\%), monochrome (linear decoration 11.0), fracture 2.5YR 6/6, paint red (pottery group 176). - 188. wall sherd/beginning of horizontal handle, medium, fine lustrous, stemmed bowl FS 304, monochrome (linear decoration 11.0), fracture 2.5YR 5/4, surface Gley $16 / \mathrm{N}$, paint black (pottery group $\Delta 6 \delta / 91) .-189$. base, medium, fine lustrous, kylix FS 264, diam. $8.3 \mathrm{~cm}$ (62\%), monochrome (linear decoration 11.0), fracture/core 5 YR 6/3, fracture/near surfaces 2.5YR 5/8, paint red (pottery group 366). -190 . base, medium, fine lustrous, goblet/kylix, diam. $10 \mathrm{~cm}$ (42\%), monochrome (linear decoration 11.0), paint red (pottery group 306). - 191. rim, small, fine lustrous, closed shape?, diam. $11 \mathrm{~cm}(8 \%)$, monochrome (linear decoration 11.0), fracture 7.5YR 6/4, paint black, rim type 1.171 (pottery group 378/I). for similar rim in closed shapes cf. Catling 2009b, Fig. 181/WS69 (wash levels, not stratified). - 192. base, medium, fine lustrous, kylix FS 256/257, diam. $12 \mathrm{~cm}$ (17\%), banded, surface 7.5YR 7/4, fracture 2.5YR 6/6, paint red (pottery group 306). - 193. base, small, fine lustrous, kylix FS 256/257, diam. $10 \mathrm{~cm}(8 \%)$, banded, surface 10YR 8/3, fracture $7.5 \mathrm{YR} 7 / 4$, paint red (pottery group 305). - 194. rim, medium, fine lustrous, kylix, diam. $18 \mathrm{~cm}(15 \%)$, rim band? (linear decoration 1.0?), monochrome interior not to be excluded, fracture $2.5 \mathrm{YR} 6 / 6$, rim type 1.176 , paint worn off (pottery group 370). - 195. rim, small, fine lustrous, kylix, diam. $19 \mathrm{~cm} \mathrm{(4 \% ),} \mathrm{rim} \mathrm{band} \mathrm{(linear} \mathrm{decoration} \mathrm{1.0),} \mathrm{surface} \mathrm{10YR}$ 8/3, fracture 7.5YR 7/4, paint brown, rim type 1.112 (pottery group 305). - 196. rim, small, fine lustrous, kylix/cup, diam. $12 \mathrm{~cm}$ (12\%), rim band (linear decoration 1.0), surface 7.5YR 7/4, fracture 7.5YR 6/2, paint black and red, rim type 1.114 (pottery group 370). -197 . rim, small, fine lustrous, cup FS 237, diam. $11 \mathrm{~cm}$ (5\%), rim band (linear decoration 1.0), foliate band FM 64, surface 7.5YR 7/4, fracture 7.5YR 7/4, paint brown and black, rim type 1.49 (pottery group 305). -198. handle, big, fine lustrous, goblet/crater, ladder, surface 7.5YR $7 / 4$, fracture 2.5YR 6/8, paint red (pottery group $\Delta 6 \delta / 191$ ). -199 . disk base/beginning of handle, small, fine lustrous, small stirrup jar, diam. $2.7 \mathrm{~cm}$, concentric circles, reserved triangle at handle, surface 10YR $8 / 3$, paint red (pottery group 306 ).

Fig. 13. Trench $\Delta 6 \delta$. Fresco dump. -200 . rim/stem/handle, big, fine plain, carinated kylix FS 267, diam. $10.4 \mathrm{~cm}$ (rim $50 \%$ ), surface 10YR $8 / 3$, fracture 7.5YR 7/4-7/6, rim type 1.172 (pottery group $120 \zeta$ ). -201. rim/base/handle, big, fine plain, carinated kylix FS 267, diam.
$10.1 \mathrm{~cm} \mathrm{(30 \% ),} \mathrm{diam.} \mathrm{base} 6 \mathrm{~cm}$ (15\%), surface 7.5YR 7/4, fracture 2.5YR 6/8, rim type 1.202 (pottery group $119 \delta$ ). -202 . rim/base/handle, big, fine plain, carinated kylix FS 267, diam. $9 \mathrm{~cm}$, diam. base $6 \mathrm{~cm}$, surface. - 203. rim/beginning of handle/base, big, fine plain, carinated kylix FS 267, diam. $9.4 \mathrm{~cm}$, diam. base $5.8 \mathrm{~cm}$, surface 10YR $8 / 3$, fracture $5 Y R 7 / 6$, rim type 1.340 (pottery group 145 ). -204 . rim, big, fine plain, kylix, diam. $11.1 \mathrm{~cm}$, rim type 1.188. - 205. rim/handle, medium, fine plain, kylix, c. diam. $20 \mathrm{~cm}$, surface $10 \mathrm{YR} 8 / 4$, fracture 5YR 7/6, rim type 1.181 (pottery group 127a). -206 . rim/handle, medium, fine plain, kylix with high swung handles FS 272, diam. $17 \mathrm{~cm}$ (rim c. $15 \%$ ), surface $10 \mathrm{YR} 8 / 4$, fracture $2.5 \mathrm{YR} 6 / 8$, rim type 1.34 (pottery group 131). - 207. rim/handle, small, fine plain, conical kylix FS 274, surface 7.5YR 7/4, fracture 2.5YR 6/6, rim type 1.64 (pottery group 175). - 208. base/beginning of handle, medium, fine plain, surface $2.5 \mathrm{Y} 7 / 2$, fracture $5 \mathrm{Y} 7 / 2$, goblet (pottery group 150 ). -209 . base/ beginning of handle at lower part of wall, big, fine plain, carinated kylix FS 267, diam. $6.3 \mathrm{~cm}$ (10\%), surface 10YR 8/7, fracture 7.5YR $7 / 4$ (pottery group 119ק). -210 . base, big, fine plain, carinated kylix FS 267, diam. $7.6 \mathrm{~cm}$, surface $7.5 \mathrm{YR} 8 / 4$, fracture $5 \mathrm{YR} 7 / 6$ (pottery group 1208). - 211. base, big, beginning of handle at lower part of wall, fine plain, carinated kylix FS 267, diam. $6.5 \mathrm{~cm}(100 \%)$, surface $2.5 \mathrm{Y} 8 / 2-8 / 3$, fracture $2.5 \mathrm{Y} 8 / 2$ (pottery group $120 \beta$ ). -212 . base, medium, fine plain, carinated kylix FS 267 , surface $2.5 Y$ 8/2-7/2, frac-

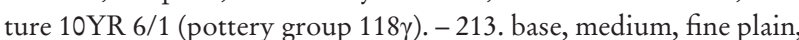
carinated kylix FS 267, diam. 6.4-6.6 cm (100\%), surface 2.5Y 7/2, fracture 10YR $7 / 4$ (pottery group 118ß). - 214. stem/beginning of handle at lower part of wall, big, fine plain, kylix FS 264/265/266/272, surface 5 Y 8/2, fracture 5 Y $7 / 2$ (pottery group $120 \sigma \tau$ ). -215 . base/ beginning of two handles at lower part of wall, big, fine plain, kylix, surface 10YR 8/3, fracture 7.5YR 7/4 (pottery group 1198). - 216 . stem, medium, fine plain, surface 10YR 8/4, fracture 5YR 6/6, kylix (pottery group $119 \gamma$ ).

Fig. 14. Trench $\Delta 6 \delta$. Fresco dump. - 217. rim/beginning of handle/ base, big, fine plain, angular bowl FS 295, diam. rim $17 \mathrm{~cm}(90 \%)$ diam. base $5.7 \mathrm{~cm}(100 \%)$, surface 10YR 7/4, fracture 2.5YR 6/6, rim type 1.208 (pottery group 120a/A3). - 218. rim/ handle/base, big, fine plain, angular bowl FS 295, diam. rim $16.8 \mathrm{~cm}$ (almost $100 \%$ ), diam. base $4.8 \mathrm{~cm}(100 \%)$, height $6.70 \mathrm{~cm}$, surface 10YR 8/1, fracture $5 Y R$ $7 / 6$, rim type 1.55 (pottery group 374,366 ).-219 . rim/handle, big, fine plain, angular bowl FS 295, diam. $15 \mathrm{~cm}(15 \%)$, surface 10YR 8/7, fracture 5 YR $7 / 4$, rim type 1.32 (pottery group $128 \beta$ ). -220 . rim/base, big, fine plain, conical handless cup FS 204, diam. rim $11 \mathrm{~cm}(17 \%$,), diam. base $4.7 \mathrm{~cm}(100 \%)$, height $5.7 \mathrm{~cm}$, surface 10YR $8 / 3$, fracture $2.5 Y R \quad 7 / 6$, rim type 1.10 (pottery group $120 \eta$ ). -221 . rim/base, big, fine plain, conical handless cup FS 204, diam. $\operatorname{rim} 12.8 \mathrm{~cm}$, diam. base $4.65 \mathrm{~cm}(100 \%)$, height $4.9-5.2 \mathrm{~cm}$, surface 10YR 8/4, fracture 5 YR $6 / 6$, cut marks at base, rim type 1.14 (pottery group $120 \gamma$ ). -222 . base, big, fine plain, polished (?), crater FS 7-9, diam. $11 \mathrm{~cm} \mathrm{(30 \% ,),} \mathrm{the}$ base is irregularly made and one side is much thinner, both profiles met on the same fragment have been drawn, surface 7.5YR 7/4, frac-

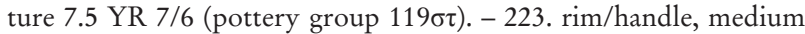
coarse, gritty, micaceous, basin FS 294?, diam. $30 \mathrm{~cm}$ (13\%), surface-fracture 2.5YR 4/6, secondary burnt, (pottery group 125). -224 . rim, medium coarse, burnished?, basin, diam. $36 \mathrm{~cm}(8 \%)$, surface 5YR 6/4, fracture 5YR 5/4, rim type 1.53 (pottery group $\Delta 6 \delta / 19$ ). 225. rim, medium, medium coarse, cooking pot, diam. $27 \mathrm{~cm} \mathrm{(6 \% ),}$ exterior surface 2.5 YR $5 / 2-5 / 3$, interior surface $2.5 Y R$ 6/8, fracture 2.5YR 6/8, secondary burnt (pottery group 369). -226 . wall sherd/ 
handle, big, medium coarse, gritty, hydria, hole for attachment of handle, surface 7.5YR 8/4-7/4, fracture 5YR 6/1 (pottery group 19i).

Trench B158/south-eastern pottery deposit. - 227. wall sherd/beginning of handle, medium, fine lustrous, closed shape, rock work FM 28, paint red (pottery group 757). -228 . wall sherd, medium, fine lustrous, closed shape, crocus FM 10, circles FM 41, 2.5 Y 8/2, fracture/near exterior surface $7.5 \mathrm{YR} 7 / 4$, fracture/near interior surface 10YR $7 / 3$, paint black and brown (pottery group 757 ). -229 . wall sherd, small, fine lustrous, closed shape, ivy FM 12, surface 10YR $8 / 3$, fracture 10 YR $8 / 3$, paint brown (pottery group 757 ). -230 . wall sherd, small, fine lustrous, closed shape, ivy FM 12 (pottery group 765). - 231. wall sherd, small, fine lustrous, closed shape, urchin FM 27, spiraloid? Surface 2.5 Y 8/2, fracture 2.5YR 6/8, paint brown (pottery group 765). - 232. wall sherd, small, fine lustrous, closed shape, isolated wavy band FM 53, unidentifiable, surface 10YR 8/3, fracture 7.5YR 7/4, paint black (pottery group 765). - 233. wall sherd, small, fine lustrous, closed shape, hatched loop ? FM 63, surface $2.5 \mathrm{Y}$ $8 / 2$, fracture $2.5 Y R$ 6/8, paint red (pottery group 765 ). -234 . rim, small, fine lustrous, in and out bowl FS 220, diam. $17 \mathrm{~cm} \mathrm{(6 \% ),} \mathrm{band}$ at rim (linear decoration 1.0), group of lines, foliate band FM 64, zig zag on interior FM 61, surface 2.5YR 8/3, fracture 10YR 8/3-7/3, paint brown and red (pottery group 765).

Fig. 15. Trench B158/south-eastern pottery deposit. -235 . rim, medium, fine lustrous, goblet FS 263, diam. $17 \mathrm{~cm}(9 \%)$, monochrome (linear decoration 11.0), fracture 2.5YR 5/6, paint red, rim type 1.85 (pottery group 757). - 236. rim with beginning of handle, medium, fine lustrous, goblet FS 263, diam. $16 \mathrm{~cm}$ (6\%), monochrome (linear decoration 11.0), fracture 7.5YR 6/3, paint black, largely worn off, rim type 1.42 (pottery group 779). -237 . rim, medium, fine lustrous, goblet FS 263, diam. $14 \mathrm{~cm}(7 \%)$, monochrome (linear decoration 11.0), fracture Gley $16 / \mathrm{N}$, paint black, rim type 1.69 (pottery group 757). - 238. rim with beginning of handle, medium, goblet/kylix, diam. $16 \mathrm{~cm}(6 \%)$, monochrome (linear decoration 11.0), fracture 7.5YR $5 / 3$, paint red, rim type 1.42 (pottery group 779 ). -239 . rim, medium, fine lustrous, goblet FS 263, diam. $16 \mathrm{~cm} \mathrm{(3 \% ),} \mathrm{monochrome} \mathrm{(linear}$ decoration 11.0), fracture $2.5 \mathrm{YR} 7 / 8$, paint red, rim type 1.68 (pottery group 763). - 240. base, big, fine lustrous, goblet FS 263, diam. $7.80 \mathrm{~cm}(44 \%$ ), monochrome (linear decoration 11.0), fracture upper part 10YR 6/1, fracture base 2.5YR 7/6, black and red paint (pottery group 773). - 241. base, medium, fine lustrous, goblet FS 263, diam. $7 \mathrm{~cm}(22 \%)$, monochrome (linear decoration 11.0), fracture 2.5YR $7 / 8$, red paint (pottery group 779). -242 . base, medium, fine lustrous, goblet FS 263, diam. $8 \mathrm{~cm}$ (29\%), monochrome (linear decoration 11.0), base painted underneath, fracture $2.5 \mathrm{YR} 7 / 6$, black and red paint (pottery group 757). - 243. rim, medium, fine lustrous, kylix FS 264, diam. $16 \mathrm{~cm} \mathrm{(3 \% ),} \mathrm{monochrome} \mathrm{(linear} \mathrm{decoration} \mathrm{11.0),}$ fracture 2.5YR 7/8, paint red, rim type 1.68 (pottery group 763). -244 . rim, medium, fine lustrous, kylix FS 264, diam. $16 \mathrm{~cm}$ (6\%), monochrome (linear decoration 11.0), fracture 2.5YR 7/6, paint red, rim type 1.142 (pottery group 765). - 245. rim, handle, big, fine lustrous, kylix FS 264, diam. $15 \mathrm{~cm}$ (37 \%), monochrome (linear decoration 11.0), fracture 2.5YR 6/8, paint red, rim type 1.68 (pottery group 773 ). - 246. rim, handle, small, fine lustrous, kylix, monochrome painted (linear decoration 11.0), fracture $2.5 \mathrm{Y} 7 / 2$, paint black, rim type 1.94 (pottery group 765). - 247. rim, medium, fine lustrous, closed vessel, diam. $10 \mathrm{~cm}(20 \%)$, monochrome painted (linear decoration
11.0), 2.5YR 6/6, paint, rim type 1.306 (pottery group 763). cf. Catling 2009b, Fig. 130/V5 for similar rim from monochrome closed vessel. -248. rim/beginning of handle, big, medium coarse, water jar, diam. $12-12.4 \mathrm{~m} \mathrm{(50 \% ),} \mathrm{monochrome,} \mathrm{surface} \mathrm{2.5YR} \mathrm{7/4,} \mathrm{fracture} \mathrm{10YR}$ 8/3-7/3, paint red (pottery group 779). - 249. rim, small, fine lustrous, goblet, c. diam. c. $15 \mathrm{~cm}$, monochrome interior, line on the exterior rim (linear decoration 15), surface 7.5YR 8/4-7/4, fracture 7.5YR 6/2, black paint, rim type 1.151 (pottery group 757 ). -250 . rim, medium, fine lustrous, goblet, diam. $12 \mathrm{~cm}$ (12\%), monochrome interior, line on the exterior rim (linear decoration 15), surface 10YR 8/2-7/2, fracture 10YR 6/3, paint black, rim type 1.150 (pottery group 765).251. rim/beginning of handle, medium, fine lustrous, goblet FS 263, monochrome interior, line on the exterior rim (linear decoration 15), surface 10YR 8/2, fracture 2.5YR 6/6, paint black, rim type 1.151 (pottery group 765). - 252. rim, big, fine lustrous, goblet/one handled goblet FS 263, diam. 12-13 cm (39\%), monochrome interior, line on the exterior rim (linear decoration 15), fracture 2.5YR 6/6, surface 10YR 7/3, fracture 2.5YR 6/6, red paint, rim type 1.42 hollowed (pottery group 768). - 253. rim, medium, fine lustrous, goblet/ kylix, diam. $15 \mathrm{~cm}(11 \%)$, monochrome interior, line on the exterior rim (linear decoration 15), fracture 2.5YR 6/6, red paint, rim type 1.70 (pottery group 763). - 254. rim, medium, fine lustrous, goblet/cup, diam. $12 \mathrm{~cm}(14 \%)$, monochrome interior, line on the exterior rim (linear decoration 15), surface 10YR 8/3, fracture 7.5YR 6/4, black paint, rim type 1.124 (pottery group 763 )

Fig. 16. Trench B158/south-eastern pottery deposit. - 255. rim, medium, fine lustrous, goblet/kylix, diam. $18 \mathrm{~cm} \mathrm{(24 \% ),} \mathrm{line} \mathrm{at} \mathrm{rim}$ (linear decoration 1.0), surface 10YR 8/4-7/4, fracture 2.5YR 6/8, red paint, rim type 1.28 (pottery group 757 ). -256 . rim, medium, fine lustrous, goblet FS 254/255, diam. $21 \mathrm{~cm}(11 \%)$, band at rim (linear decoration 1.0), lily FM 9, surface 7.5YR 8/4, fracture $2.5 \mathrm{YR}$ $6 / 8$, red paint, rim type 1.85 (pottery group 765 ). -257 . rim, medium, fine lustrous, goblet FS 254/255, diam. $18 \mathrm{~cm}$ (8\%), band at rim (linear decoration 1.0), spiral, fracture 2.5YR 7/6, red paint, rim type 1.44 (pottery group 765). - 258. rim, medium, fine lustrous, goblet FS $254 / 255$, diam. $26 \mathrm{~cm}$ (6\%), band at rim (linear decoration 1.0), running spirals FM 46, fracture 2.5YR 6/6, black paint, rim type 1.300 (pottery group 779). -259 . rim, medium, fine lustrous, goblet FS 254/255, diam. $20 \mathrm{~cm}$ (14 \%), band at rim (linear decoration 1.0), curve-stemmed spiral FM 49, surface 7.5YR 6/4, fracture 5YR 6/6, red paint, rim type 1.44 (pottery group 765). -260 . rim, medium, fine lustrous, goblet FS 254/255, diam. $14 \mathrm{~cm}(8 \%)$, band at rim (linear decoration 1.0), curve-stemmed spiral FM 49, surface 10YR 8/2, fracture $10 \mathrm{YR} 7 / 3$, black paint, rim type 1.309 (pottery group 765). -261 . wall sherd, small, fine lustrous, goblet/kylix, band close at rim, curvestemmed spiral FM 49/ wavy line FM 53, surface 10YR 7/1-7/2, paint brown (pottery group 779). -262 . rim with beginning of handle, medium, fine lustrous, goblet FS 254/255, diam. $19 \mathrm{~cm}(8 \%)$, band at rim (linear decoration 1.0), pendent rock FM 32, single contour line, surface 7.5YR 7/4, fracture/core Gley $16 / \mathrm{N}$, fracture/near surfaces 2.5 YR 6/4, black paint, rim type 1.44 (pottery group 765 ). - 263. wall, fine lustrous, goblet FS 254/255, pendent rock pattern FM 32, surface $10 \mathrm{YR} 7 / 3$, fracture $5 \mathrm{YR} 5 / 6$, red and brown paint (pottery group 763 ). - 264. wall, medium, fine lustrous, goblet FS 254/255, pendent rock FM 32, surface 7.5YR 7/4-6/4, fracture 2.5YR 7/6, red paint (pottery group 763). - 265. wall, big, fine lustrous, goblet FS 254/255, group of three lines, line close to stem, argonaut FM 22, surface 2.5YR 7/67.5YR $7 / 4$, fracture/core 7.5YR 6/4, fracture/near surfaces $2.5 \mathrm{YR}$ 
6/8, red paint (pottery group 765). - 266. Rim, medium, fine lustrous, goblet/Crater, diam. $24 \mathrm{~cm}(8 \%)$, deep rim band at exterior? (linear decoration 1.3.1), fracture 2.5YR 6/6, paint brown, rim type 1.300 (pottery group 757). - 267. Rim, medium, fine lustrous, kylix, diam. $18 \mathrm{~cm}(8 \%)$, band at rim (linear decoration 1.0), pendent rock pattern FM 32, double contour line, wavy lines FM 53, surface 7.5YR 7/4, fracture 2.5YR 6/6, paint red, rim type 1.33 (pottery group 757). -268. rim, handle, medium, fine lustrous, kylix, diam. $14 \mathrm{~cm}$ (11\%), band at rim (linear decoration 1.0), horizontal stripes at handle, surface and fracture 2.5YR 6/6, paint red, rim type 1.80 (pottery group 763). - 269. base, medium, fine lustrous, kylix, diam. $9 \mathrm{~cm}(25 \%)$, monochrome, broad band at stem, lines at disk base, surface 10YR $8 / 3$, fracture $2.5 Y R$ 7/6, paint brown and red (pottery group 757).

Fig. 17. Trench B158/south-eastern pottery deposit. - 270. rim, medium, fine lustrous, mug FS 225, diam. $15 \mathrm{~cm}(8 \%)$, stipple pattern FM 77,2, surface 10YR $8 / 3$, fracture 5 YR $7 / 8$, red and black paint, rim type $1.97 \mathrm{~b}$ (pottery group 765). -271 . rim, small, fine lustrous, one handled bowl FS 283 (ridges at rim), diam. $14 \mathrm{~cm}(8 \%)$, band at rim (linear decoration 1.0), spiral, surface 7.5YR 7/3, fracture 5YR 7/4, paint red (pottery group 763). - 272. rim, small, fine lustrous, cup FS 219, diam. $10 \mathrm{~cm} \mathrm{(8 \% ),} \mathrm{stipple} \mathrm{pattern} \mathrm{FM} \mathrm{77,2,} \mathrm{surface} \mathrm{7.5YR}$ 8/4-7/4, fracture 2.5YR 7/6, red paint, rim type 1.47 (pottery group 765). - 273. base, small, fine lustrous, cup FS 219, diam. $3 \mathrm{~cm}$ (34\%), stipple pattern FM 77,2, band and line at base, surface 7.5YR 7/4, fracture 5YR 6/4, red and black paint (pottery group 757). -274 . rim, medium, fine lustrous, cup FS 220, diam. 9,8 cm (14\%), band at rim (linear decoration 1.0), group of lines and broad band at base, isolated wavy bands FM 53, rim type 1.124 (pottery group 763). - 275. rim/ beginning of handle/base, medium, fine lustrous, cup FS 220, diam. rim $11 \mathrm{~cm}$, diam. base $3.5 \mathrm{~cm}$ (rim $14 \%$, base $100 \%$ ), band at rim (linear decoration 1.0), group of lines and broad band at base, groups of vertical wavy bands FM 53, surface 10YR 8/3, fracture/near exterior surface $7.5 \mathrm{YR} 6 / 4$, fracture/near interior surface $10 \mathrm{YR} 7 / 3$, paint red and brown, rim type 1.49 (pottery group 763). - 276. rim, small, fine lustrous, cup FS 220, diam. $10 \mathrm{~cm}(8 \%)$, band at rim (linear decoration 1.0), ivy? FM 12, surface/fracture 7.5YR 7/4, paint red, rim type 1.113 (pottery group 763). - 277. base, medium, fine lustrous, cup FS 220, diam. $5 \mathrm{~cm}$ (31\%), group of lines and broad band at base, angular stem FM 19, surface 10YR 8/2, fracture 10YR 5/2-5/3, paint brown and black (pottery group 779). - 278. base, small, open form, diam. $1.7 \mathrm{~cm}(100 \%)$, group of lines at base, line at base, surface 10YR $7 / 3$, fracture 7.5YR 7/4, paint red (pottery group 763). - 279. rim, medium, fine lustrous, basin FS 294, diam. $23 \mathrm{~cm}$ (8\%), band at interior rim and band under rim on exterior, wavy line at lip FM 53 (linear decoration 8.1), wavy line at body FM 53, rim type 1.310, surface 7.5YR 8/4, fracture 2.5YR 7/6, paint red and brown (pottery group 765). - 280. rim, big, fine lustrous, conical rhyton FS 199 , diam. $11 \mathrm{~cm}$ $(17 \%)$, group of broad and thin lines, dashes at rim, surface $2.5 \mathrm{Y} 8 / 2$, fracture 10YR 6/3, paint red (pottery group 763). - 281. wall sherd, big, fine lustrous, conical rhyton FS 199, group of four lines, multiple stem (hooked shape) FM 19, surface 10YR 8/3-7/3, fracture 5YR $7 / 3-7 / 4$, paint red (pottery group 757,765 ). -282 . rim/beginning of handle, medium, fine lustrous, piriform jar? FS 31, diam. $5 \mathrm{~cm}$ (34\%), lines at neck, stipple pattern FM 77,1, surface $2.5 \mathrm{Y} 8 / 2$, fracture 10YR $6 / 3$, paint (pottery group 779). -283 . wall sherd, handle, medium, fine lustrous, alabastron FS 84/85, monochrome neck, band at lower body, rock pattern FM 32, surface 2.5YR 7/4, fracture 10YR 8/3-7/3, paint (pottery group 768). - 284. wall sherd, small, fine lustrous, closed shape, stemmed ivy FM 12, rock pattern FM 31, surface 5YR $7 / 3$, fracture 2.5 YR $6 / 8$, paint red (pottery group 757 )

Fig. 18. Trench B158/south-eastern pottery deposit. - 285. wall sherd, handle, medium, fine lustrous, small piriform jar FS 31, parallel chevrons FM 58, monochrome neck, surface 7.5YR 7/4, fracture 2.5YR 7/6, paint red (pottery group 757). - 286. wall sherd, small, fine lustrous, closed shape, motif with filling of lines (papyrus/spiral? Cf. FM 11,49), surface 10YR 8/3, fracture 7.5YR 6/4, paint red and brown (pottery group 763 ). -287 . wall sherd, medium, fine lustrous, closed shape, curved stripes FM 67, surface 10YR 8/3, fracture 10YR 6/3, paint brown and black (pottery group 765). -288 . wall sherd, medium, fine lustrous, closed shape, curved stripes FM 67, surface 2.5YR 7/4, fracture 10YR $8 / 3-7 / 3$, paint (pottery group 765 ). -289 . wall sherd, medium, fine lustrous, closed shape, curved stripes FM 67, surface 7.5YR 7/4, fracture 2.5YR 6/8, paint red (pottery group 763). - 290. $\mathrm{rim} /$ beginning of handle, base, big, fine plain, carinated kylix FS 267, diam. rim 10.4-11.8 cm, diam. base $5.8 \mathrm{~cm}$ (rim $100 \%$, base $74.8 \%$ ), height $10.4 \mathrm{~cm}$, surface $7.5 \mathrm{YR} 7 / 4$, fracture $2.5 \mathrm{YR} 7 / 6$, painted stipe underneath base (potters mark), rim type 1.304 (pottery group 776). - 291. rim, handle, base, big, fine plain, carinated kylix FS 267, diam. rim $11 \mathrm{~cm}$, diam. base $5.6 \mathrm{~cm}$ (R $39 \%$, B $100 \%)$, height $10.4 \mathrm{~cm}$, surface 10 YR $8 / 1-8 / 2$, fracture 2.5 YR $7 / 8$, rim type 1.30 a (pottery group 773). - 292. rim/beginning of handle, base, big, fine plain, carinated kylix FS 267, diam. rim $11 \mathrm{~cm}(28 \%)$, surface $2.5 \mathrm{Y} 8 / 2-7 / 2$, fracture 10YR 6/3, rim type 1.31 (pottery group 776). - 293. rim, handle, big, carinated kylix FS 267, fine plain, diam. $12 \mathrm{~cm}$ (36\%), surface 10YR 8/4, fracture 7.5YR 6/4, rim type 1.31 (pottery group 773). - 294. $\mathrm{rim} /$ beginning of handle, big, carinated kylix FS 267 , diam. rim $11 \mathrm{~cm}$ (28\%), surface 2.5 Y $8 / 2-7 / 2$, fracture 10YR 6/3, rim type 1.31 (pottery group 779). -295 . rim, stem/beginning of base, big, fine plain, carinated kylix FS 267 , diam. rim 10-10.4 cm (50\%), surface $2.5 \mathrm{Y}$ $7 / 2$, fracture $2.5 \mathrm{Y} 7 / 3$, rim type 1.31 (pottery group 773 ). -296 . rim, medium, carinated kylix FS 267, fine plain, diam. rim $11.6 \mathrm{~cm}(28 \%)$, surface 10 YR $7 / 3$, fracture 2.5 YR $7 / 6$, rim type 1.172 (pottery group 779). - 297. base, medium, goblet, fine plain, diam. b $5 \mathrm{~cm}$ (75\%), surface 7.5YR 7/4-7/6, fracture 2.5YR 6/8, painted stripe underneath base (potters mark?) (pottery group 763). - 298. rim/beginning of handle, big, fine plain, kylix with high swung handle FS 267, diam. rim $12 \mathrm{~cm}(28 \%)$, surface 10YR 8/4-7/4, fracture 7.5YR 7/4, rim type 1.191 shorter (pottery group 757 )

Fig. 19. Trench B158/south-eastern pottery deposit. - 299. rim/ beginning of handle, big, fine plain, goblet/crater, surface 10YR $8 / 2-7 / 2$, fracture Gley $18 / 10 \mathrm{Y}-7 / 10 \mathrm{Y}$, rim type 1.5 thicker (pottery group 779). -300 . rim, handles, big, goblet/crater, fine plain, diam. rim $26 \mathrm{~cm}$, surface $2.5 \mathrm{Y} 7 / 2$, fracture Gley $17 / 10 \mathrm{Y}$, rim type 1.44 (pottery group 779). - 301. rim, handles, big, crater, fine plain, diam. $19 \mathrm{~cm}(8 \%)$, surface 10YR 7/3-6/3, fracture/core Gley $17 / 10$ Y, fracture/near surfaces 7.5YT 6/4, rim type 1.188 (pottery group 768, 773). - 302. rim, big, crater, fine plain, diam. $24 \mathrm{~cm} \mathrm{(8 \% ),} \mathrm{surface} \mathrm{10YR}$ $7 / 2$, fracture $2.5 \mathrm{YR} 7 / 4-7 / 6$, rim type 1.44 (pottery group 768,773 ).

Fig. 20. Trench B15 $\delta /$ south-eastern pottery deposit. - 303. rim, handle, base, big, conical bowl FS 295, fine plain, diam. rim $21 \mathrm{~cm}$ (48\%), diam. base $5 \mathrm{~cm}(100 \%)$, height c. $7.8 \mathrm{~cm}$, surface Gley 1 10YR 7/1-6/1, fracture/core 10YR 8/4, fracture/near surfaces $10 \mathrm{YR}$ 
6/2, rim type 1.302 (pottery group 768,773 ). -304 . rim, handle, base, big, conical bowl FS 295, fine plain, diam. rim $18 \mathrm{~cm}$ (R $33 \%$ ), diam. base $5 \mathrm{~cm}(33 \%)$, height $7 \mathrm{~cm}$, surface Gley $17 / \mathrm{N}-6 / \mathrm{N}$, fracture Gley $16 / \mathrm{N}$, rim type 1.311 (pottery group 768 ). -305 . rim with beginning of handle, medium, conical bowl FS 295, fine plain, diam. rim $11 \mathrm{~cm}$ (19\%), surface 10YR $8 / 3$, fracture 7.5YR 6/6, rim type 1.152 (pottery group 779). - 306. rim, base, big, conical cup FS 204, fine plain, diam. $\operatorname{rim} 12.2 \mathrm{~cm}(100 \%)$, diam. base $3.6 \mathrm{~cm}(100 \%)$, height $4.9 \mathrm{~cm}$, surface 10YR $8 / 2$, fracture $2.5 \mathrm{Y} 6 / 6$, cut marks at base (pottery group 769 ). - 307. rim, base, big, conical cup FS 204, fine plain, diam. rim $12 \mathrm{~cm}$ (50\%), diam. base $3.8 \mathrm{~cm}(100 \%)$, height $5.2 \mathrm{~cm}$, surface $5 \mathrm{YR} 6 / 6$ and 7.5YR 7/4, fracture 2.5YR 6/6, cut marks at base, rim type 1.64 (pottery group 768). - 308. rim, base, medium, conical cup FS 204, fine plain, diam. rim $12 \mathrm{~cm}(17 \%)$, diam. base $3 \mathrm{~cm}(37 \%)$, height $5.6 \mathrm{~cm}$, surface 10 YR $8 / 2$ and 2.5 YR $6 / 6$, fracture 2.5 Y $6 / 6$, cut marks at base (pottery group 768). - 309. rim, base, big, conical cup FS 204, fine plain, diam. rim 12-13 cm (48\%), diam. base $3.8 \mathrm{~cm}(42 \%)$, height $4.95 \mathrm{~cm}$, surface 10YR $8 / 3-7 / 3$, fracture $2.5 \mathrm{YR} 7 / 6$ (pottery group 768). - 310. rim, base, big, conical cup FS 204, fine plain, diam. rim $12 \mathrm{~cm}$ (R $34 \%)$, diam. base $3.8 \mathrm{~cm}(42 \%)$, height $7.8 \mathrm{~cm}$, surface 10YR $8 / 2$ and 2.5 YR $6 / 6$, fracture 2.5 YR $6 / 6$, cut marks at base (pottery group 773). - 311. rim, base, big, conical cup FS 204, fine plain, diam. rim $11 \mathrm{~cm}(18 \%)$, diam. base $4.2 \mathrm{~cm}(100 \%)$, height $5 \mathrm{~cm}$, surface $7.5 \mathrm{YR} 7 / 4$, fracture $2.5 \mathrm{Y} 6 / 6$, cut marks at base (pottery group 779). - 312. rim, base, big, conical cup FS 204, fine plain, diam. rim $11.8 \mathrm{~cm}(44,8 \%)$, diam. base $4.2 \mathrm{~cm}(100 \%)$, height $5.7 \mathrm{~cm}$, surface 10YR $8 / 3$, fracture 7.5 YR $7 / 4$, cut marks at base (pottery group 768)

Byzantine Pit 20, below floor of west stoa. -313 . rim, medium, goblet FS 263, fine lustrous, diam. rim $15 \mathrm{~cm}(12 \%)$, monochrome interior (linear decoration 15), fracture 5YR 6/6, surface 5YR 7/4-7/6, red paint. - 314. rim/beginning of handle, medium, goblet FS 263, fine lustrous, diam. rim $13.5 \mathrm{~cm}(12 \%)$, monochrome interior (linear decoration 15), fracture 5 YR $7 / 6$, surface 10 YR $8 / 2$, red paint. - 315. rim, small, goblet/cup, fine lustrous, diam. rim $10.8 \mathrm{~cm}$ (7\%), monochrome interior, line on the exterior rim (linear decoration 15), fracture 10YR 8/2, surface 10YR 8/2, black paint. - 316. wall, big, fine lustrous, closed shape, max. diam. $18 \mathrm{~cm}$, three lines, scale pattern FM 70, fracture/near exterior surface 7.5YR 6/4, fracture/near interior surface 7.5YR 6/2, surface 10YR 7/2-7/2, black paint. - 317. rim, small, fine plain, carinated kylix FS 267, fracture 2.5YR 6/6, surface 7.5YR $7 / 4$.

Floor of south stoa, in situ. - 318. rim/stem, big, fine plain, semiglobular kylix, diam. rim $13.5 \mathrm{~cm}(10 \%)$, secondary burnt, fracture 7.5YR 7/4, surface 10YR 7/3. - 319. rim, big, fine plain, angular bowl FS 295, diam. rim $13.5 \mathrm{~cm}(12 \%)$, secondary burnt, fracture $2.5 \mathrm{Y}$ $7 / 2$, surface $2.5 Y 7 / 2$. -320 . rim/handles/base, big, fine plain, angular bowl FS 295, diam. rim $15 \mathrm{~cm}(100 \%)$, height $6 \mathrm{~cm}$, secondary burnt, fracture Gley $18 / 10$ Y, surface Gley $18 / 10$ Y. - 321. rim/base, big, fine plain, conical bowl FS 204, diam. rim $13.5 \mathrm{~cm}$ (60\%), height $5.1 \mathrm{~cm}$, secondary burnt, fracture 5YR 7/6, surface 7.5YR 7/4.

\section{Acknowledgements}

I am very grateful to the director of the Ayios Vasileios Project, Adamantia Vasilogamvrou, for permission to study and publish the material presented in this article. This study has been funded by INSTAP and the Austrian Science Fund FWF (Project No. P 28023). I am indebted to Afroditi Maltezou, Maria Tsouli and the director from the Ephoreia of Laconia Evangelia Pantou for providing excellent working conditions and for all their support. For fruitful discussions concerning issues of chronology and aspects of the early Mycenaean period in Laconia and beyond I would like to thank Adamantia Vasilogamvrou, Reinhard Jung, Vasco Hachtmann, Joseph Maran, Jeremy Rutter, Birgitta Eder and Sofia Voutsaki. I would like to express my gratitude to Nektarios Karadimas for clarifying issues of stratigraphy relating to the excavation in the area of the archive. Dora Kondyli has assisted the progress of the study in many ways and I would like to thank her deeply for this. I am very grateful to María Antonia Negrete Martínez for the layout of the text and the figures and for all her help and also to Chris Cumberpatch for language corrections and stylistic improvements. For the drawing and digitalisation of the largest part of the material I owe my thanks to Anna Poelstra-Traga. Reinhard Jung has also prepared some drawings during his stay at the storage room at Sparta and for this I am gratefull. I am much obliged to Giota Menegaki and Viki Katsichti for the cleaning and restoration of the pottery from Building B. Last but not least, I am indebted to the three anonymous reviewers for their important corrections and critical comments. Their help was crucial for the final preparation of this article. The same is true for the scientific editor Estella Weiss-Krejci. I owe her my deepest gratitude for her patience during the editing of the text.

\section{References}

ANDREADAKI-VLAZAKI 2011

M. Andreadaki-VlazaKi, LM IB pottery in Khania. In: Th. M. Brogan, E. Hallager (Eds.), LM IB Pottery: Relative Chronology and Regional Differences. Acts of a workshop held at the Danish Institute at Athens in collaboration with the INSTAP Study Center for East Crete, 27-29 June 2007. Monographs of the Danish Institute at Athens 11/1, Aarhus 2011, 55-74.

Andreadaki-Vlasaki, Papadopoulou 1997

M. Andreadaki-Vlasaki, E. Papadopoulou, LM IIIA: 1 pottery from Khamalevri, Rethymnon. In: E. Hallager, B. PÅlsson Hallager (Eds.), Late Minoan III Pottery: Chronology and Terminology. Acts of a Meeting Held at the Danish Institute at Athens, August 12-14,1994. Monographs of the Danish Institute at Athens 1, Athens 1997, 111-151.

Aravantinos, Vasilogamvrou 2012

V. Aravantinos, A. Vasilogamvrou, The first Linear B documents from Ayios Vasileios (Lakonia). In: P. Carlier, C. De Lamberterie, M. Egetmeyer, N. Guilleux, F. Rougemont, J. Zurbach (Eds.). Études Mycéniennes 2010. Actes du XIII[e] colloque international sur les textes égéens (Sèvres, Paris, Nanterre, 20-23 septembre 2010). Biblioteca di Pasiphae X, Pisa 2012, $41-54$.

AsCHENBRENNER et al. 1992

S. A. Aschenbrenner, W. D. Coulson, W. P. Donovan, R. Hope Simpson, W. A. McDonald, N. C. Wilkie, Late Helladic settlement: stratigraphy and architecture. In: W. A. McDonald, N. C. Wilkie (Eds.), Excavations at Nichoria in Southwest Greece II: The Bronze Age Occupation. Minneapolis 1992, 358-454.

BADER 2010

B. BADER, Processing and analysis of ceramic finds at the Egyptian Site of Tell el-Dab a/Avaris ("eves" and other strange animals). In: B. Horejs, R. Jung, P. PAvúk (Eds.), Pottery Analysis; Processing - Classification - Publication, Studia Archaeologica et Medievalia 10, Bratislava 2010, 209-233. 


\section{BetAnCourt 1980}

P. P. Betancourt, Cooking Vessels from Minoan Kommos: A Preliminary Report. Institute of Archaeology, University of California, Occasional Paper 7, Los Angeles 1980.

Blegen, Rawson 1966

C. W. Blegen, M. Rawson, The Palace of Nestor at Pylos in Western Messenia I: The Buildings and Their Contents. Princeton 1966.

BLEgen et al. 1973

C. W. Blegen, M. Rawson, W. Taylour, W. P. Donovan, The Palace of Nestor at Pylos in Western Messenia III: Acropolis and Lower Town, Tholoi and Grave Circle, Chamber Tombs, Discoveries Outside the Citadel. Princeton 1973.

Catling 1996

H. W. Catling, Minoan and 'Minoan' pottery at the Menelaion, Sparta. In: D. Evely, I. S. Lemos, S. Sherratt (Eds.), Minotaur and Centaur: Studies in the Archaeology of Crete and Euboea presented to Mervyn Popham. British Archaeological Reports British Series 638, Oxford 1996, 70-78.

Catling 2009a

H. W. Catling, Sparta. Menelaion I: The Bronze Age. The British School at Athens Suppl. 45/I: Text, Athens 2009.

Catling 2009b

H. W. Catling, Sparta. Menelaion I: The Bronze Age. The British School at Athens Suppl. 45/II: Figure and Plates, Athens 2009.

Coldstream, Huxley 1972

J. N. Coldstream, G. L. Huxley, Kythera: Excavations and Studies Conducted by the University of Pennsylvania Museum and the British School at Athens. London 1972.

Cummer, SCHOFField 1984

W. W. Cummer, E. Schofield, Ayia Irini. House A. Keos: Results of Excavations Conducted by the University of Cincinnati under the Auspices of the American School of Classical Studies at Athens III. Mainz 1984

Dawkins 1910

R. M. Dawkins, Laconia I: Excavations at Sparta, 1910: § 2. The Mycenaean city near Menelaion, Annual of the British School at Athens 16/1909-1910, 1910, 4-11.

DiCKINSON 1972

O. T. P. K. Dickinson, Late Helladic IIA and IIB: some evidence from Korakou, Annual of the British School at Athens 67, 1972, 103-112.

DiCKINSON 1992

O. T. P. K. Dickinson, Part I: The Late Helladic I and II pottery. In: W. A. McDonald, N. C. Wilkie (Eds.), Excavations at Nichoria in Southwest Greece II: The Bronze Age Occupation. Minneapolis 1992 , 469-488, 521-534, 548-570.

Dickinson 2014

O. T. P. K. Dickinson, Late Helladic I revisited: the Kytheran connection. In: D. Nakassis, J. Gulizio, S. A. James (Eds.), KE-RAME-JA: Studies presented to Cynthia W. Shelmerdine. Philadelphia 2014, 3-15.

DiETZ 1980

S. DieTz, Asine II: Results of the Excavations East of the Acropolis 1970-1974. The Middle Helladic Cemetery, the Middle Helladic and Early Mycenaean Deposits. Acta Instituti Atheniensis Regni Suecia: Series in quarto 24/2, Stockholm 1980.

FRENCH 1964

E. FrenCH, Late Helladic IIIA 1 pottery from Mycenae, Annual of the British School at Athens 59, 1964, 241-261.
FRENCH 1965

E. French, Late Helladic IIIA 2 pottery from Mycenae, Annual of the British School at Athens 60, 1965, 159-202.

FRENCH 2011

E. B. French, The Post-Palatial Levels, Well Built Mycenae 16/17. Oxford 2011

French, TOMLINSON 1999

E. B. French, J. E. Tomlinson, The mainland 'conical cup'. In: P. P. Betancourt, V. Karageorghis, R. Laffineur, W.- D. Niemeier (Eds.), Meletemata: Studies in Aegean Archaeology Presented to Malcolm H. Wiener as He Enters His 65th Year, Vol. I. Liège - Austin 1999, 259-265.

FrizeLl 1980

B. S. Frizell, An Early Mycenaean Settlement at Asine: The Late Helladic IIB-IIIAl Pottery. Göteborg 1980.

FrIZELl 1996

B. S. Frizell, Mycenaean Asine: a question of II B or not II B. In: E. De Miro, L. Godart, A. Sacconi (Eds.), Atti e memorie del secondo Congresso internazionale di micenologia, Roma-Napoli, 14-20 ottobre 1991, Vol. 3: Archeologia. Incunabula Graeca 98, Rome, 1996, 1287-1293.

FURUMARK 1941

A. Furumark, The Mycenaean Pottery: Analysis and Classification. Stockholm 1941.

HachTMANn forthcoming

V. Hachtmann, Late Helladic I to IIA Pottery from Ayios Vasilios at Xirokambi, Laconia: The 'Platform Deposit', forthcoming.

HATZAKi 2005

E. Hatzani, Knossos: The Little Palace. The British School at Athens Suppl. 38, London 2005.

Hiesel 1975

G. Hiesel, Abschnitt M. In: P. Gercke, W. Gercke, G. Hiesel, Tiryns-Stadt 1971: Graben H. Tiryns VIII, Mainz 1971, 17-26.

Horejs 2010

B. Horejs, Possibilities and limitations in analysing ceramic wares. In: B. Horejs, R. Jung, P. Pavúk (Eds.), Pottery Analysis; Processing - Classification - Publication, Studia Archaeologica et Medievalia 10, Bratislava 2010, 15-27.

Howell 1992

R. J. Jowell, The Middle Helladic settlement: the pottery. In: W. A. McDonald, N. C. Wilkie (Eds.), Excavations at Nichoria in Southwest Greece II: The Bronze Age Occupation. Minneapolis 1992, 43-204.

Hruby 2006

J. A. Hruby, Feasting and ceramics: A view from the Palace of Nestor at Pylos. PhD Disseration, University of Cincinnati. Cincinati 2006.

IMMERWAHR 1971

S. A. Immerwahr, The Athenian Agora XIII: The Neolithic and Bronze Ages. Results of Excavations Conducted by the American School of Classical Studies at Athens. Princeton 1971.

Jones 2008

R. E. Jones, Chemical Analysis (in I. K. Whitbread, R. E. Jones, Appendix 2: petrographic and chemical analysis of Middle and Late Helladic I-II pottery). In: W. D. TaYlour, R. Janko, Ayios Stephanos: Excavations at a Bronze Age and Medieval Settlement in Southern Laconia. The British School at Athens Suppl. 44, London 2008, CD-114-117. 
Jones, RutTER 1977

R. E. Jones, J. B. Rutter, Resident Minoan potters on the Greek mainland? Pottery composition analyses from Ayios Stephanos, Archaeometry 19, 1977, 211-219.

JUNG 2002

R. Jung, Kastanas. Ausgrabungen in einem Siedlungshügel der Bronze- und Eisenzeit Makedoniens 1975-1979: Die Drehscheibenkeramik der Schichten 19-11. Prähistorische Archäologie in Südosteuropa 18, Kiel 2002.

JUNG 2010

R. JUnG, Classification, Counting and publication of Aegean-type pottery around the Mediterranean. In: B. Horejs, R. Jung, P. PAvúk (Eds.), Pottery Analysis; Processing - Classification - Publication, Studia Archaeologica et Medievalia 10, Bratislava 2010, 145- 162.

KarantZali 2001

E. Karantzali, The Mycenaean Cemetery at Pylona on Rhodes. British Archaeological Reports British Series 988, Oxford 2001.

KARDAMAKI 2013

E. Kardamaki, Ein neuer Keramikfund aus dem Bereich der Westtreppe von Tiryns: Bemalte mykenische Keramik aus dem auf der Westtreppenanlage deponierten Palastschutt. PhD Dissertation, University of Heidelberg. Heidelberg 2013.

KILIAN 1988

K. Kilian, Myceneans up to date, trends and changes in recent research. In: E. B. French, K. A. Wardle (Eds.), Problems in Greek Prehistory. Papers Presented at the Centenary Conference of the British School of Archaeology at Athens, Manchester, April 1986. Bristol 1988, 115-152.

KIRIATZI 2010

E. Kiriatzi, "Minoanising" pottery traditions in southwest Aegean during the Middle Bronze Age: understanding the social context of technological and consumption practices. In: A. PHILIPpa-Touchais, G. Touchais, S. Voutsaki and J. Wright (Eds.), Mesohelladika: La Grèce continentale au Bronze Moyen, actes du Colloque international, organisé par l'Ecole française d'Athènes, en collaboration avec l'American School of Classical Studies at Athens et le Netherlands Institute in Athens, Athènes, 8-12 mars 2006. Bulletin de correspondance hellénique Suppl. 52, Athens, 683-699.

LindBlom, Manning 2011

M. Lindblom, S. W. Manning, The chronology of the Lerna shaft graves. In: W. Gauss, M. Lindblom, R. Angus, K. Smith, J. C. Wright (Eds.), Our Cups Are Full: Pottery and Society in the Aegean Bronze Age. Papers Presented to Jeremy B. Rutter on the Occasion of his 65th Birthday. Oxford 2011, 140-153.

Maran 1992

J. Maran, Kiapha Thiti: Ergebnisse der Ausgrabungen II/2. 2. Jt. v. Chr. Keramik und Kleinfunde. Marburger Winckelmann-Programm 1990, Marburg 1992.

MARTIN 1992

S. L. Martin, Mycenaean pottery from the settlement, part II: The Late Helladic IIIA1 pottery. In: W. A. McDonald, N. C. WilkIE (Eds.), Excavations at Nichoria in Southwest Greece II: The Bronze Age Occupation. Minneapolis 1992, 488-494, 534-537, 571-585.

MounTJOY 1981

P.A. MounTJoy, Four Early Mycenaean Wells from the South Slope of the Acropolis at Athens, Miscellanea Graeca 4, Gent 1981.

MounTJOy 1986

P. A. MounTJoy, Mycenaean Decorated Pottery: A Guide to Identification. Gothenburg 1986.
MountJoy 1993

P. A. Mountjoy, Mycenaean Pottery: An Introduction. Oxford University Committee for Archaeology Monograph 36, Oxford 1993.

MounTJOy 1995

P. A. MounTJoy, Mycenaean Athens. SIMA Pocket-Book 127, Jonsered 1995.

Mountjoy 1996

P. A. Mountjoy, Asine Chamber Tomb I:1: the pottery. In: R. HÄGG, G. C. Nordquist, B. Wells (Eds.). Asine III: Supplementary Studies on the Swedish Excavations 1922-1930. Acta Instituti Atheniensis Regni Sueciae: Series in quarto 45/1, Stockholm $1996,47-67$.

MounTJOY 1997

P. A. Mountjoy, The destruction of the Palace at Pylos Reconsidered, Annual of the British School at Athens 92, 1997, 109-137.

MounTJOY 1999

P. A. MounTJoy, Regional Mycenaean Decorated Pottery. Rahden/ Westf. 1999.

MounTJOY 2008

P. A. MountJoy, The Late Helladic pottery. In: W. D. TAYlour, R. Janko, Ayios Stephanos: Excavations at a Bronze Age and Medieval Settlement in Southern Laconia. The British School at Athens Suppl. 44, London 2008, 299-387.

MounTJOY 2013

P. A. Mountjoy, Three Mycenaean vases from the Dodecanese. In: G. Graziadio, R. Guglielmino, V. Lenuzza, S. Vitale (Eds.),

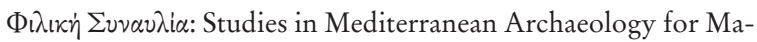
rio Benzi. Oxford 2013, 135-138.

Orton, Tyres, Vince 1993

C. Orton, P. Tyres, A. Vince, Pottery in Archaeology. Cambridge Manuals in Archaeology, Cambridge 1993.

Podzuweit 1977

C. Podzuweit, Ein mykenischer Kieselmosaikfussboden aus Tiryns, Archäologischer Anzeiger 1977, 123-137.

Podzuweit 2007

C. Podzuwert, Studien zur spätmykenischen Keramik. Tiryns Forschungen und Berichte 14, Wiesbaden 2007.

RUTTER 1993

J. B. RutTer, A group of Late Helladic IIA pottery from Tsoungiza, Hesperia 62, 53-93.

RUTTER 1995

J. B. Rutter, Lerna III: A Preclassical Site in the Argolid. The Pottery of Lerna IV. Princeton - New Jersey 1995.

RUTTER 2006

J. B. RutTer, Neopalatial and later Minoan pottery (in J. B. RutTER, A. VAn de Moortel, Chapter 3: Minoan pottery from the southern area). In: J. W. SHAw, M. C. SHAw (Eds.), Kommos V: An Excavation on the South Coast of Crete by the University of Toronto under the auspices of the American School of Classical Studies at Athens. The Monumental Minoan Buildings at Kommos. Princeton - Oxford 2006, 377-630.

RUTTER 2015

J. B. RutTER, Ceramic technology in rapid transition: the evidence from settlement deposits of the shaft grave Era at Tsoungiza (Corinthia). In: W. Gauss, G. Klebinder-Gauss, C. von Rüden (Eds.), The Transmission of Technical Knowledge in the Production of Ancient Mediterranean Pottery. Proceedings of the International Conference at the Austrian Archaeological Institute at Athens 23rd - 25th November 2012. Vienna 2015, 207-223. 
RUTTER, RUTTER 1976

J. B. Rutter, S. H. Rutter, The Transition to Mycenaean: A Stratified Middle Helladic II to Late Helladic IIA Pottery Sequence From Ayios Stephanos in Lakonia. Monumenta Archaeologica 4, Los Angeles 1976.

SCHOFIELD 2011

E. Schofield, Keos X. Ayia Irini: The Western Sector. Results of Excavations Conducted by the University of Cincinnati under the Auspices of the American School of Classical Studies at Athens X, Mainz 2011.

SCHÖNFELD 1988

G. SchöNFELD, Bericht zur bemalten mykenischen Keramik: Ausgrabungen in Tiryns 1982/83, Archäologischer Anzeiger 1988, 153-211.

SHELMERDINE 1992

C. W. Shelmerdine, Mycenaean pottery from the settlement, part III: Late Helladic IIIA2-IIIB pottery. In: W. A. McDonALD, N. C. Wilkie (Eds.), Excavations at Nichoria in Southwest Greece II: The Bronze Age Occupation. Minneapolis 1992, 495521, 537-547, 586-617.

STOCKHAMMER 2008

P. W. Stockhammer, Kontinuität und Wandel: Die Keramik der Nachpalastzeit aus der Unterstadt von Tiryns. PhD Dissertation, University of Heidelberg 2008.

STUbBings 1947

F. H. Stubbings, The Mycenaean Pottery of Attica, Annual of the British School at Athens 42, 1947, 1-75.

TAYlOUR, JANKo 2008

W. D. TAYlour, R. Janko, The Bronze architecture and stratigraphy. In: W. D. TAYlour, R. Janko, Ayios Stephanos: Excavations at a Bronze Age and Medieval Settlement in Southern Laconia. The British School at Athens Suppl. 44, London 2008, 13-119.

Thomas 2005

P. M. Thomas, A deposit of LH III B1 pottery from Tsoungiza, Hesperia $74,2005,451-573$

Thomas 2011a

P. M. Thomas, A deposit of LH IIIA2 pottery from Tzoungiza, Hesperia $80,2011,171-228$.

Thomas 2011b

P. M. Thomas, Mycenaean tablewares and the curious careers of the angular kylix and shallow angular basin. In: W. Gauss, M. LindBlom, R. A. K. Smith, J. C. Wright (Eds.), Our Cups Are Full: Pottery and Society in the Aegean Bronze Age. Papers Presented to Jeremy B. Rutter on the Occasion of his 65th Birthday. Oxford 2011, 297-305.

VASILOGAMVROU 2013

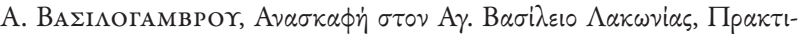

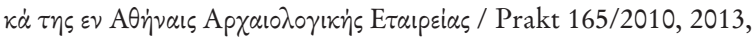
$65-80$.

VASILOGAMVROU 2014

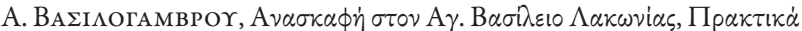

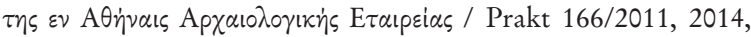
59-68.

VASILOGAMVROU 2015a

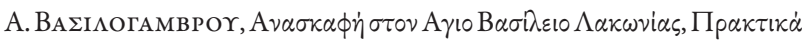

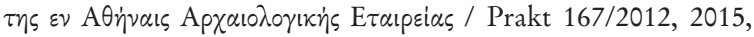
$63-76$.

VASILOGAMVROU 2015b

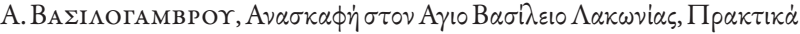

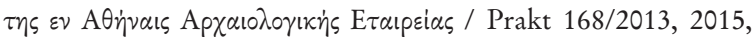
97-116.
VITALE 2011

S. Vitale, The Late Helladic IIIA2 Pottery from Mitrou and its Implications for the Chronology of the Mycenaean Mainland. In: W. Gauss, M. Lindblom, R. Angus, K. Smith, J. C. Wright (Eds.), Our Cups Are Full: Pottery and Society in the Aegean Bronze Age. Papers Presented to Jeremy B. Rutter on the Occasion of his 65th Birthday. Oxford 2011, 331-344.

VITALE 2013

S. Vitale, Two Late Helladic IIIA1 deposits from Mitrou, east Lokris: a chronological, typological, and functional analysis of the pottery. In: G. Graziadio, R. Guglielmino, V. Lenuzza, S. Vitale (Eds.), Фı $\lambda \iota \kappa \eta \dot{~} \Sigma v v \alpha v \lambda i \alpha$ : Studies in Mediterranean Archaeology for Mario Benzi. British Archaeological Reports International Series 2460, Oxford 2013, 123-133.

WARDLE 1973

K. A. WARdLE, A group of Late Helladic III B2 pottery from within the citadel at Mycenae: the Causeway Deposit, Annual of the British School at Athens 68, 1973, 297-348.

WARREN 2011

P. M. Warren, Late Minoan IB pottery from Knossos: stratigraphical museum excavations, the North Building. In: Th. M. BRoGan, E. Hallager (Eds.), LM IB Pottery: Relative Chronology and Regional Differences. Acts of a Workshop Held at the Danish Institute at Athens in Collaboration with the INSTAP Study Center for East Crete, 27-29 June 2007, vol. 1. Monographs of the Danish Institute at Athens 11/1-2, Athens 2011, 183-195.

WATROUS 1992

L. V. Watrous, Kommos III: An Excavation on the South Coast of Crete. The Late Bronze Age Pottery. Princeton 1992.

Whitbread, Jones 2008

I. K. Whitbread, R. E. Jones, Appendix 2: petrographic and chemical analysis of Middle and Late Helladic I-II pottery. In: W. D. Taylour, R. Janko, Ayios Stephanos: Excavations at a Bronze Age and Medieval Settlement in Southern Laconia. The British School at Athens Suppl. 44, London 2008, CD-89-117.

WIENER 2011

M. H. Wiener, Conical cups: from mystery to history. In: W. Gauss, M. Lindblom, R. Angus, K. Smith, J. C. Wright (Eds.), Our Cups Are Full: Pottery and Society in the Aegean Bronze Age. Papers Presented to Jeremy B. Rutter on the Occasion of his 65th Birthday. Oxford 2011, 355-368.

ZERNER 2008

C. Zerner, The Middle Helladic pottery, with the Middle Helladic wares from Late Helladic deposits and the potters' marks. In: W. D. Taylour, R. Janko, Ayios Stephanos: Excavations at a Bronze Age and Medieval Settlement in Southern Laconia. The British School at Athens Suppl. 44, London 2008, 177-298.

Eleftheria Kardamaki Institute for Oriental and European Archaeology Austrian Academy of Sciences Hollandstraße 11-13 1020 Vienna Austria eleftheria.kardamaki@oeaw.ac.at D orcid.org/0000-0003-3450-3784 